Higher Education

\title{
Improving Higher Education in the Slovak Republic
}
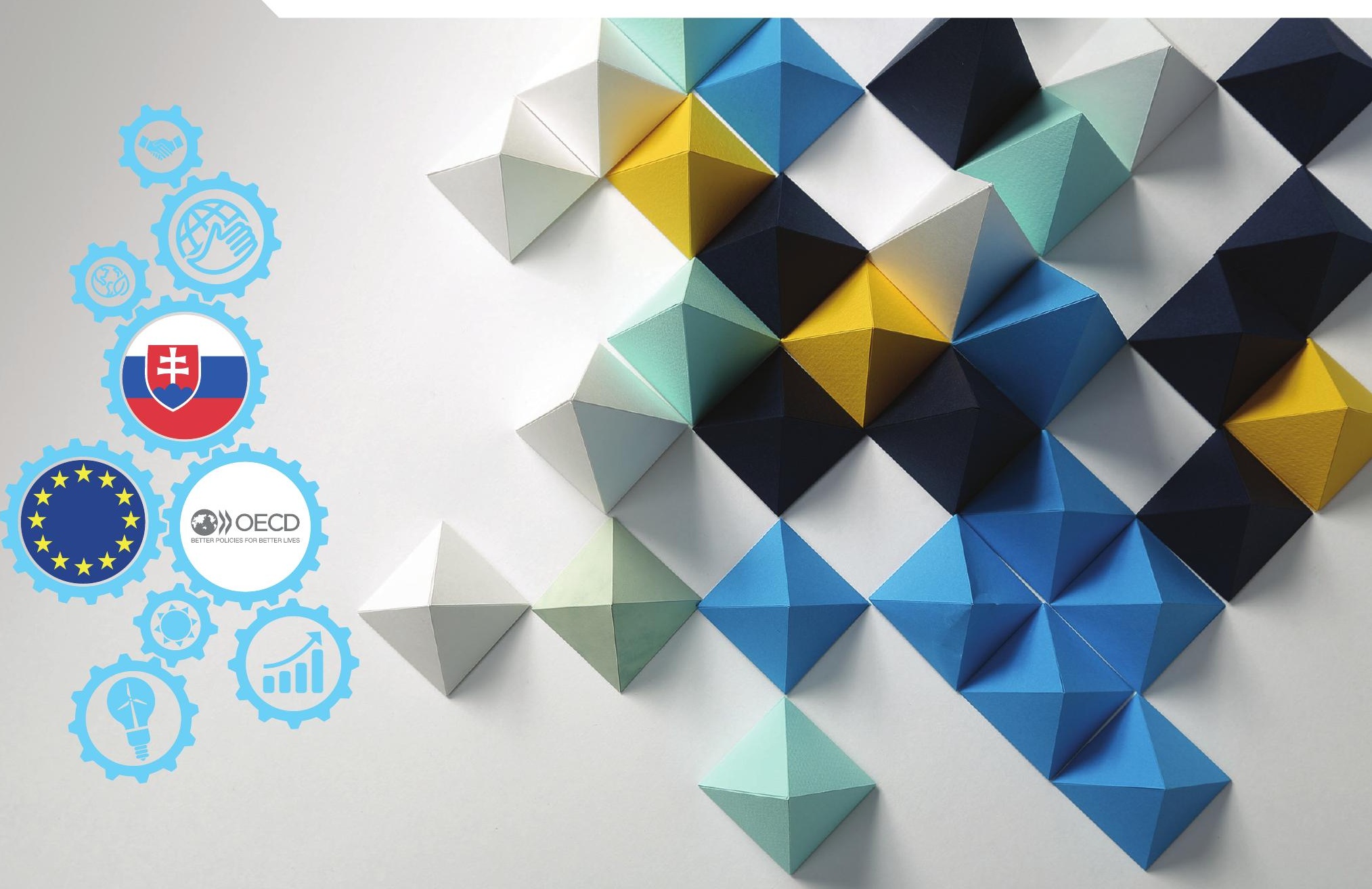

Q $1 / O E C D$ 

Higher Education

\section{Improving Higher Education in the Slovak Republic}

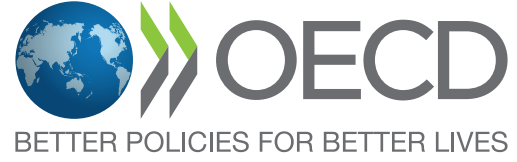


The project "Improving Higher Education in the Slovak Republic" was co-funded by the European Union via the Structural Reform Support Programme (REFORM/IM2020/004).

This publication was produced with the financial assistance of the European Union. The views expressed herein can in no way be taken to reflect the official opinion of the European Union.

This document, as well as any data and map included herein, are without prejudice to the status of or sovereignty over any territory, to the delimitation of international frontiers and boundaries and to the name of any territory, city or area.

The statistical data for Israel are supplied by and under the responsibility of the relevant Israeli authorities. The use of such data by the OECD is without prejudice to the status of the Golan Heights, East Jerusalem and Israeli settlements in the West Bank under the terms of international law.

Note by Turkey

The information in this document with reference to "Cyprus" relates to the southern part of the Island. There is no single authority representing both Turkish and Greek Cypriot people on the Island. Turkey recognises the Turkish Republic of Northern Cyprus (TRNC). Until a lasting and equitable solution is found within the context of the United Nations, Turkey shall preserve its position concerning the "Cyprus issue".

Note by all the European Union Member States of the OECD and the European Union

The Republic of Cyprus is recognised by all members of the United Nations with the exception of Turkey. The information in this document relates to the area under the effective control of the Government of the Republic of Cyprus.

\section{Please cite this publication as:}

OECD (2021), Improving Higher Education in the Slovak Republic, Higher Education, OECD Publishing, Paris, https://doi.org/10.1787/259e23ba-en.

ISBN 978-92-64-81992-4 (print)

ISBN 978-92-64-69925-0 (pdf)

Higher Education

ISSN 2616-9169 (print)

ISSN 2616-9177 (online)

Photo credits: Cover $\odot$ elettaria/Shutterstock.com. 


\section{Foreword}

Higher education plays a crucial role in countries around the world. It equips learners with the skills to lead productive working lives and sparks the knowledge creation and innovation that fosters economic growth and social progress. Moreover, long-term trends such as globalisation, digitalisation and demographic change, as well as shocks such as the coronavirus (COVID-19) pandemic, transform economies and societies, putting pressure on higher education systems to evolve and respond to emerging needs.

In the Slovak Republic, fast growth in higher education participation from the early 1990s has led to a rising share of young adults with a higher education qualification. However, student enrolment has declined significantly in the past decade, and the country has found it difficult to make its higher education system attractive to domestic and international students. While Slovak graduates do better in the labour market than their counterparts without a higher education qualification, they often experience a mismatch between their qualifications and labour market needs. Research performance remains low compared to neighbouring countries, and many institutions are weakly connected to their external environment.

Slovak policy makers have outlined ambitious goals for higher education and initiated policy reforms in recent years, most notably in quality assurance. Nonetheless, Slovak higher education stakeholders have not reached broad agreement on the problems their higher education system faces, its causes, and the actions that should be taken to improve its performance. As a result, work remains to be done to carefully identify, design and implement reforms that can significantly change higher education practices and outcomes, such as governance and funding reforms.

The project "Improving Higher Education in the Slovak Republic" offers an international perspective on the performance of the Slovak higher education system and provides an action plan focused on governance and funding reforms, placing special emphasis on implementation planning. The project unfolded in parallel with new policy plans for higher education - a proposed reform of the Act on Higher Education that would make changes to institutional governance and new funding proposed in the national recovery and resilience plan submitted to the European Commission - and seeks to provide actionable input that can inform these plans.

The project builds on detailed comparative analysis, recent studies of higher education in the Slovak Republic conducted by national and international organisations, and engagement with a wide range of stakeholders. Engagement included interviews and group discussions with higher education stakeholders and an international peer-learning webinar on higher education governance and funding. Regular meetings were also held with a working group of policy makers, including, in particular, representatives from the Slovak Ministry of Education, Science, Research and Sport, the Slovak Accreditation Agency for Higher Education, the Institute for Educational Policies and the Research Agency.

The project is a collaboration between the European Commission's Directorate-General for Structural Reform Support, the Institute for Strategies and Analysis in the Office of the Government of the Slovak Republic and the OECD's Directorate for Education and Skills. 



\section{Acknowledgements}

This publication is part of the OECD programme of work on higher education policy and was produced with the financial assistance of the European Union.

The OECD is grateful for the support of Agota Kovács at the European Commission's Directorate-General for Structural Reform Support (DG REFORM) and Veronika Rybánska and Natália Cedzová at the Institute for Strategies and Analysis (ISA) in the Government Office of the Slovak Republic. Together with the OECD team, the DG REFORM and ISA team formed the advisory group for the project "Improving Higher Education in the Slovak Republic", setting the direction for the project and providing regular advice on the project's activities and outputs. We are grateful for the ISA team to have hosted a pre-project meeting in Bratislava and then accommodated the switch to fully remote project activities as a result of the ongoing coronavirus (COVID-19) pandemic.

Warm thanks go to the members of the Slovak working group: Josef Jurkovič, Marcel Vysocký and Peter Ondreička from the Ministry of Education, Science, Research and Sport; Renata Hall and Robert Redhammer from the Slovak Accreditation Agency for Higher Education; Pavol Galás and Jan Tomán from the Institute for Educational Policies; Barbara Pavlíková and Andrea Uhrínová from the Research Agency. Working group members participated in regular project meetings, providing key input on national higher education policy developments and feedback on the OECD's proposals and written outputs. We are grateful as well for the many stakeholders who shared their time and insights during the project's interviews and roundtable discussions (a list of participating organisations is included in Annex B), and to the 100 stakeholders who attended the international peer-learning webinar organised by the project team on funding and governance. The stakeholders' insights and opinions provided the OECD team with important information that contributed to the interpretation of published data and research and to the formulation of recommended policy actions contained in this report.

We are also grateful to the international experts and practitioners who took the time to share their experience with governance and funding reforms with the OECD team and the Slovak stakeholders who participated in the international peer-learning webinar. International experts who contributed to the project include Andreas Zehetner (University of Applied Sciences Upper Austria, Austria); Ken Thomasson (Ministry of Higher Education and Science, Denmark); Tomi Halonen, Anita Lehikoinen and Birgitta Vuorinen (Ministry of Education and Culture, Finland); Petri Suomala (Aalto University, Finland), Tim Conlon (Higher Education Authority, Ireland), Ana Costa Freitas (University of Évora, Portugal), António Cunha (University of Minho, Portugal), Pedro Teixeira (University of Porto, Portuga), and Christina Whitfield (State Higher Education Executive Officers Association, United States).

This report was prepared by the OECD's Higher Education Policy team in the Directorate for Education and Skills with contributions from external experts (Miroslav Stefanik, Slovak Academy of Sciences, independent local expert for the project; Jonathan Medow, Oliver Sheldrick and Aleš VIk, independent higher education consultants). Patricia Mangeol was the project leader responsible for co-ordinating the review. The authors of this report were: Chapter 1 (Introduction), Patricia Mangeol; Chapter 2 (Higher education in the Slovak Republic), Miroslav Stefanik and Patricia Mangeol, with research assistance from Cléa Frambourt and Chloé Michaud; Chapter 3 (An action plan to improve higher education in the 
Slovak Republic), Patricia Mangeol with input from Miroslav Stefanik on national data and policies and research assistance from Cléa Frambourt and Chloé Michaud; Annex A (Higher education reforms in Portugal and Finland), Jonathan Medow, Oliver Sheldrick and Patricia Mangeol.

Shizuka Kato led the data review and validation process and provided input on the draft report. Chloé Michaud, Jonathan Medow and Oliver Sheldrick researched and drafted international policy examples. Aleš Vlk provided advice on the project activities and draft report.

The authors also wish to thank colleagues in the OECD for their input and advice, including Luka Boeskens, Tomoya Okubo, Simon Roy and Daniel Sanchez Serra (Directorate for Education and Skills), and Ricardo Espinoza and Laura Reznikova (OECD Centre for Skills).

Thomas Weko, team leader and senior analyst of the OECD Higher Education Policy team, provided analytical guidance and advice throughout the project. Paulo Santiago, Head of the Policy Advice and Implementation Division in the Directorate of Education and Skills and Andreas Schleicher, Director of the Directorate for Education and Skills, reviewed the publication.

Julie Harris edited the report; Cassandra Morley, Stephen Flynn and Cécile Bily provided administrative support to the project. Rachel Linden assisted with the editorial and production processes.

While the report draws on data and analysis from the OECD, Slovak data sources and a range of other published sources, any errors or misinterpretations remain the responsibility of the OECD team. 


\section{Table of contents}

Foreword

Acknowledgements 5

$\begin{array}{lr}\text { Executive summary } & 9\end{array}$

1 Introduction 13

1.1. Purpose and scope 14

1.2. Working methods 14

1.3. Analytical approach 15

$\begin{array}{ll}\text { 1.4. Structure of the report } & 17\end{array}$

$\begin{array}{ll}\text { References } & 18\end{array}$

2 Higher education in the Slovak Republic 19

2.1. The Slovak Republic's economy and labour market context 20

2.2. Key features of the Slovak Republic's higher education system 21

$\begin{array}{ll}\text { 2.3. Performance of Slovak higher education } & 27\end{array}$

$\begin{array}{ll}\text { Notes } & 42\end{array}$

$\begin{array}{ll}\text { References } & 43\end{array}$

3 An action plan to improve higher education in the Slovak Republic 47

3.1. Structure and summary of the action plan 48

3.2. Action Step 1: Developing and implementing a co-ordinated higher education strategy 51

3.3. Action Step 2: Using funding to support and reward higher education performance 71

3.4. Action Step 3: Enabling responsive institutional governance and management 93

$\begin{array}{lr}\text { References } & 109\end{array}$

Annex A. Higher education reforms in Portugal and Finland 117

Rationale and approach 117

$\begin{array}{ll}\text { Portugal: HEl governance reform } & 119\end{array}$

Finland: Institutional landscape rationalisation 133

$\begin{array}{ll}\text { Conclusions and relevance to higher education in the Slovak Republic } & 147\end{array}$

References 151

Annex B. Participating stakeholder organisations 157 


\section{Tables}

Table 2.1. Slovak government agencies that play a role in higher education 25

Table 2.2. Trends in tertiary education attainment rates of 25-34 year-olds by gender $(2009,2019) \quad 27$

Table 2.3. Employment rates of graduates, by education attainment and age in the Slovak Republic (2019) 35

Table 2.4. Employment rates of young adults who have recently completed higher education, by educational attainment and years since graduation, Slovak Republic (2018)

Table 2.5. Relative earnings of workers in the Slovak Republic, by educational attainment (2018)

Table 2.6. Quantity and impact of scientific production in selected countries (2018)

Table 3.1. TEF metrics aligned with aspects of quality

Table 3.2. Total expenditure on educational institutions per full-time equivalent student for core educational services, ancillary services and R\&D (2017)

Table 3.3. Allocation of public contributions to public HEls in the Slovak Republic (2020)

Table 3.4. Bijzonder Onderzoeksfonds (BOF) funding indicators and allocation

Table 3.5. Institutional autonomy in select European countries (2016)

Table 3.6. University governance bodies pre- and post-Universities Act in Finland (2009) 102

Table 3.7. University governance bodies pre- and post-RJIES in Portugal (2007)

Table A A.1. Key indicators for Finland, Portugal and the Slovak Republic (2017-19) 118

Table A A.2. University governance bodies pre- and post-RJIES (2007) in Portugal 124

Table A A.3. EUA University Autonomy Tool ranking of Finland, Portugal and the Slovak Republic (2017) 128

Table A A.4. Finnish higher education public funding allocation model (2020) 134

Table A A.5. Aalto University tenure track time allocations 142

Table A A.6. University governance bodies pre- and post-Universities Act, 2009

\section{Figures}

Figure 1.1. Factors affecting outcomes for graduates and employers

Figure 1.2. Executive capacity in the Slovak Republic compared to OECD/EU countries (2020) 17

Figure 2.1. Number of students and HEls in the Slovak higher education system (1991-2020) 22

Figure 2.2. Overview of Slovak HEls (2019) 23

Figure 2.3. Regional distribution of Slovak HEls and number of students (2019) 23

Figure 2.4. University application process at the national level in the Slovak Republic (2010 19) 28

Figure 2.5. University application process at the HEI level in the Slovak Republic (2019) 29

Figure 2.6. Share of 25-34 year-olds with tertiary education in OECD countries, by level of tertiary education (2019)

Figure 2.7. Cross-country variation in job automatability and percentage of jobs at risk of significant change in selected countries $(2012,2015)$

Figure 2.8. Key indicators for developing relevant skills, Slovak Republic and OECD average (2012, 2015, 2018)

Figure 2.9. Skills mismatches in the Slovak Republic (2018)

Figure 2.10. Publication performance of Slovak R\&D (2018)

Figure 3.1. Public expenditure on higher education per full-time student (2010-17)

Figure 3.2. Relative share of public, private and international expenditure on higher education institutions, by final source of funds (2017)

Figure 3.3. Human resources in Slovak higher education

Figure 3.4. Governing bodies in Slovak higher education institutions

Figure A A.1. Illustrative goals, outputs and outcomes of the HEl governance reform in Portugal 127

Figure A A.2. Illustrative goals, outputs and outcomes of the HEl network rationalisation reform in Finland 145

\section{Boxes}

Box 3.1. Objectives of the proposed Learning Slovakia Strategy (2016)

Box 3.2. The National Action Plan for External Quality Assurance of HEls (2021)

Box 3.3. Higher education reforms in the Slovak Republic's national recovery and resilience plan (2021) 56

Box 3.4. Recent recommendations to reform Slovak higher education 57

Box 3.5. Practices supporting labour-market-relevant education 81

Box 3.6. UAS Upper Austria: An example of public policy and institutional governance 98 


\section{Executive summary}

\section{Performance of the Slovak Republic's higher education system}

The Slovak higher education system experienced rapid enrolment growth between 1990 and 2009, and by 2019 about $39 \%$ of Slovaks aged 25-34 had obtained a higher education qualification, which was more than double that of 2009. Since 2009, the country has seen a steady decline in student enrolment. While this is due, in part, to falling school-age cohorts, there are serious concerns that the quality of Slovak higher education, in both teaching and research, is insufficient to attract young Slovaks.

Despite a rise in international student enrolment, close to one out of five Slovak learners chooses to undertake higher education abroad, a share second only to Luxembourg in the OECD. While higher education graduates have higher employment rates and wages than individuals who have completed upper secondary education or less, these employment and earnings premia are lower in the Slovak Republic than on average among OECD countries. Labour market mismatches, especially over-qualification, are common, in part due to the inability of the Slovak higher education system to adapt to changing economic and labour market needs.

The Slovak Republic has a good basis of skills on which to build as Slovak higher education graduates perform higher than average on the literacy and numeracy assessments of the OECD Survey of Adult Skills. However, its higher education graduates perform below average in problem solving in a technologically rich environment. This is a particular problem because the expansion of digital technologies is expected to affect the Slovak economy more than that of other countries: the Slovak Republic is the OECD country with the highest share of jobs at risk of automation due to the large size of its manufacturing sector. The higher education system will therefore need to equip graduates with skills for a labour market in which newly created jobs will more often demand digital skills than those they replace. In addition, transversal skills, those applicable in a wide range of settings, including socio-emotional skills, will be important - for young people and workers who will need to change jobs or careers.

The research activity of the Slovak Republic's higher education institutions (HEls) is modest, comparatively speaking. Recent policy changes have given academics greater incentives to focus on the quality of their research, as well as its quantity. However, there are impediments to the improvement of Slovak research, ranging from ineffective funding application and allocation processes to limited collaboration between academic researchers and the private sector. While the Slovak Republic's accession to the European Union (EU) created new funding opportunities for research and development, the country has a poor record of making use of those opportunities.

\section{Reforming the Slovak Republic's higher education system}

Higher education system reform is a complex undertaking that requires strong collaboration between national policy makers and autonomous HEls to be successful. In the Slovak Republic, higher education stakeholders have not reached broad agreement about the problems they face and their causes. They have found it difficult to formulate a shared vision that can be translated into concrete policy and institutional 
actions, shape the financing of the system, and result in a model of higher education institutional governance and management that effectively balances autonomy and responsiveness.

Nonetheless, successive Slovak governments have articulated ambitious reform goals, and they have implemented some reforms. These include amending the Higher Education Act to create different institutional types by mission and introducing performance-related components in the institutional funding formula. However, the impact of these reforms on the system's performance in teaching and research has been limited to date. A major reform of quality assurance, passed in 2018 and to be implemented by the end of 2022, requires HEls to put internal structures and processes in place to assure and improve educational quality. The reform of quality assurance holds significant promise for driving a greater focus on quality in HEls. However, it will take time to realise its full effects and its impact will depend upon complementary improvements to the system's financing and governance.

From a financial perspective, the combination of low levels of government investment and fast enrolment growth between 1990-2009 led to substantial under-funding compared to other OECD countries. In the past decade, per-student funding has risen due to falling student numbers but remains at a level insufficient to spur reform and improvement. While the European Union is a growing source of funds, EU investments have centred on infrastructure but not on human resources, which are vital to improving the quality of teaching and research. In addition, efforts to hold publicly funded institutions accountable for the outcomes they achieve with public spending are relatively recent and have not focused on assessing and improving the quality of teaching.

Institutional governance and management arrangements that enable institutions to exercise their autonomy to be effective and responsive to societal needs while protecting academic freedom are widely agreed principles. However, it is not easy to translate these principles into appropriate structures and processes, and higher education governance and management are the most contested reform areas discussed in this report.

Slovak HEls have a complex governance structure established in law and applicable to all, despite significant heterogeneity in size and focus among institutions. Slovak law establishes a balance of power in HEls in which academic governing bodies are responsible for performing key managerial responsibilities - such as choosing and potentially dismissing the rector or approving the institutional budget - while university rectors have limited managerial tools at their disposal. Higher education institutions continue to be weakly engaged with their wider environment, notwithstanding the creation of boards of trustees. This creates problems of transparency, accountability and low responsiveness to the needs of Slovak citizens.

\section{An action plan to improve higher education in the Slovak Republic}

The objective of this project is to assist Slovak authorities in developing and implementing higher education governance and funding reforms to help improve the performance of the nation's higher education system. The action plan provided in this report includes ten actions to be taken between 2021 and 2024. It builds on analysis and advice provided by recent national and international projects, input provided by Slovak stakeholders throughout the project, and a rich body of policy experience across OECD countries.

The following table lists the policy actions, suggested timeframes, and organisations that might take responsibility for implementing the actions. It also assigns a broad cost estimate to each action: "low", "medium" or "high". These indications should be interpreted as follows:

Low: Actions that focus on policy processes and can be undertaken by existing bodies or bodies funded through other actions.

Medium: Actions that focus on policy processes or the provision of financial incentives requiring investment of a limited scale. 
High: Actions that require substantial new investments.

The table aims to provide a starting point for the implementation of the ten policy actions, based upon the OECD's assessment of implementation considerations in the Slovak Republic. Timeframes, responsibilities and costs will need to be discussed and refined by the Slovak authorities in close collaboration with higher education stakeholders.

\begin{tabular}{|c|c|c|c|}
\hline Policy action & Potential timing & Potential lead organisation & Potential cost \\
\hline \multicolumn{4}{|c|}{ Developing and implementing a co-ordinated higher education strategy } \\
\hline $\begin{array}{l}\text { 1. Establish a small multi-stakeholder Higher } \\
\text { Education Task Force responsible for co- } \\
\text { ordinating the development and } \\
\text { implementation of higher education reforms }\end{array}$ & Q4 2021 & $\begin{array}{l}\text { Established by and accountable to } \\
\text { the Prime Minister's Office } \\
\text { Membership identified by Ministry of } \\
\text { Education, Science, Research and } \\
\text { Sport (MoE) in collaboration with } \\
\text { key agencies and stakeholder } \\
\text { organisations }\end{array}$ & Medium \\
\hline $\begin{array}{l}\text { 2. Develop a mid-term higher education vision } \\
\text { and strategy articulating linkages between } \\
\text { goals, actions and monitoring results }\end{array}$ & $\begin{array}{l}\text { Q1-Q2 2022: Stakeholder } \\
\text { engagement } \\
\text { Q3 2022: Strategy } \\
\text { presentation and adoption }\end{array}$ & $\begin{array}{l}\text { Higher Education Task Force, } \\
\text { reporting to the Prime Minister's } \\
\text { Office }\end{array}$ & Low \\
\hline $\begin{array}{l}\text { 3. Develop indicators of quality teaching and } \\
\text { research, and strengthen data collection }\end{array}$ & Q1 2022 & $\begin{array}{l}\text { Expert Group, reporting to the } \\
\text { Higher Education Task Force }\end{array}$ & Low \\
\hline \multicolumn{4}{|c|}{ Using funding to support and reward higher education performance } \\
\hline $\begin{array}{l}\text { 4. Map out investments required to implement } \\
\text { a mid-term higher education strategy, new } \\
\text { funding sources and options for enhancing } \\
\text { higher education funding levels (the funding } \\
\text { envelope) }\end{array}$ & Q2 2022 & $\begin{array}{l}\text { MoE, supported by the Ministry of } \\
\text { Finance and the Higher Education } \\
\text { Task Force }\end{array}$ & Low \\
\hline $\begin{array}{l}\text { 5. Establish an approach and process for the } \\
\text { development of institutional contracts and } \\
\text { possible performance parameters }\end{array}$ & Q1-Q2 2022 & $\begin{array}{l}\text { Higher Education Task Force, } \\
\text { reporting to the MoE }\end{array}$ & $\begin{array}{l}\text { Medium to } \\
\text { High }\end{array}$ \\
\hline $\begin{array}{l}\text { 6. Use the institutional contracts to allocate } \\
\text { targeted funding to enhance teaching and } \\
\text { research quality }\end{array}$ & Q2-Q3 2022 & $\begin{array}{l}\text { Expert Group, reporting to Higher } \\
\text { Education Task Force } \\
\text { MoE implementing revisions } \\
\text { recommended by Higher Education } \\
\text { Task Force }\end{array}$ & High \\
\hline $\begin{array}{l}\text { 7. Consider revisions to the funding formula } \\
\text { for higher education and research allocation } \\
\text { mechanisms }\end{array}$ & $\begin{array}{l}\text { Q1 2022: Recommendations } \\
\text { Q4 2022: Implementation of } \\
\text { revisions to funding formula } \\
\text { and research allocation } \\
\text { mechanisms }\end{array}$ & $\begin{array}{l}\text { Expert Group, reporting to Higher } \\
\text { Education Task Force } \\
\text { MoE implementing revisions } \\
\text { recommended by the Higher } \\
\text { Education Task Force }\end{array}$ & Medium \\
\hline \multicolumn{4}{|c|}{ Enabling responsive institutional governance and management } \\
\hline $\begin{array}{l}\text { 8. Reduce the level of prescription of the } \\
\text { legislation and introduce a small number of key } \\
\text { requirements supporting } \mathrm{HEl} \text { effectiveness and } \\
\text { openness }\end{array}$ & $\begin{array}{l}\text { Q1-Q3 2022: Stakeholder } \\
\text { engagement } \\
\text { Q4 2022: Legislation passed } \\
\text { Q2 2024: New governance } \\
\text { arrangements in place }\end{array}$ & $\begin{array}{l}\text { Higher Education Task Force for } \\
\text { stakeholder engagement } \\
\text { MoE for legislation drafting }\end{array}$ & Low \\
\hline $\begin{array}{l}\text { 9. Create incentives for public HEls to adopt a } \\
\text { new governance structure on an accelerated, } \\
\text { pilot basis }\end{array}$ & $\begin{array}{l}\text { Q2 2022: Incentives designed } \\
\text { Q1 2023: New governance } \\
\text { adopted by pilot HEls }\end{array}$ & MoE & Medium \\
\hline $\begin{array}{l}\text { 10. Establish appropriate supports to foster } \\
\text { best practice in HEl governing bodies }\end{array}$ & $\begin{array}{l}\text { Q3 2022: Guidance on } \\
\text { institutional governance }\end{array}$ & Higher Education Task Force, MoE & Medium \\
\hline
\end{tabular}





\section{Introduction}

This chapter first outlines the purpose, scope and working methods of the project. It then provides an overview of the analytical approach used in the project, including a description of the context and focus of the action plan to improve higher education in the Slovak Republic. The chapter closes with an outline of the report's structure. 


\subsection{Purpose and scope}

This project is a collaboration between the European Commission's Directorate-General for Structural Reform Support (DG REFORM), the Institute for Strategies and Analysis (ISA) in the Government Office of the Slovak Republic, and the Higher Education Policy team in the OECD's Directorate for Education and Skills.

National and international studies have consistently highlighted weaknesses in the quality of the Slovak Republic's higher education system, and the Slovak government has placed the improvement of higher education institutional performance at the centre of its policy agenda. Thus, the purpose of this project is to help Slovak authorities to identify and implement higher education governance and funding reforms that improve the quality of teaching and research in the nation's higher education system. While efficiency and equity are important dimensions of well-functioning higher education systems, they do not form the primary focus of this project.

The project provides a comparative assessment of higher education performance in the Slovak Republic and a targeted action plan that provides ten policy actions in three areas: (i) developing and implementing a co-ordinated higher education strategy, (ii) using funding to support and reward higher education performance, and (iii) enabling responsive institutional governance and management.

\subsection{Working methods}

This project began in June 2020 and concluded with the release of this report in November 2021. The European Commission-Slovak Republic-OECD project team established a Slovak Working Group to provide regular input on the project. It was composed of policy makers from the Ministry of Education (MoE), the Institute for Education Policies, the Slovak Accreditation Agency for Higher Education (SAAHE) and the Research Agency. It met four times, providing input in June 2020 on the project plan and factfinding activities; in October 2020 to provide input on the OECD's preliminary diagnosis and policy directions; in January 2021 to discuss recent higher education developments in the Slovak Republic, their relevance to the project and discuss implementation considerations for reforming the governance and funding of higher education, and in June 2021 to provide feedback on the recommended policy actions presented in this report.

Between September 2020 and March 2021, several activities were organised by the OECD, with the participation as observers of the European Commission's DG REFORM, the Slovak Government Office and an independent local expert. These included:

- interviews with 28 key stakeholders, including higher education institution (HEI) leaders, staff and students, as well as representatives from the business, innovation and research ecosystem

- a peer-learning webinar with presentations from six international experts from Austria, Denmark, Finland, Ireland, Portugal and the United States to share insights about reforming higher education governance and funding from a policy and institutional perspective, that brought together about 100 Slovak participants

- institutional roundtable discussions with 17 stakeholders from 5 Slovak higher education institutions, including leaders, academic and professional staff and students.

This report and action plan use several sources of information:

- OECD and European Union international datasets

- background information and select data provided by an independent local expert and reviewed by the Slovak Working Group, describing the Slovak higher education system's key features and performance 
- stakeholder input received through bilateral interviews and institutional roundtables

- comparative analysis based on international expert input and desk-based comparative research

\subsection{Analytical approach}

\section{Higher education performance}

Performance in higher education involves three dimensions: the efficiency of higher education systems - the output achieved for a given level of financial and human inputs; its quality - the value of outputs achieved against widely agreed indicators or procedures; and its equity - the distribution of higher education opportunities and benefits among all learners (OECD, 2020[1]).

Achieving an efficient, high-quality and equitable higher education system poses significant challenges to governments and higher education institutions across OECD countries. Higher education systems have to cope with the rapid expansion of higher education systems (as well as sharp reductions in some countries in recent years), the rising costs of higher education and growing demands placed on HEls to meet the needs of the individuals and communities they serve, including an increasingly diverse student population and employers with new and fast-changing skills demands (OECD, 2019[2]).

This project focuses primarily on the quality of higher education, both at the national level, by examining quality in a comparative perspective, and at the institutional level, by examining the types of measures that government and HEls could use to identify and measure quality, and the policies that could be used to support and reward quality.

Multiple factors shape the ability of HEls to achieve quality outcomes across their core missions - teaching, research and engagement. Below we map out these factors and their interplay as they shape one important outcome of higher education systems: the labour market outcomes of graduates (Figure 1.1).

\section{Figure 1.1. Factors affecting outcomes for graduates and employers}

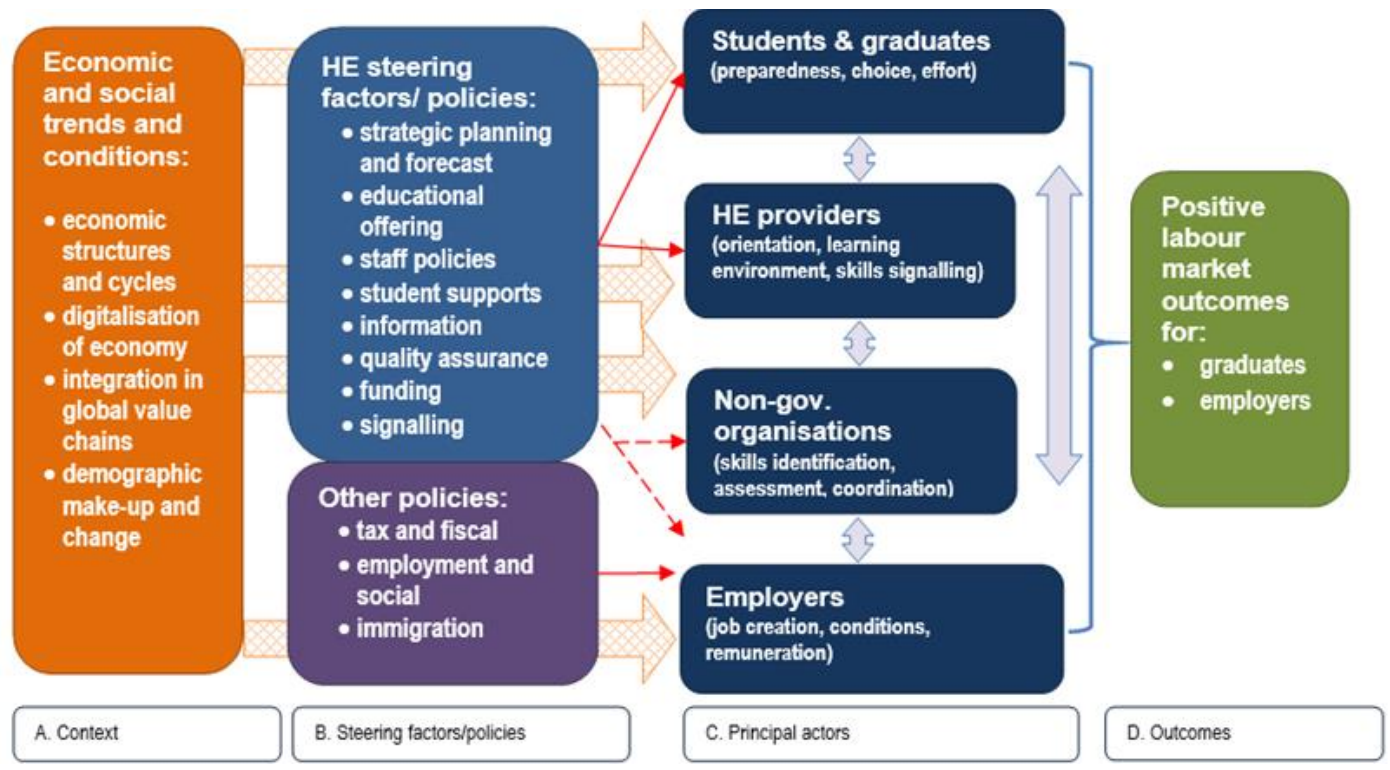

Source: OECD (2020[3]), Labour Market Relevance and Outcomes of Higher Education in Four US States, https://doi.org/10.1787/38361454en, Figure 1.1. 
The analysis in this report recognises that the performance of Slovak HEls must be assessed in light of the economic and social context that shapes the actions of institutions and the outcomes they can achieve.

It focuses on the actions that government can take to steer the actions of HEls, support and reward quality improvements, and enable institutional governance and management processes and practices that are responsive to the needs of higher education stakeholders and the broader Slovak society.

\section{Context and focus of the action plan}

Recent international and national studies highlighting the need to improve the quality of the higher education system provided a wide range of recommendations for system improvement, placing a particular focus on the governance and funding of the system (see in particular the European Commission's Peer Counselling on the Governance of Higher Education Institutions in the Slovak (2018[4] $)$ and the Learning Makes Sense study (To dá rozum) (2021 $\left.{ }_{[5]}\right)$, discussed in Chapter 3, Box 3.4).

In addition, over the course of 2020 and 2021, the Slovak government has identified higher education reform as a key policy priority to support the country's economic prosperity and social well-being. Its vision for higher education was most recently set out in the "Modern and Successful Slovakia" plan (Moderné a Úspešné Slovensko). The plan aims to "increase the performance of Slovak universities, promote their diversification, focus on inclusion, international co-operation and collaboration with the private sector, so that the universities can contribute to reinforcing the quality of human capital, social inclusion, and the innovation potential of the Slovak Republic, increased economic competitiveness, economic growth and sustainable jobs" (Government of the Slovak Republic, 2021 ${ }_{[6]}$ ).

The Slovak Republic's national Recovery and Resilience plan was prepared in the spring of 2021 in the context of the European Commission's Resilience and Recovery Facility (RRF). The RRF is a large-scale financial instrument to "help [member states] repair the immediate economic and social damage brought about by the coronavirus pandemic" and help ensure "a sustainable and inclusive recovery that promotes the green and digital transitions" (European Commission, $2021_{[7]}$ ).

The government's new vision for higher education complements existing reform plans, most notably a government-led proposal to make important changes to the Higher Education Act, with a particular focus on modifying the internal governance structure of higher education institutions (HEls). The government has announced plans to submit an amendment to the national parliament and adopt an amended act by the end of 2021.

Against this policy backdrop, this action plan aims to help the Slovak government in three ways. It aims to help Slovak authorities: 1) refine their current policy plans in light of the OECD's analysis; 2) consider additional actions that could help achieve the government's goal of a higher quality higher education system; and 3) carefully prepare for the successful implementation of higher education reform.

Furthermore, implementation - the process by which policy objectives translate into actions that result in changes in practice - is a major focus of this action plan. This is a priority because previous OECD work suggests that fragile implementation planning has often hindered the effectiveness of education and skills reforms in the Slovak Republic (OECD, 2020[8]). While this challenge is not unique to higher education, it is of particular relevance, as the Slovak government considers large-scale, complex higher education reforms to address the wide range of problems the country faces in this field, as presented in Chapter 2.

Previous analysis of policy making in the Slovak Republic underpins the need for a strong focus on implementation. For instance, according to the Sustainable Governance Indicators (SGI) compiled annually for 41 OECD and European Union (EU) countries by the Bertelsmann Foundation (Bertelsmann Stiftung, 2020[9]), the Slovak Republic ranks 38 out of 41 in terms of the effectiveness of its policy implementation, adequacy of its institutional arrangements and co-ordination across institutional lines of government decision making (see Figure 1.2). 


\section{Figure 1.2. Executive capacity in the Slovak Republic compared to OECD/EU countries (2020)}

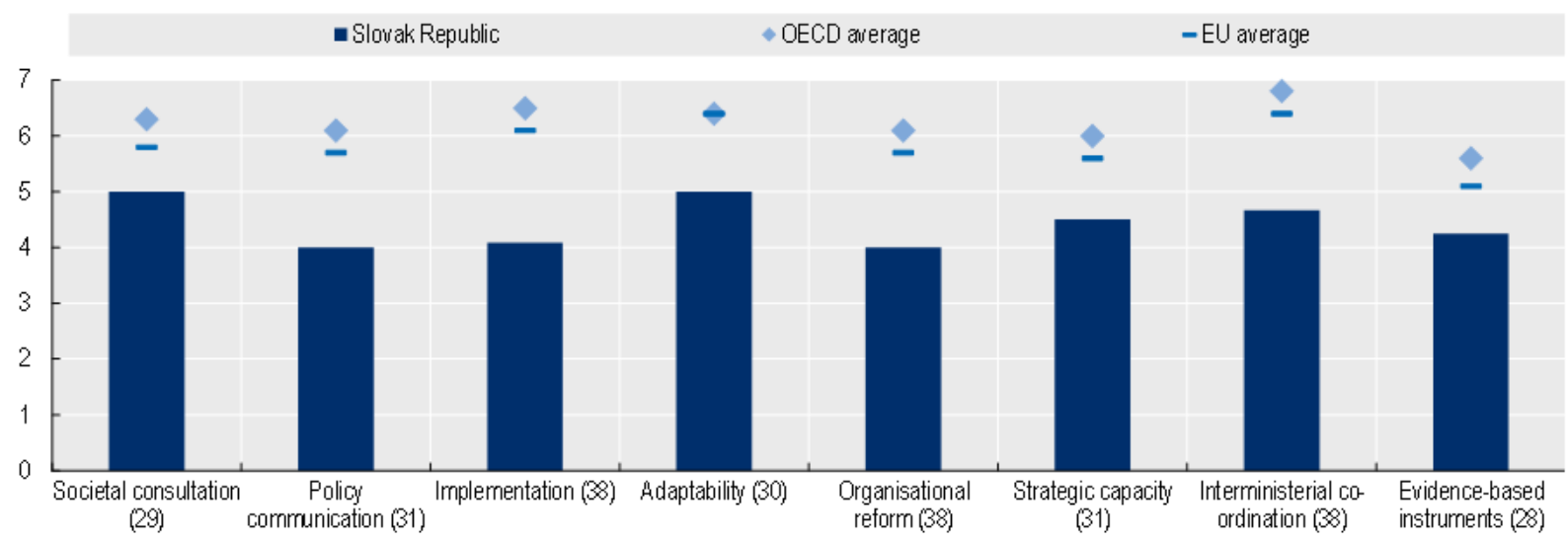

Note: These indicators are not specific to education policy. National experts give scores on a scale of 1 (lowest) to 10 (highest).

The number in parentheses represents the rank of the Slovak Republic among 41 OECD and EU countries.

Source: Bertelsmann Stiftung (2020[9]), Sustainable Governance Indicators 2020, https://www.sgi-network.org/2020/.

StatLink त्ञाज्य https://doi.org/10.1787/888934278921

\subsection{Structure of the report}

The report contains two further chapters and two annexes.

Chapter 2 provides an overview of the Slovak Republic's higher education system's key features and its higher education performance from a comparative perspective.

Chapter 3 contains an action plan to improve higher education in the Slovak Republic. This action plan, which includes ten policy actions across three pillars, aims to provide a roadmap for the Slovak government to implement higher education reform in a carefully sequenced manner. Each pillar can be regarded as a action step in the reform process. These include:

1. developing and implementing a co-ordinated higher education strategy;

2. using funding to enable and reward higher education performance; and

3. enabling responsive institutional governance and management.

For each pillar (or action step), we provide:

- a review of current policies and practices

- a discussion of challenges limiting the adoption of effective reforms

- relevant international experience that points to possible policy reforms, and

- a set of concrete policy actions that the Slovak government may wish to consider.

Annex A presents two in-depth case studies of higher education reforms in Portugal and Finland relevant to the areas of reform discussed in this report and considered by the Slovak authorities. These cases studies offer insights on the reform context in Portugal and Finland, the policy design and implementation process, and outlines some lessons learnt that the Slovak Republic may consider alongside the policy actions recommended in the action plan.

Annex B provides a list of organisations that participated in the project's stakeholder interviews and roundtable discussions. 
18 | 1. INTRODUCTION

\section{References}

Bertelsmann Stiftung (2020), Sustainable Governance Indicators 2020, https://www.sginetwork.org/2020/ (accessed on 14 December 2020).

European Commission (2021), The Recovery and Resilience Facility, https://ec.europa.eu/info/business-economy-euro/recovery-coronavirus/recovery-andresilience-facility en (accessed on 31 May 2021).

European Commission (2018), Peer Counselling on the Governance of Higher Education Institutions in the Slovak Republic, document provided to the OECD for the project "Improving Higher Education in the Slovak Republic".

Government of the Slovak Republic (2021), Moderné a Úspešné Slovensko (Modern and Successful Slovakia), https://www.slov-lex.sk/legislativne-procesy/-/SK/dokumenty/LP-2021112 (accessed on 4 August 2021).

MESA10 (2021), “Learning Makes Sense" project, https://en.todarozum.sk/ (accessed on 10 August 2021).

OECD (2020), Labour Market Relevance and Outcomes of Higher Education in Four US States: Ohio, Texas, Virginia and Washington, Higher Education, OECD Publishing, Paris, https://dx.doi.org/10.1787/38361454-en.

OECD (2020), OECD Skills Strategy Slovak Republic: Assessment and Recommendations, OECD Skills Studies, OECD Publishing, Paris, https://dx.doi.org/10.1787/bb688e68-en.

OECD (2020), Resourcing Higher Education: Challenges, Choices and Consequences, Higher Education, OECD Publishing, Paris, https://dx.doi.org/10.1787/735e1f44-en.

OECD (2019), Benchmarking Higher Education System Performance, Higher Education, OECD Publishing, Paris, https://dx.doi.org/10.1787/be5514d7-en. 


\section{Higher education in the Slovak Republic}

This chapter provides context for the OECD-European Commission-Slovak Republic Project's action plan to improve higher education in the Slovak Republic. It starts with a brief overview of the Slovak economic context, describes key features of the Slovak higher education system and presents the Slovak Republic's higher education performance from an international perspective. 


\subsection{The Slovak Republic's economy and labour market context}

Over the past two decades, the Slovak Republic has sustained robust economic growth of almost $4 \%$ on average, experienced falling unemployment rates, and living standards converging towards the OECD average (OECD, 2019 $\left.{ }_{[1]}\right)$. However, the Slovak Republic's benefits from participating in the global economy remained limited by its downstream positioning in global value chains. While the Slovak Republic has pockets of innovative activities in information communication and technology (ICT) and engineering, biomedicine, and bioeconomy, the country's economy continues to rely on the manufacturing sector (MIRRI, 2020[2]). While productivity gains in the manufacturing sector have been particularly large - multiplied by more than five since 1995, well above increases in Austria, the Czech Republic, Hungary and Slovenia - the productivity of business services only increased by $20 \%$ over the period, the smallest increase in the region. Productivity and innovation have also been disproportionately concentrated in large manufacturing firms, with little benefits to local small and medium-sized enterprises (SMEs) (OECD, $\left.2019_{[1]}\right)$.

While a large share of Slovaks has benefitted from the economic development of the past decades and the country benefits from lower income inequality than on average among OECD countries, some regions and groups continue to face significant barriers to economic success. The coronavirus (COVID-19) pandemic may exacerbate these difficulties, as it has particularly affected sectors such as tourism, retail and construction, hitting workers hard in these sectors, who were already facing economic challenges, including low-skilled workers, women, youth, and Roma populations (OECD, 2021 ${ }_{[3]}$ ).

The pandemic may also accelerate the digital transformation across economic sectors and increase automation, already taking place at a fast pace in the Slovak Republic. OECD estimates based on the Survey of Adult Skills (a product of the Programme for the International Assessment of Adult Competencies, PIAAC) suggest that about $34 \%$ of Slovak workers face a high risk of seeing their jobs automated, and another $31 \%$ face significant changes in their job tasks due to automation (Nedelkoska and Quintini, 2018[4] $)$. Moreover, the share of jobs at risk of being automated is the highest among OECDPIAAC countries due to the size of the Slovak manufacturing sector (OECD, 2020[5]).

The impact of the digital transformation on labour market demand is difficult to predict, particularly with the disruption caused by the pandemic. Forecasts on future labour market demand in the Slovak Republic conducted before the pandemic by Cedefop, and the National Project on Forecasting Labour Market Developments (Národný projekt: Prognózy vývoja na trhu práce, NPPVTP) suggested that strong labour market demand across both high-skilled and medium-skilled occupations was likely to extend into the future. Most employment growth is expected in medium-skilled occupations, followed by high-skilled occupations. Forecasts suggest that employment growth in medium-skilled occupations will be driven by replacement demand resulting from the large shares of workers nearing retirement age, while employment growth in high-skilled occupations will be driven by new job creation (OECD, 2020[5]).

With a population of 5.4 million, the Slovak Republic has one of the fastest ageing populations among OECD countries, resulting in a shrinking working-age population. For every ten adults of working age in the Slovak Republic, approximately two adults are currently aged 65 and over. This ratio is currently low compared to most OECD countries but will increase drastically and surpass the European Union (EU) average in 2050. In 2060, it is projected that there will be six adults aged 65 and over for every ten adults of working age. This trend poses a significant challenge to the Slovak economy. For instance, the total number of employed persons could decrease by one-fifth, and the catch-up rate of per capita income with the average for OECD countries might slow down and even be reversed in the long term. This drop in the contribution of labour utilisation to economic growth will make productivity improvements an even more critical driver of economic growth in the future (OECD, 2020 $[5]$ ). The knowledge and skills of workers in the Slovak Republic thus represent an increasingly important focus of government policy to sustain and promote economic prosperity and well-being in the country. 
The Slovak Republic has seen impressive growth in the higher education attainment rate, which doubled for 2534 year-olds- from $16.3 \%$ in 2005 to $31.3 \%$ in 2015 (OECD, 2021[6]). The attainment rate for $25-34$ year-olds reached $39.2 \%$ in 2019 , just below the rate in the EU28 of $40.9 \%$ (Eurostat, $2021_{[7]}$ ). This rapid and recent expansion can be explained by historical events, such as the change of political regime, the separation of the Czechoslovak Republic into two independent states, the creation of new public universities in the country, and the convergence with economic and social trends seen in Western Europe. It can also be explained by the high premium for higher education when attainment was low, attracting many young people to pursue a higher education degree, traditionally conceived of as a theoretical programme, with very few options for short-cycle or vocationally oriented higher education.

However, the Slovak Republic faces significant challenges across its "skills pipeline", from school-level education, higher education through to adult education (OECD, 2020[5]). The higher education system plays a pivotal role in helping Slovaks of all ages succeed in a labour market that is likely to transform in important ways in future years.

\subsection{Key features of the Slovak Republic's higher education system}

\section{Historical context and the current landscape}

Slovak higher education has witnessed significant changes during the last three decades of independent statehood, after being a part of the Czechoslovak education system from 1918 until 1993 (except for a short period of Slovak independent statehood during the Second World War). Since 1993, the Slovak Republic has been building its higher education system in the face of challenges similar to those met by other post-communist Central and Eastern European (CEE) countries. Among other issues, the Slovak higher education system underwent a transformation of the governance and management structures of its higher education institutions (HEIs), curricula changes, and the incorporation of research into the mission of mainly teaching-oriented institutions (Westerheijden and Sorensen, 1999 ${ }_{[8]}$ ). Most importantly, CEE post-communist countries had to deal with the massification of higher education, which took place in Western European countries decades earlier (Trow, 1972[9]; Neave, 1986[10]; OECD, 2006 [11]). Furthermore, Slovak higher education, its structure and regional distribution played an important role in the nation building of the newly established state.

The Slovak higher education sector has since grown in size and changed in structure. In 1991, the Slovak higher education system (still a part of then Czechoslovak Republic) consisted of $13 \mathrm{HEls}$ and 52 faculties ${ }^{1}$ accommodating approximately 62000 students (CVTI, 2021[12]). Following a period of rapid massification, the number of students in Slovak HEls peaked in 2008, then decreased steadily. In 2020, there were $33 \mathrm{HEls}$ and 128 faculties, with a total student enrolment of around 137000 (CVTI, 2021 [13]). This downward trend is a key feature of contemporary Slovak higher education, resulting from a combination of demographic factors and issues specific to the higher education system, including a decline in the share of young Slovaks applying to Slovak HEls and a high share preferring to study abroad (see the section entitled "Performance of Slovak higher education").

The types of HEls in the Slovak Republic have also changed over the past decades, with the introduction of state and private HEls alongside public HEls. State HEls provide professional education in key areas of public service (e.g. health, defence, police). As shown in Figure 2.1. , while student enrolment has declined substantially since 2009, the number of HEls and faculties within HEls (that used to exist as independent legal entities until 2002) have remained broadly stable. 
Figure 2.1. Number of students and HEls in the Slovak higher education system (1991-2020)

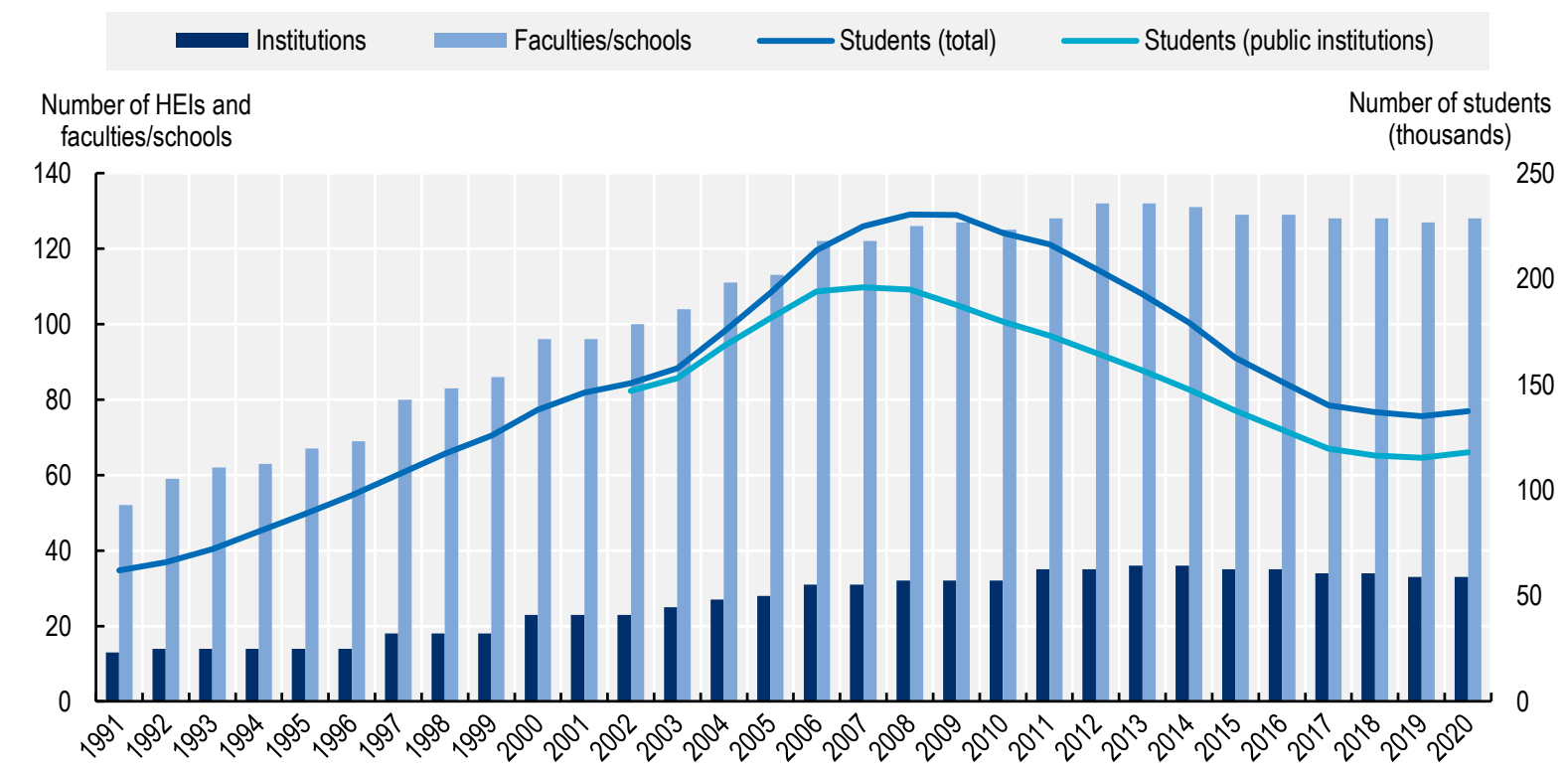

Note: Students refer to both full-time and part-time students. Only HEls providing full-time study programmes are included in the number of institutions.

Source: CVTI (2021 [12]), Časové rady [Timelines], https:/www.cvtisr.sk/cvti-sr-vedecka-kniznica/informacie-0-skolstve/statistiky/casoverady.html?page id=9724.

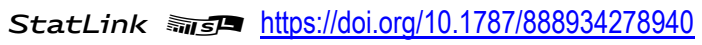

In the academic year 2020/21, the Slovak higher education system was comprised of:

- 20 public HEls, with 117955 students and 106 faculties

- 10 private HEls, with 15356 students and 16 faculties

- 3 state HEls, with 4010 students and 6 faculties

- 5 foreign-based HEls that have permission to provide higher education in the Slovak Republic. ${ }^{2}$

The average size of HEls is small in the Slovak Republic, although there is high variability across HEls. In 2020, the average number of students per HEI was approximately 5900 among the public HEls, 1500 among private HEls and 1300 among state HEls (CVTI, 2021[13]).

However, 19 of the total 33 Slovak universities reported having fewer than 2500 students and 10 reported having fewer than 1000 in 2019. By contrast, the largest Slovak university - Comenius University in Bratislava (UK Bratislava) - reported more than 20000 students, twice as many as the second-largest university - Slovak University of Technology in Bratislava (STU Bratislava). St. Elizabeth College of Health and Social Work in Bratislava (VŠZaSP Bratislava) was the largest private university with around 8000 students, while the Slovak Medical University (SZU Bratislava), with around 2000 students, ranked as the largest state HEI (see Figure 2.2. ).

Slovak HEls are also highly heterogeneous in terms of their level of internationalisation (measured by the share of international students) and research performance (measured by the number of publications per employee registered in the Web of Science Contents Connect database (Clarivate, 2021[14])). Moreover, the western part of the Slovak Republic is home to most HEls and the largest ones, with almost one-third of all HEls located in Bratislava (see Figure 2.3). Nonetheless, the high diversity of Slovak HEls does not translate into any variation in their status or funding allocation model, as discussed later. 
Figure 2.2. Overview of Slovak HEls (2019)

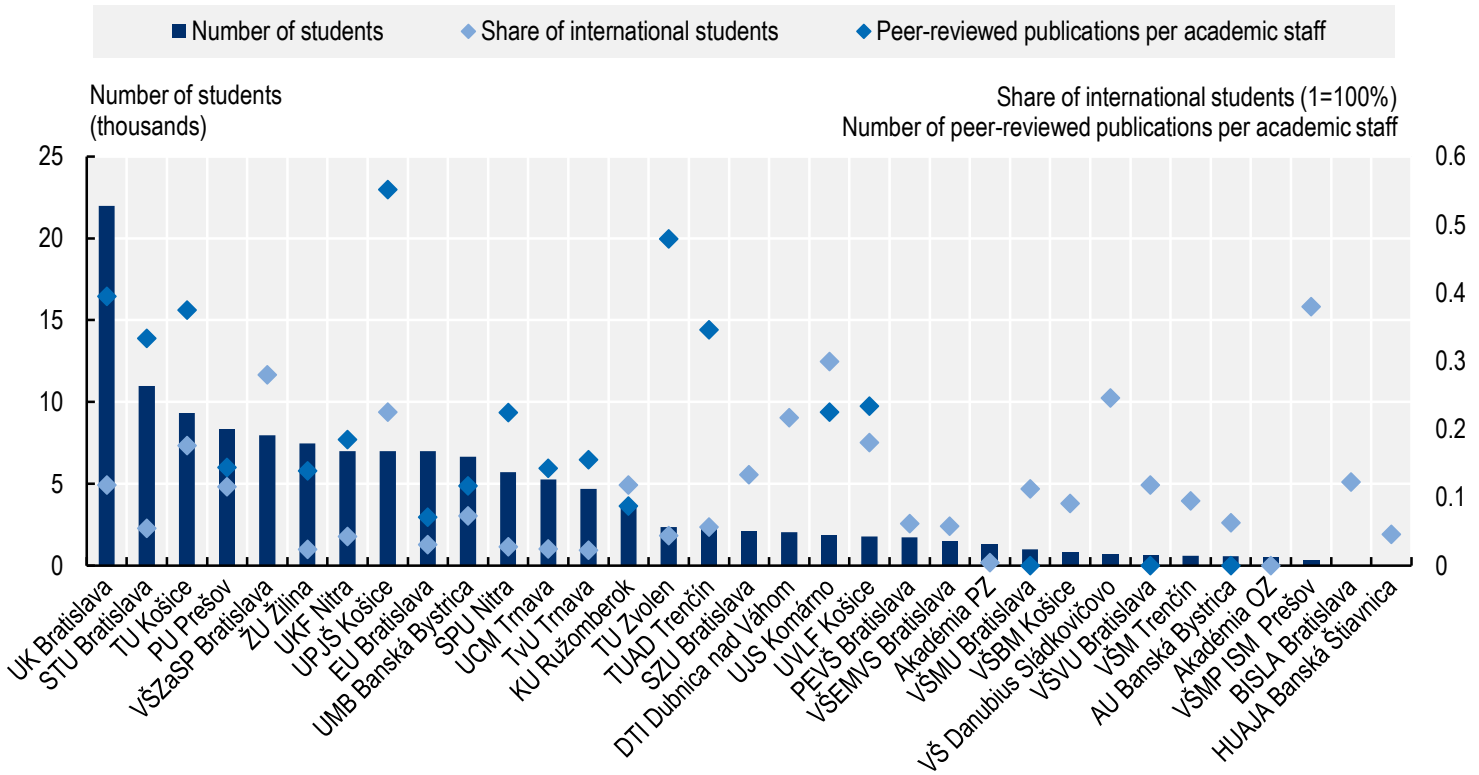

Note: Students refer to both full-time and part-time students.

Sources: Ministry of Education, Science, Research and Sport of the Slovak Republic $\left(2019_{[15]}\right)$, Výročná správa o stave vysokého školstva za rok 2019 [Annual Report on the State of Higher Education for 2019], https://www.minedu.sk/vyrocne-spravy-o-stave-vysokeho-skolstval; CVTI (2021 [16]), Štatistická ročenka - vysoké školy [Statistical Yearbook - Universities], https://www.cvtisr.sk/cvti-sr-vedecka-kniznica/informacie-0skolstve/statistiky/statisticka-rocenka-publikacia/statisticka-rocenka-vysoke-skoly.html?page_id=9596.

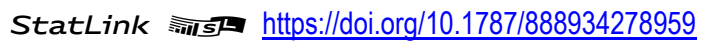

Figure 2.3. Regional distribution of Slovak HEls and number of students (2019)

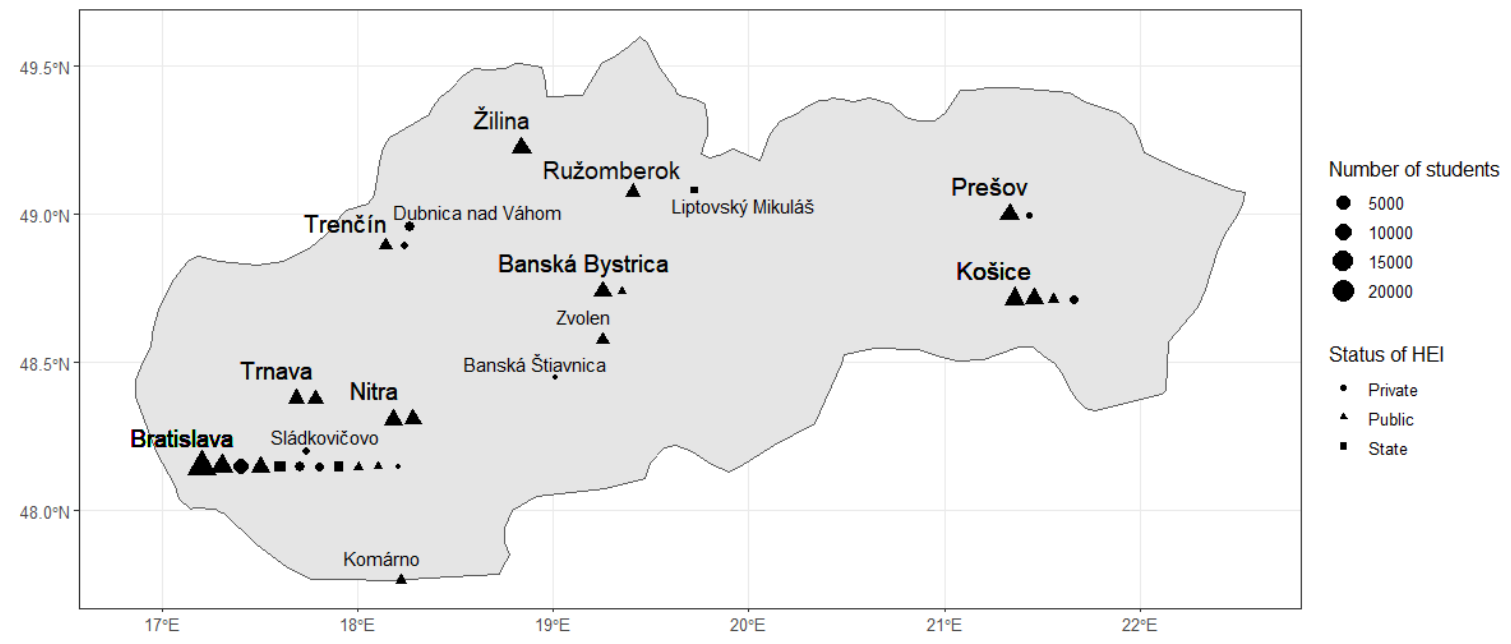

Note: Students refer to both full-time and part-time students.

Sources: Ministry of Education, Science, Research and Sport of the Slovak Republic (2019[15]), Výročná správa o stave vysokého školstva za rok 2019 [Annual Report on the State of Higher Education for 2019], https://www.minedu.sk/vyrocne-spravy-o-stave-vysokeho-skolstval; CVTI $\left(2021_{[16]}\right)$, Štatistická ročenka - vysoké školy [Statistical Yearbook - Universities], https://www.cvtisr.sk/cvti-sr-vedecka-kniznica/informacie-0skolstve/statistiky/statisticka-rocenka-publikacia/statisticka-rocenka-vysoke-skoly.html?page_id=9596. 


\section{Legislative framework}

\section{Types of institutions and key actors in higher education}

The Act on Higher Education No. 131/2002 (hereafter "HE Act") is the main legislation organising the Slovak higher education system (National Council of the Slovak Republic ${ }_{[17]}$ ). The HE Act recognises and defines the types of HEls: public, state and private. Public HEls are funded and regulated by the Ministry of Education, Science, Research and Sport (MoE); state HEls are funded and regulated by ministries with responsibility in the area in which they deliver education (e.g. the Ministry of Health for state medical universities); private HEls operate within the legislative framework but do not receive government funding. The legislation sets out in detail the internal governance structure of HEls at both the institution and faculty levels, as discussed in Chapter 3.

The HE Act was amended in 2007 to introduce three types of institutional profiles, respectively called "university", "higher education institution" and "professional higher education institution", according to the level of teaching provision and the kind of research pursued. Universities provide programmes at all three levels of higher education - bachelor's, master's and doctoral levels - and focus on carrying out basic research. Universities' study programmes are expected to be carried out in close connection with leadingedge research undertaken by the university. Professional HEls are to provide study programmes at the first level (bachelor's) and to conduct applied research. HEls are to be an intermediate type of institution, conducting basic research like universities, but only providing first- and second-level study programmes bachelor's and master's degree programmes (Reichert, $2009_{[18]}$ ). These three institutional profiles were little discussed during the project, suggesting they have had a limited impact on the orientation of Slovak HEls.

In addition, the HE Act identifies three national bodies representing higher education stakeholders in their interactions with the MoE, the key funder of the Slovak higher education system:

- The Higher Education Council (HEC) is an association whose membership mainly comprises HEI employees, appointed by academic senates, either at the HEl or faculty level.

- The Student Higher Education Council (SHEC) is the highest representative body of higher education students in the Slovak Republic. It comprises two student representatives from each $\mathrm{HEI}$. One of the student representatives is elected by the student part of the academic senate, and the other is elected through a direct vote by all the students of the HEI.

- The Slovak Rectors Conference is a platform for all Slovak rectors and represents them in discussions with the MoE, the HEC and SHEC. In November 2020, nine rectors announced the creation of an alternative rectors' platform, open to all interested in higher education reform (Alternatívna platforma slovenských rektoriek a rektorov).

The MoE plays a crucial role in steering the Slovak higher education system, particularly with regard to the public HEls, which it funds. The MoE's main policy lever is the annual allocation of public funding through a formula, discussed in Chapter 3 (see in particular Table 3.4). The MoE also keeps the central registers of HEls, HEls consortia, and HEl study programmes, of higher education students and employees, of theses and publications and manages a financial information system for public HEls called IS SOFIA. In addition, the ministry performs a monitoring role by issuing a comprehensive annual report with key information and data on the higher education system (MoE, 2019[15]). The Ministry also issues regulations, policies and procedures and communicates related changes to HEls, such as instructions for accounting, tuition fees, or keeping internal records of students and research publications.

Substantial changes in higher education policy require legislative amendments to the HE Act or the introduction of new acts, such as the 2018 Act on Quality Assurance in Higher Education, discussed below. Amendments of the HE Act are relatively frequent, with five changes to the Act made in 2019. In 2020, 
changes were made to accommodate responses to the COVID-19 crisis, notably authorising distance education activities and prolonging terms for some elected academic functions.

In addition to the MoE, several government agencies play an essential role in Slovak higher education policy, as presented in Table 2.1.

\section{Table 2.1. Slovak government agencies that play a role in higher education}

\begin{tabular}{l}
\multicolumn{1}{c}{ Agency } \\
\hline $\begin{array}{l}\text { Research Agency (RA) } \\
\text { (http://www.vyskumnaagentura.sk/en/) }\end{array}$ \\
\\
\hline Slovak Research and Development Agency (APVV) \\
(https://www.apvv.sk/?lang=en)
\end{tabular}

(https://www.apvv.sk/?lang=en)

The RA is a research grant agency bilaterally administered by MoE and the Ministry of

Economy. RA administers the allocation of EU funds under the Operational Programme

Research and Innovation (https://www.opvai.sk/). It issues calls for larger project proposals, including investment projects or supporting public-private research collaborations. The annual allocation of RA is not published.

APVV is a smaller research grant agency that supports particular research activities as well as international research collaborations. APVV usually supports middle-sized projects up to EUR 250 000. In 2018, APVV allocated EUR 39.2 million, out of which EUR 21.35 million was on research projects of HEls (Statistical Office of the Slovak Republic, $\left.2019_{[19]}\right]$. Allocation channeled through APVV was volatile in time, though the transparency of the decision process is considered higher in comparison to the Scientific, Cultural and Educational Grant Agencies (VEGA or KEGA) (MoE, 2016[20]).

Scientific, Cultural and Educational Grant Agencies (VEGA and KEGA)

VEGA and KEGA are funded from the state contribution to public HEls, as one of its items, with the total allocation being annually decided and published by the MoE. VEGA (https://www.minedu.sk/podpora-vysokoskolskejvedy-a-techniky-vega-kega/)

is also co-financed from the resources allocated to the Slovak Academy of Science (a different item in the state budget).

VEGA and KEGA support small-scale research, cultural and educational projects, with usual annual budgets of a few thousand euros, covering everyday expenses of selected research, cultural and teaching activities. KEGA is focused on supporting cultural and educational activities, VEGA on research activities. In 2020, KEGA allocated EUR 4.4 million to cover 505 projects of public HEls (KEGA, 2020[21]). In 2019, VEGA allocated EUR 11.75 million to HEls and EUR 4.5 million to the Slovak Academy of Sciences (VEGA, 2020[22]).

Slovak Centre of Scientific and Technical Information (CVTI)

(https://www.cvtisr.sk/)

CVTI hosts the research librarian services, including registers of Slovak research publications, and facilitates access to international research databases. It supports open access publishing and plays a co-ordinating role in international research collaboration. It notably initiated a nationwide academic ethics initiative within the SK4EAR project. It also collects and processes statistics of the educational sector (e.g. the number of students, graduates or teachers). Since 2014, CVTI integrated the Institute for Information and Prognosis in Education, responsible for collecting educational statistics. In the area of higher education, these include:

- $\quad$ admission to HEls (including applicants, accepted and enrolled)

- $\quad$ numbers of HEl students and graduates

- numbers of HEl employees, working hours and salaries

- HEls financing

- basic information on social and economic conditions of HEI students (during study and shortly after graduation through a tracking tool).

National Institute for Certified Educational Measurements (NUCEM) (https://www.nucem.sk/en)

State Vocational Education Institute (ŠIOV) (https://siov.sk/)

National Institute for Education (ŠPú) (https://www.statpedu.sk/en/) Methodological Pedagogical Centre (MPC) (https://mpc-edu.sk/)
NUCEM administers national and international testing of students' outcomes and other data collection initiatives (including the OECD Programme for International Student Assessment [PISA], the OECD Teaching and Learning International Survey [TALIS] or the PIAAC).

ŠIOV administers projects focused on the development of vocational educational programmes. ŠIOV also provides a structure for the national contact points of international professional networks, such as the National Skills Observatory, European Quality Assurance in Vocational Education and Training (EQAVET) and the Electronic Platform for Adult Learning in Europe (EPALE).

ŠPÚ steers the pedagogical processes at the level of primary and secondary education. ŠPÚ, together with the MPC, support teachers at the primary and secondary level with methodological instructions and training. 


\section{Accreditation and quality assurance}

The Act on Quality Assurance in Higher Education No. 269/2018 and on amendment of Act No. 343/2015 on Public Procurement (hereafter "QA Act"), passed in 2018, introduced a new model for the accreditation of higher education institutions and study programmes in the Slovak Republic (National Council of the Slovak Republic $[23])$. This new model introduces an independent quality assurance body - the Slovak Accreditation Agency for Higher Education (SAAHE) - and places a strong focus on the capacity of HEls to create effective systems of quality assurance in line with European-level practices. This model contrasts with the previous model, where an Accreditation Commission served as an advisory body to the government, but the government was responsible for granting accreditations.

The law sets out a governance structure for the SAAHE that aims to ensure that stakeholders' views are represented in decision making. The SAAHE's highest executive body is the Executive Board, a ninemember entity whose members (except for the Chair, who is selected via public competition) are appointed by the MoE based on nominations received from the Slovak Rectors Conference (two members), the Student Council for Higher Education (two members), the Higher Education Council (two members), representative associations of employers, professional organisations established by law, the Slovak Academy of Sciences, research and development institutions (out of several nominations, two members are appointed by MoE). The QA Act further identifies several funding sources for the SAAHE, including: 1) fees for the agency's activities; 2) funds from the state budget allocated by the MoE; 3) revenues from business activity; and 4) other revenues. Finally, the QA Act requires the SAAHE to be assessed by the European Association for Quality Assurance in Higher Education (ENQA) at least once every five years. The next assessment is planned for 2024.

The SAAHE supports the accreditation process by publishing standards to be met by HEls. It has published three sets of QA standards since 1 September 2020: 1) standards for the internal quality assurance system of HEls; 2) standards for study programmes; and 3) standards for habilitation procedures as well as procedures for appointing professors. In addition to standards, the SAAHE also published the list of evaluators conducting quality assurance processes, which it identified based on an open call for applications. ${ }^{3}$

The QA Act obliges HEls to develop and maintain an internal system of quality assurance. The first applications for the internal quality assurance system of $\mathrm{HEl}$ evaluation were expected in the second half of 2021. HEls' internal quality assurance systems will be assessed in the next accreditation process, which was initially expected to be completed by 2024. However, a legislative amendment in December 2020 moved the deadline to 2023. Accreditations will be granted by the SAAHE, based on applications submitted by HEls, and after assessing HEls' internal quality assurance systems.

While both institutional and programmatic accreditation exists in the Slovak Republic, programmatic accreditation is expected to be phased out, and programme quality to be ensured internally by HEls. Programme-level accreditations were conducted in two recent rounds, by 1 September 2020 for programmes in fields where HEls had not yet provided programmes and by 31 March 2021 for programmes in fields in which HEls had already provided programmes. 


\subsection{Performance of Slovak higher education}

The following section presents an overview of the performance of Slovak higher education in education and research from a comparative perspective.

\section{Education performance}

\section{Attainment}

Increased investments in higher education have yielded significant growth in the share of Slovaks participating in and attaining tertiary education. At the beginning of the 1990s, tertiary education attainment in the Slovak Republic lagged that of other European countries. However, the share of tertiary educated in the 25-34 year-old age bracket more than tripled between 1998 and 2019, from 11\% to over 39\% (OECD, 2021[6]). Table 2.2 presents tertiary education attainment for 25-34 year-olds in 2009 and 2019.

\section{Table 2.2. Trends in tertiary education attainment rates of $25-34$ year-olds by gender $(2009,2019)$}

\begin{tabular}{l|c|c|c|c|c|c|c}
\hline & \multicolumn{2}{|c|}{ Men } & \multicolumn{2}{c|}{ Women } & \multicolumn{2}{c}{ Total } \\
\hline & 2009 & 2019 & 2009 & 2019 & 2009 & 2019 \\
\hline Slovak Republic & $17 \%$ & $31 \%$ & $24 \%$ & $48 \%$ & $21 \%$ & $39 \%$ \\
\hline OECD average & $32 \%$ & $39 \%$ & $41 \%$ & $51 \%$ & $36 \%$ & $45 \%$ \\
\hline EU23 average & $29 \%$ & $38 \%$ & $40 \%$ & $51 \%$ & $35 \%$ & $44 \%$ \\
\hline
\end{tabular}

Note: Data for the Slovak Republic: There is a break in the time series, as data for 2019 refer to International Standard Classification of Education (ISCED) 2011 while data for 2009 refer to ISCED 1997.

The EU23 average refers to the average of 23 EU countries that were also OECD members as of the end of 2019 (see Endnote 4 for the countries).

Source: OECD (2020[24]), Education at a Glance 2020: OECD Indicators, https://doi.org/10.1787/69096873-en, Table A1.2.

\section{Access, completion and choice of study programmes}

\section{Access}

Access to higher education has increased significantly in recent decades (Figure 2.4). This is due to the expansion of the system and a reduction in student cohorts without a corresponding reduction in the number of institutions. This has led to a steadily growing acceptance rate, resulting in decreased selectivity of HEls. In 2019, around $90 \%$ of applicants to Slovak HEls were accepted, and around $90 \%$ of accepted applicants enrolled (MoE, 2019[15]).

The high acceptance rate is a consequence of the decline of the age cohorts usually entering higher education on the one hand and the decline in the number of applications received by Slovak HEls on the other. For example, in 2019 , the reference population of 19 -year-olds declined to approximately $70 \%$ of its 2010 level (Eurostat, 2021 ${ }_{[25]}$ ), while the number of higher education applications dropped to $54 \%$ of its 2010 level (MoE, 2019[15]). This suggests that both demographic decline and the low attractiveness of higher education as a pathway for young adults contribute to shrinking the size of higher education cohorts.

Application statistics produced annually by the MoE reveal different rates of selectivity among HEls. Small HEls with a focus on the arts (VŠMU, VŠVU Bratislava and AU Banská Bystrica), along with the state police academy (Akadémia PZ), and HEls in the healthcare field are able to be the most selective in their acceptance process (accepting every third applicant), and have seen more than $80 \%$ of accepted applicants enrol in the HEI (MoE, 2019 $\left.{ }_{[15]}\right)$. Various causes explain the differences in selectivity rates, including the small number of study spaces available in highly specialised institutions. However, it may 
also be a signal of the greater attractiveness of these HEls. In contrast, some HEls have acceptance rates close to $100 \%$ and a low share of enrolled students, as illustrated in Figure 2.5).

\section{Figure 2.4. University application process at the national level in the Slovak Republic (2010 19)}

Bachelor's and long first-degree programmes

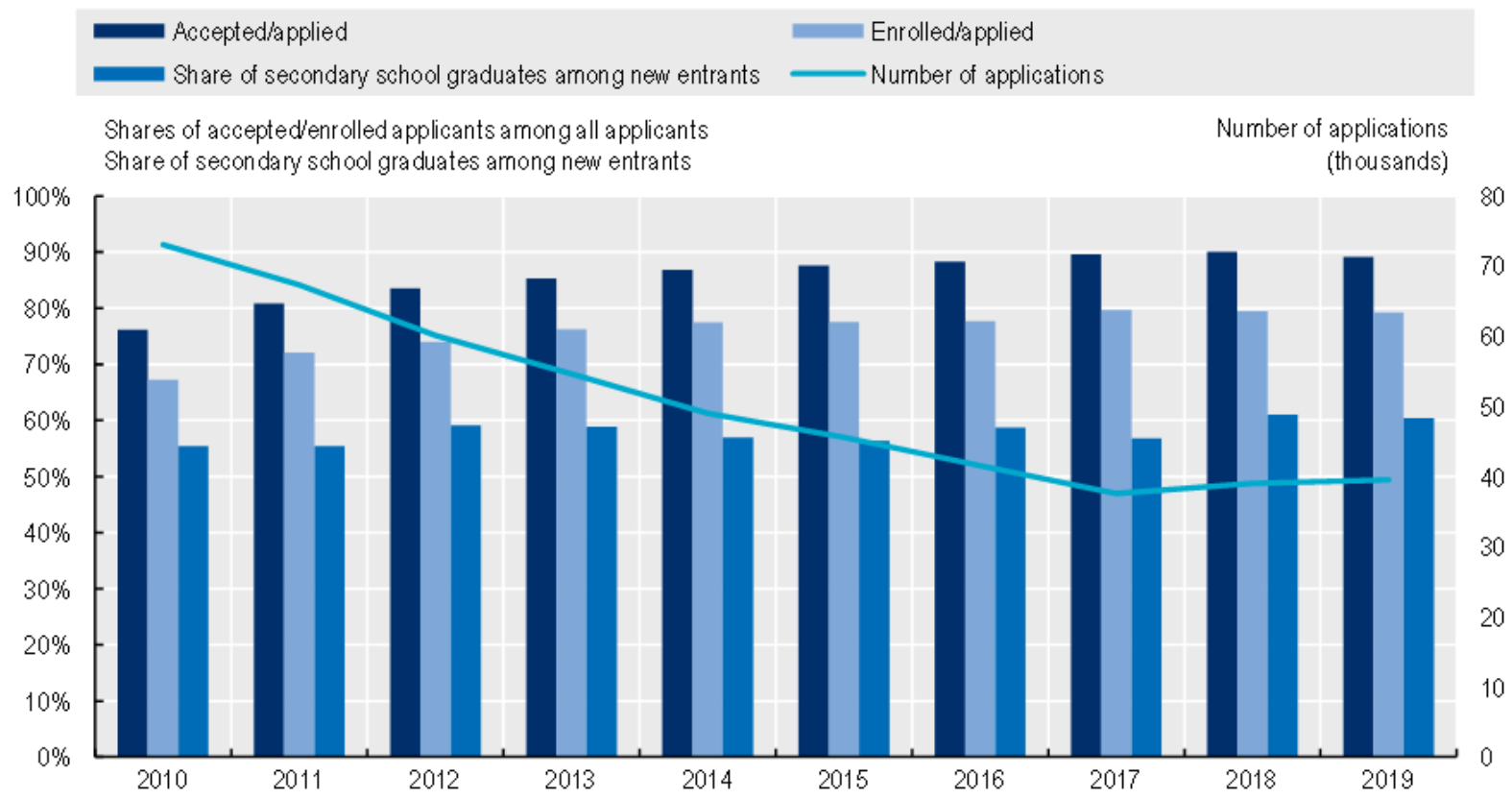

Source: Ministry of Education, Science, Research and Sport of the Slovak Republic (2019 [15]), Výročná správa o stave vysokého školstva za rok 2019 [Annual Report on the State of Higher Education for 2019], https://www.minedu.sk/vyrocne-spravy-o-stave-vysokeho-skolstval.

StatLink 케느 https://doi.org/10.1787/888934278997

While the average selectivity of Slovak HEls has declined, this does not mean that students from all backgrounds can access higher education. Some groups remain significantly under-represented in Slovak higher education (particularly Roma students), raising key equity issues (OECD, 2019 $\left.{ }_{[1]}\right)$.

In addition, adult learners comprise a small share of higher education students in the Slovak Republic. Approximately $85 \%$ of new entrants at the bachelor level in the Slovak Republic are below the age of 25 . While this is broadly in line with the OECD average (84\%), the share of students below the age of 25 varies significantly across countries, from more than $96 \%$ in Belgium, Japan and Korea, to $68-69 \%$ in Israel, Sweden and Switzerland. The gap between the Slovak Republic and the OECD average widens at the master level, as $88 \%$ of new entrants at master level are below the age of 30 in the Slovak Republic, significantly above the OECD average of $74 \%$. Similarly, $66 \%$ of new entrants at the doctoral level are below 30 in the Slovak Republic, significantly above the OECD average of 57\% (OECD, 2020, pp. 212, Table B4.3[24]). The age profile of higher education students is consistent with findings of recent analysis that pointed out the need to increase the accessibility and attractiveness of educational and training opportunities for adults in the Slovak Republic (OECD, 2020[5]). 
Figure 2.5. University application process at the HEl level in the Slovak Republic (2019)

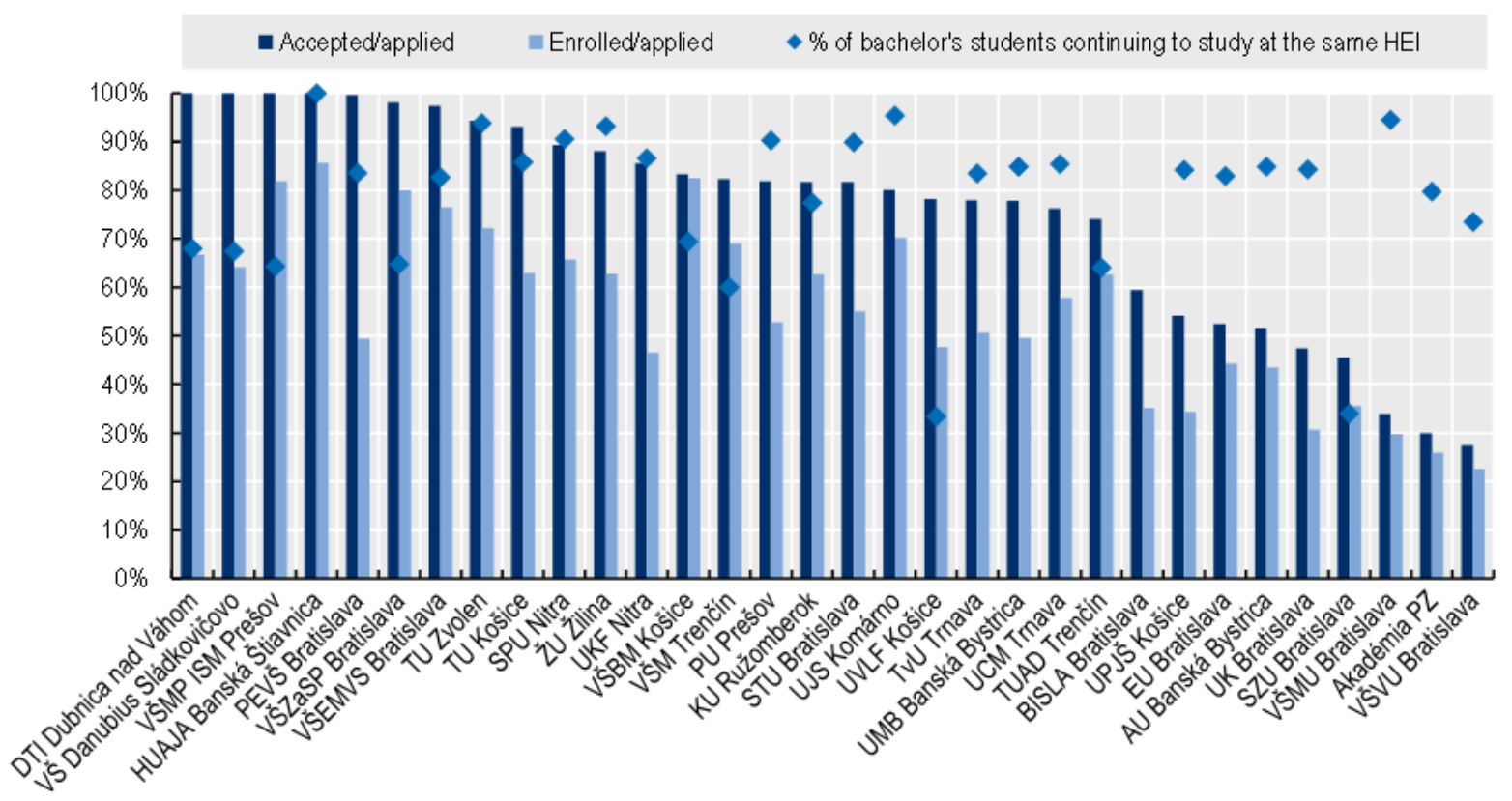

Sources: Ministry of Education, Science, Research and Sport of the Slovak Republic (2019[15]), Výročná správa o stave vysokého školstva za rok 2019 [Annual Report on the State of Higher Education for 2019], https://www.minedu.sk/vyrocne-spravy-o-stave-vysokeho-skolstval; CVTI (2021 [16]], Štatistická ročenka - vysoké školy [Statistical Yearbook - Universities], https://www.cvtisr.sk/cvti-sr-vedecka-kniznica/informacie-0skolstve/statistiky/statisticka-rocenka-publikacia/statisticka-rocenka-vysoke-skoly.html?page_id=9596.

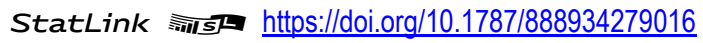

\section{Completion}

Higher education completion rates refer to the proportion of students who enter a higher education programme and graduate from it within the theoretical duration of the programme or within a set timeframe (for example the theoretical duration of the programme plus three years). While students may leave a programme for a variety of reasons, such as to pursue attractive employment opportunities or to find a programme better fit to their needs (OECD, 2019 $\left.{ }_{[26]}\right)$, completion rates provide important information on whether complete higher education "on time", and therefore on the efficiency of HEIs (OECD, 2019 [27]).

In 2017, across the eight OECD countries that submitted cross-cohort data (as no true cohort data was available for the Slovak Republic), $77 \%$ of students who entered a bachelor's programme completed it within the theoretical duration of the programme. The Slovak Republic was significantly below this average with a $62 \%$ completion rate. At short-cycle higher education level (a level few Slovak students pursue), the Slovak Republic had the lowest completion rate at 55\% among the eight countries with cross-cohort data, below the eight-country average of $70 \%$ (OECD, 2019, pp. 225, Table B5.1[26]).

There are notable gender differences with respect to completion rates in the Slovak Republic. In line with every other country with cross-cohort data, women in short-cycle and bachelor's programmes had higher completion rates than men. This difference was smaller in short-cycle higher education programmes, with a 6 percentage-point difference between women and men in the Slovak Republic (57\% for women, 51\% for men), below the 10 percentage-point difference on average in the eight countries with cross-cohort data ( $75 \%$ for women, $65 \%$ for men). By contrast, it was comparatively larger at bachelor's level reaching 
17 percentage points ( $70 \%$ for women, $53 \%$ for men) in the Slovak Republic, above the OECD average of 12 percentage points ( $82 \%$ for women, $70 \%$ for men). (OECD, 2019, pp. 225, Table B5.1[26]).

\section{Choice of study programmes}

Students' choice of study programmes is not a measure of performance per se. However, it provides important information on the potential alignment of the skills of future graduates with the needs of the labour market. The following section briefly reviews attainment rates - which provide information about the field of graduates currently in the labour force, and entry rates - which provide indications as to the profile of future graduates.

Higher education attainment data reveal that the Slovak Republic is the OECD country with the largest share of higher education graduates holding a master's degree, with $31 \%$ holding such qualification level in 2019 , compared to $14 \%$ on average among OECD countries (OECD, 2020[24]) (see Figure 2.6). This feature is shared, albeit to a lesser extent, by Central and Eastern European countries, such as the Czech Republic, Poland and Slovenia. This is due to the very high share of students (nearly $90 \%$ ) who complete a bachelor's degree and continue immediately to a master's degree programme the following academic year (Lukáč and Hall, 2019[28]).

\section{Figure 2.6. Share of 25-34 year-olds with tertiary education in OECD countries, by level of tertiary education (2019)}

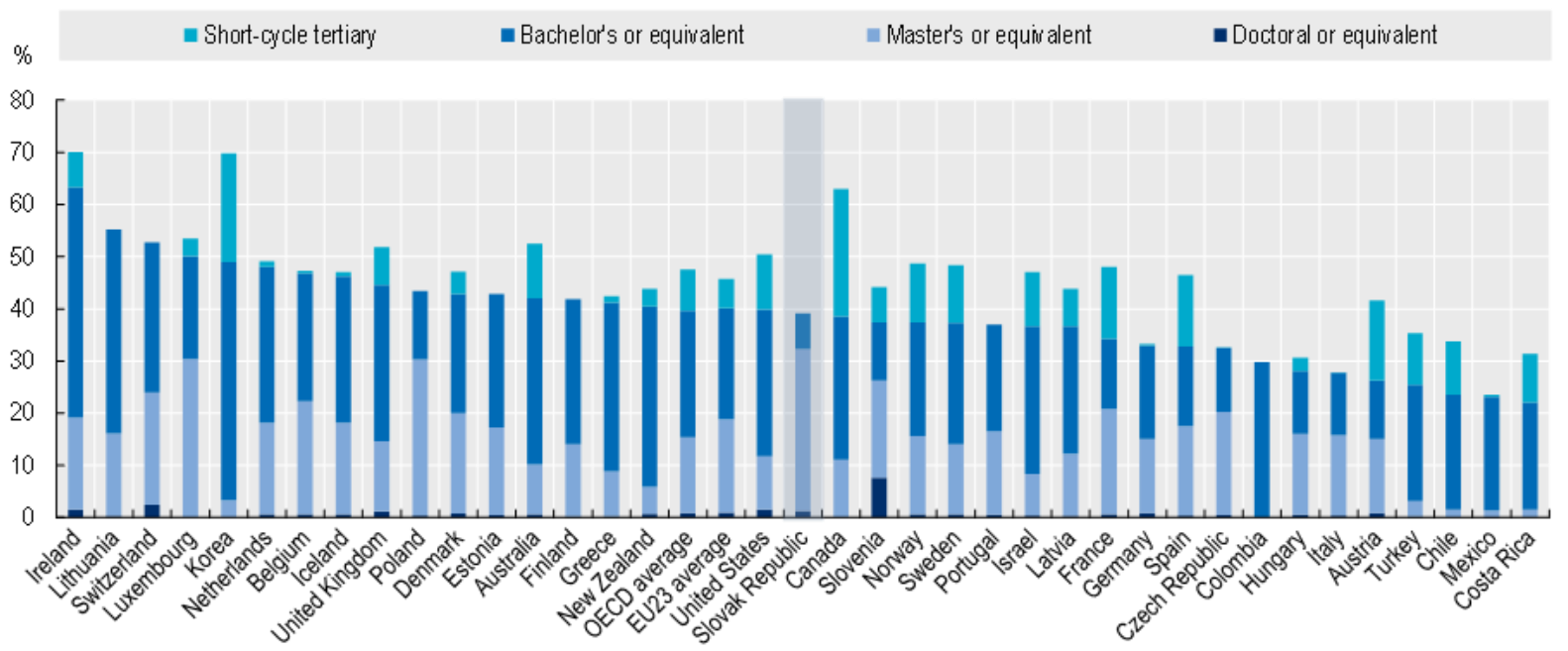

Note: Countries are ranked in descending order of the percentage of 25-34 year-olds with a bachelor's, master's or doctoral or equivalent degree. Some categories might be included in other categories. Refer to the source for more information.

The EU23 average refers to the average of 23 EU countries that were also OECD members as of the end of 2019 (see Endnote 4 for the countries).

Chile: Year of reference differs from 2019. Refer to the source for more details.

Source: OECD (2020[24]), Education at a Glance 2020: OECD Indicators, https://doi.org/10.1787/69096873-en, Figure A1.6.

StatLink 제그 https://doi.org/10.1787/888934279035

By contrast, in 2019, only $7 \%$ of Slovak higher education graduates held a bachelor's degree as their highest qualification, compared to $24 \%$ among OECD countries. Short-cycle tertiary education is also very limited in the Slovak Republic, with no data reported for 2019 versus $8 \%$ on average in the OECD. At the other end of the spectrum, the share of doctoral graduates ( $1 \%$ of all higher education graduates) in the 
Slovak Republic is similar to the OECD average. This suggests that Slovak students do not view the bachelor's degree, and even less, short-cycle tertiary education, as standalone educational pathways.

Turning to entry rates provides information about the choice of current students and future graduates. Excluding international students in 2018, the bachelor's entry rate for students under the age of 25 was $38 \%$ in the Slovak Republic, below the OECD average of $44 \%$. The master's entry rate for students under the age of 30 was $27 \%$, almost twice the share on average in the OECD (14\%), suggesting continued student preference for pursuing master's level studies. The doctoral entry rate for students under the age of 30 was $1.5 \%$, above the OECD average of $1 \%$ (OECD, 2020, pp. 212, Table B4.3[24]).

Students choose their field of study based on their career aspirations and preferences, which are often formed well before they enter higher education (Hofer, Zhivkovikj and Smyth, 2020[29]). Looking at the fields of recent graduates sheds light on the potential alignment between the knowledge and skills of graduates and the needs of the labour market. Looking at 2018 graduates from all tertiary education levels (shortcycle to doctoral), the field of business, administration and law was the most popular, although only one in five graduates in the Slovak Republic completed programmes in this area, compared to one in four graduates on average in the OECD. The health and welfare field was the second most popular, with $17 \%$ in the Slovak Republic, slightly above the OECD average of $15 \%$. The field of education was the third most popular in the Slovak Republic, with $14 \%$ of graduates, above the OECD average of $10 \%$. The field of engineering, manufacturing and construction concentrated $14 \%$ of OECD country graduates and $12 \%$ of Slovak graduates, making it the third most popular among OECD countries and the fourth most popular in the Slovak Republic. Only $4 \%$ of graduates in the OECD and in the Slovak Republic completed programmes in information and communication technologies, despite high labour market demand for graduates from these fields across OECD countries (OECD, 2020, pp. 224, Table B5.2[24]).

Entry patterns by field of study reveal a strong gender bias in study choices in the Slovak Republic, consistent with other OECD countries. In bachelor programmes, there was an overwhelming majority of women (77\%) among students entering health and welfare fields in 2017 in the Slovak Republic, which is the same proportion found on average across OECD countries. At the other end of the spectrum, men dominated science, technology, engineering and mathematics (STEM) fields, with $71 \%$ of new entrants in bachelor programmes in the Slovak Republic, slightly above the OECD average of $70 \%$. The gap was narrower in the business, administrative and law field, with 59\% of women entering this field at the bachelor level in the Slovak Republic, yet it remained above the OECD average of 54\% (OECD, 2019, pp. 205, Table B4.2[26])

\section{Internationalisation}

The Slovak Republic faces significant brain drain as large numbers of young people completing upper secondary education choose to leave the country to pursue their higher education studies. The Slovak Republic has one of the highest rates of higher education students enrolled abroad, second only to Luxembourg, with $19 \%$, compared to $4 \%$ on average in the EU $23^{4}$ and $2 \%$ on average in OECD countries (OECD, 2020, pp. 240, Table B6.3[24]). Due to historical ties and language similarities ${ }^{5}$, the Czech Republic represents the top study destination for Slovak students. In 1992, the number of Slovak students studying in the Czech Republic was around 2500 according to an estimate from the MoE (Šerý et al., 2013[30]). Almost 30 years later, around 22000 Slovak students are enrolled in study programmes within the Czech higher education institutions, accounting for almost half of all international students (OECD, 2021[6]).

On the other hand, the Slovak Republic is lagging in attracting international students, especially at advanced levels of study. Although international students make up $9 \%$ of new entrants at the bachelor level in the Slovak Republic and on average across OECD countries, the Slovak Republic fails to attract more international students at higher levels of education. For example, the share of international new entrants at the master's level on average among OECD countries $(21 \%)$ is almost three times that of the Slovak Republic (8\%). Similarly, at the doctoral level, one out of ten new entrants is international in the 
Slovak Republic (10\%), compared to three out of ten on average in the OECD (29\%) (OECD, 2020, pp. 212, Table B4.3[24]).

There have been improvements in recent years, however, with 7 international students per 100 national students (whether enrolled at home or abroad) in 2018, compared to 6 on average in OECD countries (OECD, 2020, pp. 240, Table B6.3[24]). National data suggests the figure might be higher, with international students representing about $11 \%$ of all students enrolled at the bachelor's, master's and doctoral levels in 2020 (CVTI, 2021 ${ }_{[16]}$ ). It is notable that the upward trend in international enrolment is driven in large part by Ukrainian students, who typically study in Slovak-language programmes, combined with a decline in domestic students. In 2020 , Ukrainian students represented approximately $37 \%$ of international students enrolled in Slovak institutions at the bachelor's, master's and doctoral level (CVTI, 2021 $\left.{ }_{[16]}\right)$.

However, despite progress in attracting international students, the ratio between international students in the Slovak Republic and Slovaks studying abroad shows a pattern opposite to the OECD average. In 2018, there were three foreign or international students for each national student studying abroad, on average among OECD countries, while this ratio was 0.4 in the Slovak Republic (OECD, 2020, pp. 240, Table B6.3[24]).

Furthermore, international students in the Slovak Republic concentrate in selected fields of study (e.g. medicine, veterinary medicine, pharmacy) and tend to study separately from Slovak students. According to a recent study, the limited availability of English-language programmes in Slovak higher education, the low internationalisation of the curriculum, and the low integration of international students and staff within the Slovak higher education environment limit the benefits of internationalisation for both domestic and international students (MESA10, 2021 [31]).

\section{Skills and labour market outcomes}

The following section focuses on two measures often used to assess higher education outcomes: graduates' information-processing skills, as measured by the OECD Survey of Adult Skills (PIAAC), and graduate labour market outcomes. However, a wide range of factors beyond higher education influence graduate skills and labour market outcomes - for instance, broader economic and employment conditions influence the opportunities available to higher education graduates. The data provided must thus be read with this caveat in mind.

Slovak higher education graduates scored relatively well in key information-processing skills in the Survey of Adult Skills (PIAAC) (the first cycle was collected in 2011-12). Comparing mean scores, Slovak graduates scored above the OECD average in numeracy (274 compared to 266) and literacy (276 compared to 262). However, the value added by higher education to the literacy of secondary education graduates is relatively smaller than on average among OECD countries, with the literacy scores of secondary school graduates approaching those of higher education graduates (OECD, 2019[32]).

Slovak graduates scored below the OECD average in problem solving in a technologically rich environment, which is particularly important to succeed in an interconnected and digital world. Some $25.6 \%$ of adults in the Slovak Republic had high levels of skills in the area (scoring at Level 2 or 3), below the OECD average of $29.7 \%$ (OECD, 2019, pp. 58, Figure $2.15_{[32]}$ ). This suggests that the skills of graduates may not be well matched to the needs of businesses making growing use of robotics and information technology (IT) solutions in the Slovak labour market.

In addition, Slovak workers' soft skills, such as management, communication and self-organisation seem under-developed compared to OECD countries (OECD, 2019[1]). Data collected by Profesia, the largest Slovak work portal, suggests that soft skills appear more often in job descriptions than technical skills: while four soft skills were listed among the top ten most sought-after skills in 2010, six soft skills appeared in the top ten in 2020, a larger number than technical skills. In addition, new skills such as "teamwork" and "responsibility" have entered the top ten and "independence" has become more important in 2020 
compared to 2010 (Molnárová, 2021 [33]). Given that the Slovak Republic is the OECD country with the highest percentage of jobs at high risk of automation (see Figure 2.7), soft and transversal skills are likely to be increasingly important to labour market success.

Figure 2.7. Cross-country variation in job automatability and percentage of jobs at risk of significant change in selected countries $(2012,2015)$

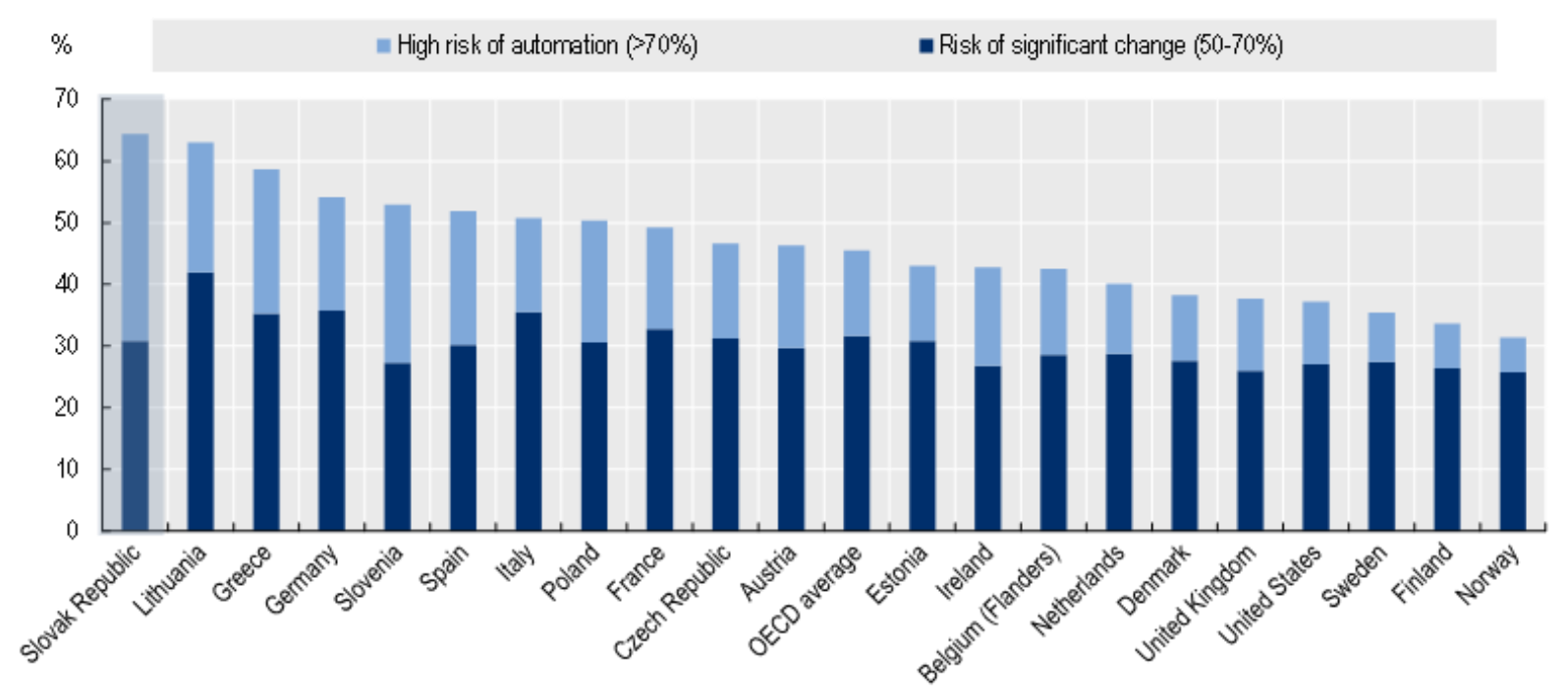

Note: "High risk" means more than $70 \%$ probability of automation. "Risk of significant change" means $50-70 \%$ probability.

Source: Nedelkoska and Quintini (2018[4]]), Automation, skills use and training, https://doi.org/10.1787/2e2f4eea-en, Figure 4.2.

StatLink 제 SR https://doi.org/10.1787/888934279054

In some OECD countries, individuals continue to develop labour-market-relevant skills, including through adult education. However, as illustrated in Figure 2.8, Slovak adults are among the least willing to participate in adult education compared to the OECD average, with a normalised score of 0.49 compared to a normalised score of 5.14 on average in the OECD. This puts pressure on the higher education system to equip young graduates with transversal skills so they can adapt to changes in job requirements and to provide programmes attractive to workers who will need to upgrade their skills later in life. 
Figure 2.8. Key indicators for developing relevant skills, Slovak Republic and OECD average (2012, 2015, 2018)

Relative position in country ranking (based on normalised scores), where higher values reflect better performance

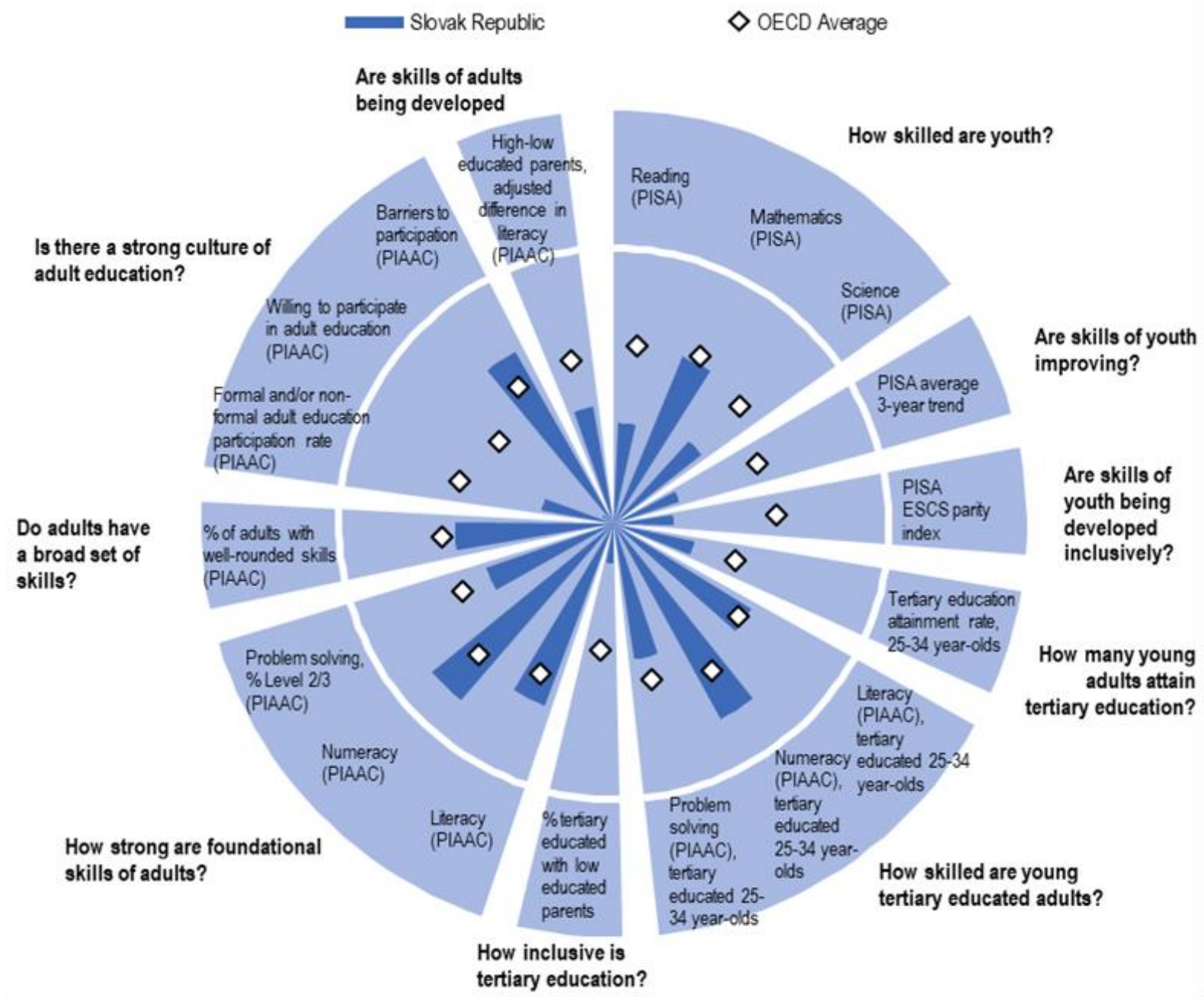

Note: How to read this chart: The normalised scores indicate the relative performance across OECD countries. So the further away from the core of the chart, the better the performance. For example, the indicator "willing to participate in adult education" has a low score compared to the average, indicating a share of employees willing to participate near the bottom of the ranking.

The OECD average (when using PIAAC data) is based on the sample of OECD countries/regions assessed in the Survey of Adult Skills (PIAAC). Source: OECD (2020[24]), OECD Skills Strategy Slovak Republic: Assessment and Recommendations, https://doi.org/10.1787/bb688e68-en, Figure 1.4 .

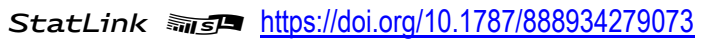

In terms of employment outcomes, 2020 data provided to the OECD team by the MoE suggests high rates of employment across study fields 6-18 months after completing higher education, with an average employment rate for graduates from over more than 2600 study programmes reaching $95.2 \%$ after 6 months, with very high rates across fields. ${ }^{6} \mathrm{MoE}$ uses this data as part of the funding formula calculation (specifically, to calculate the graduate employment coefficient).

However, OECD data based upon standard international methodologies highlight key challenges regarding graduate employment and earnings in the Slovak Republic, compared to other countries. Across OECD 
countries, higher education graduates have higher employment rates than individuals who have completed upper secondary education. This is true in the Slovak Republic but to a lesser extent than on average among OECD countries for bachelor's, master's and doctoral degree holders, with the exception of graduates from short-cycle tertiary programmes (Table 2.3).

Table 2.3. Employment rates of graduates, by education attainment and age in the Slovak Republic (2019)

\begin{tabular}{|c|c|c|c|c|c|c|c|c|c|c|c|c|}
\hline & \multirow{2}{*}{\multicolumn{2}{|c|}{$\begin{array}{l}\text { Below upper } \\
\text { secondary }\end{array}$}} & \multirow{2}{*}{\multicolumn{2}{|c|}{$\begin{array}{c}\text { Upper } \\
\text { secondary }\end{array}$}} & \multicolumn{8}{|c|}{ Tertiary } \\
\hline & & & & & \multicolumn{2}{|c|}{$\begin{array}{c}\text { Short-cycle } \\
\text { tertiary }\end{array}$} & \multicolumn{2}{|c|}{$\begin{array}{c}\text { Bachelor's or } \\
\text { equivalent }\end{array}$} & \multicolumn{2}{|c|}{$\begin{array}{l}\text { Master's or } \\
\text { equivalent }\end{array}$} & \multicolumn{2}{|c|}{$\begin{array}{l}\text { Doctoral or } \\
\text { equivalent }\end{array}$} \\
\hline & $\begin{array}{c}25-64 \\
\text { year- } \\
\text { olds }\end{array}$ & $\begin{array}{c}25-34 \\
\text { year- } \\
\text { olds }\end{array}$ & $\begin{array}{c}25-64 \\
\text { year- } \\
\text { olds }\end{array}$ & $\begin{array}{c}25-34 \\
\text { year- } \\
\text { olds }\end{array}$ & $\begin{array}{c}25-64 \\
\text { year- } \\
\text { olds }\end{array}$ & $\begin{array}{c}25-34 \\
\text { year- } \\
\text { olds }\end{array}$ & $\begin{array}{c}25-64 \\
\text { year- } \\
\text { olds }\end{array}$ & $\begin{array}{c}25-34 \\
\text { year- } \\
\text { olds }\end{array}$ & $\begin{array}{c}25-64 \\
\text { year- } \\
\text { olds }\end{array}$ & $\begin{array}{c}25-34 \\
\text { year- } \\
\text { olds }\end{array}$ & $\begin{array}{c}25-64 \\
\text { year- } \\
\text { olds }\end{array}$ & $\begin{array}{c}25-34 \\
\text { year- } \\
\text { olds }\end{array}$ \\
\hline Slovak Republic & $38 \%$ & $34 \%$ & $78 \%$ & $81 \%$ & $91 \%$ & $\mathrm{~m}$ & $75 \%$ & $67 \%$ & $85 \%$ & $81 \%$ & $85 \%$ & $87 \%$ \\
\hline OECD average & $59 \%$ & $60 \%$ & $77 \%$ & $78 \%$ & $82 \%$ & $84 \%$ & $84 \%$ & $83 \%$ & $88 \%$ & $88 \%$ & $93 \%$ & $\mathrm{~m}$ \\
\hline EU23 average & $57 \%$ & $58 \%$ & $77 \%$ & $80 \%$ & $83 \%$ & $86 \%$ & $84 \%$ & $82 \%$ & $88 \%$ & $87 \%$ & $93 \%$ & $88 \%$ \\
\hline
\end{tabular}

Note: $\mathrm{m}$ : Data are not available - either missing or the indicator could not be computed due to low respondent numbers.

The EU23 average refers to the average of 23 EU countries that were also OECD members as of the end of 2019 (see Endnote 4 for the countries).

Source: OECD (2021[6]), OECD Education Statistics, https://doi.org/10.1787/edu-data-en.

There are important differences in graduate employment between age groups in the Slovak Republic. Young higher education graduates have difficulties transitioning to the labour market: $79 \%$ of young higher education graduates (all levels) aged 25-34 are employed in 2019, one of the lowest rates across OECD countries, and 6 percentage points below the OECD average. By contrast, the employment rate for 45-54 year-olds higher education graduates is one of the highest across OECD countries, at $94 \%$ compared to the OECD average of $90 \%$ (OECD, 2020, pp. 82, Table A3.3[24]).

Looking at employment trajectories upon graduation, $82 \%$ of Slovak adults holding a bachelor's degree as their highest attainment aged 15-34 at graduation were employed less than two years after their graduation, compared to $85 \%$ after two to three years, and declining to $73 \%$ after four to five years (Table 2.4 ).

\section{Table 2.4. Employment rates of young adults who have recently completed higher education, by educational attainment and years since graduation, Slovak Republic (2018)}

Adults aged 15-34 at graduation, not in education

\begin{tabular}{l|r|r|r|r|r|r}
\hline & \multicolumn{3}{|c|}{ Bachelor's or equivalent } & \multicolumn{3}{c}{ Master's or equivalent } \\
& $\begin{array}{l}\text { Less than two } \\
\text { years }\end{array}$ & $\begin{array}{c}\text { Two to three } \\
\text { years }\end{array}$ & $\begin{array}{c}\text { Four to five } \\
\text { years }\end{array}$ & $\begin{array}{c}\text { Less than two } \\
\text { years }\end{array}$ & $\begin{array}{c}\text { Two to three } \\
\text { years }\end{array}$ & $\begin{array}{c}\text { Four to five } \\
\text { years }\end{array}$ \\
\hline Slovak Republic & $82 \%$ & $85 \%$ & $73 \%$ & $78 \%$ & $81 \%$ & $77 \%$ \\
\hline OECD average & $80 \%$ & $87 \%$ & $87 \%$ & $83 \%$ & $89 \%$ & $89 \%$ \\
\hline EU23 average & $80 \%$ & $87 \%$ & $86 \%$ & $82 \%$ & $89 \%$ & $89 \%$ \\
\hline
\end{tabular}

Note: The time periods of "less than two years", "two to three years" and "four to five years" refer to 0-23 months, 24-47 months and 48-71 months since completion, respectively.

The EU23 average refers to the average of 23 EU countries that were also OECD members as of the end of 2019 (see Endnote 4 for the countries).

Source: OECD (2020[24]), Education at a Glance 2020: OECD Indicators, https://doi.org/10.1787/69096873-en, Table A3.5. 
On the contrary, on average in OECD countries, employment rates increase as graduates gain working experience: $80 \%$ of adults holding a bachelor's degree as their highest attainment aged 15-34 at graduation were employed less than two years after their graduation, compared to $87 \%$ after two to three years and $87 \%$ after four to five years. Similarly, for master's degree holders, their employment rate rises from $78 \%$ two years after graduation to $81 \%$ after two to three years, before falling to $77 \%$ after four to five years. Once again, the Slovak trend does not match the OECD average, as $83 \%$ of adults holding a master's degree as their highest attainment aged 15-34 at graduation were employed less than two years after graduation, compared to $89 \%$ after two to three years and $89 \%$ after four to five years on average among OECD countries (Table 2.4).

Higher education graduates across OECD countries enjoy an earnings premium compared to workers with upper secondary education as their highest educational credential. In 2019, Slovak graduates aged 25-64 earned $55 \%$ more than upper secondary graduates, consistent with the OECD average (54\%). However, this average figure is partly a result of the distribution of graduates across levels of study - with a much greater share completing master's degrees in the Slovak Republic than in the rest of the OECD - and of wide differences by level of study, as illustrated in Table 2.5. Graduates with a master's degree or above enjoy an earnings premium that is about two-thirds of the average figure in the OECD $(60 \%$ compared to $89 \%$ ). In contrast, this premium is only half in the Slovak Republic, compared to the OECD average for bachelor's degree graduates (23\% compared to $43 \%$ ). However, the earnings premium for short-cycle tertiary graduates is almost 1.5 times higher in the Slovak Republic than on average in the OECD, at $19 \%$ compared to $14 \%$.

\section{Table 2.5. Relative earnings of workers in the Slovak Republic, by educational attainment (2018)}

25-64 year-olds with income from employment (full-time full-year workers)

\begin{tabular}{l|r|r|r|r}
\hline & \multicolumn{4}{|c}{ Baseline: Upper secondary education = 100 } \\
\cline { 2 - 6 } & Below upper secondary & $\begin{array}{c}\text { Short-cycle higher } \\
\text { education }\end{array}$ & $\begin{array}{c}\text { Bachelor's or equivalent } \\
\text { Master's, doctoral or } \\
\text { equivalent }\end{array}$ & \begin{tabular}{c} 
Men \\
\hline Slovak Republic
\end{tabular} \\
\hline OECD average & 78 & 114 & 123 & 160 \\
\hline EU23 average & 83 & 119 & 143 & 189 \\
\hline
\end{tabular}

Note: Slovak Republic: Index 100 refers to the combined ISCED Levels 3 and 4 in the ISCED 2011 classification.

The EU23 average refers to the average of 23 EU countries that were also OECD members as of the end of 2019 (see Endnote 4 for the countries).

Source: OECD (2020[24]), Education at a Glance 2020: OECD Indicators, https://doi.org/10.1787/69096873-en, Table A4.1.

As in the rest of the OECD, the earnings of higher education graduates increase with age. In 2018, higher education graduates aged $45-54$ earned $28 \%$ more than their peers with upper secondary education in the Slovak Republic, which is well below the age-related earning premium observed on average among OECD countries (48\%). It is below that of neighbouring countries, such as the Czech Republic (34\%) and Hungary $(30 \%)$, but is above countries with a low premium for older graduates, such as Estonia, Latvia and Lithuania, where it is below $10 \%$. However, for those without higher education, the Slovak Republic is one of the few OECD countries, alongside Estonia, Latvia and Lithuania, where older workers with an upper secondary or post-secondary non-tertiary education earn less than younger workers (OECD, 2020, pp. 90, Figure A4.3[24]).

The moderate earnings premium of higher education graduates compared to those with upper secondary education in the Slovak Republic and the relatively low progression of earnings with age may in part explain falling rates of applications and enrolment in higher education in the Slovak Republic, as discussed earlier. 
Furthermore, many graduates work in jobs that are not well matched to their programme of study. As shown in Figure 2.9, while qualification mismatch - having a qualification that is higher or lower than that required for one's job - was significantly lower in the Slovak Republic $(20 \%)$ than on average in the OECD $(36 \%)$, the Slovak Republic had the fourth highest rate of field-of-study mismatch among countries with available data, at $37 \%$, above the OECD average of $32 \%$. Moreover, while the methodology tends to overestimate over-qualification in countries experiencing rapid higher education attainment, the Slovak Republic was the EU/European Economic Area (EEA) country with the highest share of over-qualified higher education graduates.

OECD analysis further shows that the imbalance between graduate skills and the demand for skills in the labour market comes with a cost: it reduces the productivity and salaries of Slovak workers by an estimated $6 \%$, a high level by international standards considering that gains to labour productivity from reducing skill mismatch ranges from $2.3 \%$ in Poland to $10.1 \%$ in Italy (Giorno, 2019[34]).

Many factors contribute to skills mistmatches in the labour market. Recent OECD analysis suggests that, in the Slovak Republic, the "curricula of higher education courses generally prepare students in theoretical rather than practical ways and do not equip students with the mix of technical and transversal competencies demanded in the labour market" (OECD, 2020, p. 93 $3_{[5]}$ ). At the same time, workplaces in the Slovak Republic may not be making full use of graduate skills. Practices that are known to positively affect the performance of employees and firms are often referred to as high-performance workplace practices (HPWP) and include, among others, quality mentoring and leadership, the provision of workplace training, and employee incentives such as awards, bonus pay, and flexible working hours (OECD/ILO, $2017_{[35]}$ ). The adoption of HPWP is associated with more effective skills use; however, only $17 \%$ of all Slovak jobs adopted HPWP in 2012, compared with $26 \%$ among OECD-PIAAC countries (OECD, 2020[5]). 


\section{Figure 2.9. Skills mismatches in the Slovak Republic (2018)}

\section{OECD Skills for Jobs database}
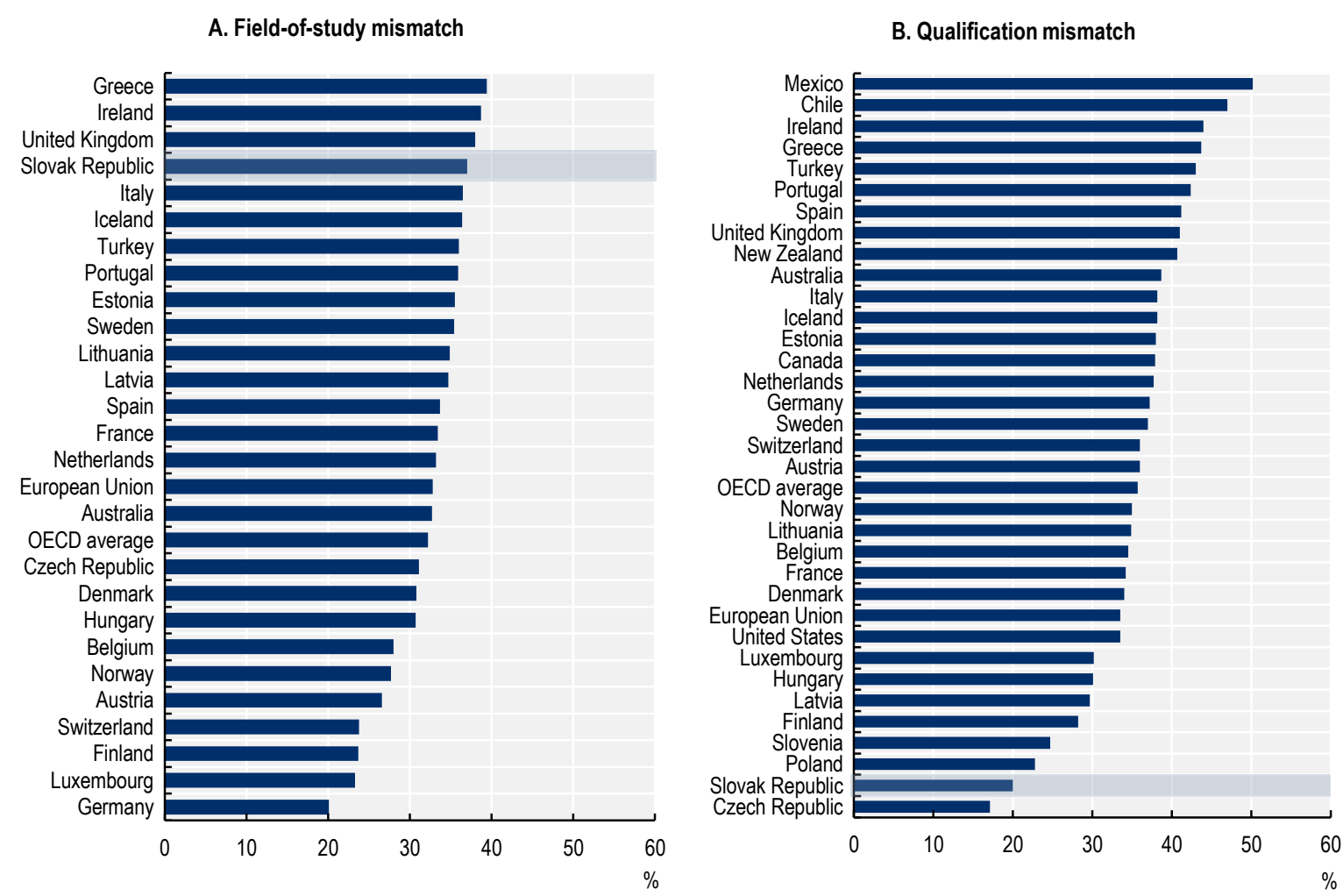

C. Overqualification of tertiary graduates

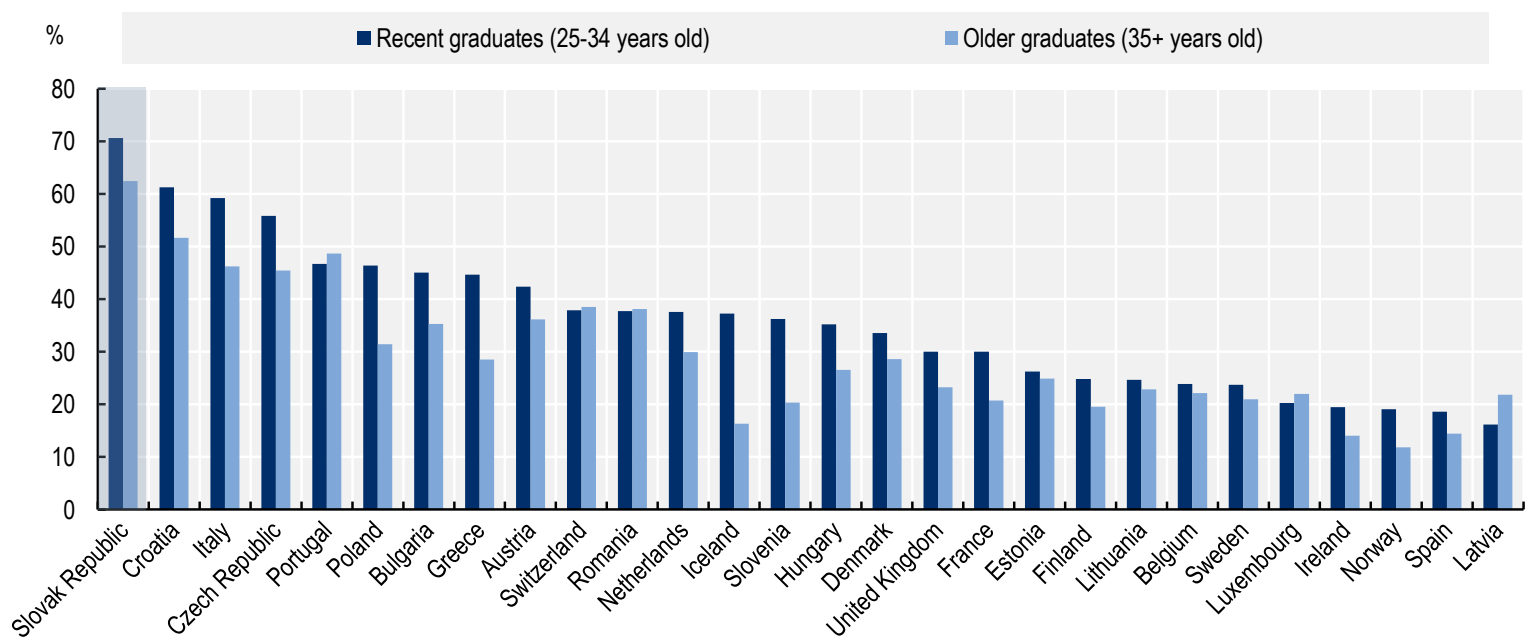

Note: The countries considered across the different indicators change due to the availability of data. The field-of-study indicator can only be calculated for workers aged 15-34. The qualification mismatch index calculates the share of under- or over-qualified workers by computing the modal (i.e. most common) educational attainment level for each occupation and using this as a benchmark to measure whether individual workers' qualifications match the "normal" education requirement of the occupation. This approach has the advantage of being comparable across countries. However, occupational averages will tend to be driven by the majority of older workers with longer tenure. This means that the index might tend to reflect historical rather than current entry requirements. This could lead to over-estimated rates of over-qualification for countries that have seen an increase in tertiary attainment, such as the Czech Republic, the Slovak Republic and Poland. 
Source: OECD (2020[5] ), OECD Skills Strategy Slovak Republic: Assessment and Recommendations, https://doi.org/10.1787/bb688e68-en, Figure 3.3.

StatLink 페대 https://doi.org/10.1787/888934279092

\section{Research and development performance}

Research and development (R\&D) is a key component of higher education performance. Research outcomes are often measured using output indicators, such as publications and citations, doctoral degrees awarded, successful patent applications, external research funding obtained, income from science and technology transfers, publishing and researchers, etc. Input indicators, such as the number of doctoral students/candidates and patent applications, as well as spending on R\&D, are also useful indicators to analyse countries' potential progress in this area.

Gross domestic expenditure on R\&D (GERD) in the Slovak Republic has more than doubled in recent years as the country received substantial funding through the EU structural funds. GERD increased from USD 600 million in 2009 to USD 1900 million in 2015, and declined to USD 1400 million in 2018. Despite this general upward trend, GERD was $0.8 \%$ of gross domestic product (GDP) in 2018, below the OECD average of $2.4 \%$ (OECD, $\left.2021_{[36]}\right)$.

Reflecting on the increase in GERD, there has been significant progress in terms of scientific research production in recent years. Between 2009 and 2018, the total number of scientific publications in the Scopus database across OECD countries increased from approximately 1.3 million to 1.6 million, an increase of around $20 \%$. By comparison, the production of scientific publications almost doubled in the Slovak Republic over the same period, from 3200 to 5900 (OECD, 2021[36]). However, the amount of scientific production is still low compared to international peers. As shown in Table 2.6, the number of publications per thousand inhabitants aged 25-64 was 1.9 in 2018, below the OECD average of 2.7.

Until recently, Slovak HEls received funding for research activities based mainly on the number of publications, which led researchers to focus on the quantity rather than the quality of publications. In 2018, while the number of publications per full-time equivalent researcher was 0.36 in the Slovak Republic, which was close to the OECD average of 0.35 , the average GERD per publication was one of the lowest among OECD countries (Figure 2.10. ). The average impact of these publications, measured by the average number of citations per document, was also one of the lowest (Table 2.6). In 2017, the financing of public HEls was revised to motivate publishing in international, high-impact research journals, as further discussed in Chapter 3. Nevertheless, the capacity of the Slovak higher education system to produce highimpact research needs more time to adjust.

\section{Table 2.6. Quantity and impact of scientific production in selected countries (2018)}

Fractional counts

\begin{tabular}{|c|c|c|c|c|}
\hline & $\begin{array}{c}\text { Number of publications } \\
\text { per thousand inhabitants } \\
\text { aged } 25-64\end{array}$ & $\begin{array}{c}\text { OECD rank } \\
\text { (number of publications) }\end{array}$ & $\begin{array}{l}\text { Percentage of } \\
\text { publications among the } \\
\text { world's } 10 \% \text { most cited }\end{array}$ & $\begin{array}{c}\text { OECD rank } \\
(10 \% \text { most cited })\end{array}$ \\
\hline Finland & 4.2 & 6 & 12.2 & 11 \\
\hline OECD average & 2.7 & - & 9.7 & - \\
\hline Czech Republic & 2.9 & 16 & 5.1 & 33 \\
\hline Germany & 2.5 & 21 & 11.4 & 12 \\
\hline Slovak Republic & 1.9 & 28 & 4.5 & 35 \\
\hline
\end{tabular}

Note: OECD calculations based on Scopus Custom Data, Elsevier, Version 1.2021, May 2021.

Sources: OECD (2021 [37]), Historical population, https://stats.oecd.org/Index.aspx?DataSetCode=HISTPOP; OECD (2021 [36] $)$, OECD Science, Technology and Innovation Scoreboard, https://www.oecd.org/sti/scoreboard.htm. 


\section{Figure 2.10. Publication performance of Slovak R\&D (2018)}

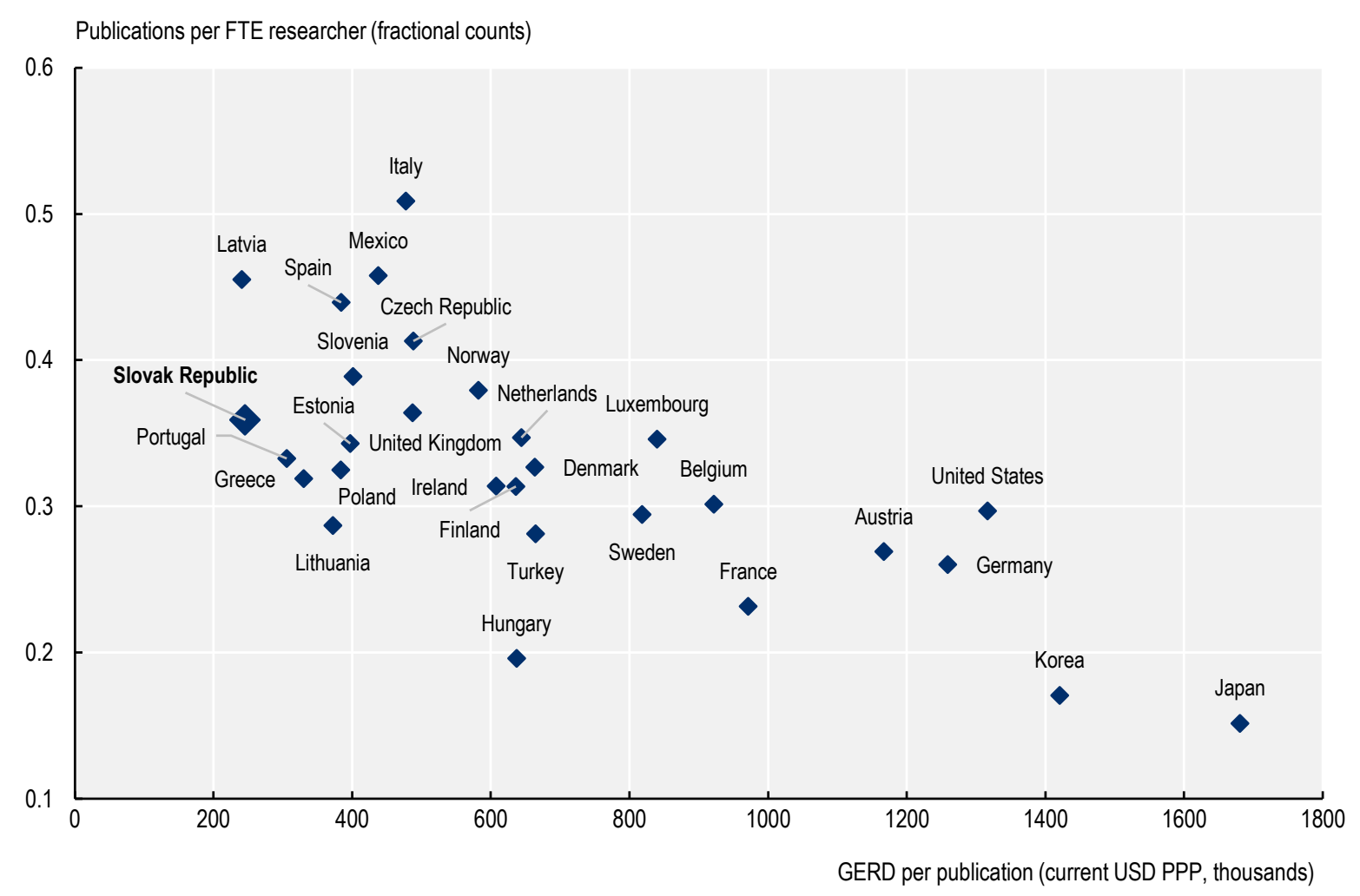

Note: OECD calculations based on Scopus Custom Data, Elsevier, Version 1.2021, May 2021.

Source: OECD (2021 [36]), OECD Science, Technology and Innovation Scoreboard, https://www.oecd.org/sti/scoreboard.htm.

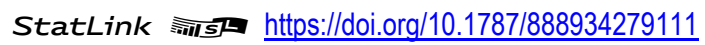

Another way to look at the performance of the R\&D system supported by public resources is the number of applications to European Research Council (ERC) grants ${ }^{7}$ by individual countries. Slovak applications were consistently low between 2006 and 2015, with 36 applications in 2007, compared to 80 from the Czech Republic, 177 from Hungary and 193 from Poland (Technology Centre of the CAS, 2017[38]). Since 2007, the ERC has supported only two project proposals from the Slovak Republic, one of the lowest numbers among the EU28 member states (European Research Council, 2021[39]).

Higher education rankings also continue to play an important role in comparing the performance of higher education institutions worldwide, particularly with respect to research, as they rely largely on bibliometric indicators $\left(O E C D, 2019_{[27]}\right)$. According to various university rankings, Slovak higher education institutions perform consistently below institutions in neighbouring countries:

- Times Higher Education (THE) World University Ranking 2021: Six Slovak universities are listed in the rank 1001+, namely Comenius University in Bratislava, the Slovak University of Agriculture in Nitra, Pavol Jozef Šafárik University in Košice, the Slovak University of Technology in Bratislava, the Technical University of Košice, the University of Žilina (Times Higher Education, 2021 [40]).

- THE Young University Ranking 2021 (universities established less than 50 years ago): None of the Slovak universities is listed among 414 evaluated institutions (Times Higher Education, 2021[41]).

- QS World University Ranking 2021: Four Slovak HEls are included in the final top 1000 universities that are selected out of over 5500 institutions evaluated and considered: Pavol Jozef Šafárik University in Košice (the 651-700 range), Comenius University in Bratislava (the 701-750 range), 
the Slovak University of Technology in Bratislava (the 801-1000 range) and Technical University of Košice (the 801-1000 range) (Quacquarelli Symonds Limited, 2021[42]).

- Best Global Universities 2021: This ranking published by U.S. News includes more than 1600 universities around the world. Among Slovak HEls, Comenius University in Bratislava scores the highest (rank 572), followed by the University of Pavol Šafárik Košice (1148) and Slovak University of Technology Bratislava (1321). In the same ranking, Hungary is represented by 8 institutions, the Czech Republic by 11, and Poland by 31 institutions (U.S. News, 2021 [43]).

- Academic Ranking of World Universities (ARWU 2020): This ranking list includes only Comenius University in Bratislava in the world rank 601-700 (Shanghai Ranking Consultancy, 2020[44]).

According to the Universitas 21 Ranking, a benchmark for governments that focuses on ranking national higher education systems instead of individual universities, Slovak higher education scores below neighbouring countries. The Slovak Republic was ranked $38^{\text {th }}$ out of 50 higher education systems in 2020, with particular weaknesses regarding joint scientific publications with industry and knowledge transfer (Universitas 21, 2021 [45]). 


\section{Notes}

1. The names of the HEls and their faculties had to be listed in the annex to the Higher Education Act (172/1990), which was a federal legislation valid for both the Czech and Slovak Republics of the then Czechoslovakia.

2. The five foreign-based institutions are the College of International and Public Relations Prague (Czech), the Hochschule Fresenius University of Applied Sciences (German), the MOD'SPE PARIS Central Europe (French), the Old Polish University (Polish) and Szent István University (Hungarian) (Eurydice, 2020[46]).

3. The standards, as well as the list of evaluators, can be found at https://saavs.sk/ (accessed on 2 June 2021).

4. The EU23 average refers to the average of $23 \mathrm{EU}$ countries that were also OECD members as of the end of 2019. The 23 countries included in this average are Austria, Belgium, the Czech Republic, Denmark, Estonia, Finland, France, Germany, Greece, Hungary, Ireland, Italy, Latvia, Lithuania, Luxembourg, the Netherlands, Poland, Portugal, the Slovak Republic, Slovenia, Spain, Sweden and the United Kingdom.

5. Slovak students are able to study in Czech study programmes, so they have the same conditions as Czech nationals, including tuition-free education at public and state HEls. Due to significant demographic decline in the Czech Republic, HEls have been intensively targeting Slovak students.

6. Natural sciences: 95.75\%; Technical sciences/Engineering: 94.7\%; Health sciences: 97.34\%; Social sciences/Humanities: $95.18 \%$.

7. Grants include Starting, Consolidator, Advanced, Proof of Concepts and Synergy grants. For more details, see the European Research Council website at https://erc.europa.eu/. 


\section{References}

Clarivate (2021), Current Contents Connect, https://clarivate.com/webofsciencegroup/solutions/webofscience-current-contents-connect/ (accessed on 2 June 2021).

CVTI (2021), Časové rady [Timelines], https://www.cvtisr.sk/cvti-sr-vedecka-kniznica/informacieo-skolstve/statistiky/casove-rady.html?page id=9724 (accessed on 1 July 2021).

CVTI (2021), Štatistická ročenka - súhrnné tabul'ky [Statistical Yearbook - Summary Tables], https://www.cvtisr.sk/cvti-sr-vedecka-kniznica/informacie-o-skolstve/statistiky/statistickarocenka-publikacia/statisticka-rocenka-suhrnne-tabulky.html?page id=9603 (accessed on 1 July 2021).

CVTI (2021), Štatistická ročenka - vysoké školy [Statistical Yearbook - Universities], https://www.cvtisr.sk/cvti-sr-vedecka-kniznica/informacie-o-skolstve/statistiky/statistickarocenka-publikacia/statisticka-rocenka-vysoke-skoly.html?page id=9596 (accessed on 1 July 2021).

European Research Council (2021), Statistics, https://erc.europa.eu/projects-figures/statistics (accessed on 1 July 2021).

Eurostat (2021), Population by educational attainment level, sex and age (\%) [edat_lfse_03], https://appsso.eurostat.ec.europa.eu/nui/show.do?dataset=edat Ifse 03\&lang=en (accessed on 1 July 2021).

Eurostat (2021), Population on 1 January by age and sex [demo_pjan], http://appsso.eurostat.ec.europa.eu/nui/show.do?dataset=demo pjan (accessed on 1 July 2021).

Eurydice (2020), Slovakia - Institutions, https://eacea.ec.europa.eu/nationalpolicies/eurydice/content/institutions-39 en (accessed on 1 July 2021).

Giorno, C. (2019), "Increasing the benefits of Slovakia's integration in global value chains", OECD Economics Department Working Papers, No. 1552, OECD Publishing, Paris, https://dx.doi.org/10.1787/877b7b28-en.

Hofer, A., A. Zhivkovikj and R. Smyth (2020), "The role of labour market information in guiding educational and occupational choices", OECD Education Working Papers, No. 229, OECD Publishing, Paris, https://dx.doi.org/10.1787/59bbac06-en.

KEGA (2020), Ročná správa za činnost' KEGA v roku 2020 [Annual Report on the Activities of KEGA in 2020], Cultural and Educational Grant Agency (KEGA), Bratislava, https://www.minedu.sk/data/att/18483.pdf (accessed on 10 August 2021).

Lukáč, S. and R. Hall (2019), Prechod z prvého na druhý stupeň VŠ [Transition from the First to the Second Level of University], https://analyza.todarozum.sk/docs/401026001im1a/ (accessed on 1 July 2021).

MESA10 (2021), “Learning Makes Sense” Project, https://en.todarozum.sk/ (accessed on 10 August 2021). 
MIRRI (2020), Supporting the transformation of the Slovak economy by increasing its innovation performance, Ministry of Investments, Regional Development and Informatization of the Slovak Republic (MIRRI), Bratislava, https://www.mirri.gov.sk/wpcontent/uploads/2021/03/RTDI-in-Slovakia-AS-IS-report.pdf (accessed on 10 August 2021).

MoE (2019), Výročná správa o stave vysokého školstva za rok 2019 [Annual Report on the State of Higher Education for 2019], Ministry of Education, Science, Research and Sport of the Slovak Republic (MoE), Bratislava, https://www.minedu.sk/vyrocne-spravy-o-stave-vysokehoskolstva/ (accessed on 1 July 2021).

MoE (2016), Učiace sa Slovensko [Learning Slovakia], Ministry of Education, Science, Research and Sport of the Slovak Republic (MoE), Bratislava, https://www.minedu.sk/data/att/10640.pdf (accessed on 9 August 2021).

Molnárová, I. (2021), Ako má vyzerat' absolvent [What should a graduate look like?], https://saavs.sk/wp-content/uploads/2021/05/PrezentaciaSkills final-4.pptx (accessed on 9 July 2021).

National Council of the Slovak Republic (2018), Zákon č. 269/2018 Z.z. o zabezpečovaní kvality vysokoškolského vzdelávania a o zmene a doplnení zákona č. 343/2015 Z. z. [Act No. $269 / 2018$ on quality assurance in higher education and on the change and supplement to Act No. 343/2015], https://www.slov-lex.sk/pravne-predpisy/SK/ZZ/2018/269/20181101 (accessed on 13 August 2020).

National Council of the Slovak Republic (2002), Zákon č. 131/2002 Z.z. o vysokých školách a zmene a doplnení niektorých zákonov [Act No. 131/2002 on higher education and on the change and supplement to some acts], https://www.zakonypreludi.sk/zz/2002-131 (accessed on 13 August 2020).

Neave, G. (1986), "On Shifting Sands: Changing Priorities and Perspectives in European Higher Education from 1984 to 1986", European Journal of Education, Vol. 21/1, pp. 7-24, https://doi.org/10.2307/1502728.

Nedelkoska, L. and G. Quintini (2018), "Automation, skills use and training”, OECD Social, Employment and Migration Working Papers, No. 202, OECD Publishing, Paris, https://dx.doi.org/10.1787/2e2f4eea-en.

OECD (2021), Economic Policy Reforms 2021: Going for Growth: Slovak Republic, OECD Publishing, Paris, https://www.oecd.org/economy/growth/Slovak-Republic-country-note-goingfor-growth-2021.pdf (accessed on 10 August 2021).

OECD (2021), Historical population, https://stats.oecd.org/lndex.aspx?DataSetCode=HISTPOP (accessed on 1 August 2021).

OECD (2021), OECD Education Statistics, https://doi.org/10.1787/edu-data-en (accessed on 1 July 2021).

OECD (2021), OECD Science, Technology and Innovation Scoreboard, https://www.oecd.org/sti/scoreboard.htm (accessed on 1 August 2021).

OECD (2020), Education at a Glance 2020: OECD Indicators, OECD Publishing, Paris, https://dx.doi.org/10.1787/69096873-en. 
OECD (2020), OECD Skills Strategy Slovak Republic: Assessment and Recommendations,

OECD (2019), Benchmarking Higher Education System Performance, Higher Education, OECD Publishing, Paris, https://dx.doi.org/10.1787/be5514d7-en.

OECD (2019), Education at a Glance 2019: OECD Indicators, OECD Publishing, Paris, https://dx.doi.org/10.1787/f8d7880d-en.

OECD (2019), OECD Economic Surveys: Slovak Republic 2019, OECD Publishing, Paris, https://dx.doi.org/10.1787/eco surveys-svk-2019-en.

OECD (2019), Skills Matter: Additional Results from the Survey of Adult Skills, OECD Skills Studies, OECD Publishing, Paris, https://dx.doi.org/10.1787/1f029d8f-en.

OECD (2006), "Cross-border Post-secondary Education in Europe", in Internationalisation and Trade in Higher Education: Opportunities and Challenges, OECD Publishing, Paris, https://doi.org/10.1787/9789264015067-5-en.

OECD/ILO (2017), Better Use of Skills in the Workplace: Why It Matters for Productivity and Local Jobs, OECD Publishing, Paris, https://dx.doi.org/10.1787/9789264281394-en.

Quacquarelli Symonds Limited (2021), QS World University Rankings, https://www.topuniversities.com/university-rankings/world-university-rankings/2021 (accessed on 6 August 2021).

Reichert, S. (2009), Institutional diversity in European higher education: Tensions and challenges for policy makers and institutional leaders, European University Association, Brussels, https://eua.eu/downloads/publications/institutional\%20diversity\%20in\%20european\%20higher \%20education\%20\%20tensions\%20and\%20challenges.pdf (accessed on 10 August 2021).

Šerý, O. et al. (2013), Slováci v České republice: s dưrazem na dojižd'ku za prací a do vysokých škol (Slovaks in the Czech Republic: with emphasis on commuting to work and universities), 16th International Colloquium on Regional Sciences, Valtice, http://dx.doi.org/10.5817/CZ.MUNI.P210-6257-2013-13.

Shanghai Ranking Consultancy (2020), ARWU World University Rankings, https://www.shanghairanking.com/rankings/arwu/2020 (accessed on 1 July 2021).

Statistical Office of the Slovak Republic (2019), Yearbook of Science and Technology 2019, Statistical Office of the Slovak Republic, Bratislava.

Technology Centre of the CAS (2017), ERC choropleth map, http://svizualizace.tc.cas.cz/maps/main.html (accessed on 10 August 2021).

Times Higher Education (2021), World University Rankings 2021, https://www.timeshighereducation.com/world-university-rankings/2021/worldranking\#!/page/0/length/25/sort by/rank/sort order/asc/cols/stats (accessed on 1 July 2021).

Times Higher Education (2021), Young University Rankings 2021, https://www.timeshighereducation.com/world-university-rankings/2021/young-universityrankings\#!/page/0/length/25/sort by/rank/sort order/asc/cols/stats (accessed on 1 July 2021). 
Trow, M. (1972), "The Expansion and Transformation of Higher Education", International Review of Education, Vol. 18/1, pp. 61-84, http://dx.doi.org/10.1007/bf01450272.

U.S. News (2021), 2021 Best Global Universities Rankings, https://www.usnews.com/education/best-global-universities/rankings (accessed on 6 August 2021).

Universitas 21 (2021), U21 Ranking of National Higher Education Systems, https://universitas21.com/rankings (accessed on 1 August 2021).

VEGA (2020), Výročná správa [Annual Report], Scientific Grant Agency (VEGA), Bratislava, https://www.minedu.sk/data/att/16941.pdf (accessed on 10 August 2021).

Westerheijden, D. and K. Sorensen (1999), "People on a bridge: Central European higher education institutions in a storm of reform", in Jongbloed, B., P. Maassen and G. Neave (eds.), From the Eye of the Storm: Higher Education's Changing Institutions, Kluwer Academic Publishers, Dordrecht, https://doi.org/10.1007/978-94-015-9263-5 2. 


\section{An action plan to improve higher education in the Slovak Republic}

This chapter presents the OECD-European Commission-Slovak Republic Project's action plan to improve higher education in the Slovak Republic. The chapter first outlines the structure of the action plan. It then reviews the action plan's three areas of recommendation: 1) developing and implementing a co-ordinated higher education strategy; 2) using funding to support and reward higher education performance; and 3 ) enabling responsive institutional governance and management. The chapter closes with a table summarising the recommended policy actions and key implementation considerations. 


\subsection{Structure and summary of the action plan}

\section{Structure}

This action plan includes ten policy actions across three areas of recommendations to be implemented between 2021 and 2024, and aims to provide a roadmap for the Slovak government to implement higher education reform in a carefully sequenced manner.

Each area of recommendation can be regarded as a step in the reform process, although there will be some timing overlap, as noted in the action plan's summary table provided below:

\section{- Action Step 1: Developing and implementing a co-ordinated higher education strategy}

The Government of the Slovak Republic has a key role to play in developing a higher education strategy in close collaboration with autonomous higher education institutions (HEls). Such a strategy needs to be ambitious but realistic, well communicated, and supported by a large share of higher education stakeholders to generate change in institutional culture and practices.

It needs to build on a shared, evidence-based understanding of higher education challenges, identify clear objectives and the public policy and institutional actions to achieve them. It also needs a concrete plan to implement the strategy and to monitor progress towards the objectives.

Well-designed institutional contracts can help translate the strategy at the institutional level, provided government and HEls have the capacity to design and implement such contracts effectively. Collaboration between government and HEls needs to improve to support the effective development and use of institutional contracts as a key tool to increase the performance of Slovak higher education.

- Action Step 2: Using funding to enable and reward higher education performance

The level of public funding and the method through which government allocates it to HEls can, together, constitute powerful policy levers to shape institutional behaviours and improve quality in teaching, research and engagement. However, to maximise the impact of funding levers, investments need to be designed to enable and incentivise an institutional culture focused on continuous improvement. This means that the actions of HEls, as well as those of individual staff and students, need to collectively focus on the continuous improvement of teaching and learning, research and engagement with the wider society.

This requires a detailed understanding of current barriers to quality improvement to identify issues that may be addressed through funding mechanisms and those that require other changes, such as changes to the legislative and policy framework. It also requires making budget provisions to help HEls build professional teams to ensure transparent and effective use of funding and to help public authorities develop and manage new policy processes, such as the introduction of institutional contracts.

\section{- Action Step 3: Enabling responsive institutional governance and management}

Successfully implementing higher education reform requires that HEls have governance and management arrangements that permit them to make strategic use of public investments to advance their institutional priorities and contribute to national policy objectives.

Governance and management arrangements must be designed in a way that strikes a balance between the legitimate interest of the government to ensure strategic, efficient and accountable use of public resources and the essential need for HEls to function with full scientific and artistic autonomy from the government.

The development of appropriate governance and management arrangements thus requires careful delineation between key principles that need to be established in law, such as enabling HEls to 
responsibly exercise their autonomy based on a clear profile and mission and organisational choices that HEls must make based upon their own needs and characteristics.

Developing appropriate governance and management structures and processes is a challenging process. While it requires a legal framework that sets key parameters and provides sufficient flexibility for HEls to manage their own affairs, such a process fundamentally requires committed individuals in institutional governing and management bodies who have appropriate supports and incentives to shift institutional practices. The shift required is one that would take the Slovak Republic from a higher education model largely concerned with meeting the fast-growing student demand observed in the 1990s and 2000s to one where student enrolment is decreasing, performance remains low, and where HEls need to re-evaluate their role to best respond to a changing global environment and the needs of the wider Slovak economy and society.

In the sections that follow, we outline these three areas of recommendation. For each area of recommendation, we describe in sequence:

- The current state of policy and practice,

- Challenges limiting the adoption of effective reforms,

- Relevant international experience that points to possible policy reforms, and

- Concrete policy actions that the Slovak government may wish to consider.

\section{Summary}

The action plan builds on analysis and advice provided by recent national and international projects, input provided by Slovak stakeholders throughout the project, and a rich body of policy experience across OECD countries.

The following Table lists the policy actions, suggested timeframes, and organisations that might take responsibility for implementing the actions. It also assigns a broad cost estimate to each action: "low", "medium" or "high". These indications should be interpreted as follows:

- Low: Actions that focus on policy processes and can be undertaken by existing bodies or bodies funded through other actions.

- Medium: Actions that focus on policy processes or the provision of financial incentives requiring investment of a limited scale.

- High: Actions that require substantial new investments.

The Table aims to provide a starting point for the implementation of the ten policy actions, based upon the OECD's assessment of implementation considerations in the Slovak Republic. Timeframes, responsibilities and costs will need to be discussed and refined by the Slovak authorities in close collaboration with higher education stakeholders.

\begin{tabular}{l|l|l|l}
\hline \multicolumn{1}{c|}{ Policy action } & \multicolumn{1}{c|}{ Potential timing } & \multicolumn{1}{c}{ Potential lead organisation } & Potential cost \\
\hline \multicolumn{1}{c|}{ Developing and implementing a co-ordinated higher education strategy } \\
\hline $\begin{array}{l}\text { 1. Establish a small multi-stakeholder Higher } \\
\begin{array}{l}\text { Education Task Force responsible for co- } \\
\text { ordinating the development and } \\
\text { implementation of higher education reforms }\end{array}\end{array}$ & $\begin{array}{l}\text { Q4 } 2021 \\
\begin{array}{l}\text { Established by and accountable to } \\
\text { the Prime Minister's Office } \\
\text { Membership identified by Ministry of } \\
\text { Education, Science, Research and } \\
\text { Sport (MoE) in collaboration with } \\
\text { key agencies and stakeholder } \\
\text { organisations }\end{array}\end{array}$ & Medium \\
\hline $\begin{array}{l}\text { 2. Develop a mid-term higher education vision } \\
\text { and strategy articulating linkages between } \\
\text { goals, actions and monitoring results }\end{array}$ & $\begin{array}{l}\text { Q1-Q2 2022: Stakeholder } \\
\text { engagement } \\
\text { Q3 2022: Strategy }\end{array}$ & $\begin{array}{l}\text { Higher Education Task Force, } \\
\text { reporting to the Prime Minister's } \\
\text { Office }\end{array}$ & Low \\
\hline
\end{tabular}


50 | 3. AN ACTION PLAN TO IMPROVE HIGHER EDUCATION IN THE SLOVAK REPUBLIC

\begin{tabular}{l|l|l|l}
\hline \multicolumn{1}{c|}{ Policy action } & \multicolumn{1}{c|}{ Potential timing } & \multicolumn{1}{c}{ Potential lead organisation } & Potential cost \\
\hline & presentation and adoption & & \\
\hline $\begin{array}{l}\text { 3. Develop indicators of quality teaching and } \\
\text { research, and strengthen data collection }\end{array}$ & Q1 2022 & $\begin{array}{l}\text { Expert Group, reporting to the } \\
\text { Higher Education Task Force }\end{array}$ & Low \\
\hline
\end{tabular}

\section{Using funding to support and reward higher education performance}

4. Map out investments required to implement a mid-term higher education strategy, new funding sources and options for enhancing higher education funding levels (the funding envelope)

5. Establish an approach and process for the development of institutional contracts and possible performance parameters

6. Use the institutional contracts to allocate targeted funding to enhance teaching and research quality

7. Consider revisions to the funding formula for higher education and research allocation mechanisms

\begin{tabular}{|l|l|l}
\hline Q2 2022 & $\begin{array}{l}\text { MoE, supported by the Ministry of } \\
\text { Finance and the Higher Education } \\
\text { Task Force }\end{array}$ & Low \\
\hline Q1-Q2 2022 & $\begin{array}{l}\text { Higher Education Task Force, } \\
\text { reporting to the MoE }\end{array}$ & $\begin{array}{l}\text { Medium to } \\
\text { High }\end{array}$ \\
\hline Q2-Q3 2022 & $\begin{array}{l}\text { Expert Group, reporting to Higher } \\
\text { Education Task Force } \\
\text { MoE implementing revisions } \\
\text { recommended by Higher Education } \\
\text { Task Force }\end{array}$ & High \\
\hline $\begin{array}{l}\text { Q1 2022: Recommendations } \\
\text { Q4 2022: Implementation of } \\
\text { revisions to funding formula } \\
\text { and research allocation } \\
\text { mechanisms }\end{array}$ & $\begin{array}{l}\text { Expert Group, reporting to Higher } \\
\text { Education Task Force } \\
\text { MoE implementing revisions } \\
\text { recommended by the Higher } \\
\text { Education Task Force }\end{array}$ & Medium \\
\hline
\end{tabular}

\section{Enabling responsive institutional governance and management}

8. Reduce the level of prescription of the legislation and introduce a small number of key requirements supporting $\mathrm{HEI}$ effectiveness and openness

9. Create incentives for public HEls to adopt a new governance structure on an accelerated, pilot basis

10. Establish appropriate supports to foster best practice in HEI governing bodies
Q1-Q3 2022: Stakeholder engagement

Q4 2022: Legislation passed Q2 2024: New governance arrangements in place

Q2 2022: Incentives designed

MoE

Higher Education Task Force for

Low stakeholder engagement

MoE for legislation drafting

Q1 2023: New governance adopted by pilot HEls

Q3 2022: Guidance on institutional governance
Higher Education Task Force, MoE

Medium 


\subsection{Action Step 1: Developing and implementing a co-ordinated higher education strategy}

\section{Current state of policy and practice}

The Slovak higher education system has transformed in major ways since the country's transition to an independent, democratic state in the early 1990s. Changes were driven partly by legislation and policy, such as bringing academic freedom and legal independence to HEls and including the Slovak Republic in the Bologna Process, and by massive increases in student enrolment (Reichert, 2009[1]).

Over the past 15 years, Slovak have sought to anchor the Slovak higher education system more firmly within the European Union, to promote modernised and labour-market-relevant educational programmes, high-quality, internationally competitive research, and greater engagement of higher education institutions in supporting the economic development of the Slovak Republic and its regions.

Government has pursued these goals through a range of strategies, some focusing on broad transformation, others with a targeted focus. The sections that follow review these strategies, namely (i) an attempt at comprehensive higher education reform, (ii) reforms of system structure and quality assurance, (iii) plans for reforming institutional governance, and (iv) new investments and funding reform plans.

\section{An attempt at comprehensive higher education reform}

One of the most comprehensive higher education reform plans developed in recent years was part of the 2016 National Programme for the Development of Education ("Learning Slovakia"), which aimed to reform the entire education system in the Slovak Republic (MoE, 2016[2]). This plan included four strategic objectives for higher education, namely improving the quality of educational programmes, fostering highquality research, supporting greater involvement of HEls in regional development and improving the effectiveness of HEls through funding and governance reforms. The plan encompasses a range of measures to achieve these objectives, as outlined in Box 3.1.

According to the 2018 European Commission's peer counselling on the governance of higher education institutions in the Slovak Republic (see Box 3.4 for details), the Learning Slovakia plan was based upon the work of a task force of independent experts, who produced a 226-page long discussion document made available for public comment, generating almost 4000 contributions.

While this plan was not implemented in its entirety, it generated significant debate and led to smaller reforms, most notably in the area of quality assurance as discussed below.

\section{Box 3.1. Objectives of the proposed Learning Slovakia Strategy (2016)}

\section{Objective 1: Quality higher education}

The strategy proposed reforming the internal quality assurance processes conducted by HEls (1.1) and external quality assurance, which would be managed by a new Accreditation Commission guaranteeing that internal quality assurance systems are effectively implemented (1.2), thereby meeting the European Association for Quality Assurance in Higher Education (ENQA) and the European Quality Assurance Register for Higher Education (EQAR) standards (1.3).

Additionally, the strategy advocated for improved teacher quality by promoting their work (1.4) and reforming candidates' selection procedures, thereby making teaching positions available to a larger number of professional and international experts (1.5). A shift would be operated towards a system of 
study fields focused on educational results, connections to practical requirements and linked to the national qualifications framework (1.6).

Creating partnerships with employers to foster professional programmes and on-site training would further enable students to acquire the skills needed in the labour market (1.7) while the internationalisation of HEls would be accelerated through increased mobility opportunities (1.8). Bachelor's degree studies would be allowed to be carried out according to a more flexible structure (a "liberal studies" model) where students have more options to shape their programme and choose courses from different university departments (1.9).

Links between HEls and secondary schools would be tightened by ensuring that HEls co-operate in setting minimum exit standards in secondary schools (1.10) and by guaranteeing that discriminatory barriers hindering access to higher education are lifted (1.12), notably by developing new forms and methods of teaching, such as external or distance education (1.13). HEls would finally have the opportunity to specialise and choose their mission (1.11).

\section{Objective 2: Quality higher education research}

Improving the quality of higher education research would be achieved by creating a favourable environment for research and development (R\&D) through increased co-operation. The Slovak Republic would target the development of human resources, notably by supporting the professional development of its doctoral graduates and creating post-doctoral positions (2.1).

A more effective system of R\&D and other creative activities would be implemented to offer more institutional support to HEls (2.2) and promote the acquisition of knowledge in areas where universities reach an international level based on an objective assessment of creative activity (2.3).

Additionally, support would be given for solving specific problems in Slovak society that cannot be addressed in other ways (2.4). Ensuring that grant agencies operate in a transparent manner to foster competition (2.5), as well as developing consortia of universities and enterprises and support for infrastructure - in particular university science parks and research centres built for European funds (2.6) were also priorities for the Slovak government.

\section{Objective 3: HEl support for regional development}

The creation of flexible schemes between HEls and private companies would support innovation projects addressing the needs of Slovak businesses (3.1), while specific grant schemes would support projects focused on HEls' cultural, environmental and sporting activities, thereby increasing their share in regional and social development (3.2). HEls would further contribute to their community and social development by providing various other services (3.3).

\section{Objective 4: Improving the effectiveness of higher education}

The strategy proposed reforms of the financing and governance of higher education to improve the system's effectiveness. Increasing the volume of public resources allocated to HEls on the basis of a contract between the Ministry of Education, Science, Research and Sport and HEls over a period of three years (4.2) and allowing HEls to secure their own resources would increase the total volume of $\mathrm{HEI}$ resources (4.1).

The internal management system of HEls would support the internal integrity of higher education institutions and ensure an appropriate balance between the competencies and responsibilities of its individual parts (4.3). Additionally, higher education legislation would be simplified to strengthen the autonomy of HEls (4.4). The systematic computerisation of management processes in higher education would reduce the administrative burden of HEls (4.5).

Source: MoE (2016[2]), Učiace sa Slovensko [Learning Slovakia], https://www.minedu.sk/data/att/10640.pdf. 


\section{Reforms of system structure and quality assurance}

After limited government steering during the period of fast enrolment growth until the early 2000s, governments have attempted to steer HEls towards greater quality in two ways: by introducing different institutional profiles to concentrate research excellence among a small number of HEls, and by creating a new regime of quality assurance promoting rigorous standards controlled by an independent agency.

After a change of government in 2006, an amendment to the Act on Higher Education No. 131/2002 (hereafter "HE Act") introduced three types of institutions differentiated according to their mission, namely "universities", "professional HEls" and "HEls". "Research universities" were no longer identified (Reichert, $\left.2009_{[1]}\right)$. The intention was to pursue differentiation between research and professionally focused institutions along a single criterion of evaluation: research intensity. The amendment's classification scheme was to be tanligbly implemented through a differentiated funding formula.

The amendment introduced threshold levels in areas such as the number of students per level of education and per head of staff, research performance and third-party grant income to determine the institutional type. To obtain the title of university, HEls were required to reach threshold levels in six areas, five of which were research-related, namely the number of doctoral students per staff, the number of doctoral graduates, the research results of their theses, the average grant income per professor and overall research performance (Reichert, $\left.2009_{[1]}\right)$.

In the area of quality assurance, the 2018 Act on Quality Assurance in Higher Education introduced a critical policy shift ending a model that had been criticised as ineffective as described in Chapter 2 (Machlica et al., 2017 ${ }_{[3]}$ ). The new model involves an independent agency, the Slovak Accreditation Agency for Higher Education (SAAHE), which is responsible for formulating standards for HEls' internal quality assurance processes and criteria that will be used in the external quality assurance activities it will undertake. Among other areas, the new model focuses explicitly on strengthening the labour market relevance of higher education. In particular, it requires each $\mathrm{HEI}$ to regularly monitor and evaluate study programmes in co-operation with relevant employers and other stakeholders (OECD, 2020 $[4]$ ). In 2021, the SAAHE and the Ministry of Education, Science, Research and Sport (MoE) took a number of steps to support effective implementation of the new quality assurance model, publishing an action plan outlined in Box 3.2.

It is not yet possible to assess the types of changes Slovak HEls will pursue to meet new quality assurance standards and the extent to which implementation will vary across HEls, since implementation is ongoing until 2022. However, several institutional stakeholders interviewed by the OECD team expressed hopes that the system would strengthen HEls' focus on quality, noting in particular the value of re-thinking long established processes in light of new standards of quality.

At the same time, other higher education stakeholders suggested potential limitations of the new model. For instance, a few higher education stakeholders noted that the new list of evaluators published by the SAAHE, in charge of assessing HEls' internal quality assurance systems, would have benefitted from a greater diversity of profiles, rather than continued reliance on established Slovak and Czech academic networks. 


\section{Box 3.2. The National Action Plan for External Quality Assurance of HEls (2021)}

The National Action Plan for External Quality Assurance of HEls in the Slovak Republic was set up jointly by the SAAHE and the MoE and carried out within the scope of the international project, "Supporting European QA Agencies in Meeting the European Standards and Guidelines (SEQA-ESG)". This action plan focuses on increasing the efficiency of the SAAHE's activities and on improving its processes to the level necessary for a well-functioning external quality assurance system.

In 2021 and 2022, MoE and, in particular, the SAAHE are expected to implement several important measures identified within the following five areas:

- Explaining the principles and strengthening the internal quality assurance systems at HEls in the Slovak Republic by providing thematic consultations on guidelines and interpretation of standards, technical support throughout their application process, professional events, frequently asked questions and answers and financial support.

- Improving the level of stakeholder involvement in quality assurance at HEls by increasing the involvement of employers in the quality assurance system at HEls along with the number of students involved in quality assurance systems, notably through the student satisfaction survey. The SAAHE conducted the first student survey regarding students' perceptions of the quality of Slovak HEls in 2021. The survey is expected to be repeated every year to assess HEls' improvements based on student feedback and taken into account in their accreditation process. The first survey gathered the views of almost 20000 students in the first two degrees, representing $16 \%$ of the student population in the Slovak Republic, regarding the overall perception of students about their HEls, the impact of the pandemic on higher education, and their preparedness for the labour market (SAAHE, 2021[5]).

- Ensuring the quality of experts involved in external quality assurance of higher education, by improving the selection and training of reviewers and optimising the feedback on their activities in order to propose improvement measures, notably by drawing on international experiences.

- Ensuring the effective performance of the SAAHE by optimising its organisational structure and institutional capacity, systemising its internal quality assurance procedures, preparing its full membership in ENQA and registration in EQAR and supporting HEls throughout their internal quality evaluation.

- Building confidence in Slovak HEls and in the quality assurance system by ensuring the correct establishment and implementation of quality assurance standards and providing transparent information regarding decision making for quality education (e.g., access to study programmes).

Source: MoE (2021[6]), National Action Plan for External Quality Assurance of Higher Education Institutions in the Slovak Republic, https://www.minedu.sk/data/att/20126.pdf.

\section{Plans for reforming institutional governance}

There have been several attempts in the Slovak Republic to modernise the model of university governance inherited from the change of political regime in the 1990s. This model presents several weaknesses, especially as it results in HEls that are insufficiently focused on the needs of students and their wider social and economic environment, as further discussed in Action Step 3. 
Over the past few years, the 2016 Learning Slovakia plan recommended reforming institutional governance to improve the accountability and integrity of institutions while increasing their autonomy, a direction that was also supported by the findings of the 2018 European Commission peer counselling on university governance (Box 3.4).

In 2020, the newly elected Slovak government set out to pursue legislative reform to make changes in various areas following directions that are broadly similar in their objectives and key features as elements recommended in previous national policy plans and echoing recommendations made by international organisations. Key areas of focus and objectives according to a document outlining the government's rationale and shared with the OECD team are listed below:

- A first area focuses on increasing the quality of higher education teachers by creating professor and associate professor positions accessible without the requirement of a formal title (surpassing changes in access to higher education employment implemented in 2018, discussed later in this report). The amendment proposes that the MoE create minimal national criteria for these positions and separates the process of habilitation from the accreditation of titles. These changes are expected to help open up the Slovak higher education system to international academic and non-academic professionals as well as to guarantee a minimal quality of higher education teachers across the country.

- A second area proposes to harmonise the length for full-time and part-time studies, in an attempt to make study options more attractive to a greater range of learners, including adults with work responsibilities, and limit the number of young Slovaks emigrating to pursue higher education.

- A third area focuses on the governance of public HEls, aiming to strengthen the position of the board of trustees and of the rector, to re-balance powers between academic governing bodies and those whose executive capacity is limited in several ways, as further described later in this chapter. Governance changes are also expected to end the dual structure where governing bodies exist at both institutional and faculty levels.

- A fourth area relates to the implementation of institutional contracts, between the government and each $\mathrm{HEI}$. These contracts are expected to increase strategic planning and diversification in Slovak higher education.

Governance changes have raised significant concerns among higher education stakeholders interviewed by the OECD during the project. Common concerns included the risk that the reinforcement of executive entities such as the board of trustees versus that of academic bodies could lead to a decrease in institutional autonomy and academic freedom, as well as the view that there are more relevant and pressing changes that should be addressed - such as improving the funding available to the system - to foster quality improvements. Persistent disagreement with respect to governance changes are discussed in detail later in this chapter.

\section{New investments and funding reform plan}

The 2016 Learning Slovakia plan called for increasing public funding to higher education, diversifying HEls' sources of funding, and for multi-year funding contracts to be established between government and HEls. While these broad funding reforms have not been implemented - and there has been a decrease in higher education funding in 2021 - Slovak authorities have implemented several changes to the annual allocation formula to incentivise a focus on performance (see Action Step 2).

Most recently, changes to higher education funding have been proposed as part of the Slovak government's national reform plan developed in the context of the European Union's Recovery and Resilience Facility, a financial relief plan for member states to respond to the pandemic. The Slovak Republic's national plan was approved by the European Commission in June 2021. The higher education 
chapter of the plan proposes a comprehensive reform package underpinned by substantial new funding. The plan includes five key reforms:

- change to university funding through the introduction of new institutional performance contracts

- a new "periodic scientific performance evaluation system" that would identify excellent research and research teams to foster the diversification of the higher education system

- the implementation of the new approach to higher education accreditation currently underway

- HEl governance reform

- concentration of excellent education and research capacities.

The plan includes quantitative targets to be achieved, timelines for implementation, and a costing plan totalling EUR 203.9 million. The objective is to create conditions for attracting talented students and academics from the Slovak Republic and abroad by offering attractive teaching, research and housing facilities. Key elements of the plan are presented in Box 3.3.

\section{Box 3.3. Higher education reforms in the Slovak Republic's national recovery and resilience} plan (2021)

The following reforms and investments are envisioned as part of Chapter 8 "Increasing the performance of universities" of the Slovak Republic's national recovery and resilience plan (RRP), approved in June 2021 by the European Commission.

- Change to university funding through the introduction of performance contracts: The government funding methodology will be modified to take greater account of high-quality and inclusive education, excellent research, graduate job placement, co-operation with the private sector, and teacher and student internationalisation, and to align with the scientific performance evaluation methodology under development. The introduction of performance contracts signed between MoE and public HEls will support the specialisation and diversification of HEls based on their strengths. Performance contracts should be introduced by Q4 2022 and $90 \%$ of HEls should have signed performance contracts by Q4 2023.

- Introduction of a periodic scientific performance evaluation system: This aims to support the diversification of HEls and the identification of excellent research teams at individual HEIs. It will be implemented with the involvement of international evaluators and with a focus on the independence and transparency of the assessment panel. The periodic evaluation of scientific performance should be defined by Q1 2022 in Act No. 172/2005 while the evaluation of academic research at HEls should be launched by Q4 2022.

- Continuing the reform of higher education accreditation: The amendment to Act No. 269/2018 on quality assurance in higher education sets new standards and criteria for accrediting study programmes imposing stricter requirements for guaranteeing and providing study programmes, improving their quality and implementing long-term processes to monitor their quality. $90 \%$ of HEls are expected to apply for review of the compliance of internal quality systems and study programs with the standards by Q4 2022.

- Reforming higher education governance: This is envisaged through the amendment of Act No. 131/2002 on higher education by Q4 2021. Changes would entail revising the competences of individual self-governing HEI bodies, professionalising HEI management, enabling greater integration of the internal structures of HEls and removing the restrictions for filling vacant associate professor and professor positions, in turn promoting openness of the academic environment to applicants from professional practice and abroad. 
- Concentration of excellent educational and research capacities, aimed at reducing the number of HEls by supporting their consolidation into larger organisations capable of competing internationally, while creating a competitive and diversified environment internally. A roadmap for merging at least two HEls elaborating a timeline and individual steps leading to the merger should be approved by Q4 2021 and the formal merger process for a least two HEls should be completed by Q2 2026.

Investments supporting the strategic development of HEls include EUR 203.9 million to complement the reform of $\mathrm{HEl}$ funding as well as the concentration of the education and research capacities. Modernisation of $\mathrm{HEI}$ infrastructure and facilities, including student housing, access for people with disabilties, and the digitalisation of teaching, are expected to improve the quality of Slovak higher education and to attract talented students and academics. At least $262.647 \mathrm{~m} 2$ of area of colleges and dormitories are expected to be renovated by Q2 2026, with energy savings of more than $30 \%$. Mergers will additionally involve direct transactional costs and require new infrastructure capacities. At least two calls for support for the strategic development of HEls should be announced by Q3 2022.

Source: Government of the Slovak Republic $\left(2021_{[7]}\right)$, Plán Obnovy - Cestovná mapa k lepšiemu Slovensku [Recovery Plan: A Roadmap to a Better Slovakia].

\section{Stakeholder and international calls for reform}

Alongside government strategies, some stakeholders have advocated for broad changes to the Slovak education system in recent years. The project "Learning Makes Sense" (To dá rozum), conducted from 2016 to 2020 on the basis on an extensive number of stakeholder interviews and surveys, and the establishment in late 2020 of an "Alternative Rectors Platform" (Vznik Alternativnej platformy slovenskych rektoriek a rekorov), are examples of the push for reform. Both highlight the need for a more studentcentred and high-performing higher education system.

In parallel, recent international studies called for reforming the governance of universities, such as the 2018 European Commission's peer counselling on governance of higher education institutions in the Slovak Republic, and more broadly made recommendations to improve the skills of Slovak citizens and workers (OECD, 2020[4]).

Recommendations for higher education from Learning Makes Sense (To dá rozum) and the 2018 European Commission's peer counselling on governance of higher education institutions in the Slovak Republic are summarised in Box 3.4.

\section{Box 3.4. Recent recommendations to reform Slovak higher education}

\section{Learning Makes Sense (To dá rozum) (2016-20)}

The Learning Makes Sense initiative delivered ambitious recommendations to reform Slovak higher education in early 2020. Qualitative data was collected using 398 semi-structured individual interviews and 23 group interviews, with a wide range of respondents from the education sector from early childhood to higher education as well as from the government and governmental agencies. Quantitative data were collected through a questionnaire intended for a variety of respondents: 26 questionnaires were created, to get a better understanding of the various perspectives, and approximately 15000 responses were received.

At the core of the recommendations was a new model of higher education linking qualifications to the demands of the labour market by increasing the supply of professional bachelor's programmes and 
introducing applied learning in academically-oriented study programmes. The report also highlighted the need for increased internationalisation of Slovak HEls.

In the area of teaching quality, the report recommended establishing centres for developing the teaching skills of academic staff, decreasing the number of teaching contact hours, and providing customised support for learners in recognition of their varying needs, abilities and interests. To improve the quality of doctoral studies, the report recommended that doctoral schools focus on applied and soft skills in addition to research skills, and that the academic titles of "professor" and "docent" be suppressed and replaced by the demonstration of a high level of research or teaching performance as the main qualification criteria, so as to open positions to international and younger candidates.

The report highlighted the need to address issues of academic integrity, recommending that HEls implement software to detect plagiarism, develop and implement their Codes of Conduct, and withdraw any fraudulently received university degrees as part of a strict ethics policy.

The report advocated for increasing teachers, researchers and professional staff's wages to match the OECD average as well as a comprehensive reform of training programmes for academic staff, including providing a teaching guide to help academic staff implement changes; establishing centres for developing teaching skills; and providing access to high-quality and diverse training programmes, in an effort to make the profession more attractive.

The report emphasised that the effective management of higher education institutions requires simplifying management processes and strengthening the rector's position by ensuring that he/she is selected rigorously by the board and academic senate - the academic senate would additionally nominate half of the board, thereby strengthening the connection of the board to the HEI.

Finally, according to the report, a funding reform is needed at the HEI level to improve the quality and international impact of Slovak research and to help HEls have more visibility, stability and diversity by implementing performance contracts.

\section{European Commission's peer counselling on governance of higher education institutions in the Slovak Republic (2018)}

Peer counselling is part of the toolbox of the strategic framework for European co-operation in education and training, offering tailor-made policy advice to a country undergoing structural reform, by peers from national administrations with experience in the relevant policy area. It is intended to provide a forum for finding solutions to national challenges in a participatory event. Peer counselling is administered and co-financed through the Erasmus+ programme Key Action 3 by the Directorate-General for Education, Youth, Culture and Sport of the European Commission.

In the context of the peer counselling on university governance in the Slovak Republic, the peer countries included Austria, Estonia, Ireland and Poland. The exercise also brought together the European University Association (EUA) and the Slovak experts behind the draft of "Learning Slovakia Strategy". The group engaged intensively with the national case over the course of two days, on 15-16 March 2018 in Bratislava. An unpublished summary of the analysis was shared with the OECD as part of this project.

The peer counselling resulted in five recommendations:

1. Adopting a more strategic mid-term vision and continuous steering from public authorities. The exercise suggested that more strategic steering from the state would be beneficial. In particular, the state needs to provide evidence on the future skills needs of society and the labour market and communicate its expectations in meeting those needs to HEls. The national priorities in turn need to be reflected in the funding and accreditation systems. A vision and clear goals should be developed to engage stakeholders effectively. 
2. Enhancing the autonomy of HEls coupled with increased internal and external accountability, and more effective inclusion of external stakeholders in governance bodies. The main guiding principle of the future reform of higher education governance in the Slovak Republic should be more autonomy coupled with more accountability. Slovak authorities have initiated an analysis of self-government and management of universities, pointing out that the efforts aimed at deepening university autonomy in the Slovak Republic have so far concentrated mainly on financial autonomy, and less on the internal organisation and management of the institutions. Because financial and organisational autonomy are closely connected, and the financial management capacity of HEls remains limited, there is a need for a more comprehensive view of autonomy and to focus on organisational autonomy. Finally, the exercise pointed out that the Slovak Republic has not achieved a balance between autonomy in management and accountability for results.

3. Less legal prescription of internal governance and improved self-government at HEI level. The exercise recommended that legislation be less detailed and more flexible, should not mandate internal governance arrangements at the faculty level, and only regulate HEI-level structures. Individual higher education institutions should be empowered to decide on the details of internal governance and management on the basis of their specific conditions and needs.

4. Modifying the structure and functioning of governing bodies. Findings suggested that the competences of the academic senate regarding financial matters should be reviewed; the rector should be granted more powers to allocate funds between faculties; and the composition of the boards should be more representative of different stakeholder groups, including external members, but possibly also representatives of the non-academic staff. It was also advised to re-evaluate the duplication of governance bodies at both the central level of the university and at the level of the faculties. It was suggested that while HEls should design the governing structures of faculties, legislation should specify minimum requirements to set up a new entity and principles of governance that should be respected. Lastly, findings suggested that nonacademic matters such as finances and management could be largely overseen by the board, while academic matters largely remain influenced by academic staff and students, notably through the academic senate. This distinction of roles and portfolios, providing checks and balances are implemented, would guarantee effective and more flexible governance.

5. Increased public funding is required. It was noted that although public funding for HEls had increased in recent years at the time of the exercise, this was not enough to compensate for previous decreases resulting from smaller student cohorts from 2010 and 2014. It was suggested that more funding should be made available to HEls pursuing reform efforts.

Sources: European Commission (2018[8]), Peer Counselling on the Governance of Higher Education Institutions in the Slovak Republic; MESA10 (2021 [9]), "Learning Makes Sense" Project, https://en.todarozum.skl.

\section{Challenges limiting the adoption of effective reforms}

The reform attempts of past Slovak governments outlined in the preceding section have not led to a comprehensive overhaul of the higher education system, and have had limited success in improving its performance. The historical context and timing of higher education expansion in Slovakia offers one source of explanation for this persistent challenge: the country has been unable to address "the widening array of challenges and the increasing number of problems with quality of provision which the rapid, unorchestrated expansion has caused" (Reichert, 2009, p. 84[1]). These issues are now compounded by the opposite pattern unfolding in Slovak higher education, namely the decline of enrolment resulting from a combination of demographic factors, high emigration rates among young Slovaks, and lower rates of application to higher education, as discussed in Chapter 2. 
In some countries - such as neighbouring Hungary - falling student numbers have pressured both government and HEls to work together to enhance the higher education system's attractiveness, with a focus on recruiting international students and enhancing innovation in the delivery of higher education (OECD/European Union, 2017[10]).

By contrast, in the Slovak Republic, the lack of collaboration between the Slovak government and higher education stakeholders, the lack of agreement among key stakeholders about the problems to be addressed and their causes, and the discontinuity in reform efforts persistently undermine the ability of both government and HEls to address these problems. These issues are examined in turn in the sections that follow.

\section{Limited collaboration among government and higher education stakeholders}

Policy development in higher education takes place without effective collaboration with stakeholders, despite the existence of representative bodies set up in legislation. The government plays a key role in Slovak higher education as the main funder of public HEls and main driving force behind education reforms. The government typically develops reform plans through its analytical teams with little engagement of the higher education sector and economic and social stakeholders, such as employers. Some higher education stakeholders interviewed by the OECD highlighted the frequent lack of communication from government on reform plans, a lack of systematic engagement, a practice of consulting a limited number of individuals and publishing reform plans once already advanced, limiting the opportunity for broad discussion. Some noted that while the law establishes bodies representing higher education stakeholders that government must consult ahead of legislative changes (outlined in Chapter 2 under "Key features of the Slovak Republic's higher education system"), these rarely play a consensusbuilding role. This can lead to changes passed through the national Parliament that have low support from higher education stakeholders, or that underestimate the financial and human resources needed at the institutional level to implement reforms.

At the same time, Slovak HEls have displayed a limited pattern of collaboration with external actors, whether government or the private sector. This results in part from the internal governance structure of HEls as set out in law, which provides rectors and boards of trustees with a limited capacity to identify and pursue institution-wide interests and academic senates at both institution and faculty levels with broad powers, but a limited external orientation.

The "top-down" culture of policy making in the Slovak Republic and the inward focus of HEls contribute to weakly developed norms and routines of collaboration in policy making. Even in areas of mutual interest, the lack of established communication and collaboration channels has hampered co-operation. This has been the case for instance between businesses and HEls, despite efforts from both sides to increase cooperation to address the long-standing issues of skills mismatch and research funding and performance (EBRD, 2017[11]).

The Digital Coalition of the Slovak Republic provides an example of the limitations of such collaborations (European Commission, 2017[12]). A private-sector initiative aiming at improving digital skills and creating synergies between IT associations, industry leaders and HEls, the coalition gathers 80 partners, including businesses and universities. Yet, it has had limited success in strengthening the ties between academic research and the private sector. Similarly, in a survey of universities and businesses by the UniversityBusiness Cooperation in 2017, Slovak HEls emphasised the importance of developing mechanisms to enhance co-operation with businesses, whereas none of these mechanisms were in place in over $40 \%$ of the businesses in the sample (Galán-Muros et al., 2018[13]). 


\section{Lack of widely shared understanding of problems, objectives and solutions}

Limited engagement and collaboration between government and stakeholders contributes to diverging views of the higher education system in the Slovak Republic. Several studies conducted by national and international bodies point to key problems in Slovak higher education (European Commission, 2018[8]; OECD, 2020[4]; MESA10, 2021 [9] $)$. The "Performance of Slovak higher education" section in Chapter 2 echoes findings from these studies, showing persisting high rates of emigration of Slovak students (despite improvements in attracting international students), high rates of skills mismatch and over-qualification, and a low international performance and visibility of Slovak research and innovation.

The majority of stakeholders interviewed by the OECD acknowledge these systemic weaknesses. According to these stakeholders, the high proportion of higher education students leaving the country and low performance of Slovak HEls in international university rankings provides evidence of the system's low quality. They generally identified contributing factors, such as the system's under-funding and a lack of incentives to develop high-quality, labour-market-relevant programmes. In contrast, a small but notable number of higher education institutional stakeholders interviewed by the OECD perceived the overall low quality of teaching and research in the Slovak Republic as driven by a small number of low-quality institutions in a highly heterogeneous landscape. They viewed the high rates of students abroad as the result of misconception about Slovak higher education rather than evidence of low quality, suggesting it should be addressed by better signalling the quality of Slovak higher education to students and employers.

Besides disagreement on the extent of the Slovak Republic's performance challenges, the views of stakeholders interviewed by the OECD were particularly polarised in terms of the actions that should be taken to improve performance. Some higher education institutional stakeholders viewed higher education governance arrangements as a key driver for the lack of quality improvement and strongly supported opening leadership positions to outsiders and/or changing the distribution of power between governing entities to strengthen the managerial capacity of rectors, for example. Conversely, other institutional stakeholders suggested that any intervention from government in university governance, in particular to modify collegial decision making, would undermine the universities' self-governing nature and independence, in turn threatening academic freedom. This latter group suggests that reforms to the system should focus only on funding reforms.

Building the foundations of productive consultation requires trust and a shared base of evidence for discussion. While deepening trust is a long-term undertaking, it is possible to improve the shared evidence base available to support the engagement of higher education stakeholders. For instance, stakeholder disagreements regarding the factors leading students to study abroad suggests a better understanding of students' needs and motivations is required. However, there has not been regular student, graduate or employer surveys that could provide a nuanced assessment of the learning experience of students or of employers' perception of skills obtained by Slovak graduates. This situation is, however, poised to change given the new student survey launched by the SAAHE, described in Box 3.2.

Similarly, concerns about the use of national averages when looking at performance data in an international context, rather than a deeper exploration of heterogeneous performance among Slovak HEls, call for more granular analysis of higher education outcomes measures. An example of this would be to analyse labour market outcomes - employment rate and earnings - according to graduates' programme, field of study and institution, taking account of graduate demographic characteristics and of the national and local economic context. Background information provided to the OECD suggests that while the Slovak Republic has the capacity to identify the labour market outcomes of graduates shortly after graduation, as the Slovak Centre of Scientific and Technical Information (CVTI) collects basic information on social and economic conditions of $\mathrm{HEI}$ students (during their study and shortly after graduation). However, this was little discussed during the project, suggesting the data may have limitations or not be widely used. 


\section{Discontinuity and lack of alignment in reform efforts}

Reforming the higher education system requires different types of reforms, which need to be aligned in their objectives and co-ordinated in their implementation to be effective. Efforts are taking place in this regard, but they are recent. For instance, in 2018, the European Commission's peer counselling on governance of higher education institutions in the Slovak Republic highlighted the disconnect between broad policy objectives, operational funding mechanisms, and the system of quality assurance (European Commission, 2018[8] $)$. As an example, the annual revisions to the funding formula for HEls are not connected to a broader policy framework, which may limit the effectiveness of incentives built in the funding formula to effectively shift institutional behaviour. Recent OECD analysis further suggests that quantitative and qualitative targets have rarely been established when new policies are implemented, and performance indicators in use often vary across government bodies (OECD, 2020[4]).

The Slovak Republic's national RRP described earlier (see Box 3.3) includes broad system-wide targets and references several reforms underway, which represents a step in the direction of clarifying government objectives, the ways success will be measured, and to connect previously disconnected reform under a connected plan. However, it is not yet clear how policy instruments - such as the current funding formula or future performance contracts with HEls - will incentivise HEls to take action towards meeting these targets.

Similarly, concurrent higher education reforms reveal the weak alignment in policy design between different streams of reform. Most recently, the investment approach outlined in the national RRP focuses strongly on physical infrastructure with little investment in digital infrastructure - a potentially important aspect to modernising higher education and making the Slovak higher education system more flexible and attractive to domestic and international students, itself a key government objective. The plan is also not explicit on how this new European funding might be used to support large-scale changes in the processes and practices of HEls and government that aim to improve teaching and research quality. Such processes, such as the introduction of institutional contracts, revised and improved quality assurance processes and new institutional governance arrangements, require in particular that adequate human resources - with appropriate skills profiles - be in place in HEls and government. As discussed in Action Step 2, "Using funding to support and reward higher education performance", HEls face constraints in the ways in which they can manage their human resources, due to limitations in how European structural funds can be used, legislation on the employment of higher education staff, and the demographic profile of the higher education workforce. Taking into account the complex interplay of these factors through effective engagement with higher education stakeholders thus appears important to support reform success.

Another example relates to quality assurance processes. The SAAHE is carrying out prominent reforms of the accreditation system in parallel to the proposed legislative amendment and work on the Slovak Republic's RRP. While the SAAHE and MoE recently issued a National Action Plan for External Quality Assurance of HEls (see Box 3.2). that offers a good starting point for developing a more concrete understanding of quality, it is not yet clear how this effort may help guide broader higher education reforms and investments currently envisioned. Input from stakeholders interviewed by the OECD suggest that this lack of connection between different reforms results from a lack of co-ordination and communication channels between (and within) the bodies responsible for the various reforms within government, and between these bodies and HEls.

Furthermore, despite relative agreement among recent governments around the need for reform in higher education, there is insufficient continuity in reform efforts. This is due, in part, to frequent political shifts, leading to difficulties in achieving objectives described in planning documents (OECD, 2020[4]). According to the Working Group of Slovak policy makers supporting the project, better co-operation among government bodies responsible for reform and between government and HEls, as well as clear performance indicators and a stronger evidence base to measure progress, could substantially improve 
the identification of common objectives and priorities. In turn, common objectives and priorities, when set for the medium to long term, could help improve the continuity of reform efforts.

\section{Relevant international experience}

International approaches to developing and implementing comprehensive higher education reforms vary based on an array of factors. These include the legal underpinnings and historical developments that have shaped how the higher education system operates, and, in particular, the way government and autonomous HEls work together. Another important factor is the extent to which data is collected and disseminated to create an agreed-upon evidence base on which government and higher education stakeholders can rely to identify targets and monitor performance improvement.

Latvia provides an example of a government-driven, long-term education strategy associated with clear indicators of performance. Norway provides an example of how stakeholder engagement is embedded in policy making, shaping both the direction of policy and the monitoring of implementation. England (United Kingdom) provides an example of a system with a well-developed approach to conceptualising quality teaching and identifying data to measure and reward progress made by highly autonomous HEls.

\section{Latvia: An example of comprehensive strategy development}

Latvia's Education Development Guidelines are a six-year mid-term strategy for education, which ensure alignment, co-ordination and continuity in Latvia's education policy for the 2014-20 planning period. The guidelines define clear principles, goals, responsibilities and lines of action of education policy for all types and levels of education, coupled with indicators to monitor progress towards set goals. The main purpose of the guidelines, adopted in 2014 by the Parliament (Saeima), is to achieve high-quality inclusive education for personal development, human welfare and sustainable national growth. Through the guidelines, the government aims to encourage actors of the education system to move toward national goals and foster a strategic use of resources (Government of Latvia, 2014 ${ }_{[14]}$ ).

Latvia's Education Development Guidelines fall within its government planning framework, linking education policy with broader national objectives. The government planning framework includes Latvia's comprehensive Sustainable Development Strategy for 2030 (Latvia 2030), which defines long-term economic development directions, the National Development Plan for Latvia 2014-20, which sets the medium-term strategy, and a number of sectoral planning documents, such as the Guidelines for Science, Technology Development and Innovation (OECD, 2019 ${ }_{[15]}$ ).

The guidelines describe several education policy goals, such as developing educational infrastructure or improving efficiency of resources management through resource consolidation (Government of Latvia, $\left.2014_{[14]}\right)$. For each of the policy goals, lines of actions are defined with detailed activities, timelines, responsible bodies, outputs and key performance indicators (KPIs).

For example, the line of action "international competitiveness" includes 10 activities, 6 policy outputs and $12 \mathrm{KPIs}$. As part of this line of action, the activity "Support measures for international mobility and crossborder co-operation" is under the responsibility of the Ministry of Education and the National Centre for Education, with participation from members of industry, HEls, social partners and the State Education Development Agency. This activity is to be developed by the second half of 2020 , and falls within the funding of the EU Erasmus+ programme. For this activity, KPIs include the number and share of students enrolled in a mobility or exchange programme. An interim evaluation showed that Latvia outperformed the 2017 target set for the first indicators (2 156 students compared to a target of 1960) and under-performed on the second indicator ( $8 \%$ of graduates compared to a $15 \%$ target) (Latvian Ministry of Education and Science, 2019[16]). In addition to the interim evaluation, a final impact assessment to be issued in 2021 by the Ministry of Education and Science will further help identify specific areas for improvement and shed light on areas where data is currently lacking but needed to measure progress. 
Regular assessments of the guidelines serve as a basis to revise the policy objectives and indicators chosen. For example, as assessments showed that the involvement of stakeholders following the implementation of the 2014-17 Guidelines was not optimal - mainly because of governance arrangements involving too many stakeholders and diluting implementation responsibilities - these findings have informed a new model for engaging stakeholders and defining their roles and responsibilities, established in the 2021-27 Guidelines (OECD, 2019[15]).

\section{Norway: Providing a structure for stakeholder collaboration}

Norway's Skills Policy Council and the Future Skills Needs Committee were established by the Ministry of Education, as a new governance arrangement to support the implementation of Norway's Skills Strategy 2017-21. The purpose of these bodies was to address the fragmentation of skills policy in Norway, which resulted from the diversity of policy areas falling into the skills umbrella, the large number of stakeholders involved, and multiple levels of governance at which decisions regarding skills policy are taken. These bodies are expected to improve the co-ordination of skills policy in two complementary ways.

The Skills Policy Council is an overarching co-ordination body chaired by the Ministry of Education, which comprises representatives from ministries, local governments, and social partners such as employer and employees organisations (OECD, 2019[17]). It brings together all actors with a role in skills policy to co-ordinate, reflect on the objectives and review the Skills Strategy.

The Future Skills Needs Committee is tasked with generating data and building evidence-based assessment of skills needs in Norway in the short, medium and long term, and is funded by the Ministry of Education. It gathers, organises and builds on existing data and evidence, and informs the development of new evidence. Its missions also include facilitating the work of governing bodies through disseminating evidence to different actors, and providing regular assessments of priority areas and skills needs. These assessments aim to inform agenda setting and policy planning at the national and regional levels, and to provide information to support decision making by employers and learners. It is composed of representatives from the social partners (employers and labour unions) and ministries, as well as experts, and builds on existing structures, as its secretariat is located within Skills Norway, a pre-existing directorate of the Ministry of Education and Research (OECD, 2020[18]). Information and evidence produced is used to inform discussions, reports and recommendations of skills policy made by the Skills Policy Council.

Norway's Skills Policy Council and Skills Needs Committee have enabled greater co-ordination among different actors responsible for the skills policy and its implementation (OECD, 2020[18]). The Skills Needs Committee created common databases and integrated information systems that help inform the policy process. The Skills Policy Council has enhanced collaboration across government ministries. Nevertheless, Norway's example also shows that the creation of new bodies involving a diversity of stakeholders requires defining a clear mandate and processes, and takes time to build and to have tangible effects.

\section{England (United Kingdom): Using awards to reward quality}

In England (United Kingdom), the Teaching Excellence and Student Outcomes Framework (TEF), introduced by the Government of England, represents a unique approach to assessing and rewarding teaching quality at HEls utilising a system of awards.

The TEF was developed to "introduce a framework to recognise universities offering the highest teaching quality" (Copeland, 2017[19]). The primary goals of TEF, as set by the government, was to develop a framework that: better informed students' choices about what and where to study; raised esteem for teaching; recognised and rewarded excellent teaching; better meets the needs of employers, business, industry and the professions" (UK Department for Education, 2017[20]). TEF's primary lever for rewarding $\mathrm{HEI}$ performance is an award system that is intended to have positive reputational impact and that allows 
institutions to increase student fees, an important part of institutional funding in England. TEF "awards" involve gold, silver or bronze levels. HEls and recipients who receive an award, at any level, can increase their tuition fee cap from GBP 9000 to GBP 9 250. England utilises a buffer body for the management, implementation and maintenance of the TEF: the Office for Students (OfS). The OfS is the independent regulator of higher education in England and has a range of additional duties alongside maintaining the TEF, including promoting value for money and ensuring student choice in higher education (OfS, 2018[21]).

The TEF system is based on three key areas of assessment: teaching quality; learning environment; and student outcomes and learning gain. Assessment of institutions against the TEF criteria is carried out by a panel of peers "comprised of experts in teaching and learning as well as student representatives and 'employment and widening participation experts"' (UK Department for Education, 2017[20]). The TEF assessment panels access HEI data on the core metrics from centralised data sources, with individual HEIs' submission statements providing additional qualitative context to the data and further evidence. The core metrics of the TEF rely largely on independent data, collected by buffer bodies or other government actors, as outlined in Table 3.1. .

\section{Table 3.1. TEF metrics aligned with aspects of quality}

\begin{tabular}{|c|c|c|}
\hline Aspects & Metric & Source \\
\hline \multicolumn{3}{|c|}{ Core metrics } \\
\hline Teaching quality & $\begin{array}{l}\text { Teaching on my course (a metric referencing whether } \\
\text { staff are good at explaining concepts, and made their } \\
\text { subject interesting, intellectually stimulating and } \\
\text { challenging) }\end{array}$ & National Student Survey \\
\hline Teaching quality & Assessment and feedback & National Student Survey \\
\hline Teaching quality & $\begin{array}{l}\text { Student voice (a metric referencing the extent to which } \\
\text { students are able to provide feedback to their HEI, and } \\
\text { whether feedback has been acted upon) }\end{array}$ & National Student Survey \\
\hline Learning environment & Academic support & National Student Survey \\
\hline Learning environment & Learning resources & National Student Survey \\
\hline Learning environment & Continuation & Higher Education Statistics Agency \\
\hline $\begin{array}{l}\text { Student outcomes and } \\
\text { learning gain }\end{array}$ & Sustained employment or further study & $\begin{array}{l}\text { Longitudinal Education Outcomes dataset } 3 \text { years after } \\
\text { qualification }\end{array}$ \\
\hline $\begin{array}{l}\text { Student outcomes and } \\
\text { learning gain }\end{array}$ & Above median earnings threshold or further study & $\begin{array}{l}\text { Longitudinal Education Outcomes dataset } 3 \text { years after } \\
\text { qualification }\end{array}$ \\
\hline $\begin{array}{l}\text { Student outcomes and } \\
\text { learning gain }\end{array}$ & Highly skilled employment or further study & $\begin{array}{l}\text { Destination of Leavers from Higher Education declared } \\
\text { activity } 6 \text { months after qualification (subsequently } \\
\text { replaced by Student Outcomes Survey captured } \\
15 \text { months after graduation) }\end{array}$ \\
\hline \multicolumn{3}{|c|}{ Supplementary metrics } \\
\hline Teaching quality & Grade inflation & $\begin{array}{l}\text { Mandatory provider declaration for providers with } \\
\text { degree-awarding powers }\end{array}$ \\
\hline $\begin{array}{l}\text { Student outcomes and } \\
\text { learning gain }\end{array}$ & $\begin{array}{l}\text { Differential degree attainment (a metric referencing } \\
\text { differential degree completion outcomes for } \\
\text { disadvantaged students) }\end{array}$ & $\begin{array}{l}\text { Mandatory provider declaration for providers with } \\
\text { degree-awarding powers }\end{array}$ \\
\hline
\end{tabular}

Note: TEF acts as a form of performance-based funding by enabling high-performing institutions to increase their funding, albeit through tuition as opposed to direct government funding. It similarly acts as a public transparency initiative, attempting to communicate directly with students about HEI performance.

Sources: UK Department for Education (2017[20]), Teaching Excellence and Student Outcomes Framework Specification, https://assets.publishing.service.gov.uk/government/uploads/system/uploads/attachment_data/file/658490/Teaching_Excellence_and_Student Outcomes_Framework_Specification.pdf, and updated with the 2018 TEF core and supplementary metrics accessed via James, G. et al. (2019[22]), Evaluation of the Statistical Elements of the Teaching Excellence and Student Outcomes Framework, https://assets.publishing.service.gov.uk/government/uploads/system/uploads/attachment_data/file/940301/5._ONS_Statistical_Evaluation__accessible_Sept_2020.pdf. 
Reports have found mixed evidence of impact, including that $52 \%$ of university applicants had heard of TEF, and $56 \%$ had heard of the associated awards. Regarding raising esteem for teaching, $66 \%$ of academics contacted for an independent review of the TEF stated that it had a positive impact on teaching excellence for their institution, with $61 \%$ stating that it had a positive impact on teaching excellence for the HE sector as a whole (Vivian et al., 2019[23]). While recognition of the award level among students is reasonably high given its relatively short time in the public sphere, concerns have been raised that the use of gold, silver and bronze is overly simplistic, and that the term "bronze" - while in reality a sign of meeting or exceeding core quality standards - has a more negative implication that could hurt the reputation of the sector (UK Department for Education, 2019[24]).

\section{Proposed actions for the Slovak Republic}

The Slovak government has identified key performance challenges facing the higher education system. While there is strong impetus for reform in government and some parts of Slovak society, and opportunities for change as new European funding will soon be provided to the Slovak Republic, there are concerns within the higher education sector that reforms that are already underway - such as the reform of quality assurance - constitute an important step forward that should be implemented before considering additional reforms. In addition, past reform attempts in higher education suggest Slovak authorities must take particular care in designing, co-ordinating and implementing its reform plans.

Particular emphasis is thus needed on the co-ordination and sequencing of the various reform efforts underway and on collaboration with HEls through the reform design and implementation process. Reforms should be guided by clear and widely supported objectives as well as indicators and reliable data to measure progress. Careful implementation planning is needed, taking into account the need for financial and human resources to implement reform, in both government and $\mathrm{HEI}$ (also see the next section, "Using funding to support and reward higher education performance").

Examples from Latvia, Norway and England (United Kingdom) offer examples from which the Slovak Republic can draw to develop a long-term and regularly updated education strategy, to establish effective mechanisms for ongoing collaboration and engagement with stakeholders, and to conceptualise and measure quality teaching in higher education.

Three policy actions are recommended to Slovak authorities, which should be implemented in close collaboration with HEls.

\section{Policy action 1. Establish a small multi-stakeholder Higher Education Task Force responsible for co-ordinating the development and implementation of higher education reforms}

The Slovak government is considering higher education reforms that aim for transformative change, to be accomplished within a relatively short timeframe. To balance the need for large-scale change with that of effective implementation, the Slovak Republic needs to establish structures and procedures that allow for regular, transparent and results-oriented consultation between government and HEls.

We recommend that the Prime Minister's Office establish a Higher Education Task Force (hereafter "the Task Force") that works closely with the Ministry of Education. The Task Force would aim to expand and structure stakeholder engagement and serve as a steering body to develop a higher education strategy that connects the many reform efforts underway and clarifies their value to higher education stakeholders and the public. The Task Force should be broadly inclusive of stakeholders and follow an agreed schedule.

The recommendation that the Task Force be accountable to the Prime Minister's Office is meant to emphasise: 
- The importance of higher education as an engine for economic prosperity and social well-being in the Slovak Republic in the years to come.

- The interdependencies between higher education and wider policy issues (e.g. population decline, vulnerability of the Slovak economy to automation, perceptions of relatively widespread corruption and a need to improve the business and regulatory environment - see OECD $\left.\left(2019_{[25]}\right)\right)$.

- The importance of aligning government-wide fiscal priorities with the policy reform agenda.

The Task Force would:

- Lead a process of stakeholder engagement:

- The process should allow for sufficient time and breadth of engagement to generate a productive national debate on the role of higher education for the country's future prosperity, build agreement on key performance challenges in higher education and identify key solutions with broad stakeholder support.

- This process should engage higher education stakeholders beyond legally established consultation bodies to more effectively reach the users of the higher education system (students and employers) and individuals who play a critical role in the functioning of HEls (academic staff - both tenured and on fixed-term contracts - and professional and administrative staff).

- It should also include stakeholders in the broader economy and society, who represent the wider society. This includes businesses, non-HEl actors active in research, development, technology and innovation, as well as education and social actors (e.g. representatives from the education system, groups representing the interests of disadvantaged communities).

- Secure appropriate expertise:

- The Task Force should create an expert working group to provide recommendations on quality concepts, metrics and data (Policy action 2), institutional contracts that deliver new targeted funding for key reform priorities (Policy action 6) and on the revision of funding allocation mechanisms (Policy action 7). The expert group should include both Slovak and international experts, and individuals with both practical responsibilities in government and HEls (policy makers, bursars/senior HEI leaders in charge of budget and finance matters) and academic knowledge of performance measurement and financing in higher education.

- The Task Force should develop connections with the international higher education policy community, including university alliances and professional higher education associations, to obtain advice on specific issues (for instance, from countries that have set up institutional contracts). In particular, it could create an ongoing international expert advisory group to provide advice on a regular basis (e.g. annually) to the Slovak Republic's government and key higher education stakeholders on opportunities to improve higher education performance.

- Assess reform implementation capacity:

- The Task Force should consider which key policy bodies are well positioned (especially in terms of their capacity) to lead and support the implementation of higher education reforms and how these bodies could work together. In particular, it should help identify the potential roles of the MoE, the Institute for Education Policies, SAAHE, the Research Agency, the Slovak Centre of Scientific and Technical Information (CVTI) and others to support reform implementation.

On the basis of the above steps, the Task Force should develop and recommend a higher education strategy and implementation plan to the government (see Policy action 2).

In addition, the Task Force could play an important role in helping government identify an appropriate public entity - or consider creating a new one using the model of buffer bodies in OECD countries 
(e.g. Ireland's Higher Education Authority or New Zealand's Tertiary Education Commission) - to ensure the strategic design and management of institutional contracts (see also Policy action 5). Such an entity should have the ability to provide guidance and support to HEls in their data collection and strategic reflection on their profile and mission, help centralise data collection and dissemination to a range of users, and help with various areas where sector-wide, co-ordinated efforts would be valuable, such as scaling up HEl-business partnerships.

Key parameters for the Task Force operations include the following:

- Small size and an uneven number of members to facilitate deliberations and conclusions (e.g. 11 members).

- Include a minimum number of individuals representing policy makers (MoE, SAAHE, Institute for Education Policies, Research Agency, Ministry of Finance), higher education stakeholders (HEI leaders, academic and professional staff, students and recent graduates), employers and nongovernmental organisations working on matters of higher education. Members should be proposed by the Ministry of Education. The Chair should be proposed by the Minister of Education and agreed upon by the heads of the SAAHE, Rector's Conference, Higher Education Council, Student Higher Education Council and of an organisation representing employers and non-governmental organisations.

- Be supported by funding from the government to ensure adequate size and quality of Task Force staff.

- Be in place for a sufficient time period (e.g. 24 months).

\section{Policy action 2. Develop a mid-term higher education vision and strategy articulating linkages between goals, actions and monitoring of results}

On the basis of the work of the Task Force (Policy action 1) and the proposal of teaching and research quality concepts, indicators and data systems (Policy action 2), the MoE should adopt a higher education strategy and implementation plan that connects reform efforts into a coherent, mid-term plan.

The higher education strategy and implementation plan should:

- Articulate the vision for the Slovak higher education system now and in the future, and how it is expected to contribute to economic prosperity and social well-being. Such a vision should take account of expected labour market changes, making use of tools such as skills assessment and anticipation (SAA) systems [for further details on SAA, see OECD (2020[4])].

- Connect the goals of the various higher education reforms underway with the vision, and identify the benefits of these reforms for key stakeholder groups, including prospective and current students, graduates, higher education staff, employers and the broader Slovak society.

- Identify thematic areas where the Slovak Republic may develop a comparative advantage in research and innovation, teaching, and engagement with wider society, as well as areas where the country has a particular need to generate new knowledge. This should take account of other government policies, such as the Smart Specialisation Strategy developed by the Ministry of Investments, Regional Development and Informatization [see MIRRI (2020[26])], as well as broader social issues and trends in the Slovak Republic, ranging from ageing and emigration to the social integration of Roma.

- Identify whether the three types of HEI profiles created by the 2007 Amendment to the Higher Education Act should be strengthened or revisited to more effectively encourage specialisation and meet economic and social needs, drawing on the experience of differentiated systems (e.g. Finland's Universities of Applied Sciences, Ireland's Technological Universities). 
- Identify potential scenarios for institutional groupings to support greater higher education performance, especially in research and innovation, by concentrating resources:

- Scenarios could include a range of options from collaborations maintaining distinct identities, consortia where identities are maintained but more activities are shared, to full mergers. The approaches taken by France and Finland, discussed in this report, provide examples in this area.

- The scenarios should identify the local and regional implications of these approaches in co-ordination with regional actors, given the importance of HEls in the economic development of regions and cities.

- Scenarios should also identify the financial incentives that government would provide to support such processes and make clear the benefits of mergers and groupings to all parties involved. Attention should be placed on how new forms of higher education delivery, such as digitally enabled teaching and learning could support the provision of higher education to some student groups, such as part-time students, for instance.

- Identify core concepts and indicators of quality teaching, research and engagement, which the government will use to monitor the performance of HEls and of the higher education system as a whole (Policy action 2), and actions to enhance the capacity in HEls and the government to monitor performance, including through appropriate data collection.

- Set out parameters for the development of institutional contracts (Policy action 5) that will become a key policy tool to connect the national higher education strategy to institutional strategies.

\section{Policy action 3. Develop widely agreed concepts and measures to drive quality improvements in teaching and research}

The expert working group created in Policy action 1 should:

- Develop concepts of quality teaching and research that could be used in the Slovak context, and metrics to measure these concepts, and specifically:

- Develop concepts of quality teaching and research.

- Based on these concepts, draft a set of core indicators that would be applicable to all HEls. These core indicators should build on the standards developed by the SAAHE and draw from international examples, such as those in place in the United Kingdom (see above) and Denmark and the Flemish Community of Belgium (see Action Step 2). Attention should be paid to designing appropriate benchmarks of performance that allow for the measurement of progress over time, recognising that HEls will have different contexts and profiles. Importantly, a focus on measuring performance can have unintended effects, from reducing the accessibility and equity of higher education to reducing the supply of programmes in fields where quality may be low at present but that are important to meet the needs of Slovak society. Indicators should thus be designed to monitor any unintended effects, and specifically to monitor the accessibility and equity of higher education and the provision of quality programmes across a diverse range of fields. These indicators should be complemented by institution-specific indicators agreed by government and HEls as part of institutional contracts (see Policy action 5). Denmark provides examples of this approach, as shown in the next section.

- Consult Slovak HEls and the users of higher education - especially students and employers on the draft set of quality concepts and indicators.

- Assess measurement limitations, and propose approaches to remedy those caveats, including by combining multiple measures and data sources, both quantitative and qualitative.

- Design new data tools to collect information on Slovak higher education to: 
- Monitor the labour market outcomes of graduates. This should enable the detailed analysis of employment and earnings according to various characteristics of students and higher education programmes. Such an approach would help identify the levels and fields of study leading to the best labour market outcomes, supporting both student choice and HEls' programme design. It would also provide evidence on the groups of students who face poorer outcomes, and help inform public policy and institutional measures to support inclusion and equity in higher education.

- Understand upper secondary students' expectations and motivations in choosing what and where to study, higher education students' views on the quality of their learning experience, and employers' views on the quality of graduate skills. This could include building on the SAAHE's work to survey students undertaken in 2021 (see Box 3.2 for further details) to design student, graduate and employer surveys that could be implemented on a cyclical basis. This would help ensure that both HEls and policy makers obtain regularly updated information from students, graduates and employers, and update public policies and institutional strategies to ensure the Slovak higher education system remains responsive to student, graduate and employer needs.

- Assess working conditions of higher education staff - academic and professional, their engagement in professional development, as well as their attitudes to and readiness for innovation (including digitalisation in higher education - both of core activities such as teaching and research as well as administrative functions). This could include collection of data through higher education staff surveys and interviews.

- In line with standards set out by the SAAHE, assess HEls' data collection capacities, including whether a dedicated structure to conduct data collection and analysis exists at HEls and how well it supports institutional data collection. Particular attention should be paid to how digital technologies are (or may be) used to support the development of data capacities and the efficient collection, processing and reporting of data on higher education performance. This could include the collection of data through surveys and interviews of HEls' leadership teams and teaching and learning centres staff, as applicable.

In designing these data tools, the expert working group should highlight the time and resource implications of developing and testing these types of data tools, and the estimated time and resource implications for the implementation of these tools by HEls. It should make special efforts to streamline data collection tools and connect them with existing processes of data collection where possible. 


\subsection{Action Step 2: Using funding to support and reward higher education performance}

The sections that follow focus on:

- The current state of policy and practice with respect to higher education funding,

- Challenges limiting the adoption of effective reforms,

- Relevant international experience that points to possible policy reforms, and

- Concrete policy actions that the Slovak government may wish to consider.

\section{Current state of policy and practice}

\section{Level of funding}

The level of public resources devoted to higher education remains low in the Slovak Republic from an international perspective, despite significant increases in the past two decades. Public expenditure on higher education amounted to about $0.7 \%$ of the national gross domestic product (GDP) in 2017, compared to $1 \%$ on average in OECD countries (OECD, 2020 [27]). This figure remains well below the $1.2 \%$ of GDP target that had been set in the 2016 "Learning Slovakia" strategy. In terms of R\&D funding, the gross domestic expenditure on R\&D (GERD) was $0.84 \%$ in the Slovak Republic in 2018 , compared to $2.38 \%$ on average in OECD countries, and $2.03 \%$ on average in the EU28 (OECD, 2020[28]).

Over the past two decades, the increase in total public expenditure for higher education, combined with falling student numbers, has resulted in a substantial increase in public expenditure per student, as shown in Figure 3.1. The spike in 2015 is due to exceptional drawing of the European Structural and Investment Funds (ESIF), because of an overlap between two budgetary periods and a special exemption allowing the Slovak Republic to use resources from the 2007-14 budgetary period until the end of 2016. However, while the level of per-student public expenditure in the Slovak Republic has increased, surpassing that of several countries in the region, it remains well below the OECD and EC23 average and that of highperforming countries, such as Finland and Germany.

\section{Sources of funding}

Public funding represented $68 \%$ of total funding for higher education institutions in 2017 , a figure equivalent to the OECD average but slightly below the average in the EU23 (73\%). Countries included in the EU23 average are the $23 \mathrm{EU}$ countries that were also members of OECD as of the end of 2019, namely Austria, Belgium, the Czech Republic, Denmark, Estonia, Finland, France, Germany, Greece, Hungary, Ireland, Italy, Latvia, Lithuania, Luxembourg, the Netherlands, Poland, Portugal, the Slovak Republic, Slovenia, Spain, Sweden and the United Kingdom. Funds from EU structural funds ("international sources") represent $3 \%$ of the total, a figure equivalent to the OECD average but slightly below the EU23 average (4\%) (Figure 3.2).

Public HEls are eligible for the state contribution distributed annually by the MoE. State HEls focus on providing professional education in key public sector areas (e.g. police, armed forces, health sector), and are financed from the state budget by ministries with a responsibility in each area (e.g. Ministry of Interior, Ministry of Defence and Ministry of Health). Private HEls do not receive any regular direct contribution from the state budget related to providing higher education. 
Figure 3.1. Public expenditure on higher education per full-time student (2010-17)

Funding per full-time equivalent students, direct expenditure, measured in USD at constant prices and constant PPP

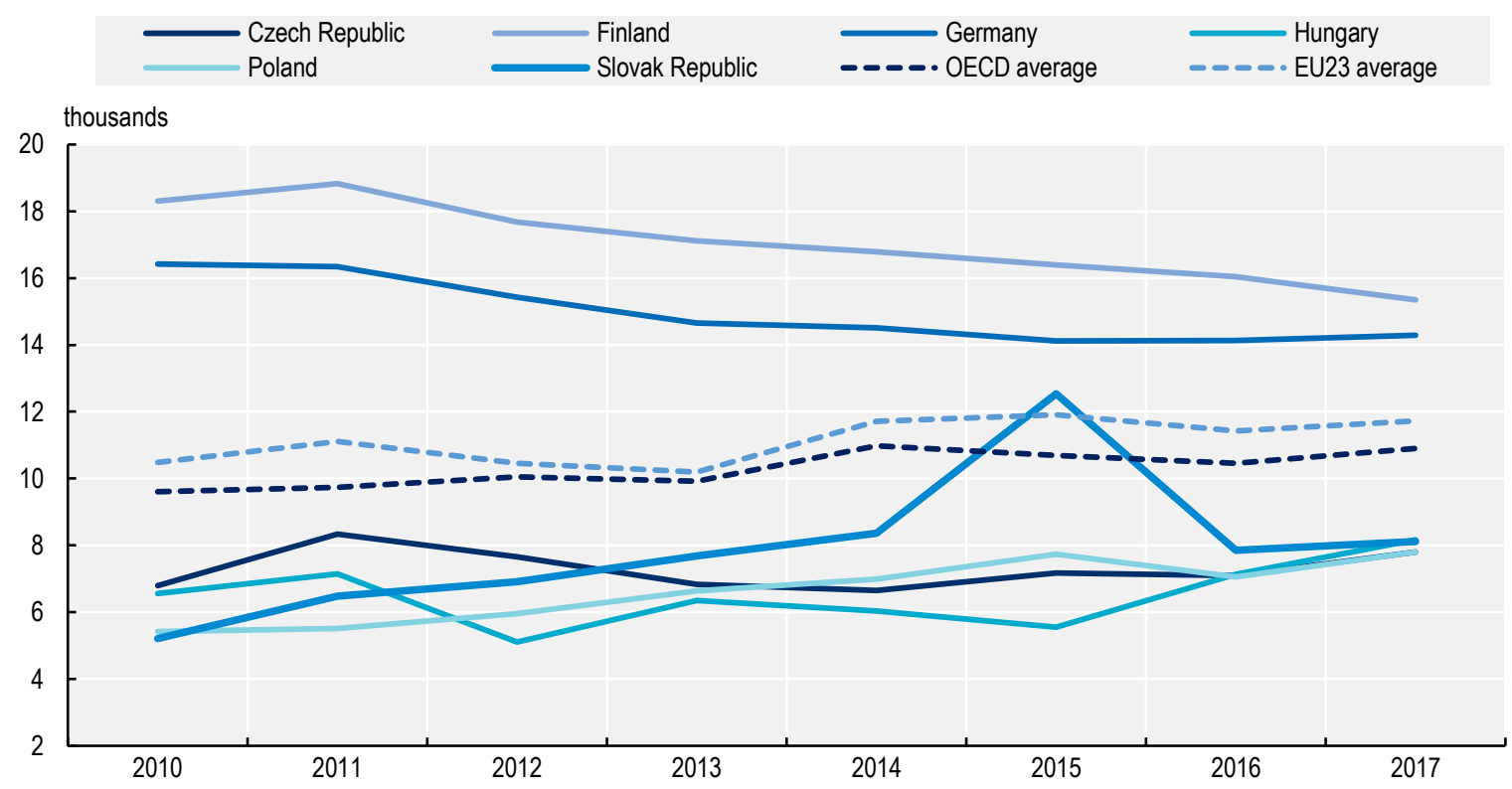

Note: PPP stands for purchasing power parity.

The EU23 average refers to the average of 23 EU countries that were also OECD members as of the end of 2019.

Source: OECD (2021 [29]), OECD Education Statistics, https://doi.org/10.1787/edu-data-en.

StatLink 제내 https://doi.org/10.1787/888934279130

Figure 3.2. Relative share of public, private and international expenditure on higher education institutions, by final source of funds (2017)

After transfers between public and private sectors

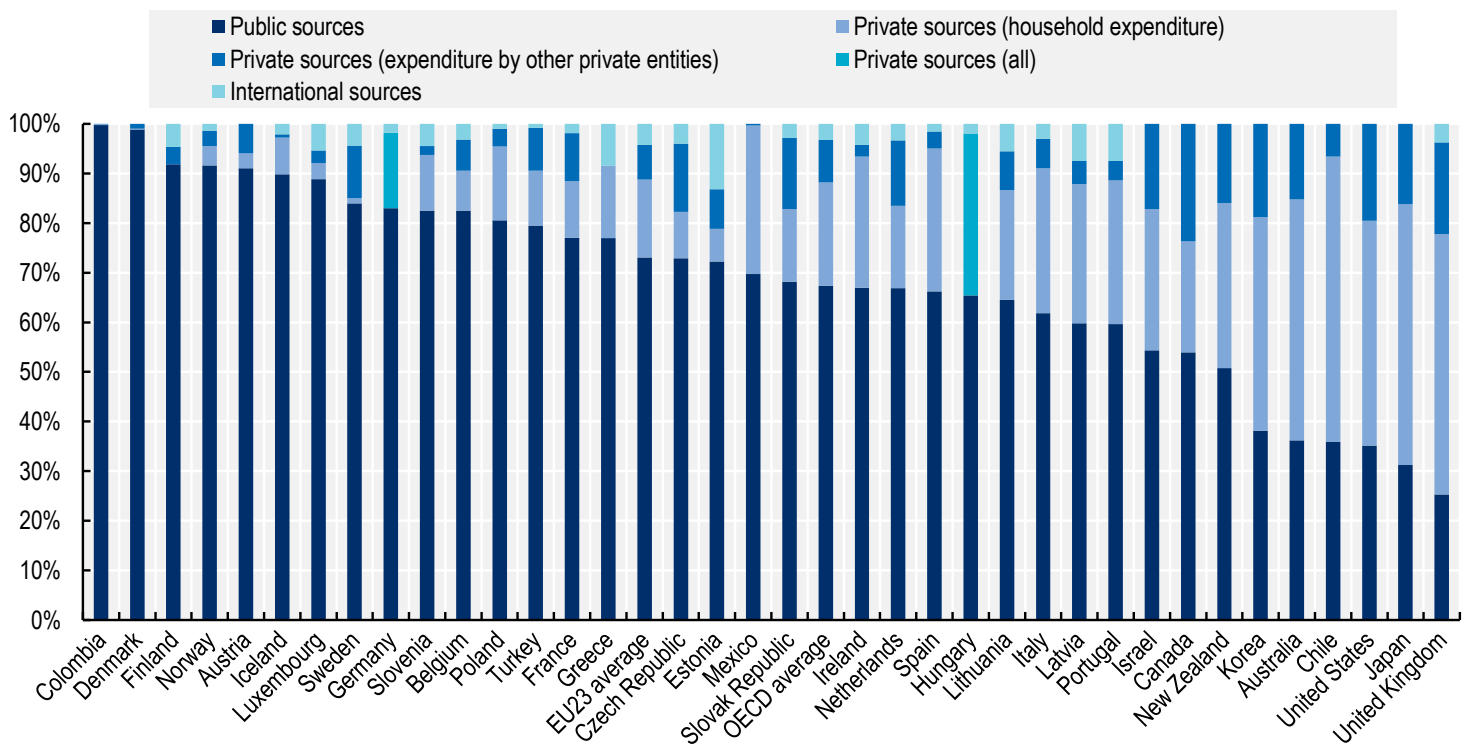


Note: Public expenditure figures presented here exclude undistributed programmes. Private expenditure figures include tuition fee loans and scholarships (subsidies attributable to payments to educational institutions received from public sources). Loan repayments from private individuals are not taken into account, and so the private contribution to education costs may be under-represented. See the source for more information.

The EU23 average refers to the average of 23 EU countries that were also OECD members as of the end of 2019.

Colombia and Costa Rica: Year of reference 2018.

Information on data for Israel: https://oe.cd/israel-disclaimer.

Source: OECD (2020[27]), Education at a Glance 2020: OECD Indicators, https://doi.org/10.1787/69096873-en, Table C3.1.

StatLink 제피 https://doi.org/10.1787/888934279149

Private funding is another important source of funding for Slovak HEls. Private funding excluding household expenditures account for a relatively high share (14\%) of current $\mathrm{HEI}$ revenues, significantly above the OECD average of $9 \%$. Given that $29 \%$ of HEI revenues come from private sources, both in the Slovak Republic and on average across OECD countries, the main difference lies in the repartition between private funds coming from households and from third parties: $21 \%$ of HEI revenues come from households in OECD countries, above the Slovak average of 15\% (OECD, 2020, pp. 299, Figure C3.2[27]). Universities with a technical orientation in particular attract funding from private companies by providing services as part of university-industry partnerships.

Similarly to one-third of OECD countries, public HEls in the Slovak Republic do not charge tuition fees to domestic full-time students (OECD, 2020[27]). They are allowed to charge tuition fees within a framework defined by MoE from specific groups of students, including international students, students prolonging their study beyond the usual programme length and part-time students. These groups form a sizeable population: in 2019 , part-time students represented approximately $20 \%$ of students in public HEls (CVTI, $\left.2021_{[30]}\right)$. Students are also charged small additional fees - on average USD 62 converted in purchasing power parities (PPPs) for the year 2017/18 (OECD, 2020, pp. 331, Figure C5.6[27]), related to administration, registration and student union membership.

Independent private HEls operate solely based on students' tuition fees, which they can charge freely. For the year 2017/18, private HEls charged on average USD 2059 in converted in PPPs annually for a bachelor's degree and USD 2464 converted in PPPs for a master's degree for national full-time students (OECD, 2020, pp. 333, Table C5.1[27]).

\section{Uses of funding}

Higher education funding supports a range of services including core services such as teaching costs and other services related to education, ancillary services such as housing, transportation or meals for students and funding for R\&D. In the Slovak Republic, expenditure for core services and R\&D is well below the OECD and EU23 average, whereas the share of funding supporting ancillary services is close to three times the average in the EU23 (Table 3.2).

\section{Table 3.2. Total expenditure on educational institutions per full-time equivalent student for core educational services, ancillary services and R\&D (2017)}

In equivalent USD converted using PPPs for GDP, direct expenditure within educational institutions

\begin{tabular}{l|r|r|r|r}
\hline & Core services & Ancillary services & R\&D & All services \\
\hline Slovak Republic & 6979 & 2096 & 2640 & 11715 \\
\hline OECD average & 11313 & 809 & 4205 & 16327 \\
\hline EU23 average & 10940 & 703 & 5044 & 16688 \\
\hline
\end{tabular}

Note: The EU23 average refers to the average of 23 EU countries that were also OECD members as of the end of 2019. Source: OECD (2020[27]), Education at a Glance 2020: OECD Indicators, Table C1.2, https://dx.doi.org/10.1787/69096873-en. 


\section{Student financial aid}

Slovak students who study on a full-time basis benefit from ancillary services provided by their institution, such as access to dormitories, meals, transportation and family subsidies. Students may also be eligible for public financial aid, though it is limited.

The Slovak Republic had the second lowest average annual amount of scholarships or grants received by students in OECD countries after Estonia in the year 2017/18 at USD 410 converted using PPPs (OECD, 2020, pp. 335-336, Table C5.3[27]). Grants are typically means-tested social stipends directly paid from the state budget to HEls. To be eligible, students should not exceed the standard length of studies, and report their study progress. Merit-based scholarships also exist in selected departments and fields.

Public loans are also available, although they serve a limited number of students. Loan programmes include "The Fund to Support Education", which, in its current form, was introduced in 2013. This programme provides loans to students, both full-time and part-time, and to teachers and educational professionals at different levels of education, to cover education-related expenses, including living costs. Eligibility criteria include enrolment in the Slovak Republic or in a comparable programme abroad and Slovak citizenship or long-term residency. Student loans are allocated based on family income, family composition and study performance (OECD, 2020, pp. 335-336, Table C5.3[27]). According to the MoE, in 2019/20, 1099 applications for loans were approved, a figure consistent with the previous year. The total expenditure was EUR 3520600 (despite a total funding envelope of EUR 4.5 million), and the average amount per loan that year was EUR 3 203. From an international perspective, the average amount of student loans in the Slovak Republic was the third lowest amount across OECD countries after Latvia and Denmark (OECD, 2020, pp. 335-336, Table C5.3[27]). According to MoE, stabilisation loans were also introduced in June 2019 to cover study and living costs of students choosing fields of studies considered by MoE as in high demand in the Slovak labour market. Graduates who find employment in their field of study in the Slovak Republic do not need to repay the loan (FNPV, 2021[31]). According to the MoE, while EUR 2662000 were made available in 2018/19 for stabilisation loans, only about 18\% was spent: 243 applications were approved for a total amount of EUR 486000 , so an average amount of EUR 2000 per loan.

\section{Allocation of funding from the government to public HEls}

In addition to the total level and sources of funding for higher education, the mechanisms through which the government allocates funding to HEls plays a key role in shaping the behaviours of HEls (OECD, 2020[32]).

In the Slovak Republic, the MoE publishes annually the methodology through which the government contribution for public HEls will be allocated, after the Parliament approves the total sum. For 2020, the formula allocated funds across four categories: teaching accounted for almost $50 \%$ of the contribution; research for approximately $37.5 \%$; further development of HEls for about $2.5 \%$; and social support to students for approximately $10 \%$ of the contribution (Table 3.3 ).

\section{Table 3.3. Allocation of public contributions to public HEls in the Slovak Republic (2020)}

\begin{tabular}{|c|c|c|}
\hline Areas & Items & Allocation mechanism \\
\hline $\begin{array}{l}\text { Teaching (around } 60 \% \text { of } \\
\text { total public spending) } \\
\text { EUR } 354838850\end{array}$ & $\begin{array}{l}\text { Salaries and insurance } \\
\text { EUR } 283653712\end{array}$ & 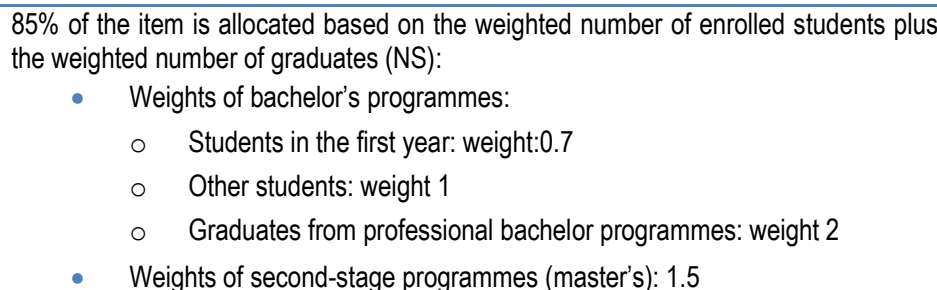 \\
\hline
\end{tabular}




\begin{tabular}{|c|c|c|}
\hline Areas & Items & Allocation mechanism \\
\hline & & $\begin{array}{l}\text { Weights of third-stage programmes (doctorates): } 12 \text { (divided by the standard } \\
\text { length of study) } \\
\text { Students in part-time form of study or paying tuition fees: weight } 0 \\
\text { NS is further weighted by coefficients capturing the specifics of the study programme: } \\
\text { - Coeff. of the field of the study (FS) } \\
\text { - Coeff. of the qualification structure of teachers (QS) } \\
\text { - Coeff. of graduate employment (GE) equals (1+graduate employment rate) })^{2} \\
13.8 \% \text { of the item is allocated based on the publishing activity during two previous years } \\
1.2 \% \text { of the item is allocated based on artistic performance during two previous years }\end{array}$ \\
\hline & $\begin{array}{l}\text { (Common) Goods and } \\
\text { services } \\
\text { EUR } 48226024\end{array}$ & $\begin{array}{l}\text { Allocated based on NS, FS and GE, plus } \\
\text { Funding from foreign grants (e.g. Horison 2020, Erasmus+) } \\
\text { ○ Academic mobility of students }\end{array}$ \\
\hline & $\begin{array}{l}\text { Specific costs } \\
\text { EUR } 15959114\end{array}$ & $\begin{array}{l}\text { Based on applications submitted by HEls, cover costs related to, e.g. practical training } \\
\text { or external lecturers }\end{array}$ \\
\hline & $\begin{array}{l}\text { Capital expenditures } \\
\text { EUR } 7000000\end{array}$ & $\begin{array}{l}\text { Based on applications submitted by HEls, cover the urgent investment in buildings and } \\
\text { reconstructions }\end{array}$ \\
\hline \multirow[t]{6}{*}{$\begin{array}{l}\text { Research (around 30\%) } \\
\text { EUR } 184631718\end{array}$} & $\begin{array}{l}\text { Research grant agency } \\
\text { (VEGA) } \\
\text { EUR } 12250000\end{array}$ & Calls for project proposals \\
\hline & $\begin{array}{l}\text { Education and Culture } \\
\text { grant agency (KEGA) } \\
\text { EUR } 4400000\end{array}$ & Calls for project proposals \\
\hline & $\begin{array}{l}\text { Research infrastructure } \\
\text { EUR } 152928099\end{array}$ & $\begin{array}{c}\text { Based on: } \\
\text { - Share of HEl's research allocation (six-year average) (weight: } 0.43) \\
\text { - } \quad \text { Share of foreign grants }(0.10) \\
\text { - } \quad \text { Share of public sector grants }(0.09) \\
\text { - Share of the total number of PhD students }(0.10) \\
\text { - Share of the total number of publications }(0.225) \\
\text { Share of the total number of artistic productions }(0.025)\end{array}$ \\
\hline & $\begin{array}{l}\text { Top teams } \\
\text { EUR } 1160000\end{array}$ & Top teams are identified by the most recent accreditation \\
\hline & $\begin{array}{l}\text { Access to electronic } \\
\text { resources } \\
\text { EUR } 2000000\end{array}$ & $\begin{array}{l}\text { Facilitated through the Slovak Centre of Scientific and Technical Information (CVTI) for } \\
\text { all public HEls }\end{array}$ \\
\hline & $\begin{array}{l}\text { Wage valourisation } \\
\text { EUR } 3074705\end{array}$ & $\begin{array}{l}\text { Equally distributed valourisation of teachers' wages, based on a long-term plan covering } \\
\text { all levels of education }\end{array}$ \\
\hline \multicolumn{2}{|l|}{$\begin{array}{l}\text { Development of HEI (2\%) } \\
\text { EUR } 11969835\end{array}$} & Distributed centrally through the MoE - Call for project proposals \\
\hline \multicolumn{2}{|c|}{$\begin{array}{l}\text { Social support of students (around 10\%) } \\
\text { EUR } 51525264\end{array}$} & $\begin{array}{l}\text { Student aid distributed through the Fund to Support Education based on claims defined } \\
\text { by legislation }\end{array}$ \\
\hline
\end{tabular}

Note: 1. The coefficient for the field of study is based on a student/teacher ratio and student/non-pedagogical employee ratio for each study field. These ratios are included in the MoE methodology.

2. The graduate employment coefficient is based on the number of graduates in full-time study programmes from the previous two calendar years and on the number of unemployed graduates for each study field.

Sources: MoE (2019[33]), Metodika rozpisu dotácií zo štátneho rozpočtu verejným vysokým školám na rok 2020 [Methodology of Breakdown of State Budget Subsidies to Public Universities for 2020], https://www.minedu.sk/vyrocne-spravy-o-stave-vysokeho-skolstva/; additional updates provided by MoE to the OECD.

The largest item - "teaching" - is allocated based on a weighted number of students and graduates. Several incentives are built into the formula, in particular to encourage a stronger institutional focus on the labour market relevance of programmes. For example, a greater weight is assigned to students enrolled 
in professional bachelor's degrees compared to those enrolled in master's degree programmes, and a coefficient is applied based on the share of graduates who are not registered as unemployed with the public employment service. The formula also aims to take account of cost differences in delivering programmes, through a field-specific coefficient.

Since 2017, incentives for academics to improve the quality of research have been strengthened: $13.8 \%$ of the "salaries and insurance" item in the "teaching" category are allocated based on publication performance over the past two years, measured by the numbers of publications registered in the international database, Web of Science (WoS). If a publication appears in the WoS database, it can generate ten times more funding than a publication that does not appear in WoS. The WoS impact factor is used to differentiate scientific journals into quartiles, with the difference in support received for an article in the first quartile potentially more than 12 times higher than for an article published in a journal from the fourth quartile. According to higher education stakeholders interviewed by the OECD, it is a common practice that a substantial share of these resources, allocated based on a methodology made available publicly, are paid to the authors.

Research funding is also allocated through competitive processes. Research grants are administrated by several agencies - the Slovak Research and Development Agency (APVV) that finances middle-sized specific and international research projects and the Scientific, Cultural and Educational Grant Agencies (VEGA and KEGA) that supports small-scale research, cultural and educational projects. The Research Agency mostly finances infrastructure projects. Despite these various structures, the Value for Money project of the Ministry of Finance pointed out that less than $20 \%$ of research funding was allocated based on competitive grant schemes (MoE, 2017[34]).

\section{Challenges limiting the adoption of effective reforms}

\section{Funding levels and priorities}

While funding per student in the Slovak Republic has increased in recent years due to declining student numbers and the influx of European funds, it remains below the level of high-performing OECD countries. In addition, HEls face limitations in the ways in which they can use additional funding. In particular, several factors constrain spending on human resources.

The total amount of funding HEls can allocate to human resources is determined by the public funding framework in two ways. First, the total amount of public funding available to HEls, which is driven by student and graduate numbers as shown previously, imposes limits on their overall spending on staff wages that form the large majority of the "teaching" category in the funding formula (see Table 3.3). With declining student numbers, there is a lower amount of public funding available for $\mathrm{HEl}$ expenditure overall, including on staff.

Second, while there has been an increase in the flows of EU structural funds to higher education in recent years, the Slovak Republic makes limited use of available EU structural funds. In 2019, the country had drawn about $23 \%$ of the total allocation of EU funds to the Slovak Republic for the budgetary period of 2014-20 (Government of the Slovak Republic, 2019[35]).

According to the Learning Makes Sense study (To dá rozum), the under-utilisation of funds during the 2014-20 period resulted from multiple challenges. These include the lack of a national strategy to use the funds, in turn leading to delays in announcing calls and implementing projects, insufficient numbers of expert evaluators to review proposals, and uncoordinated project inspections by multiple government bodies. The project also noted the significant administrative burden involved in preparing project proposals and the poor quality of those proposals, often outsourced to third parties as HEI staff themselves face high levels of administrative burden in their regular activities (MESA10, 2021 $\left.{ }_{[9]}\right)$. Another reason underlying this under-utilisation of funds relates to constraints associated with European funding that are not unique to 
the Slovak Republic: HEls in the Bratislava region were not eligible to the same amount of European Structural and Investment Funds (ESIF) as HEls in other regions despite most research activity taking place in Bratislava.

Furthermore, EU funds have mostly been targeted to capital expenditure. As shown in Figure 3.3, Panel A, the increase of total resources for public higher education between 2010 and 2019 was not accompanied by a commensurate rise in spending on wages for higher education staff. Investments planned as part of the Slovak Republic's national RRP to support the strategic development of HEls also show a major focus on physical infrastructure projects, both to upgrade and to create new school and housing facilities, as discussed above. Despite these limitations, however, European structural funds have played an increasing role in higher education funding in the Slovak Republic. New funds as part of the Recovery and Resilience Facility are likely to continue this trend, as outlined in Action Step 1 (see Box 3.3).

At the same time, while the decrease in enrolment could, in principle, reduce overall teaching costs and reallocate them towards initiatives to improve teaching quality, the size of the teaching workforce has decreased to a much lower extent that the numbers of students over the past decade. As shown in Figure 3.3 Panel B, between 2009 and 2019, while the number of higher education students dropped by around $40 \%$, the number of higher education teachers declined by approximately $10 \%$ and the number of professors increased by around $5 \%$. This might be due to the combination of academic employment rules, discussed below in "Enabling responsive institutional governance and management", and of the ageing profiles of higher education teachers.

In 2018 , approximately $11.5 \%$ of higher education teachers were 60 to 64 years old in the Slovak Republic, compared to an EU average of $9 \%$, and $12 \%$ were over the age of 65 , compared to $6 \%$ on average in the European Union in 2018 (Eurostat, 2021 [36]). Because older academic staff are more likely to have permanent employment, HEls who may want to adjust the size of their academic workforce may face difficulties.

The Slovak government has taken steps to address this challenge, by restricting the employment of higher education teachers after they reach 70 years of age. Employment contracts of higher education teachers terminate automatically after they reach 70 , and prolongations of employment contracts with persons older than 70 can only be signed for a maximum of one year, although they can be renewed. Moreover, the academic titles of staff over 70 did not count in the most recent accreditation process (Act on HEls: $\S 77$ col. 6).

\section{Limits of current funding allocation mechanisms}

\section{Funding formula}

In the Slovak Republic, the main funding instrument used by the government to incentivise the behaviour of public HEls is the funding formula. A major benefit of allocating funding through the formula is the transparency of this approach. Both the methodology for calculating the allocation and the amounts allocated to each HEl are published on the Ministry of Education's website each year, allowing for public scrutiny of changes. In a context of low trust in government, this transparency is valuable.

Secondly, the government has used the formula to introduce incentives - to reward publications in highimpact journals or graduate employment in particular. According to some stakeholders interviewed by the OECD, HEls respond to formula changes. 
Figure 3.3. Human resources in Slovak higher education
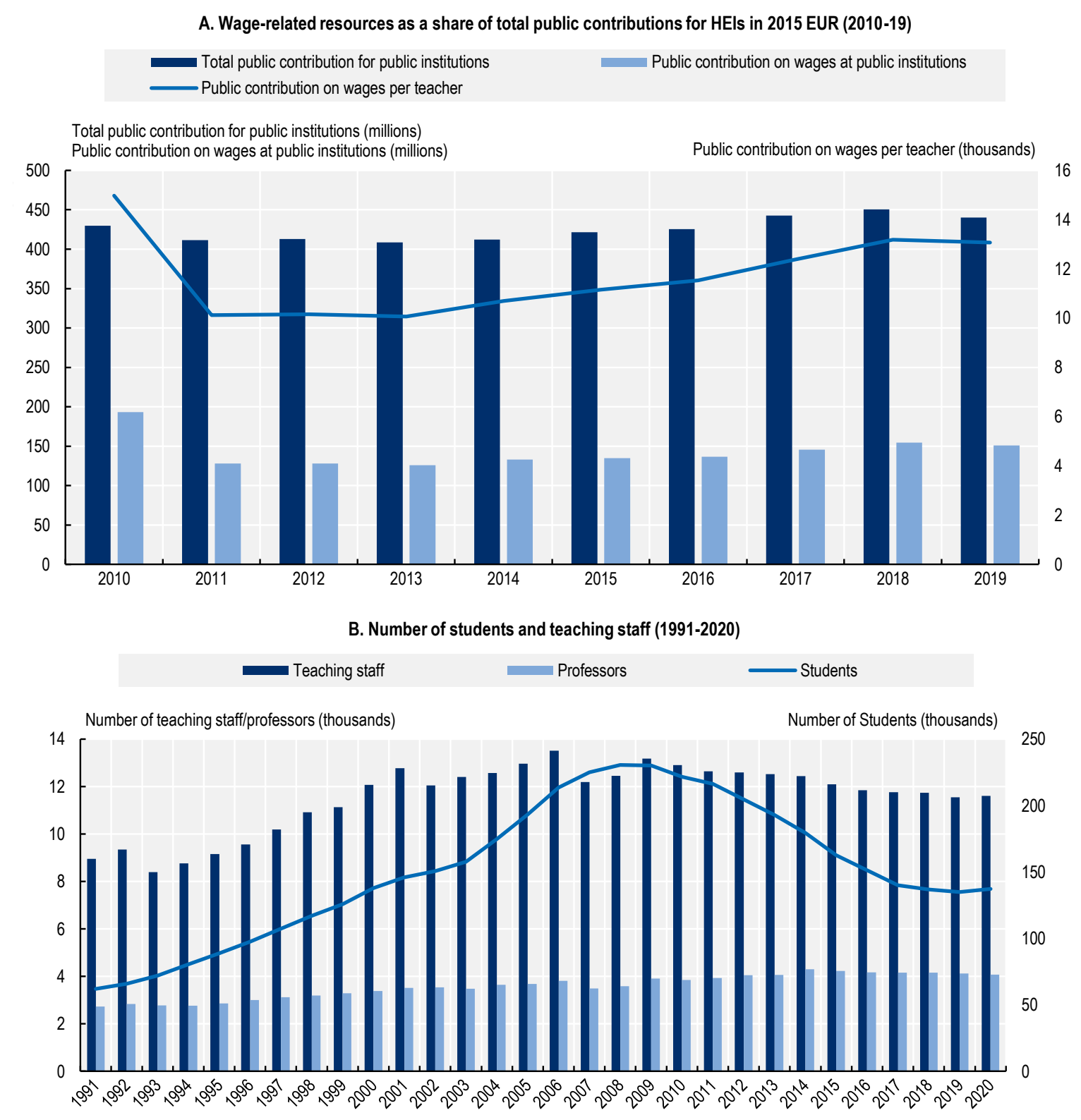

Note: Panel B: Teaching staff and students include both full-time and part-time. Professors include both "profesori (professors)" and "docenti (associate professors)".

Sources: CVTI (2021 [37]), Časové rady [Timelines], https://www.cvtisr.sk/cvti-sr-vedecka-kniznica/informacie-o-skolstve/statistiky/casoverady.html?page id=9724; MoE (2021[38]), Financovanie [Financing], https://www.minedu.sk/677-sk/financovanie/.

StatLink 제피 https://doi.org/10.1787/888934279168

However, the formula presents several limits. These relate to the components of the formula, the method through which public funding once calculated is allocated to HEls, and the general limitations of this policy instrument. In the Slovak Republic, recent policy efforts appear to have focused primarily on rewarding quality research, although some stakeholders interviewed by the OECD noted that more nuanced measures of research quality would be desirable in addition to scientometric indicators currently built into the formula. The new scientific evaluation process indicated as part of the Slovak Republic's national RRP 
might be a step in this direction. Examples from other jurisdictions, such as that of the Flemish Community of Belgium discussed later, highlight potential indicators that may help the Slovak Republic improve its current approach to measuring the quality of research.

The current funding formula is a weak instrument to promote teaching quality. Graduate employment is taken into account, but no metric aims to reward the quality of graduate employment, a concept defined by the OECD as combining earnings quality, job security and a good working environment (OECD, $2016_{[39]}$ ). Earnings measures in particular are frequently used as a proxy for the value assigned by employers to graduate skills, the extent to which graduates use the skills they obtained through their higher education studies in the workplace, and at a system level reflect the overall alignment of a higher education system with the national labour market.

Labour market mismatches are large in the Slovak Republic, in part due to the insufficient focus of the education system - at the school level and in higher education - to labour market needs (OECD, 2020[4]). At the same time, as the Slovak Republic's labour market evolves, ensuring graduates have appropriate levels and combinations of transversal skills is important to ensure graduates are prepared to succeed in occupations, jobs and tasks that do not exist today. This suggests the need for connecting funding with measures that more effectively reflect the quality of higher education teaching, in terms of skills and labour market outcomes.

The way government divides and allocates funding is important to ensure the incentives that the government builds into the formula have an impact on institutional actions. Two problems appear to limit the "incentivising power" of the funding formula in the Slovak Republic. First, frequent revisions are made, with new elements introduced, changed or removed, often on an annual basis. While policy priorities understandably change, overly frequent changes mean that HEls have little ability (and few incentives) to plan their operations strategically. The complexity of the formula can also pose challenges, as many indicators with small funding impacts may discourage HEls from taking decisive actions to improve on any specific priority area the formula aims to encourage.

The second issue relates to the timing of the funding allocation to HEls. The Ministry of Education announces at the end of each calendar year the total amount of funding available for salaries and wages (the largest component of the formula), and then divides this amount between HEls according to the number of weighted students and graduates. It is thus difficult for HEls to anticipate their allocation for the coming year, other than estimating it based on the previous year. This exacerbates the first problem (frequent changes and complexity of the formula): while government aims to use the funding formula as a strategic policy tool to encourage HEls to plan their operations to achieve certain objectives, the lack of predictability limits the policy effectiveness of this tool.

Finally, the funding formula has limitations as it is a policy tool focused on institutional actions, but it does not reach other key actors, such as students or employers. For instance, while the funding formula assigns a higher weight to students enrolled in professional bachelor's degree programmes compared to those in other bachelor's or master's degree programmes, few students choose professional bachelor's programmes and many continue to choose master's degree programmes. Furthermore, some higher education stakeholders interviewed by the OECD highlighted that graduates of professional programmes often choose to pursue a master's degree even if not required for employment.

Data presented in Chapter 2 about the earnings returns of master's graduates, which are substantially greater than those of bachelor's graduates, suggests that challenges exist about the real or perceived quality of professional (and other) bachelor's degree programmes in the Slovak Republic, by both students who make study choices and employers who reward graduates financially. These challenges require complementing the funding formula with other policies, as suggested later in this section. 


\section{Research funding}

Stakeholders interviewed by the OECD have expressed several concerns regarding the current allocation of competitive research funding. They cited both the lack of long-term stability, with amounts fluctuating between calls, and frequent cases of lower funding allocation than those requested by researchers. Other concerns included the substantial level of administrative duties required to apply for grants and low administrative support in HEls to help researchers with this task, which has been described as severely limiting individual researchers' motivation to pursue competitive research funding. This was particularly the case for small grants from VEGA and KEGA that cover core research activities (e.g. travelling and standard equipment) but make applying for such funds less attractive due to the associated administrative burden. Some stakeholders interviewed by the OECD also expressed concerns regarding the lack of transparent processes used by the agencies allocating research funding.

Many concerns exist regarding the use of EU structural funds dedicated to research and innovation, some relating to the under-utilisation of EU funds for education and research generally, as highlighted earlier in the "funding levels and priorities" section. In addition, according to the Learning Make Sense (To dá rozum) study, the management of the majority of the 2014-20 Operational Programme (OP) on Research of Innovation by the Ministry of Economy led to the transfer of a majority of these funds to business entities rather than to the higher education sector. The study argues this approach led to inefficiencies, as businesses often outsourced the research these funds supported to the Slovak Academy of Science or HEls due to their limited capacity to conduct it (MESA10, 2021 [9]).

\section{Limited use of national funding instruments}

Governments have a range of funding levers they may use to steer the actions of HEls, or directly those of higher education staff and students. The Slovak Republic could use some of these tools more strategically, both in terms of greater and better use.

\section{Institutional contracts}

Institutional contracts that tie a portion of higher education funding to performance can be useful tools to reward HEls for identifying and building on their strengths and contributing to national policy objectives. While many countries use performance contracts -13 did according to a recent OECD study on higher education resourcing - the impact of contracts depends on the amount of funding tied to institutional contracts, which varies from below $5 \%$ to close to $100 \%$ (OECD, 2020[32]).

MoE and each HEI sign a contract each year based on the allocation provided to the HEI according to the funding formula, and thus reflecting past performance according to formula criteria. No funding is attached to future plans of HEls, limiting longer-term, strategic management of institutional resources. Slovak authorities have not yet communicated the scale of funding they plan on associating with multi-year institutional contracts they are aiming to create, other than noting that the large infrastructure projects envisioned as part of the Slovak Republic's national RRP will contribute to priorities identified in performance contracts. Nevertheless, even if contracts are tied to low funding amounts, they can play an important role from an accountability and transparency perspective, by requiring the reporting of standard performance indicators. They can also play a role in forward planning, by allowing HEls to signal their plans and facilitating dialogue between HEls and government, as in the case of Denmark's Strategic Framework Contracts, described later in this section.

International experience suggests that the development of institutional contracts that focus on performance metrics requires care to avoid unintended consequences. An important one is the risk that HEls shift away from equity of access in their search to meet demanding performance goals (Dougherty et al., 2014[40]). From an implementation perspective, stable indicators known well in advance are important, as is sufficient 
human and financial resources in government (or a buffer body) and in HEls, and a collaborative relationship between government and HEls to manage contracts most effectively.

\section{Targeted funding}

Targeted funding programmes constitute an important tool that OECD countries use to achieve their policy objectives. Such programmes present the advantage of flexibility, allowing government to directly incentivise HEls to focus on certain priorities without creating variations in regular funding allocations. Targeted funding may be allocated based on a competitive basis. In such cases, it works best in contexts where there is a high level of integrity and transparency in the allocation of funding (OECD, 2020 [32]), which thus must become an important national priority when considering the use of these instruments.

Targeted funding is used for various purposes, from incentivising HEls to collaborate to develop internationally competitive research (such as in France, discussed below). It can also be used to address emerging and possibly transitory needs - for instance, in the US state of Washington, top-up funding was approved to increase the salaries of academics hired by public HEls in fields of study such as health or science, technology, engineering and mathematics (STEM), where individuals would obtain significantly higher earnings outside of academia (OECD, 2020[41]). Targeted funding can also be used to encourage HEls to develop labour-market-relevant programmes designed and delivered in partnership with employers. Examples of such programmes exist (see, for instance, Box 3.5), but they are not common in the Slovak Republic.

\section{Box 3.5. Practices supporting labour-market-relevant education}

\section{Professional bachelor's programme at the Slovak Technical University and Volkswagen}

In the Slovak Republic, the company Volkswagen and seven suppliers have developed an innovative four-year professional bachelor's programme combining practical training with university-level education at the Faculty of Mechanical Engineering of the Slovak University of Technology. Students spend three years studying at the university and one year working for Volkswagen or other companies (or one of its suppliers). The programme received formal accreditation from MoE although the process took around a year due to its novelty. Volkswagen also reportedly struggled to find a partner university. The programme has piloted since 2018 in a limited scope and has yet to deliver graduates. For more information, see https://profesijnybakalar.sk/.

\section{Nudging individual educational decisions towards labour-market-relevant HE programmes}

At the level of secondary school programmes, the self-governing regions with the support of MoE markedly reduced financing and the number of classes in study programmes considered unattractive by the labour market (Martinák and Zápražná, 2017[42]). At the level of HE, MoE adopted softer measures, aiming to steer individual study decisions through facilitating access to relevant labour market information. For example, a joint initiative with the Ministry of Labour, Social Affairs and Family and other partners, created a well-organised web page providing information from a graduate-tracking exercise. Currently, information on secondary and tertiary education graduates from 2018 is available on their unemployment rate, average wage, region and occupation of their employment, etc. For more information, see https://uplatnenie.sk/.

Another example of nudging towards labour-market-relevant programmes is the "Stabilisation loan" provided from the state fund to support education. Stabilisation loans are provided to cover the study and living costs of individuals deciding to study in fields of study considered by MoE as in high demand in the Slovak labour market. In cases where individuals upon graduation find employment in their field of study 
in the Slovak labour market, they do not need to repay the loan. For more information, see https://www.stabilizacnepozicky.sk/.

Source: OECD (2020[4]), OECD Skills Strategy Slovak Republic: Assessment and Recommendations, https://dx.doi.org/10.1787/bb688e68en.

The Slovak Republic appears to be making limited use of targeted funding instruments, resorting instead to the funding formula as the main policy lever to influence institutional behaviour. Part of this approach might be explained by significant capacity issues - highlighted below in the area of allocating research funding. In addition, some stakeholders interviewed by the OECD highlighted that targeted funding could create concerns of uneven treatment among HEls if their allocation was not as transparent as the funding formula.

Despite these challenges, there might be an opportunity for the Slovak Republic to pay special attention to developing sound mechanisms for targeted funding, as it may be an important instrument to consider in light of the multiplicity of challenges the country faces in higher education. This would require minimising the administrative burden by connecting targeted funding, for instance, to institutional contracts, and by setting a high standard of transparency in the allocation of funds from the government to HEls, as is currently done for the funding formula.

\section{Student financial aid}

The Slovak Republic has some needs-based student aid programmes that focus on student loans rather than grants. While no comparative data is available on the share of higher education students receiving financial aid in the Slovak Republic, some stakeholders interviewed by the OECD suggested that a modest share of students participate in financial aid programmes. This may be a concern even in a context where there are no tuition fees for students studying in Slovak-language programmes (that is, most domestic students), because the indirect costs of attending higher education can be high. These include, for instance, costs for housing, transportation or learning equipment - for example, digital devices in the context of remote learning. The opportunity cost of higher education can also be significant as Slovak students typically engage in long study programmes.

Financial aid can also be used to encourage study in programmes that equip students with knowledge and skills in demand in the labour market. Stabilisation loans, described earlier, aim to support access to indemand study fields, but the extent to which these loans are available and taken up by students is unknown, as well as the extent to which they have been effective in encouraging the take-up of in-demand study fields. There is an opportunity for the Slovak government to consider evaluating efforts - both financial and non-financial - to inform students about (current and future) labour market needs and to provide financial supports to higher education students pursuing in-demand fields of study. Some information-based initiatives have been developed, as illustrated in Box 3.5, but their reach and impact is unclear.

\section{Relevant international experience}

The rapid expansion of higher education systems in OECD countries over recent decades has led to greater investments from both governments and individuals. Moreover, between 1995 and 2005, the average expenditure per student across 13 OECD countries doubled, after taking inflation into account (OECD, 2020[32] $)$. While countries have different approaches to who should bear the cost of higher education, governments across OECD countries have developed increasingly sophisticated funding instruments to ensure their growing investments deliver results - in particular, increased accessibility, quality and equity of higher education. 
Denmark provides an example of a country that has continued to shift the role of performance measures in its funding model while creating a system that is more collaborative and tailored to individual HEls (de Boer et al., 2015[43]). The Flemish Community of Belgium provides examples of an innovative approach to funding research and innovation, another key area of interest for the Slovak Republic.. France provides an example with respect to using a combination of competitive funding and legislative requirements to consolidate the network of HEls - another area of interest to the Slovak Republic.

\section{Denmark: Using performance-based funding and strategic framework contracts}

Denmark has a long history of performance-based funding in higher education, with significant shifts over time that present lessons learned. Prior to 2019, performance-based funding (PBF) for teaching for institutions was comprised of two key components. First, a "taximeter scheme" of funding (now renamed but still operational), and second, a "completion bonus", which has since been discontinued (the bonus was based on the number of students that complete their degree in the prescribed time plus one year).

The taximeter scheme is based on HEl performance in terms of student examination completion - each student completion elicits a "fee" for which the university can claim government funds. Typically, universities can collect a greater per-student fee for STEM student exam completions, with social sciences and humanities providing a smaller one (Danish Ministry of Higher Education and Science, 2019[44]). Through this mechanism, the government is able to ensure that varying programme costs are accounted for in funding provisions, and as a result, incentivises institutions in delivering a mixture of different programme subjects. For courses that are evaluated as having poor labour market performance, a cap is placed on funding (OECD, 2020[41]).

As of 2019, the completion bonus has been replaced with three new funding streams: basic funding, results-based grants and quality funds. In the new funding model, taximeter funding (now termed an "activity grant", post 2019) accounts for $67.5 \%$ of all funding, while the remaining $32.5 \%$ of funding is allocated as follows: basic funding (25\%); results-based grants $(7.5 \%)$; quality funds $(<1 \%)$. The ResultsBased Grant is calculated based on how universities have performed on two indicators: duration of study and graduate employment. Any funds that remain after the allocation of the results-based grants are pooled into the quality fund and awarded via quality grants - designed to "support specific quality initiatives" outlined within strategic framework contracts (Danish Ministry of Higher Education and Science, 2019 [44]; Adam, 2020[45] $)$. Denmark has also introduced some PBF elements within the basic funding envelope itself: $5 \%$ of Basic Funding is dependent on the "quality achieved", as determined by the outcomes of the "Learning Barometer". A further $5 \%$ of Basic Funding is conditional on the achievement of strategic objectives included in the strategic framework contracts.

Strategic Framework Contracts (SFCs) were introduced in 2018, replacing the previous policy of performance contracts that had been in place since 2000 (Jongbloed and de Boer, 2020 [46]). These new framework contracts focus on building the relationship between the Ministry of Education and HEls. SFCs have shifted from measuring performance against Ministry-set indicators (used by prior iterations of performance agreements), to illustrating a series of ambitions for the institution, with indicators agreed between the $\mathrm{HEl}$ and the Minitry of Education. This includes the specific data that will be used as a measure of improvement.The contracts also have a specific funding link not present in the prior agreements. Universities risk a financial penalty if they do not meet the strategic goals set out in their contract (assessed by the Ministry at the end of the contract period). The Ministry of Education may withhold up to $5 \%$ of the 25\% Basic Funding if they decide that an HEI has under-performed.

Denmark has reformed its well-established PBF practices, seeking to adapt policies to achieve greater performance and quality from its higher education system. This has been approached from two angles. The first has been to adapt a previously $100 \%$ performance-based funding model for teaching (based on two system-wide mechanisms, the taximeter scheme and the completion bonus) to a new policy that seeks to more directly steer performance and $\mathrm{HEl}$ activity through additional system-wide and $\mathrm{HEI}$-specific 
performance indicators. The aim of these changes has been to compensate for emerging challenges that the funding model was not addressing - concerns about graduate employment outcomes and concerns about the quality of the student learning experience. Denmark has also removed a proportion of funding from the PBF model in the process through Basic Funding, balancing these changes with some increase to funding stability. Second, it has evolved its use of performance contracts to align more specifically with institutional goals and to be tied to funding.

\section{Flemish Community of Belgium: Developing research performance funding}

The Flemish Community of Belgium has spent the last two decades innovating in the design and implementation of its regional research, development and innovation (RD\&I) funding as the region sought to increase the performance of its innovation sector, recognising its important role in the broader economic development of the region (Debackere and Glänzel, 2004[47]; OECD, 2019 $9_{[48]}$ ). This example focuses on three interrelated elements of the Flemish RD\&I investment system. The first of these is the implementation of bibliometric performance indicators in the "Extraordinary Research Fund" (Bijzonder Onderzoeksfonds, or BOF). The BOF represents an important component of the overall funding of university RD\&I funding in the region, and is $50 \%$ performance-based (previously $100 \%$, until changes were made in 2019). The second component is the "Centre for Research and Development Monitoring" (Expertisecentrum Onderzoek en Ontwikkelingsmonitoring, or ECOOM), an inter-university consortium created to help steer the creation and utilisation of indicators for performance funding in RD\&I. Finally, the development of a new custom bibliometric indicator, the Flemish Academic Bibliographic Database for the Social Sciences and Humanities (VABB-SHW) is discussed.

The BOF was initially introduced as a new mechanism for distributing block research funds between Flemish universities in 1994. The allocation of these funds was based on a set of established indicators, termed "pre-allocation keys", recalculated each year, with "key" meaning "formula" (Jonkers and Zacharewicz, 2017 $[49]$ ). The Flemish government has continually adapted the indicators used in the BOF since its introduction, early indicators included degree completions, and overall investment a HEI received from other sources. Bibliometric indicators were introduced in 2003 (Engels and Guns, 2018[50]). In 2019, the BOF key was redesigned, reducing the weighting of degree completions, and introducing a new fixed allocation representing $50 \%$ of total funding. Changes were implemented with the aim to increase stability and place greater emphasis on quality over quantity of research outputs. Table 3.4. sets out the current indicators, and their weighting in funding allocations, alongside planned adaptations to weighting set to come into effect in 2024.

The Centre for Research and Development Monitoring (Expertisecentrum Onderzoek en Ontwikkelingsmonitoring, ECOOM) is a consortium of all five Flemish universities. ECOOM began as a project undertaken by researchers at $\mathrm{KU}$ Leuven University, initiated and funded by the Flemish government, to develop and implement a new bibliometric indicator for the BOF key (VABB-SHW) which continues in use. VABB-SHW is a shared database of "bibliographic references of published social sciences and humanities (SSH) research outputs by scholars who are affiliated to Flemish universities" (Ossenblok, Engels and Sivertsen, 2012[51]), designed to fill a gap in existing bibliometric sources for nonEnglish language and social science publications. The ECOOM-Antwerp group is responsible for maintaining the VABB-SHW, adding sources that meet an agreed set of criteria and delivering an updated version of the database annually (Engels and Guns, 2018[50]).

\section{Table 3.4. Bijzonder Onderzoeksfonds (BOF) funding indicators and allocation}

\begin{tabular}{l|l|r|r}
\hline \multicolumn{1}{c|}{ Funding envelope } & \multicolumn{1}{|c|}{ Indicator } & From 2019 & From 2024 \\
\hline Part A (50\% of funding envelope) & A1 Fixed allocation & $50 \%$ & $50 \%$ \\
\hline Part B (22.5\% of funding envelope) & B1 Publications - Web of Science & $10.5 \%$ & $10.5 \%$ \\
\hline
\end{tabular}




\begin{tabular}{l|l|r|r}
\hline & $\begin{array}{l}\text { B2 Publications - Flemish Academic Bibliographic Database for the Social } \\
\text { Sciences and Humanities (VABB-SHW) }\end{array}$ & $4.5 \%$ & $4.5 \%$ \\
\hline & B3 Citations - Web of Science & $7.5 \%$ & $7.5 \%$ \\
\hline \multirow{2}{*}{ Part C (27.5\% of funding envelope) } & C1 Number of doctorates & $9.25 \%$ \\
\hline & $\begin{array}{l}\text { C2 Distribution of citations in Science Citation and Social Science Citation } \\
\text { Indexes }\end{array}$ & $10 \%$ & $9.25 \%$ \\
\hline & C3 International co-publications & $3.75 \%$ & $3.5 \%$ \\
\hline & C4 Share of financial returns from EU research framework programmes & $3.75 \%$ & $3.5 \%$ \\
\hline & C5 Inter-disciplinary publications (indicator to be defined) & $0 \%$ & $2 \%$ \\
\hline & C6 Diversity of the researcher population (gender) & $1 \%$ & $1 \%$ \\
\hline
\end{tabular}

Source: Flemish Government (2019 $\left.{ }_{[52]}\right)$, Vlaamse Regering keurt BOF-besluit definitief goed: 35 miljoen euro extra voor universiteiten [Flemish Government definitively approves BOF decision: 35 million euros extra for universities], https://www.ewi-vlaanderen.be/nieuws/vlaamseregering-keurt-bof-besluit-definitief-goed-35-miljoen-euro-extra-voor-universiteiten.

ECOOM has a number of further roles within the research, development and innovation (RD\&I) landscape, including maintaining the Flemish Indicator Book, a public-facing publication of "policy indicators that chart the development of the Flemish potential in science, technology and innovation" (ECOOM, 2021 [53]). The government has encouraged ECOOM and other system stakeholders to "come forward with consensus suggestions to improve the BOF key and BOF regulation" (Engels and Guns, 2018[50]).

The use of bibliometric indicators in the BOF key has been viewed as a success by the Flemish government. Systems and datasets designed to track and measure performance within BOF have since been replicated and instituted in other areas of Flemish governance. This includes the Industrieel Onderzoeksfonds (IOF) key. The BOF key development experience presents valuable insights into how smaller non-English speaking jurisdictions can adapt commonly utilised performance metrics like bibliometrics to better align with the needs of their own HE system. The most recent edits to the BOF key, decreasing PBF, can be seen as a response to concern raised with previous versions, including that the use of bibliometric indicators created pressure for researchers in certain fields to publish at a higher rate to increase their bibliometrics presence, which in turn could lead to a more short-term approach to research, where quality could be impacted (Engels and Guns, 2018 $[50]$ ). The collaborative approach to the BOF key's development has also shown evidence of success in both the creation of a system that has considerable buy-in from institutions and also one where all universities have been able to develop expertise in how the system works, indeed helping steer it through a university consortium.

\section{France: Using funding and regulation to support institutional groupings}

In France, several initiatives have been conducted since the 1990s to foster co-operation between HEls in a higher education landscape characterised by a high number of small institutions. The government primarily used funding contracts as the mechanism through which it incentivised collaboration, providing funding to collaborating institutions on top of their regular allocation or allowing them to hire additional personnel (directly funded by government) (Williams, 2017[54]). Consolidation efforts resulted in the creation in 2006 of Centres for Research and Higher Education (Pôles de recherche et d'enseignement supérieur, PRES), bringing together a small number of HEls and providing them with flexible options to pool resources (e.g. a shared doctoral school, management of scientific equipment and facilities, strategies for internationalisation and the joint attribution of scientific publications). Although participation in PRES was optional, the initiative received a positive response from HEls: 26 PRES were constituted in 2012, whereas the government was expecting 10 by that date.

To create additional opportunities for HEls to collaborate, France introduced excellence initiatives, with a focus on capital investments, to encourage the concentration of public resources and enhance funding for a select number of internationally competitive clusters (Guiselin, 2019[55]). The first "excellence initiative" call for applications (IdEX), which is part of the Plan d'investissement pour l'avenir (PIA), attributed 
EUR 6.35 billion in 2010 over ten years to eight initiatives from institutions pursuing a grouping or merging process.

The 2013 legislation on higher education and research goes one step further in developing institutional groupings, by requiring all HEls under the supervision of the Ministry of Education and Research to be part of an institutional grouping from 2014 onwards (Légifrance, 2013[56]). HEls can choose from three types of clusters, providing different degrees and types of integration: mergers; Communities of Universities and Institutions (Communautés d'Universités et d'Etablissements, COMUE) (all participating institutions reach an agreement on the COMUE statutes and the competences that each institution transfers to the COMUE level); or Association of HEls and research institutions with one institution in charge of the co-ordination (Légifrance, 2013[57]). The 2013 law stipulates that only one grouping - whether a merged institution, a COMUE or an Association - is responsible for co-ordination of higher education per academic region (called "Academies"), except in the Paris area where different groupings coexist (Légifrance, 2013[56]).

Following requests from established COMUEs to experiment with additional forms of institutional groupings or mergers, a 2018 government regulation (ordonnance) permitted the creation of a new form of grouping called "experimental public institution" (établissement public experimental) for a ten-year trial period (Légifrance, 2018[58]). Experimental public institutions, whose creation and continuation are subject to evaluation and approval conducted by national councils in charge of the co-ordination and evaluation of higher education and research aim to provide increased flexibility to participating HEls, for instance, allowing participating institutions to choose whether or not to remain a distinct legal entity while joining the grouping (French Ministry of National Education, Youth and Sport, 2020[59]).

In 2020, $168 \mathrm{HEls}$ were part of 27 institutional groupings (7 Associations, 9 COMUEs, 2 Coordinations territoriales, and 9 experimental public institutions), representing approximately half of the total student enrolment in higher education (French Ministry of National Education, Youth and Sport, 2020[59]). These groupings, in addition to several full institutional mergers, have transformed the French institutional landscape. The groupings have different levels of integration, some of them having, for instance, obtained the ability to deliver degrees as a single entity. The process of institutional grouping was not always well understood by the public, and has encountered resistance from stakeholders, including staff and student unions, which some analysts have attributed to limited consultation and entrenched political positions (Williams, 2017[54]).

The effects of institutional groupings on international competitiveness were not as immediate as expected by the government, with a stagnation of the position of France in indicators of excellence and international competitiveness (Guiselin, 2019 ${ }_{[55]}$ ). However, the French National Committee of Scientific Research (Centre National de la Recherche Scientifique, CNRS) highlighted that the institutional groupings developed between 2015 and 2020 resulted in improved international recognition of French HEls in the 2020 Shanghai ranking, were COMUEs and experimental public institutions figured as single HEls in the ranking. The 2020 ranking places France in third place worldwide (compared to sixth in 2019 and fifth in 2015), with $30 \mathrm{HEls}$ placed in the ranking, and with the highest ranked being the COMUE Paris-Saclay, which gained 23 seats from 2019 and was ranked 14 th in the world in 2020 (CNRS, 2020[60]).

\section{Proposed actions for the Slovak Republic}

The Slovak government announced cuts to the higher education budget in 2021 of approximately EUR 21 million, according to the Ministry of Education. This decline appears related in part to budgetary pressures associated with the COVID-19 pandemic. According to some stakeholders interviewed by the OECD, it may also reflect the view that declining student numbers justify budget reductions, and that reforms of the sector should take place before an increase in funding levels. 
On the other hand, new EU funds through the Recovery and Resilience Facility (RRF) provide an opportunity for an increase in higher education funding. The Slovak Republic thus needs to consider how to use new funding strategically to help achieve the goals stated in its higher education reform plans.

To do so involves a consideration of the total amount of funding available in coming years for higher education, as well as the extent to which this funding can be used on the human resources required in $\mathrm{HEls}$ and government to undertake comprehensive changes in higher education. It also involves taking stock of the funding instruments used by the government to allocate funding to HEls, and how these may be improved or supplemented to more effectively incentivise a focus on quality teaching and research in institutions.

Examples from Denmark, the Flemish Community of Belgium and France offer insights into the design of performance-linked funding mechanisms in the area of both teaching and research. The policy changes that these countries have undergone over recent decades highlight the importance of calibrating funding instruments to meet policy objectives without creating unintended effects. They present concrete examples for the Slovak Republic in terms of the metrics it may consider for measuring quality teaching and research, the funding amounts tied to different metrics, and more broadly highlight the value of using several policy tools to achieve multiple objectives. It is crucial as well to take account of the overall policy design and implementation capacity in these countries: as it considers improving its funding policy levers, Slovak Republic will need to ensure it factors in sufficient resources and time for their efficient and transparent design and implementation.

Four policy actions are recommended to Slovak authorities, which should be implemented in close collaboration with HEls.

\section{Policy action 4. Map out investments required for implementing a mid-term higher education strategy, new funding sources and options for enhancing higher education funding levels (the funding envelope)}

The Slovak Republic's higher education funding on a per-student basis remains below the EU28 average, despite the increase resulting from declining student numbers, and funding cuts have been introduced for 2021. This suggests that HEls have limited room to make the investments required to implement reforms within their current budgets.

We therefore recommend that the Slovak Republic take stock of the costs involved by higher education reforms (those envisioned and those recommended in this action plan), of new or potential sources of funding for HEls, and map out the potential for the country to enhance higher education funding levels to support the large-scale reform efforts underway. This understanding of the funding landscape for higher education is an important complement of reforms currently envisioned to the structure and functioning of the system.

International experience presented in this report shows that a clear commitment to reform on the part of the higher education sector and a sufficient funding envelope to support reform must go hand in hand for reforms to be successful. Without a commitment to reform, it is difficult from finance ministries facing competing priorities to invest in a system they believe is not making effective use of funds. Without adequate financial support and incentives, it is difficult to garner support from higher education stakeholders given the costs of reform implementation and potential redistribution of funding and/or responsibilities between stakeholders that may result from reform.

We recommend that MoE develop, in collaboration with the Ministry of Finance and using insights generated by the Higher Education Task Force (Policy action 1):

- A mapping of expected spending required to support higher education reforms. This includes:

○ Funding attached to institutional contracts (Policy actions 5 and 6) 
- Funding to encourage the take-up of optional governance status (Policy action 9).

- An analysis of expected revenues for HEls (public, private and state institutions) from public and private sources and how these sources may be used to support the investments incurred by the reform process:

○ National funding.

- European funding - RRF and structural funds. Focus should be placed on how European funding could address the human resource needs associated with higher education reform. Assessing the use of these funds to support capacity-building initiatives (see, for instance, Policy action 10) could be of particular interest.

- Expected contribution of tuition fees.

- Expected contribution of other private funding (e.g. collaboration with the private sector).

- Potential options for the country to:

- Reduce higher education costs without compromising quality. This could include, for instance, taking into account smaller student cohorts and pursuing economies of scale through enhanced HEI collaboration.

- Increase revenues for higher education without compromising affordability for students. This could include, for instance, making greater use of European funding and enhancing all HEIs' capacity to partner with, beyond HEls that have a vocational orientation and established links with local enterprises.

\section{Policy action 5. Establish an approach and process for the development of institutional contracts and possible performance parameters}

The Slovak government announced plans to establish institutional contracts as part of the Slovak Republic's national RRP. The government aims to use these contracts to clarify and differentiate institutional profiles based on each HEl's strengths and regional skills needs. Such an approach, which supports system-level planning in multiple OECD countries, will highlight areas of strengths as well as areas of weaknesses in Slovak higher education, and needs to be conducted with great care to secure institutional support and achieve a meaningful degree of differentiation.

We thus recommend that the Task Force set out in Policy action 1 outline key parameters for institutional contracts, with a focus on aligning the achievement of government policy objectives with adequate financial support and incentives and providing sufficient room for institution-specific priorities. International experience shows that governments have experimented with various combinations of top-down steering and institutional flexibility, and suggest that this "policy finetuning" may require several years to function properly in the specific Slovak context.

Key parameters that should be identified include:

- The duration of institutional contracts (e.g. two, three or five years, with the potential to start with a first round of shorter contracts to be followed by longer contracts once the practice has been established and refined).

- Whether or not there should be a single type of institutional contract or contracts for different types of institutions. This should include consideration of the types of contracts that would be established with HEls that are part of a consortium or that merge. The design of contracts should balance the need for data on performance with the need to minimise the reporting burden for HEls. An effort should be made to focus on a small set of indicators and to simplify contract development and data collection to the extent possible, including through the adequate use of digital technologies (e.g. making use of, and expanding, data systems). 
- The indicators that will be included as part of the contracts and on which HEls will report on. This should include identifying:

- The small set of core, system-wide, indicators of teaching, research and engagement quality applying to all HEls (see Policy action 2). Reliable data sources to provide information on these indicators should be identified. Baseline data on all indicators should be collected, providing a point from which institution-specific targets could be developed.

- Quantitative indicators and qualitative approaches to report on the use of targeted funding (see Policy action 6).

- Examples of institution-specific indicators, targets and data sources.

○ Identifying the process through which HEls will report (e.g. in the HEl's annual report).

- The financial implications of institutional contracts. This should include identifying:

- The financial flexibilities attached to good performance on core performance indicators (e.g. additional funding, ability to charge tuition fees in cases where it is not currently possible) and the consequences of not meeting targets (e.g. no funding on top of regular allocation or a reduction in regular allocation).

- The possibility to use institutional contracts as an instrument through which to allocate targeted funding to HEls on top of their funding formula allocation. This could be done to promote rapid progress on key policy priorities (see Policy action 6).

- Funding to support the implementation of the contracts should also be estimated. This includes funding for human resources in government and HEls for developing and monitoring contracts and support for the improvement of data collection systems in the government and HEls.

- Sections of the institutional contracts that will be available publicly.

In addition, the government should support HEls in developing and managing contracts. This involves:

- developing a clear vision for higher education and institutional profiles

- identifying a public entity responsible for managing institutional contracts (see Policy action 1)

- developing guidance on data collection and reporting.

\section{Policy action 6. Use the institutional contracts to allocate targeted funding to enhance teaching and research quality}

OECD countries have diversified the mechanisms through which they fund higher education to optimise the strategic impact of the funding they provide. As the Slovak Republic engages in a broad reform agenda, the government may consider using the new institutional contracts as an instrument through which to allocate targeted funding to complement funding provided through the funding formula and research agencies.

This could imply linking a specific funding envelope allocating targeted funding to each institutional contract. Alternatively, targeted funding could be allocated through a new component built into the funding formula, and HEls would report on the use of targeted funding through institutional contracts.

Great caution should be taken in the design of targeted funding programmes to ensure they are efficient and effective policy instruments. This should include taking account of the following principles:

- Clear and simple eligibility criteria for the funding - for some funding programmes, all HEls might be eligible; for others, eligibility may depend on the institutional contract agreed with the government; in other cases, eligibility may be based on a competitive process.

- Transparency of the eligibility criteria, for instance, by publishing the criteria and the funding received by each HEI on the MoE's website in a manner similar to the detailed annual allocations 
published annually by the Ministry. Sections of institutional contracts where the HEls would report on use of funding should be made public.

- Sufficient funding amounts to influence behaviour.

- Quantitative and qualitative information should be included in institutional contracts to indicate the use of the targeted funding, the expected impact of new targeted funding, and the actual impact of previously received funding after an agreed-upon implementation period. Including this information in institutional contracts would consolidate and minimise the reporting requirements placed on HEls while fulfilling accountability requirements for additional public spending.

We recommend the expert working group identified in Policy action 1 provide recommendations for targeted funding in five areas:

1. Promote the development of high-quality, flexible, professionally oriented higher education programmes.

- This includes the expansion of professional bachelor's degrees, but also exploring the expansion of short-cycle tertiary education programmes in the Slovak Republic [see the examples from France and the United Kingdom presented in OECD (2020[41])].

- It could also support activities within existing programmes that expand students' opportunities to develop key transversal skills and attitudes (e.g. problem solving in a technology-rich environment, disposition towards lifelong learning), and the development of partnerships with employers to strengthen the provision of work-based learning opportunities.

- Finally, consideration could be given to how infrastructure investments, including those planned as part of the Slovak Republic's national RRP (see Box 3.3), could support the digitalisation of higher education. This could include both the digitalisation of administrative functions to make them more efficient, and of teaching, learning and research. Digitally enhanced teaching and learning in particular could be a driver for the modernisation of pedagogy, make higher education programmes more flexible and accessible to a greater range of learners from the Slovak Republic and abroad, and facilitate the supply of short, modular, study options such as micro-credentials, which are often delivered through online methods.

2. Promote research excellence through greater institutional collaboration.

- Multi-year excellence funding could be provided as part of institutional contracts (Policy action 5) to encourage institutions to consider different types of collaboration, from sharing of key services to generate efficiencies and economies of scale, through to full mergers. Mechanisms should allow HEls to take small steps to collaborate under a single entity without necessarily eliminating the identity or specialisation of partner institutions. Such a model, used, for instance, in France's "experimental public institution" (établissement public experimental), may offer a way to enhance the quality and global visibility of best-performing Slovak institutions without resorting to mergers. This method can be complex to implement, however, and lessons from international experience should be considered.

- The design of targeted funding to promote research excellence and international competitiveness should take account of wider economic policy efforts, such as the Smart Specialisation Strategy conducted by the Ministry of Investments, Regional Development and Informatization (see Policy action 2).

3. Enhance the salaries of academic and non-academic staff by allocating funding for HEls to strengthen performance bonuses for professional excellence in teaching, research and professional/administrative functions.

- Attention should be paid to avoid unintended effects, such as increased competition and uncooperative behaviours between staff. HEls should be provided guidance upon receiving 
funding on the structuring of performance bonus in a way that rewards excellence and collaboration.

- Attention should be paid to professional and administrative staff across all areas of work in HEls. This includes staff who support the day-to-day operations of HEls (e.g. academic, career, and personal supports for students, supports to staff to improve teaching and facilitate application and securing of research funding - and personal counselling and well-being supports for both students and staff, and system-wide services such as the digital technology infrastructure supporting $\mathrm{HEl}$ administrative functions and online teaching and learning). It also includes staff supporting the effective governance and management of the institution, such as professional teams supporting governing bodies (see also the increased need for professional support in a context of reforming institutional governance, as discussed in Policy actions 8-10).

4. Encourage strategic internationalisation activities.

- This could include targeted funding to attract academics and professionals from abroad to work in Slovak HEls and in key higher education entities such as the Research and Development Agency. This could take the form of increased financial incentives, but also non-financial incentives, such as ensuring international staff has access to attractive teaching and research opportunities.

- Such funding incentives should complement the planned reform of access to academic positions. It should be accompanied by improvements in the administrative and human resources capacity to support international academics and professionals as they start and pursue careers in the Slovak higher education system.

- Targeted funding could also promote capacity in Slovak HEls to seek and develop international partnerships, for instance through European University Alliances, following the promising examples of Comenius University Bratislava and Technical University in Košice, respectively partners in ENLIGHT and the ULYSSEUS alliances, as well as the Slovak Agricultural University in Nitra, leader of the INVEST alliance (Slovak Rectors Conference, 2021[61]).

5. Enhance student supports before and after higher education to support student choice and improve access and success for all qualified students. This could include:

- The provision of well-designed labour market information and career guidance services for students, to help them better understand opportunities in the labour market and make informed study choices. Such information and services should be provided early in youth's educational pathways given that study preferences and choices are often formed at the school level.

- The review of current financial supports for students to assess their adequacy based on students' needs. Such assessment should review impediments to access and completion of higher education among disadvantaged populations, especially Roma. Particular attention should be paid to the range of supports - at the school level as well as broader social supports - needed to help disadvantaged students consider participating in higher education in general and in particular in study fields with high labour market demand and good labour market returns.

\section{Policy action 7. Consider revisions to the funding formula for higher education and research allocation mechanisms}

The funding formula for higher education is the main tool through which the government allocates funding to public HEls, and plans have been announced to revise it as part of the Slovak Republic's national RRP. Efforts to review the funding formula should be accompanied by a review of other funding allocation mechanisms, both existing - such as the competitive research funding allocations - and future, such as funding potentially tied to new institutional contracts. 
To review and propose specific enhancements to the funding formula and the competitive research funding allocation, it is recommended that the expert working group created in Policy action 1:

- Identify options to restructure the funding formula and, in particular, consider:

○ building in an element of funding providing stability to HEls that complement performanceoriented funding, learning, for instance, from the example of Denmark

- assigning a sufficient weight to a small number of key teaching and research performance metrics, identified through expert work (see Policy action 2), work of the Slovak Accreditation Agency, and work on scientific performance evaluation considered as part of the Slovak Republic's national RRP

- reducing the frequency at which formula revisions are introduced, clarifying the approach and rationale for funding formula revisions, and communicating these early to HEls to facilitate their planning.

- Identify options to reform the way competitive research funding is allocated, including:

$\circ$ increasing the size of grants and making the allocation criteria transparent

- reducing the administrative burden placed on researchers applying for funding and increasing the support for researchers through an increase in competent administrative staff (see also Policy action 6)

- establishing clear expected outcomes and simplified reporting procedures.

Best practice in research granting at the European level should serve as an example in this area (e.g. European Research Council, Horizon 2020). 


\subsection{Action Step 3: Enabling responsive institutional governance and management}

The sections that follow focus on:

- The current state of policy and practice with respect to institutional governance and management,

- Challenges limiting the adoption of effective reforms,

- Relevant international experience that points to possible policy reforms, and

- Concrete policy actions that the Slovak government may wish to consider.

\section{Current state of policy and practice}

Higher education governance and management are closely connected, but distinct, concepts. In general terms, the governance of HEls can be understood as referring to the entities and processes through which the HEl takes the highest level decisions about the HEl's mission, profile, and overarching priorities and how the institution engages with the wider world. Management in higher education typically describes the entities and processes through which decisions are made to put a governing vision into practice - most importantly decisions about the allocation of the budget and about the work and performance of staff. The section that follows describes key features of institutional governance in Slovakia and their impact on institutional management, and closes with a brief overview of rules structuring the hiring and pay of academic staff - an important aspect of institutional management.

All Slovak HEls have the same institutional governance structure, which is set out in the HE Act. While the law confers an autonomous status to HEls and the capacity to set management rules through internal policies, it defines the composition and responsibilities of self-governing bodies of HEls and the relations between these bodies in a comprehensive and detailed manner. This explains the Slovak Republic's particularly low level of "organisational autonomy" on the European University Association's Autonomy Scorecard, a comparative tool published in 2011 and 2017 (Table 3.5. ).

\section{Table 3.5. Institutional autonomy in select European countries (2016)}

Autonomy score in \% and ranking in parentheses (out of 29 European higher education systems)

\begin{tabular}{|c|c|c|c|c|}
\hline & United Kingdom & Finland & Portugal & Slovak Republic \\
\hline $\begin{array}{l}\text { Organisational autonomy } \\
\text { Selection procedure for the executive head; selection criteria for the executive } \\
\text { head; dismissal of the executive head; term of office of the executive head; } \\
\text { inclusion and selection of external members in governing bodies; capacity to } \\
\text { decide on academic structures; capacity to create legal entities. }\end{array}$ & $\begin{array}{r}100 \% \\
(1)\end{array}$ & $\begin{array}{r}93 \% \\
(3)\end{array}$ & $\begin{array}{r}80 \% \\
(7)\end{array}$ & $\begin{array}{r}42 \% \\
(28)\end{array}$ \\
\hline $\begin{array}{l}\text { Financial autonomy } \\
\text { Length and type of public funding; capacity to keep surplus; capacity to borrow } \\
\text { money; ability to own buildings; ability to charge tuition fees for national/EU } \\
\text { students; ability to charge tuition fees for non-EU students. }\end{array}$ & $\begin{array}{r}89 \% \\
(3)\end{array}$ & $\begin{array}{l}67 \% \\
(11)\end{array}$ & $\begin{array}{r}70 \% \\
(7)\end{array}$ & $\begin{array}{r}70 \% \\
(7)\end{array}$ \\
\hline $\begin{array}{l}\text { Staffing autonomy } \\
\text { Ability to decide on recruitment procedures (senior academic/senior } \\
\text { administrative staff); ability to decide on salaries (senior academic/senior } \\
\text { administrative staff); ability to decide on dismissals (senior academic/senior } \\
\text { administrative staff); ability to decide on promotions (senior academic/senior } \\
\text { administrative staff). }\end{array}$ & $\begin{array}{r}96 \% \\
(3)\end{array}$ & $\begin{array}{r}92 \% \\
(6)\end{array}$ & $\begin{array}{r}62 \% \\
(18)\end{array}$ & $\begin{array}{l}61 \% \\
(19)\end{array}$ \\
\hline $\begin{array}{l}\text { Academic autonomy } \\
\text { Capacity to decide on overall student numbers; ability to select students' ability } \\
\text { to introduce programmes; ability to terminate programmes; ability to choose the } \\
\text { language of instruction; capacity to select quality assurance }(\mathrm{QA}) \text { mechanisms } \\
\text { and providers; ability to design content of degree programmes. }\end{array}$ & $\begin{array}{r}89 \% \\
(3)\end{array}$ & $\begin{array}{r}90 \% \\
(2)\end{array}$ & $\begin{array}{l}54 \% \\
(20)\end{array}$ & $\begin{array}{r}56 \% \\
(18)\end{array}$ \\
\hline
\end{tabular}


Note: The European University Association (EUA) Autonomy Scorecard offers a methodology to collect, compare and weight data on university autonomy. Ranking on a range of autonomy indicators are compiled based on questionnaires and interviews with HEls and validation with national rectors' conferences. A score of $100 \%$ indicates full institutional autonomy; a score of $0 \%$ means that an issue is entirely regulated by an external authority.

Source: Pruvot and Estermann (2017 $[62])$, University Autonomy in Europe III: The Scorecard 2017, https://www.eua.eu/downloads/publications/university\%20autonomy $\% 20$ in $\% 20$ europe $\% 20 i i i \% 20$ the $\% 20$ scorecard $\% 202017$.pdf.

The institutional governance of Slovak HEls, illustrated in Figure 3.4., is characterised by three main features: (i) a two-level governance structure with an important role of faculties; (ii) the large role of academic bodies (academic senates and scientific/art councils), and within them, of academic staff, in institutional management; and (iii) complex lines of accountability of the rector and dean. In addition, new internal quality assurance bodies are currently being implemented in Slovak HEls in response to the quality assurance reform. These features are discussed in the sections that follow.

\section{Figure 3.4. Governing bodies in Slovak higher education institutions}

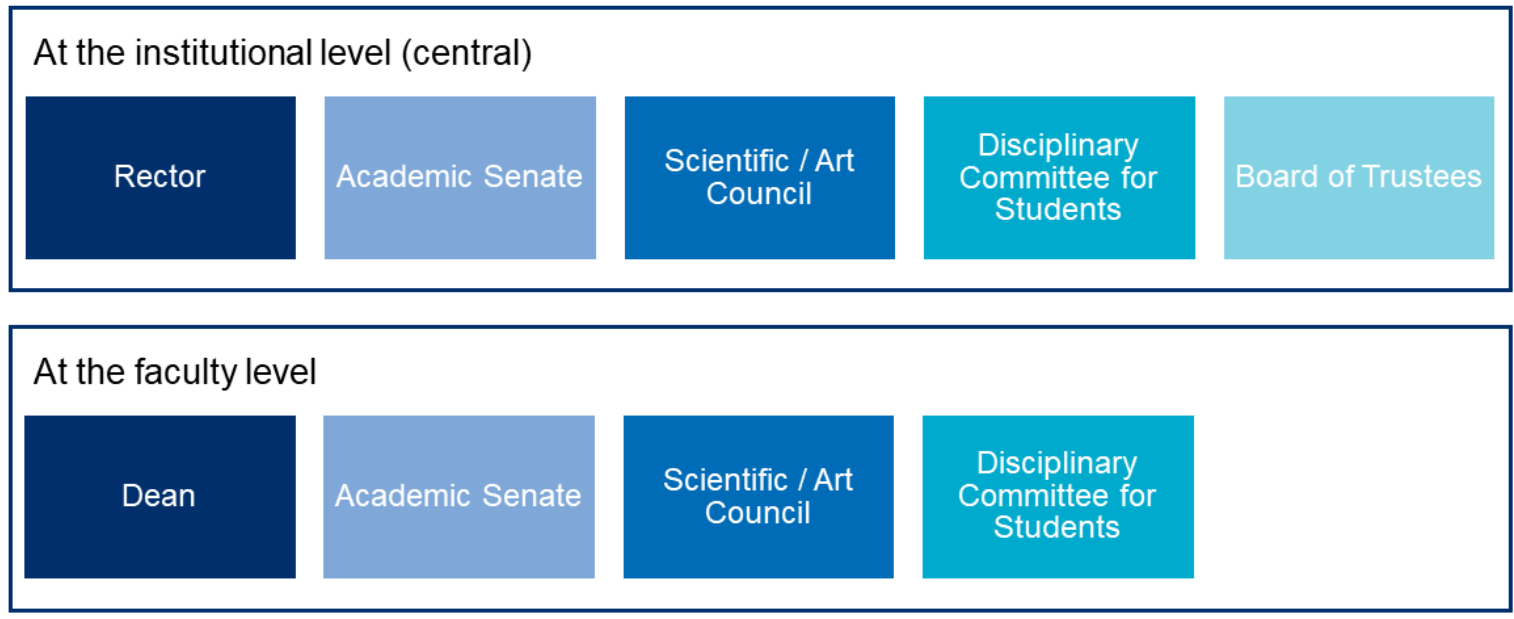

Note: The figure does not include quality assurance bodies established by HEls as a result of the ongoing quality assurance reform. Source: National Council of the Slovak Republic (2002[63]), Zákon č. 131/2002 Z.z. o vysokých školách a zmene a doplneni niektorých zákonov [Act No. 131/2002 on higher education and on the change and supplement to some acts], https://www.zakonypreludi.sk/zz/2002-131.

\section{Two-level governance with an important role of faculties}

The HE Act establishes the principle of two-level governance, according to which decision making is divided between the institutional - also referred to as central level - and faculties. Similar governing bodies are established at the institutional level and at the faculty level, with the exception of the university-wide board of trustees. The governing bodies of faculties have broad powers in managing the activities of the given faculty. In addition to issues related to study programmes and human resources, they also decide on the management of the funds allocated to their faculty and take part in decisions regarding property (e.g. the sale of property used by the faculty).

This dual structure creates a system where faculty-level interests are strongly represented. For example, the faculty dean, who is elected by the academic senate of the faculty and appointed by the rector, is accountable for some of his/her activities to the rector and for others to the academic senate of the faculty. This structure also affects the dean's dismissability: in general, a petition for a dean's dismissal is submitted by the academic senate of the faculty. While there is a possibility of the dean's dismissal by the rector, such a proposal has to be approved by the senate of the faculty, or, if the latter does not agree, by the 
senate of the HEI. This process appears rarely used in practice. The composition of the institution-wide academic senate, provides another example: this body is conceived of as representing faculty senates, and functions on the principle that each faculty should be represented by an equal number of members.

\section{Large role of academic bodies and academic staff in institutional management}

The law provides academic bodies - the academic senates and scientific/art councils - with relatively broad responsibilities in both academic and management matters. The academic senate at the university level elects the rector, decides on the existence of individual faculties, on the long-term strategy and important internal regulations of the HEI, and approves the HEl's budget and annual report. The facultylevel senate elects the dean and approves important faculty-level policies, including the conditions for admission to study and budgeting.

The scientific/art council is another type of academic body. It decides on matters related to pedagogical and research activities, which notably include the approval of the document stipulating what HEl-level body will decide on the creation and termination of study programmes (this can, but does not have to be, the scientific or art council itself). The scientific/art council also approves the determination of the criteria for the granting of academic titles, as well as the appointment of associate professors and professors. Additionally, it comments on most of the strategic documents adopted by the academic senate.

In both academic senates and scientific/art councils, academic staff play a particularly important role. While academic senates represent both employees and students, the law specifies that the academic senate must have at least 15 members, of which at least one-third are students (the specific number of members and the proportion of students is determined by the HEl's internal regulations). The academic senate of faculties must have at least 11 members, of which at least one-third must consist of students of the given faculty.

Scientific/art councils are composed of experts in the fields in which the HEI carries out its teaching, research, development, artistic and other creative activities. No less than one-quarter and not more than one-third of its members are external, i.e. non-concurrently the members of the academic community of the particular HEI. Members of these councils are appointed by the rector (or the dean at faculty level), following approval by the academic senate.

\section{Complex lines of accountability of rectors and deans}

The roles of the rector and dean are to oversee the day-to-day management of the institution and of the faculty, including the implementation of strategic directions and the use of funds. Rectors also represent the university externally. However, while rectors and deans develop budget proposals, academic senates control the approval of the budget.

The rector is elected by the academic senate of the university and is appointed by the president of the Slovak Republic. His or her primary accountability is to the academic senate, which is also the only board that can propose his or her dismissal to the president. At the same time, the university's management board (or board of trustees) establishes the performance parameters linked to the rector's salary. The academic senate of the faculty elects the dean and can petition for his/her dismissal. At the same time, the dean is also accountable for some of his/her activities to the rector, and the rector is responsible for setting the performance parameters that impact the dean's salary.

\section{New bodies to meet SAAHE standards}

New internal quality assurance bodies are currently being formed in Slovak institutions. This results from the reform of quality assurance, and specifically standards issues by the SAAHE that HEls must meet by 1 September 2022. These standards include the requirement to create internal quality assurance bodies in HEls that are independent of existing governing structures. These bodies must include representatives 
of students and of the external environment and should be designed to ensure an objective, professional, transparent and fair periodic review and approval of all study programmes in each HEI.

At the time of writing, the SAAHE indicates that most HEls have established temporary bodies for this purpose. While no systematic analysis of these bodies has been undertaken to date, the SAAHE noted substantial variation among HEls with respect to their composition. For instance, the share of student and external members in these bodies varies, as well as the head of these bodies - the rector of the HEI in some HEls, academic staff or representatives from other HEls in others.

The SAAHE further highlighted that it would be placing special emphasis on the independent evaluation and approval of study programmes conducted by these bodies in its review of internal quality assurance processes in HEls. It noted, however, that a system-wide analysis will only be possible after the deadline for compliance with the standards, therefore after September 2022.

\section{Rules governing academic employment}

Several legislative and regulatory provisions structure academic employment in the Slovak Republic (Eurydice, 2020[64]). A major feature of academic employment resides in the system of "academic titles": individuals who want to teach as professors or associate professors ("docent") are expected to obtain corresponding academic titles to access these positions in public HEls. The scientific and artistic titles of "docent" and "professor", which offer access to tenure, are awarded only in the fields of study that may be pursued in the second level (master) or in the third level (doctoral) of higher education study.

Obtaining an academic title involves a complex procedure. Acquiring a title of "docent" involves prerequisites such as obtaining a doctoral degree, preparing a habilitation thesis (separate from the doctoral thesis), and successfully completing a habilitation procedure. Individuals must also fulfil three conditions: (i) carry out scientific/artistic activities in the given field of study in the HEI; (ii) create a comprehensive scientific or artistic work in the given field of study; (iii) be a recognised scientific or artistic personality in the given field of study. Obtaining the status of "professor" requires complying with the requirements of the status of "docent", as well as successfully completing a nomination procedure (National Council of the Slovak Republic, 2002[63]).

Access to senior teaching positions for individuals without an academic title has improved due to a 2018 amendment to the HE Act, although individuals are still required to obtain a title within three years of starting employment. The 2018 amendment partially opened positions of professor and associate professor to applicants from abroad, or to those who have worked in an industry relevant to their chosen field of teaching (OECD, 2019[65]).

\section{Challenges limiting the adoption of effective reforms}

The post-2002 model of institutional governance described in the preceding section creates three main problems that may hinder the performance of Slovak HEls: i) a lack of responsiveness to changes in the wider society and to student needs, ii) obstacles to efficient and performance-oriented decision making, and iii) constraints on human resource management.

\section{Lack of responsiveness to changes in the wider society and to student needs}

Over the past two decades, Slovak HEls have had to respond to profound shifts in their environment. These include a change from a rapidly growing student body to one that is declining steadily, which has exacerbated the competition for students in a global higher education environment marked by strong student mobility. It also includes a shift from significant under-funding to the availability of European funds since the Slovak Republic's accession to the European Union in 2004. The availability of funds does not automatically translate into increased resources to HEls, however, as these funds include certain 
requirements and accessing them require processes in HEls and government to apply for, secure, and allocate funding effectively and transparently.

Stakeholder interviews led by the OECD in this project and country peer analysis conducted as part of the 2018 European Commission peer counselling exercise suggests that the governance structure of HEls in the Slovak Republic hampers their responsiveness to changes in their environment. This is due in part to the limited representation of individuals external to the university on governing bodies, and in part to the dispersion and balancing of power among different parties within the institution.

Under Slovak law, the institution-wide Board of trustees (BoT), also referred to as governing or management board, is the principal vehicle through which wider public interests are linked to the operations of HEls. The BoT must include 12 external individuals out of 14 members, including representatives from business, regional self-government and the national government, while the other two represent the academic senate. However, the BoT's main role is mostly supervisory: created following the transformation of state universities into public HEls in 2003, in which state property was transferred to public universities, the BoT decides on the management and acquisition of property and approves the budget of the HEI after its adoption by the academic senate. It also decides on the rector's salary.

The remit of BoTs does not extend to establishing a clear vision and priorities for the HEI or to developing the HEl's relationships with external actors - whether public authorities at the central or local government level, employers, or actors in the research and innovation landscape. While the level of involvement of BoTs in strategic matters varies across HEls, the limited awareness of the activities of BoTs among other HEI governing bodies appears to be a frequent problem (MESA10, 2021[9]). This may limit the ability of BoTs to shape institutional decisions, and the ability of other members of the HEls to benefit from the relationships with external stakeholders - such as employers - that the BoT may create.

Institutional governance arrangements also appear to be weakly responsive to student and graduate needs. This in due, in part, to the limitations of students' representation on HEl governing bodies. Stakeholders interviewed by the OECD reported that is difficult to find students interested in participating in university governance, which aligns with findings of The Learning Makes Sense (To dá rozum) project. This project suggested that students' low engagement results from their insufficient knowledge of the role of their representative in the academic senates and low interest for discussions not directly relevant to them (for instance, discussion of property management rather than of the quality of study programmes). The project also noted that students may be concerned about expressing critical opinions, especially in public HEls that are viewed as more hierarchical than private and state HEls (MESA10, 2021 ${ }_{[9]}$ ). By contrast, some academic staff interviewed by the OECD argued that less student representation would in fact be warranted given that students do not have a long-term view of the HEls' interests.

\section{Obstacles to efficient and performance-oriented decision making}

Current governance arrangements create three types of problems. A first issue lies in the legislative prescription of the governance structure, which means that these structures apply to all HEls regardless of their size, location and focus. Given the heterogeneity of the Slovak higher education landscape, this limits the ability of HEls to adapt their structure to their own needs, for instance, streamlining the number of governing bodies in small HEls. As noted in the 2018 European Commission's peer counselling on the governance of HEls in the Slovak Republic, when choice is provided, some if not all HEls may choose to change their governance arrangements (European Commission, 2018[8]). For example, a 2002 reform allowing HEls in Austria to choose their own governance structure led universities to choose different organisation structures fitting their particular needs. Universities of Applied Sciences (UAS) in Austria are vocational HEls that have shown particular flexibility in adapting their governance structure to their particular needs. An example of such structure is presented in Box 3.6.

The dual structure of HEl governance, with governing bodies at both university and faculty level, creates a second problem. This system was established by the 2002 Act on Higher Education, which also conferred 
the status of legal entities to HEls and ended that of faculties. The dual structure, which can be viewed as a compromise between empowering the central management of universities and maintaining a key role of faculties in steering HEls, appears to have preserved much of the power vested in faculties and made it difficult for HEls to establish institution-wide priorities. According to higher education stakeholders interviewed by the OECD, the academic senate at university level largely represents the interests of the different faculty senates, resulting in competition between faculties, as well as tensions between the institutional and faculty level regarding the appropriate level of decision making for managerial decisions.

Another issue lies in the misallocation of responsibilities for governance, management and academic tasks. In the Slovak Republic, academic bodies such as senates and scientific/art councils play a major role in managerial decisions. For instance, the HEl's academic senate approves the budget and elects the rector, while the scientific/art councils makes decisions regarding the body approving the creation or termination of study programmes or the appointment of professors and associate professors. In addition to electing and having the power to dismiss rectors and deans, academic senates often approve the nomination of their key staff members such as vice-rectors and vice-deans (MESA10, 2021 [9]). This may have an impact on the ability of university leaders to constitute effective management teams.

In contrast, the actions of rectors and deans are limited in scope (for instance they propose but do not approve budgets) and due to their accountability to academic senates. The latter may limit the ability of rectors in particular to take strategic initiatives not broadly supported by senates, and in turn may perpetuate established interests and stifle innovation. This situation may also create problematic incentives for rectors, who are not encouraged to focus on strategic management or, to the contrary, who may seek alternative approaches to obtain greater flexibility, such as longer mandates. The latter may not be desirable, as it is important that rectors are held to high standards of accountability for the overall performance of the institution they lead, with consequences in case of poor performance.

\section{Box 3.6. UAS Upper Austria: An example of public policy and institutional governance}

The University of Applied Sciences (UAS) Upper Austria is an example of an institution that has designed institutional-level levers to increase efficiency in decision making and incentivise the performance of individual faculty members, within a policy framework that strongly promotes quality and relevance.

At the policy level, the federal government of Austria provides institutional funding based on approved places, determined on the basis of economic needs and the quality of the programme. To obtain funding, HEls must enrol students in approved places. The federal government also funds fields of study leading to in-demand occupations, such as engineering and information and communication technology (ICT), at higher rates than other fields.

At the institutional level, the governance of the UAS Upper Austria includes a Board of Management, an Academic Board, the schools (or faculties) which can be seen as independent "business units" as well as several central units providing in-resource management support (see Figure below). Staff agreements include objectives for teaching, research and service. High performance in one area can lead to a reduced workload in other areas, encouraging staff members to specialise. In addition, faculty members at the UAS Upper Austria should have spent a significant amount of time in industry before joining the university, helping ensure that staff have up-to-date knowledge and skills. The university fosters partnerships with industry and employers, which often leads to the hiring of students in highdemand fields even before the end of their undergraduate or graduate studies. 


\section{Governing structure and corporate funding management of the UAS Upper Austria}

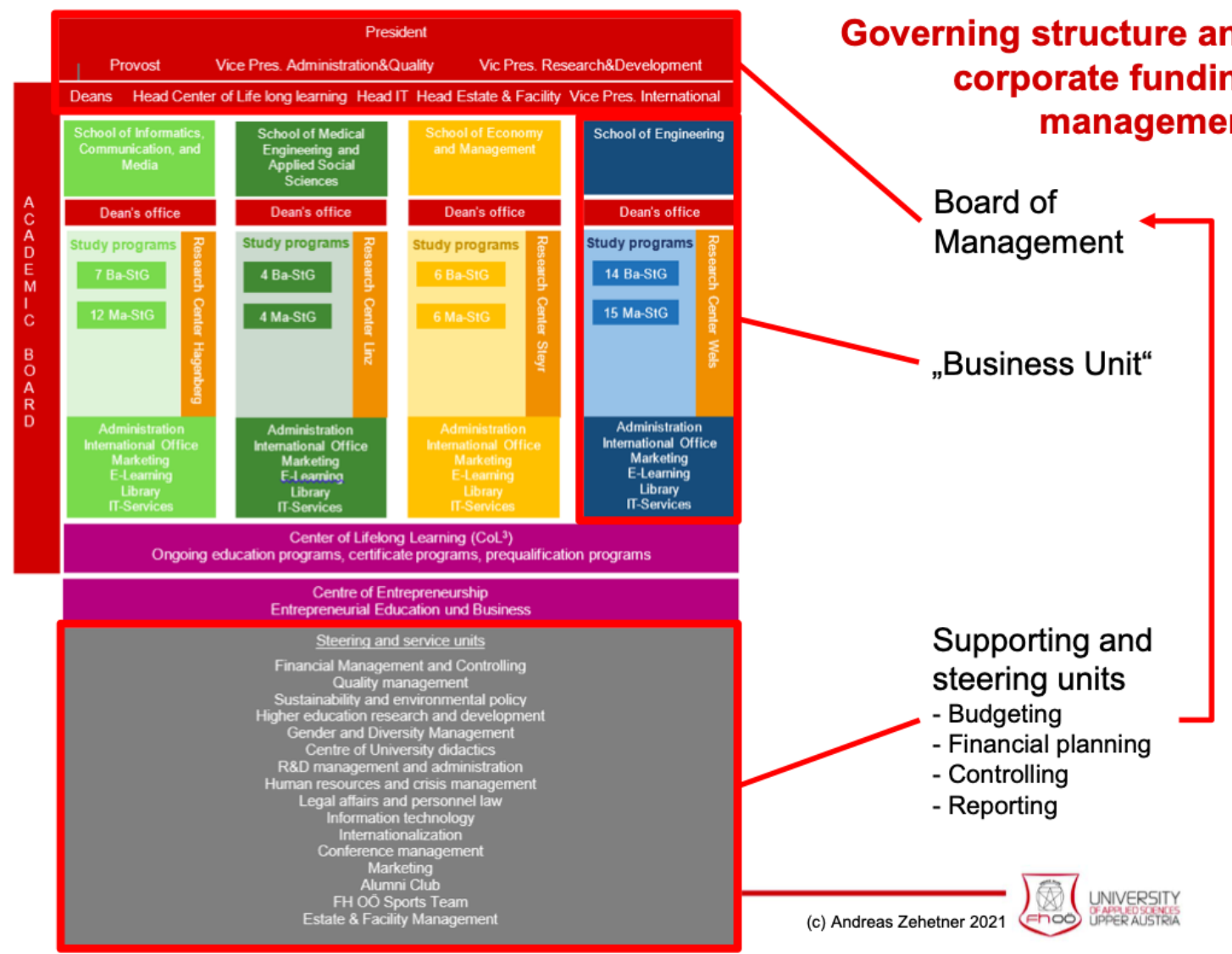

Source: Zehetner (2021 [66]), Using funding levers to promote higher education performance - An institutional perspective.

\section{Constraints on human resource management}

The ability of HEls to attract sufficient numbers of qualified staff - both academic and professional - is critical to their performance. Slovak HEls have maintained a relatively high number of teaching staff despite declining student numbers, while the increase of funds available to higher education has generally not supported an increase in teaching staff wages, as discussed earlier in the section "Using funding to support and reward higher education performance". This has thus limited the funding available to HEI leaders to create attractive working conditions for higher education employees.

This challenge was confirmed by higher education stakeholders interviewed by the OECD, who pointed out the difficulty in attracting highly skilled academic and professional staff, especially from outside academia and from abroad. Despite changes in policy described earlier, the number of individuals with such profiles in Slovak HEls appears to remain low. According to the Ministry of Education, in 2019/20, there were 824 higher education teachers from abroad, while no figures are available regarding individuals with a professional background. By comparison, and taking into account the Austrian's higher education system is about 2.5 times larger than the Slovak system in terms of student enrolment, there were more than 10000 foreign scholars in Austria in 2016 (ETER, 2019[67]). 
Unattractive salaries are another barrier to hiring and retaining competent staff. MoE publishes payroll tables annually, which are binding for all public HEls except those who adopt their own table in agreement with teaching staff unions. These tables define the level of higher education teachers' basic salaries according to their qualification level and years of experience. In 2020, the range of gross salary for teachers with entry-level qualifications and up to two years of experience started at EUR 807.50 per month and reached EUR 1706 for those with the highest qualification level and over 40 years of working experience in the higher education sector. In comparison, the average entry wage of Slovak tertiary education graduates in 2019 was EUR 1204 (Uplatnenie, 2021[68]).

MoE has tried to improve the attractiveness of higher education teaching by revising payroll tables, allowing teachers' real wages to grow since 2012. In addition, HEls can complement the basic salary set in the payroll table by personal payroll bonuses up to a level doubling the basic salary. As a result, the average gross salary of higher education teachers in 2019 reached EUR 2520 for professors, EUR 1929 for doctors and EUR 1472 for assistant professors, according to data provided by the MoE. This presents an operational human resource management tool, provided that surplus wage-eligible funding is available and effective management methods are applied to utilise the tool. Since 2017, the allocation by HEls to their staff of personal payroll bonuses is reported to have increased, although with differences across HEls, possibly as HEls responded to the incentive built into the funding formula encouraging high-quality research. Nevertheless, given the level of basic salaries, employment in HEls remains a less attractive option for many young graduates than other employment sectors.

Low levels of remuneration alongside short contracts also create challenges for those who choose to teach in higher education, especially during the first part of their careers. For instance, higher education stakeholders interviewed by the OECD reported frequent cases of higher education employees combining multiple jobs. In response, MoE introduced a maximum of three employment contracts - and only one fulltime contract - for staff in Slovak public HEls (Act on HEls, $\S 74 \mathrm{col}$. 4). Despite the obligation to keep additional employment contracts part-time, in international comparison, the Slovak Republic ranks among the countries with the lowest proportion of part-time contracts for higher education teachers.

Non-teaching staff also face relatively low remuneration levels. In 2019, the average gross salary for nonteaching staff was EUR 1060 according to data provided by MoE to the OECD, with differences again across HEls. While non-teaching staff are also eligible for personal payroll bonuses and are in principle able to combine several jobs to increase their income, some stakeholders reported that bonuses as well as combining jobs may be less prevalent among non-teaching staff than among staff who teach. This may create risks for the quality of administrative and professional support in HEls, contributing to various challenges for Slovak HEls, ranging from HEls' low effectiveness in applying to and securing international funding, to low quality support for the recruitment and management of foreign academics and professionals in Slovak higher education.

Salaries levels may continue to pose challenges in the Slovak Republic for both teaching and non-teaching staff. As noted previously, this is due to the fact that the size of public funding that contributes to teachers' salaries is tied to the total number of students through the funding formula - and student numbers are declining - and because the increase in EU structural funds has mainly resulted in increases in capital spending.

\section{Relevant international experience}

The internal governance of HEls varies greatly across OECD countries, as a result of different traditions reflected in national legislative frameworks. The analysis of institutional governance over the past four decades nonetheless reveals common patterns across OECD countries.

These include a trend in public steering and institutional governance in which government have extended wider managerial autonomy to HEls, while at the same time seeking to have institutions more strategically 
led to better exercise this wider autonomy and more responsive to their external environment. In many higher education systems, HEI governance and management responsibilities have typically shifted from collegial bodies representing the HEl's academic staff and students to executive bodies open to external members and supported by professional teams (OECD, 2003[69]; OECD, 2008 ${ }_{[70]}$; OECD, 2019 $9_{[48]}$ ).

At the same time, there has been recognition of the part of policymakers that institutional differentiation within higher education systems, including differentiation in the governance and management of higher education institutions, is beneficial, permitting institutions to adopt arrangement best fitted to their mission.

Policy in the Slovak Republic has run counter to these two trends, creating an undifferentiated framework of governance for all HEls, in which many strategic management responsibilities rest with inwardly-focused collegial bodies. As the Slovak Republic works to increase the strategic management capacity and openness of HEls to the wider world, it needs to ensure this shift does not lead to a decrease in institutional autonomy. This is particularly important as the Slovak Republic already faces lower autonomy than most other EU countries on three out of four dimensions of autonomy (organisational, staffing and academic), as shown in Table 3.5. .

In the following sections, we describe the examples of Finland and Portugal: both countries undertook complex higher education reforms focusing on or including institutional governance reform, with the aim of improving the performance of their HEls in an increasingly competitive environment. Because these countries undertook these reforms more than a decade ago, they also offer reflections on the reforms' impact and limitations.

The experience of Finland illustrates the possibility of modernising institutional governance while preserving and increasing institutional autonomy. It also shows that the change in the balance of powers between higher education stakeholders - increasing the role of professional staff and of individuals who are external to HEls - can generate concerns among the academic community, who see their role redefined and perceive it as reduced. The experience of Portugal shows that pursuing legislative reform of institutional governance without support from the academic community can limit the impact of the reform as institutional practices change less than intended.

In addition to the brief examples presented below, in-depth case studies of these countries are provided in Annex A.

\section{Finland: Applying a negotiated and incentive-based approach to system-wide and institutional governance reform}

Finland provides an example of a multi-year higher education reform that arguably resulted in the modification of underlying social and governmental expectations of the role of HEls - a shift of the scale the Slovak Republic is envisioning according to government strategic documents. This reform was characterised by public debates taking place across wider society and central government before undertaking legal changes. These debates included the commissioning of two key reports that helped guide new policy and legislation reform in the higher education sector, based on clear desired outcomes: improving efficiencies of the sector, increasing the visibility and impact of national research, driving HEIindustry collaboration, and striving for the development of globally recognised institutions.

In 2005 , the government officially called for large-scale reforms of what was termed the "innovation system", which included the higher education sector and the public research system (driven primarily through universities). The approach of the Finnish government was to promote the rationalisation of the system by providing funding incentives to encourage a bottom-up movement towards institutional mergers. The aim was to ensure that the institutions themselves collaborated and drove the mergers, creating buyin and a level of institutional autonomy in the process. Some mergers were geared toward providing a consolidated higher education offering to their region, with increased institutional efficiencies and financial 
stability (e.g. University of Eastern Finland), while other merger projects sought to represent Finland's international and R\&D ambitions for the higher education sector (e.g. Aalto University).

Beginning in parallel, and continuing on through the merger process, the Finnish MoE also used financial incentives to push institutions to specialise in specific research areas and subjects, becoming "centres of excellence" through institutional co-operation and mergers between HEls to increase their global recognition and research output. A further tool to facilitate specialisation and the creation of "centres of excellence" has been the creation of foundation universities. In terms of governance, foundation universities differ in that their board is made up entirely of members external to the university itself, representing the wider civic and business community.

The government also pursued the reform of institutional governance across the higher education system by making all universities separate legal persons through the new Universities Act, while maintaining public funding for universities. Among other changes highlighted in Table 3.6. , the governance reform strengthened the relationship of universities with their external environment by requiring the governing body of HEls to include $40 \%$ of members external to the university. It also strengthened their autonomy from government in several ways, by providing them with greater financial flexibility, the ability to set up their own organisational structures and to establish their own recruitment/human resources policies.

\section{Table 3.6. University governance bodies pre- and post-Universities Act in Finland (2009)}

Pre-Universities Act (Universities Act, 1997)
University Senate: The size is determined by the standing orders of the
university, but must contain representatives from the faculty, other
teaching and research staff and the student body. The senate is the
supreme executive body of the university. The senate is presided over
by the rector.
by the rector.

\section{Post-Universities Act}

University Board: 7 members for foundation universities, and 7 or 9-14 members for public universities. Boards in foundation universities are elected by the multi-member administrative body. In public universities, the board is selected by a combination of university community groups and the university collegium. Foundation universities have a board whose members are $100 \%$ external to the university. Public university boards are $40 \%$ external (the remaining $60 \%$ of members are a combination of representatives from the faculty, other teaching and research staff and the student body).

Multi-member administrative bodies represent the individual faculties.
The senate decides the division of faculties and other departments.
Universities may have a chancellor if they wish, with their tasks laid out
in university acts and decrees.
Rector selected by the university electoral college; universities may have
one or more vice-rectors, decided by the university senate.

The electoral college must be composed of representatives of the professors, teaching and research staff, other personnel and students. Provisions pertaining to the membership and election of the electoral college is laid out in the university's standing orders.

Faculties are directed by a dean or other director along with collegial governance practices.
Multi-member administrative bodies represent the individual faculties.

Universities may have a chancellor if they wish; their tasks are laid out in university acts and decrees.

Rector selected by the board in both foundation and public universities. Foundation universities may replace the rector with the position of president.

For public universities, the university collegium consists of 50 members representing both the faculty, other teaching and research staff and the student body - no one group may represent more than half the total. Foundation universities have a joint multi-member administrative body with a maximum of 50 members, representing both the faculty, other teaching and research staff and the student body - no one group may represent more than half the total.

A faculty or corresponding unit has a multi-member administrative body chaired by the director of the unit. The administrative body must include representation from university community groups.

Sources: Finnish Ministry of Education and Culture (1997[71])), Universities Act 645/1997, https://finlex.fi/fi/laki/kaannokset/1997/en19970645_20061453.pdf; Finnish Ministry of Education and Culture (2009[72]), Universities Act 558/2009, https://www.finlex.fi/en/laki/kaannokset/2009/en20090558.pdf.

Recent evaluation of the reform suggests that institutional autonomy has been preserved and strengthened and is viewed in Finland as strengthening an institutional culture focused on effective decision making and continuous improvement. In terms of system rationalisation, the operational goals of the structural reform have been achieved, though some of the wider outcomes (such as increases in institutional specialisation 
and position of Finnish HEls in international rankings) remain areas for ongoing policy adaptation and improvement.

\section{Portugal: Implementing government-driven institutional governance reform}

The Legal Regime of Institutions of Higher Education (Regime Jurídico das Instituições de Ensino Superior, RJIES) reform carried out in Portugal offers an example of governance and funding changes implemented to increase HEls' institutional autonomy by allowing them to manage their resources and more quickly respond to changes in their environment. Portugal's movement toward institutional autonomy, governance reform and greater accountability in the 2000s occurred alongside related developments in quality assurance. This included the inauguration of the country's quality assurance agency, A3ES, first operational in 2009 , which placed external programme quality validation alongside new autonomy and governance measures for institutions.

RJIES resulted in institutional governance changes for all HEls, including the reform of elected governance bodies and in the selection of rectors, or presidents in the case of polytechnic HEls. The functions of former $\mathrm{HEI}$ assemblies and senates that could cumulatively have hundreds of members were replaced with unicameral general councils as the highest decision making body. Under the legislation, general councils are composed of 15-35 members, depending on the size and structure of the HEI (Table 3.7. ).

\section{Table 3.7. University governance bodies pre- and post-RJIES in Portugal (2007)}

\begin{tabular}{|c|c|}
\hline Pre-RJIES & Post-RJIES \\
\hline $\begin{array}{l}\text { University assembly (64-331 members in } 14 \text { largest universities): } \\
\text { (primary governance body) }\end{array}$ & $\begin{array}{l}\text { General council composed of } 15-35 \text { members. } \\
\text { In the case of foundation status institutions, board of trustees ( } 5 \\
\text { members) sits above general council. It is appointed by the government } \\
\text { upon recommendation of the general council. }\end{array}$ \\
\hline Rector selected by university assembly & $\begin{array}{l}\text { Rector selected by the general council (ratified by the board of trustees } \\
\text { in the case of foundation institutions). }\end{array}$ \\
\hline $\begin{array}{l}\text { University assembly contains } 40 \% \text { academic staff, } 40 \% \text { students, } 20 \% \\
\text { other staff }\end{array}$ & $\begin{array}{l}\text { General council must have a majority of academic staff, } 30 \% \text { external } \\
\text { members and } 15 \% \text { students. Internal members select the external. }\end{array}$ \\
\hline $\begin{array}{l}\text { Academic senate ( } 36-179 \text { members in } 14 \text { largest universities) with } \\
\text { managerial authorities (e.g. budget proposals and annual accounts) - } \\
\text { could include up to } 15 \% \text { external members. Senates could include } \\
\text { faculty representation. } \\
\text { Administrative council responsible for current financial administration }\end{array}$ & $\begin{array}{l}\text { Management council (maximum five members, chaired and appointed } \\
\text { by rector) holds authorities with respect to administration, finances, } \\
\text { assets and human resources. In the case of foundation status } \\
\text { institutions, the board of trustees approves the rector's recommended } \\
\text { appointments to the management council. } \\
\text { Academic senates may be established as a consultative body. }\end{array}$ \\
\hline $\begin{array}{l}\text { Collegiate governance bodies were mandated at the faculty level by } \\
\text { legislation, held managerial authorities, and selected their leadership }\end{array}$ & $\begin{array}{l}\text { Academic structures are decided by universities within their statutes. } \\
\text { Teaching and research units must have a single-member executive. } \\
\text { They may have a representative collegiate body (they have generally } \\
\text { chosen to do so), which has the function of selecting the executive. If } \\
\text { there is a representative collegiate body, it must have } 15 \text { members or } \\
\text { less, have at least } 60 \% \text { teacher and researcher members, and include } \\
\text { students, non-academic staff and external representatives. } \\
\text { Scientific and technical councils and pedagogical councils with } \\
\text { membership specified in RJIES play guidance and advisory roles at the } \\
\text { teaching and research unit level. }\end{array}$ \\
\hline
\end{tabular}

Source: Government of Portugal (2007[73]), Regime jurídico das instituições de ensino superior [Legal framework of higher education institutions], https://data.dre.pt/eli/lei/62/2007/09/10/p/dre/pt/html.

While staff-student parity was previously practiced within many HEl governance bodies, RJIES imposes a minimum of only $15 \%$ of students among general council members, while professors and researchers must 
account for more than half of the general council. While representation of community actors from outside of the HEI (such as employers) was previously possible, RJIES mandated that at least $30 \%$ of general council members must be external to the HEl. These external members are nominated and selected by a vote of the internal student and academic general council members. The Chair of the general council is selected by a vote of all general council members but must be one of the external council members. This reform allowed HEls to gain autonomy while guaranteeing quality through increased accountability.

Under RJIES, university rectors and polytechnic presidents are elected by the general council through a secret ballot. This follows public announcement of openings, submission of applications, and public hearings with candidates. In the case of universities, rectors may be professors or researchers from within the institution or from other Portuguese or international institutions. For polytechnics, the role of president is also open to non-academics who have relevant professional experience.

Beyond these governance changes made for all HEls, RJIES opened the possibility of HEls attaining "foundation status" that would grant them greater operational autonomy, notably regarding financing and staffing. Among other key changes, this reform permitted HEls to employ academic and non-academic staff independently under private employment law through their status under private law. These changes are described in detail in Annex A.

\section{Proposed actions for the Slovak Republic}

When properly implemented, there are important benefits to be gained by shifting from an inwardly-oriented and collegial model of HEl governance to one in which external engagement and strategic management capacity are enhanced. These benefits include greater effectiveness and efficiency of decision-making, including in the securing and use of funds to produce high-quality teaching, research and closer engagement with society. These capabilities can assist HEls in responding to new demands - from governments with constrained budgets that require greater value for money, students with access to a larger range of study options who "vote with their feet", and employers needing new types and combinations of advanced skills who look to higher education systems to help develop these skills (or choose to import them).

Not all Slovak higher education stakeholders interviewed by the OECD believe that the governance structure of HEls need to be reformed to strengthen strategic decision making and openness to the external environment. Some argued that the institutional governance structure was not a cause of performance challenges facing the Slovak higher education system. Instead, they proposed that individuals in leadership roles, and of their relationships and working processes were the key determinants of HEls' ability for strategic decision making and performance improvement, rather than a problem linked to the governance structure itself.

Two considerations appear to be of fundamental importance when considering institutional governance changes in the Slovak Republic. First, meaningful stakeholder engagement must be conducted to identify governance changes viewed as most relevant to foster performance improvement by stakeholders and to identify areas of concern or that are most disputed as relevant levers to foster performance improvement. Second, an approach that focuses on setting key principles in legislation and providing HEls with choices in setting their own governance structure - with incentives to adopt a new structure - could be effective in addressing different institutional contexts and different perceptions of the usefulness of institutional governance changes. Such an approach may progressively demonstrate to the higher education community the benefits of modernised governance structures adopted by some leading HEls, as seen in Portugal, for example.

Three policy actions are recommended to Slovak authorities, which should be implemented in close collaboration with HEls. 


\section{Policy action 8. Reduce the level of prescription of the legislation and introduce a small number of key requirements supporting HEl effectiveness and openness}

The level of prescription regarding institutional governance prevents HEls from designing governance arrangements that are most suitable to their particular contexts. At the same time, removing legal requirements may not lead to change if institutional stakeholders who are currently empowered to make decisions on their governance structure do not view changes to governance as necessary. At the same time, taking a top-down approach requiring far-reaching governance changes may lead to important stakeholder resistance, and undermine the government's broader reform efforts in higher education.

We thus recommend that the Slovak Republic take a careful, staged approach to system-wide changes in institutional governance, including a combination of basic principles set in framework legislation and increased flexibility for HEls.

Specifically, we recommend that the Slovak government:

Pursue broad stakeholder engagement on the proposed governance changes

- As part of stakeholder engagement undertaken in Policy action 1, the Task Force should pay special attention to consulting on governance arrangements.

Include a statement of purpose and key principles in the legislation

- Such a statement would aim to clarify the purpose of reforming institutional governance, highlighting the importance of responsive governance and sound management to increase the trust of Slovak society in its higher education system.

- Key principles governing the re-balancing of powers between higher education governing bodies could be clearly stated, including:

$\circ$ the obligation of publicly funded HEls to establish governance arrangements that enable them to make strategic, efficient and accountable use of public resources

o the essential need of higher education institutions to function with full scientific and artistic autonomy from government, which requires particular attention in public HEls and as the use of public resources is shaped by government through the design of funding levers

○ the obligation of HEls to establish governance arrangements that permit them to responsibly exercise their autonomy, on the basis of clear profile and mission, formulated by a governing body that takes into account (and contains) members of university academic staff, students, and employees, and stakeholders outside the institutions who reflect its profile and mission; and an administration with management capacity sufficient to implement policies set by the governing body.

Establish key features promoting good institutional governance in the law

Governance changes should carefully balance greater openness to the external environment and enhanced managerial capacity with the need to preserve and enhance the autonomy of Slovak HEls.

We recommend the timing for implementing governance changes be no less than 18 months to ensure sufficient time for planning and to ensure the changes are informed by the implementation by HEls of the SAAHE standards by 1 September 2022. The recommendations formulated below should be examined in light of the results of this accreditation and quality assurance reform.

While HEls should be free to determine the details of their governance structure, the law could establish key features promoting good institutional governance. These could include:

- Require HEls to have institutional-level governing bodies that have distinct responsibilities (see, for instance, guidance on HEI governance in the United Kingdom (Committee of University 
Chairmen, 2001[74]) and Ireland (THEA, 2018[75]; Irish Universities Association, 2019[76])) HEls should have, at a minimum:

- A board of trustees (BoT) responsible (with the support of a professional team) for the institution's governance - including the review, revision and approval of the institution's mission, approving the annual operating budget and large sale/acquisition of infrastructure (including digital), appointing the rector according to a transparent procedure.

- An academic body responsible for a range of academic issues such as the HEl's academic strategy and promotion of research, criteria for student admissions, procedures for the award of qualifications, academic standards, the approval of content of curriculum and new programmes, policies regarding examinations including appointing internal and external examiners, and student discipline.

- Criteria for the composition and selection of the academic body should ensure an institution-wide view of academic issues rather than the strict representation of individual faculty interests.

- HEls are currently establishing internal quality assurance bodies to implement the standards published by the SAAHE. The extent to which such bodies fulfil some of the above-mentioned functions and complement or duplicate other academic bodies (e.g. academic senates) should be carefully examined.

- A rector responsible (with the support of a professional team) for implementing the vision of the $\mathrm{HEl}$ through effective human and financial resources management.

- Clear processes of consultation between governance, academic and managerial bodies to resolve matters that concern several of these areas (for instance, managerial decisions with implications for study programmes).

- Set a maximum number of BoT members, which should be low enough to ensure efficient decision making (for instance, in England, Wales and Northern Ireland [United Kingdom], the Board of Governors are required to include between 12 and 24 members (Committee of University Chairmen, 2001[74]); in Portugal, general councils are to include 15-35 members).

- Require that the HEl's BoT include a minimum share of external members representing wider society (e.g. $40 \%$, as in Finland, or a share appropriate to the Slovak context, based on consultation with HEls).

- Require that the government identify external member candidates through a process that involves higher education staff and students, and guarantees: (i) the independence of these members; (ii) the quality and relevance of their expertise and experience; and (iii) their understanding of the HEl's context and commitment to active participation in its strategic development. For instance, internal members of the BoT (staff and students) would select external members from the list provided by government to meet the minimum threshold of external members. Alternatively, internal members of the BoT could prepare a list of individuals following the same principles, and MoE could select the individuals.

- Require that the terms for BoT members be fixed in duration (e.g. four to six years), limited in number (e.g. two consecutive terms), and that board members could serve on a staggered renewal schedule.

Increase HEls' autonomy in the creation of institutional governance arrangements

The law should permit HEls to create their own additional governance arrangements according to local needs. In particular, it should be adjusted to:

- remove the obligation for HEls to have governing bodies at both $\mathrm{HEI}$ and faculty level

- authorise Slovak HEls to develop their own governance statutes and register these with the Ministry of Education 
- authorise foreign HEls to establish themselves in the Slovak Republic, within a legal framework setting minimum operating and quality standards.

\section{Policy action 9. Create incentives for public HEls to adopt a new governance structure on an accelerated basis}

The heterogeneity of the Slovak higher education landscape, the diversity of views among stakeholders regarding the value of institutional governance changes, and the current and future reform processes in higher education call for a careful reform approach. Reforming governance mechanisms is a difficult task requiring an important investment in time and resources from the $\mathrm{HEI}$ on top of regular core activities and of new activities that result from recent reforms, such as the engagement of HEls in the creation of robust internal quality assurance systems.

We thus recommend that the MoE incentivise HEls to adopt a new governance structure. Interested HEls would be required to:

- undertake the accelerated adoption, e.g. within eight months, of system-wide changes to institutional governance proposed in Policy action 8

- establish a simplified governance model with three institutional-level governing bodies with clearly delineated roles

- report on the benefits and challenge of implementation within 12 months, so that it may inform the governance reforms undertaken by other Slovak HEls, as recommended in Policy action 8.

To incentivise this, MoE support would be provided to interested HEls, in the form of:

- One-time additional funding.

- Expanded financial flexibilities of HEls, provided the interested HEls demonstrate sound financial management practices. These would build on existing flexibilities available to all Slovak HEls (such as increasing staff compensation beyond levels established in the MoE grid) and could involve a range of areas - such as those considered in Portugal's foundation status (Government of Portugal, $\left.2007_{[73]}\right)$ and presented in the detailed case study in Annex A.

\section{Policy action 10. Establish appropriate supports to foster best practice in HEl governing bodies}

The shift to a responsive form of institutional governance and management requires all individuals involved in governing bodies to take on different and potentially expanded roles in clearly delineated areas of responsibilities. Increasing the role of the BoT in setting the strategic vision for the HEI and monitoring its implementation - through institutional plans, for instance - will require BoT members to take on responsibilities they did not hold previously. Rectors, if they are to become accountable to the BoT and take on a greater role in the strategic management of the HEl's financial and human resources, will also experience a shift in both their tasks and relationships with the governing body of the HEI - the BoT - and the academic body of the HEI - the senate or equivalent body. The academic body, for its part, has a crucial role to play in assuring and improving the academic standards of the HEI, particularly as the Slovak Republic moves forward with a quality assurance system that places the responsibility for assuring and improving quality on HEls themselves, through their development of sound internal quality assurance systems.

While legislation and government regulation set key parameters, and funding incentives are key to encouraging change, the individuals working in the Slovak Republic's governing bodies will need appropriate supports to perform their responsibilities.

This would include collaboration between the MoE and the Higher Education Task Force (see Policy action 1), to develop the following supports: 
- Fund the development of guidelines for practitioners to understand how to effectively perform governing body responsibility. This could involve work performed by groupings of HEls, as done in England, Wales and Northern Ireland (United Kingdom), for instance (Committee of University Chairmen, $\left.2001_{[74]}\right)$. It could also involve the provision of funding to bodies with expertise in higher education to undertake such work of benefit to the while higher education system, as done, for instance, in the United Kingdom by the Leadership Foundation for Higher Education, in partnership with a funding body for higher education (Higher Education Funding Council for England, now Office for Students, see (Leadership Foundation for Higher Education, 2017[77])). Fund the development training programmes for individuals in governance and management positions in HEls to assist them in putting guidelines into practice.

- Recommend HEls dedicate funding to the creation of adequate supports for all governing bodies, including professional teams performing secretariat functions, stipends for governing body members (for academic staff, this could also involve course releases to allow time to perform governance-related duties; for students, this could include recognising governance-related activities as credit-bearing extracurricular activities). 


\section{References}

Adam, E. (2020), “'Governments base performance-based funding on global rankings indicators':

[45] A global trend in higher education finance or a global rankings literature fiction? A comparative analysis of four performance-based funding programs", International Journal of Educational Development, Vol. 76, p. 102197, https://doi.org/10.1016/j.ijedudev.2020.102197.

CNRS (2020), Classement de Shanghai 2020 : La recherche française progresse, https://www.cnrs.fr/fr/cnrsinfo/classement-de-shanghai-2020-la-recherche-francaiseprogresse (accessed on 28 December 2020).

Committee of University Chairmen (2001), Guide for Members of Governing Bodies of Universities and Colleges in England, Wales and Northern Ireland, Committee of University Chairmen, Bristol, https://dera.ioe.ac.uk/4503/2/01 20.pdf (accessed on 10 August 2021).

Copeland, R. (2017), Understanding the United Kingdom's Teaching Excellence Framework and its Implications, https://academicmatters.ca/understanding-the-united-kingdoms-teachingexcellence-framework-and-its-implications/ (accessed on 10 August 2021).

CVTI (2021), Časové rady [Timelines], https://www.cvtisr.sk/cvti-sr-vedecka-kniznica/informacieo-skolstve/statistiky/casove-rady.html?page id=9724. (accessed on 1 July 2021).

CVTI (2021), Štatistická ročenka - vysoké školy [Statistical Yearbook - Universities], https://www.cvtisr.sk/cvti-sr-vedecka-kniznica/informacie-o-skolstve/statistiky/statistickarocenka-publikacia/statisticka-rocenka-vysoke-skoly.html?page id=9596 (accessed on 1 July 2021).

Danish Ministry of Higher Education and Science (2019), Funding for Danish Universities, https://ufm.dk/en/education/higher-education/danish-universities/the-universities-indenmark/funding-for-danish-universities (accessed on 11 March 2021).

de Boer, H. et al. (2015), Performance-based funding and performance agreements in fourteen higher education systems, Center for Higher Education Policy Studies (CHEPS), Enschede, https://ris.utwente.nl/ws/portalfiles/portal/5139542/jongbloed+ea+performance-based-fundingand-performance-agreements-in-fourteen-higher-education-systems.pdf (accessed on 10 August 2021).

Debackere, K. and W. Glänzel (2004), "Using a bibliometric approach to support research policy making: The case of the Flemish BOF-key", Scientometrics, Vol. 59, pp. 253-276, http://dx.doi.org/10.1023/b:scie.0000018532.70146.02.

Dougherty, K. et al. (2014), "Performance Funding for Higher Education: Forms, Origins, Impacts, and Futures", The ANNALS of the American Academy of Political and Social Science, Vol. 655/1, pp. 163-184, http://dx.doi.org/10.1177/0002716214541042.

EBRD (2017), The Slovak Republic diagnostic paper: Assessing progress and challenges in developing a sustainable market economy, European Bank for Reconstruction and Development (EBRD), London, https://www.ebrd.com/documents/comms-and-bis/countrydiagnostic-paper-slovak-republic.pdf (accessed on 11 May 2021).

ECOOM (2021), Frequently Asked Questions (VABB-SHW), https://www.ecoom.be/en/vabbshw/faq\#why (accessed on 11 March 2021). 
Engels, T. and R. Guns (2018), "The Flemish Performance-based Research Funding System: A Unique Variant of the Norwegian Model", Journal of Data and Information Science, Vol. 3/4, pp. 45-60, http://dx.doi.org/10.2478/jdis-2018-0020.

ETER (2019), Internationalisation of Academic Staff in European Higher Education, European Tertiary Education Register (ETER), https://www.joanneum.at/fileadmin/user upload/ETER AnalyticalReport 01 final.pdf (accessed on 6 August 2021).

European Commission (2018), Peer Counselling on the Governance of Higher Education Institutions in the Slovak Republic, document provided to OECD for the project "Improving Higher Education in the Slovak Republic".

European Commission (2017), Digital Coalition launched in Slovakia, https://digitalstrategy.ec.europa.eu/en/news/digital-coalition-launched-slovakia (accessed on 30 April 2021).

Eurostat (2021), Distribution of academic staff at education level by age groups [educ_uoe_perd02], http://appsso.eurostat.ec.europa.eu/nui/show.do?dataset=educ uoe perd02\&lang=en (accessed on 10 August 2021).

Eurydice (2020), Slovakia - Conditions of Service for Academic Staff Working in Higher Education, https://eacea.ec.europa.eu/national-policies/eurydice/content/conditions-serviceacademic-staff-working-higher-education-65 en (accessed on 10 August 2021).

Finnish Ministry of Education and Culture (2009), Universities Act 558/2009, https://www.finlex.fi/en/laki/kaannokset/2009/en20090558.pdf (accessed on 19 July 2021).

Finnish Ministry of Education and Culture (1997), Universities Act 645/1997, https://finlex.fi/fi/laki/kaannokset/1997/en19970645 20061453.pdf (accessed on 19 July 2021).

Flemish Government (2019), Vlaamse Regering keurt BOF-besluit definitief goed: 35 miljoen euro extra voor universiteiten [Flemish Government definitively approves BOF decision: 35 million euros extra for universities], https://www.ewi-vlaanderen.be/nieuws/vlaamse-regeringkeurt-bof-besluit-definitief-goed-35-miljoen-euro-extra-voor-universiteiten (accessed on 10 August 2021).

FNPV (2021), Pôžička pre študentov [Student loan], https://www.fnpv.sk/chcem-pozicku-student (accessed on 1 June 2021).

French Ministry of National Education, Youth and Sport (2020), Repères et références statistiques 2020, https://www.education.gouv.fr/reperes-et-references-statistiques-20201316 (accessed on 28 December 2020).

Galán-Muros, V. et al. (2018), State of University-Business Cooperation: Slovakia, UniversityBusiness Cooperation in Europe, https://www.ub-cooperation.eu/index/slovakiabus (accessed on 11 May 2021).

Government of Latvia (2014), Par Izglitīibas attīstības pamatnostādṇu 2014.-2020.gadam apstiprināšanu [On approval of the Guidelines for the Development of Education for 20142020], http://m.likumi.Iv/doc.php?id=266406 (accessed on 10 August 2021). 
Government of Portugal (2007), Regime jurídico das instituições de ensino superior [Legal framework of higher education institutions], https://data.dre.pt/eli/lei/62/2007/09/10/p/dre/pt/html (accessed on 10 August 2021).

Government of the Slovak Republic (2021), Plán Obnovy - Cestovná mapa k lepšiemu Slovensku [Recovery Plan: A Roadmap to a Better Slovakia], Government of the Slovak Republic, Bratislava.

Government of the Slovak Republic (2019), EUROFONDY: Čerpanie peňazí EÚ dosiahlo $k 28$. februáru 22,57 percenta [EUROFUNDS: EU money absorption reached 22.57 per cent on 28 February], https://www.partnerskadohoda.gov.sk/eurofondy-cerpanie-penazi-eu-dosiahlo-k28-februaru-2257-percenta/ (accessed on 10 August 2021).

Guiselin, E. (2019), "Les regroupements d'établissements dans l'enseignement supérieur et la recherche : enjeux politiques et cadrage juridique", Revue française d'administration publique, Vol. 169/1, pp. 37-50, http://dx.doi.org/10.3917/rfap.169.0037.

Irish Universities Association (2019), Code of Governance for Irish universities, Irish Universities Association, Dublin, https://www.iua.ie/publications/code-of-governance-for-irish-universities2019/ (accessed on 6 August 2021).

James, G. et al. (2019), Evaluation of the Statistical Elements of the Teaching Excellence and Student Outcomes Framework, Office for National Statistics, London, https://assets.publishing.service.gov.uk/government/uploads/system/uploads/attachment dat a/file/940301/5. ONS Statistical Evaluation - accessible Sept 2020.pdf (accessed on 10 August 2021).

Jongbloed, B. and H. de Boer (2020), Performance Agreements in Denmark, Ontario and the Netherlands, Center for Higher Education Policy Studies (CHEPS), Enschede, https://ris.utwente.nl/ws/portalfiles/portal/234127256/Performance Agreements in DK ONT and NL.pdf (accessed on 10 August 2021).

Jonkers, K. and T. Zacharewicz (2017), Research Performance Based Funding Systems: a Comparative Assessment, Publications Office of the European Union, Luxembourg, http://dx.doi.org/10.2760/70120.

Latvian Ministry of Education and Science (2019), Informatīvais ziñojums "Par Izglïtības attīstības pamatnostādṇu 2014.-2020.gadam īstenošanas 2014.-2017.gadā starpposma novērtējumu" [Informative Report "On the Interim Evaluation of the Implementation of the Education Development Guidelines for 2014-2020 in 2014-2017"], https://www.izm.gov.Iv/lv/informativais-zinojums-par-izglitibas-attistibas-pamatnostadnu-20142020gadam-istenosanas-2014-2017gada-starpposma-novertejumu (accessed on 1 July 2021).

Leadership Foundation for Higher Education (2017), Insight Guide: governing bodies and academic assurance, Leadership Foundation for Higher Education, London, https://www.advance-he.ac.uk/sites/default/files/2019-05/Insight\%20Guide\%20\%20governing\%20bodies\%20and\%20academic\%20assurance.pdf (accessed on 10 August 2021). 
Légifrance (2018), Ordonnance $n^{\circ}$ 2018-1131 du 12 décembre 2018 relative à l'expérimentation de nouvelles formes de rapprochement, de regroupement ou de fusion des établissements d'enseignement supérieur et de recherche, https://www.legifrance.gouv.fr/jorf/id/JORFTEXT000037800979/ (accessed on 22 December 2020).

Légifrance (2013), Code de l'éducation - Chapitre VIII bis : Coopération et regroupements des établissements (Articles L718-2 à L718-16), https://www.legifrance.gouv.fr/codes/section Ic/LEGITEXT000006071191/LEGISCTA000027 738668/\#LEGISCTA000027738668 (accessed on 22 December 2020).

Légifrance (2013), LOI n²013-660 du 22 juillet 2013 relative à l'enseignement supérieur et à la recherche, https://www.legifrance.gouv.fr/dossierlegislatif/JORFDOLE000027197524/ (accessed on 22 December 2020).

Machlica, G. et al. (2017), "Enhancing advanced skills to better meet labour market demand in the Slovak Republic", OECD Economics Department Working Papers, No. 1416, OECD Publishing, Paris, https://dx.doi.org/10.1787/72c55c64-en.

Martinák, D. and D. Zápražná (2017), Analýza regulačných nástrojov na zlepšenie súladu odborov stredných škôl s potrebami trhu práce [Analysis of regulatory tools to improve the compliance of secondary school departments with labor market needs], Education Policy Institute, Bratislava, http://www.minedu.sk/data/att/11874.pdf (accessed on 10 August 2021).

MESA10 (2021), "Learning Makes Sense” Project, https://en.todarozum.sk/ (accessed on 10 August 2021).

MIRRI (2020), Supporting the transformation of the Slovak economy by increasing its innovation performance, Ministry of Investments, Regional Development and Informatization of the Slovak Republic (MIRRI), Bratislava, https://www.mirri.gov.sk/wpcontent/uploads/2021/03/RTDI-in-Slovakia-AS-IS-report.pdf (accessed on 10 August 2021).

MoE (2021), Financovanie [Financing], https://www.minedu.sk/677-sk/financovanie/ (accessed on 1 August 2021).

MoE (2021), National action plan for external quality assurance of higher education institutions in the Slovak Republic, Ministry of Education, Science, Research and Sport of the Slovak Republic (MoE), Bratislava, https://www.minedu.sk/data/att/20126.pdf (accessed on 10 August 2021).

MoE (2019), Výročná správa o stave vysokého školstva za rok 2019 [Annual Report on the State of Higher Education for 2019], Ministry of Education, Science, Research and Sport of the Slovak Republic (MoE), Bratislava, https://www.minedu.sk/vyrocne-spravy-o-stave-vysokehoskolstval (accessed on 1 July 2021).

MoE (2017), Revízia výdavkov na vzdelávanie - Záverečná správa [Revision of Education Expenditure - Final Report], Ministry of Education, Science, Research and Sport of the Slovak Republic (MoE), Bratislava, https://www.minedu.sk/21395-sk/revizia-vydavkov-navzdelavanie-2017/ (accessed on 10 August 2021).

MoE (2016), Učiace sa Slovensko [Learning Slovakia], Ministry of Education, Science, Research and Sport of the Slovak Republic (MoE), Bratislava, https://www.minedu.sk/data/att/10640.pdf (accessed on 9 August 2021). 
National Council of the Slovak Republic (2002), Zákon č. 131/2002 Z.z. o vysokých školách a zmene a doplnení niektorých zákonov [Act No. 131/2002 on higher education and on the change and supplement to some acts], https://www.zakonypreludi.sk/zz/2002-131 (accessed on 13 August 2020).

OECD (2021), OECD Education Statistics, OECD Publishing, Paris, https://dx.doi.org/10.1787/edu-data-en (accessed on 1 July 2021).

OECD (2020), Education at a Glance 2020: OECD Indicators, OECD Publishing, Paris, https://dx.doi.org/10.1787/69096873-en.

OECD (2020), Labour Market Relevance and Outcomes of Higher Education in Four US States: Ohio, Texas, Virginia and Washington, Higher Education, OECD Publishing, Paris, https://dx.doi.org/10.1787/38361454-en.

OECD (2020), Main Science and Technology Indicators, Volume 2020 Issue 1, OECD Publishing, Paris, https://dx.doi.org/10.1787/e3c3bda6-en.

OECD (2020), OECD Skills Strategy Slovak Republic: Assessment and Recommendations, OECD Skills Studies, OECD Publishing, Paris, https://dx.doi.org/10.1787/bb688e68-en.

OECD (2020), Resourcing Higher Education: Challenges, Choices and Consequences, Higher Education, OECD Publishing, Paris, https://dx.doi.org/10.1787/735e1f44-en.

OECD (2020), Strengthening the Governance of Skills Systems: Lessons from Six OECD Countries, OECD Skills Studies, OECD Publishing, Paris, https://dx.doi.org/10.1787/3a4bb6ea-en.

OECD (2019), Benchmarking Higher Education System Performance, Higher Education, OECD Publishing, Paris, https://dx.doi.org/10.1787/be5514d7-en.

OECD (2019), Education Policy Outlook 2019: Working Together to Help Students Achieve their Potential, OECD Publishing, Paris, https://dx.doi.org/10.1787/2b8ad56e-en.

OECD (2019), OECD Economic Surveys: Slovak Republic 2019, OECD Publishing, Paris, https://dx.doi.org/10.1787/eco surveys-svk-2019-en.

OECD (2019), OECD Skills Strategy Latvia: Assessment and Recommendations, OECD Skills Studies, OECD Publishing, Paris, https://dx.doi.org/10.1787/74fe3bf8-en.

OECD (2019), OECD Skills Strategy Poland: Assessment and Recommendations, OECD Skills Studies, OECD Publishing, Paris, https://dx.doi.org/10.1787/b377fbcc-en.

OECD (2016), How good is your job? Measuring and assessing job quality, OECD, Paris, https://www.oecd.org/sdd/labour-stats/Job-quality-OECD.pdf (accessed on 10 August 2021).

OECD (2008), Tertiary Education for the Knowledge Society: Volume 1 and Volume 2, OECD Reviews of Tertiary Education, OECD Publishing, Paris, https://dx.doi.org/10.1787/9789264046535-en.

OECD (2003), Education Policy Analysis 2003, OECD Publishing, Paris, https://dx.doi.org/10.1787/epa-2003-en. 
OECD/European Union (2017), Supporting Entrepreneurship and Innovation in Higher Education in Hungary, OECD Skills Studies, OECD Publishing, Paris/European Union, Brussels, https://dx.doi.org/10.1787/9789264273344-en.

OfS (2018), Securing Student Success: Regulatory Framework for Higher Education in England, Office for Students (OfS), Bristol, https://www.officeforstudents.org.uk/media/1406/ofs2018 01.pdf (accessed on 10 August 2021).

Ossenblok, T., T. Engels and G. Sivertsen (2012), "The representation of the social sciences and humanities in the Web of Science - A comparison of publication patterns and incentive structures in Flanders and Norway (2005-9)", Research Evaluation, Vol. 21/4, pp. 280-290, http://dx.doi.org/10.1093/reseval/rvs019.

Pruvot, E. and T. Estermann (2017), University Autonomy in Europe III: The Scorecard 2017, European University Association, Brussels, https://www.eua.eu/downloads/publications/university\%20autonomy\%20in\%20europe\%20iii\% 20the\%20scorecard\%202017.pdf (accessed on 10 August 2021).

Reichert, S. (2009), Institutional diversity in European higher education: Tensions and challenges for policy makers and institutional leaders, European University Association, Brussels, https://eua.eu/downloads/publications/institutional\%20diversity\%20in\%20european\%20higher \%20education\%20\%20tensions\%20and\%20challenges.pdf (accessed on 10 August 2021).

SAAHE (2021), Slovak Accreditation Agency for Higher Education published the first results of the largest survey of student satisfaction in the Slovak Republic, https://saavs.sk/survey-firstresults/ (accessed on 15 July 2021).

Slovak Rectors Conference (2021), Slovenské univerzity úspešné v iniciatíve European Universities [Slovak universities successful in the European Universities initiative], https://www.srk.sk/sk/aktuality/407-slovenske-univerzitu-budu-sucastou-iniciativy-europeanuniversities (accessed on 16 July 2021).

THEA (2018), THEA Code of Governance forlstitutes of Technology, Technological Higher Education Association (THEA), Dublin, https://hea.ie/assets/uploads/2018/01/THEA-Code-ofGovernance-of-Institutes-of-Technology-January-2018.pdf (accessed on 6 August 2021).

UK Department for Education (2019), Independent Review of the Teaching Excellence and Student Outcomes Framework (TEF), Department for Education, London, https://www.gov.uk/government/publications/independent-review-of-tef-report (accessed on 10 August 2021).

UK Department for Education (2017), Teaching Excellence and Student Outcomes Framework Specification, Department for Education, London, https://assets.publishing.service.gov.uk/government/uploads/system/uploads/attachment dat a/file/658490/Teaching Excellence and Student Outcomes Framework Specification.pdf (accessed on 10 August 2021).

Uplatnenie (2021), Uplatnenie, http://www.uplatnenie.sk (accessed on 1 June 2021). 
Vivian, D. et al. (2019), Evaluation of Provider-level TEF 2016-17 (Year 2): Measuring the initial impact of the TEF on the Higher Education landscape, Department for Education, London, https://www.gov.uk/government/publications/evaluation-of-provider-level-tef-2016-to-2017year-2 (accessed on 10 August 2021).

Williams, J. (2017), "Collaboration, alliance, and merger among higher education institutions", OECD Education Working Papers, No. 160, OECD Publishing, Paris, https://dx.doi.org/10.1787/cf14d4b5-en.

Zehetner, A. (2021), Using funding levers to promote higher education performance - An [66] institutional perspective, presentation provided to OECD during expert-meeting for the project "Improving Higher Education in the Slovak Republic". 



\section{Annex A. Higher education reforms in Portugal and Finland}

\section{Rationale and approach}

This annex examines two cases of higher education (HE) systems reform within OECD countries. The OECD, European Commission and the Slovak government jointly identified Portugal and Finland as relevant comparator countries for the purpose of this project. This is due to the scale and complexity of higher education reforms both countries undertook in the past two decades, the similarity of challenges those reforms sought to address, and the nature of reforms they implemented, namely higher education institution (HEI) governance reform in Portugal and $\mathrm{HEI}$ landscape rationalisation in Finland, which are issues of interest for the Slovak Republic.

Finland, Portugal, and the Slovak Republic are countries with significant differences in geography, culture, history and economy. However, they are small states among the 23 European Union members that are also members of the OECD (the EU23). All three are members of the eurozone. They share challenges related to a declining working-age population and seek to increase the visibility of their higher education systems. All three have implemented, or are considering, reforms related to the governance and organisation of higher education.

As Table A A.1 highlights, the three countries have areas of commonality as well as divergence. The Slovak Republic aligns more closely with Finland, as opposed to Portugal, depending on the indicator of comparison. Points of convergence and divergence inform the comparative approach. For example, Finland is similar to the Slovak Republic in terms of population size, which has implications for the overall number of HEls relative to population, which will be further explored with the Finland case study. Conversely, Portugal more closely aligns with the Slovak Republic in terms of the percentage of public expenditure on tertiary education and the percentage of the 25-34 year-olds with a tertiary credential. This may reflect that in both countries, mass participation in higher education is a more recent phenomenon (both Portugal and the Slovak Republic saw rapid increases in HE participation following transitions to democracy).

The approach taken to the two case studies is informed by OECD work on the political economy of reform, which highlights the importance of focusing attention not just on what type of reforms are desirable to improve policy effectiveness, but also on gaining "better understanding of the conditions which are conducive - or otherwise - to the implementation of better policies" (Tompson, $2009_{[1]}$ ). This OECD study examines contexts for macroeconomic and structural reform, as well as policy formulation, adoption and implementation in a systematic manner across a number of case studies in policy areas ranging from pension reform to labour-market and product-market regulation. The actors and interests involved include governments, political parties, business associations, labour organisations and non-profit organisations.

This annex examines the role of key stakeholders in higher education reform, including national ministries responsible for higher education, political leadership, HEI leadership, higher education sector organisations, academic and non-academic staff, students, employers and labour organisations. 
Table A A.1. Key indicators for Finland, Portugal and the Slovak Republic (2017-19)

\begin{tabular}{|c|c|c|c|c|c|c|c|c|c|c|}
\hline & $\begin{array}{c}\text { Population } \\
\text { (millions) } \\
(2018)\end{array}$ & $\begin{array}{c}\text { Youth } \\
\text { population } \\
(15-24)(\%) \\
(2018)\end{array}$ & $\begin{array}{c}\text { Working age } \\
(15-64) \\
\text { population (\%) } \\
(2018)\end{array}$ & $\begin{array}{c}\text { Old age } \\
\text { dependency } \\
\text { ratio }(65 \text { and } \\
\text { over/15-64) } \\
(2018)\end{array}$ & $\begin{array}{c}25-34 \text { year-olds } \\
\text { with a tertiary } \\
\text { education (\%) } \\
(2019)\end{array}$ & $\begin{array}{c}\text { Tertiary } \\
\text { educational } \\
\text { expenditure as } \\
\text { a percentage of } \\
\text { total public } \\
\text { spending (\%) } \\
(2017)\end{array}$ & $\begin{array}{l}\text { Completion rate } \\
\text { of full-time } \\
\text { students who } \\
\text { entered a } \\
\text { bachelor's } \\
\text { programme, by } \\
\text { the theoretical } \\
\text { duration + } 3 \\
\text { years (\%) } \\
(2017)\end{array}$ & $\begin{array}{l}\text { Employment } \\
\text { rates of tertiary- } \\
\text { educated } 25-34 \\
\text { year-olds (\%) } \\
\text { (2019) }\end{array}$ & $\begin{array}{c}\text { Number of } \\
\text { international or } \\
\text { foreign students } \\
\text { for every } \\
100 \text { national } \\
\text { students home } \\
\text { and abroad } \\
(2018)\end{array}$ & $\begin{array}{c}\text { Percentage of } \\
\text { national tertiary } \\
\text { students } \\
\text { enrolled abroad } \\
(\%) \\
(2018)\end{array}$ \\
\hline Portugal & 10.3 & 11 & 65 & 0.34 & 37 & 1.8 & 65 & 86 & 8 & 4 \\
\hline Finland & 5.5 & 11 & 62 & 0.35 & 42 & 3.1 & 73 & 85 & 8 & 4 \\
\hline Slovak Republic & 5.4 & 11 & 69 & 0.23 & 39 & 1.9 & $62 r$ & 79 & 7 & 19 \\
\hline OECD average & a & 12 & 65 & 0.26 & 45 & 2.9 & $\mathrm{~m}$ & 85 & 6 & 2 \\
\hline EU23 average & a & $\mathrm{m}$ & $\mathrm{m}$ & $\mathrm{m}$ & 44 & 2.6 & $\mathrm{~m}$ & 85 & 10 & 4 \\
\hline
\end{tabular}

Note: Symbol "m" data are not available - either missing or the indicator could not be computed due to low respondent numbers. Symbol "a" data are not applicable because the category does not apply. Symbol "r" means values are below a certain reliability threshold and should be interpreted with caution. In this case, the Slovak Republic's completion rate is derived from a cross-cohort model and is for completion rate by the theoretical duration of programme only, whereas completion rates in other countries are calculated based on a true-cohort model, and refer to the share of students from a specific cohort who graduate within the theoretical duration of the programme in which they entered plus three years.

The EU23 average refers to the average of 23 EU countries that were also members of OECD as of the end of 2019, namely: Austria, Belgium, the Czech Republic, Denmark, Estonia, Finland, France, Germany, Greece, Hungary, Ireland, Italy, Latvia, Lithuania, Luxembourg, the Netherlands, Poland, Portugal, the Slovak Republic, Slovenia, Spain, Sweden and the United Kingdom.

Sources: OECD (2019[2]), Education at a Glance 2019: OECD Indicators, https://doi.org/10.1787/f8d7880d-en; OECD (2020[3]), Education at a Glance 2020: OECD Indicators, https://doi.org/10.1787/69096873-en; OECD (2021 [4]]), Historical Population (database), https://stats.oecd.org/Index.aspx?DataSetCode=HISTPOP. 
This annex was developed through a review of primary and secondary English-language sources related to the reform processes of focus in Finland and Portugal, and through six stakeholder interviews. Based on this approach, it attempts to capture an accurate picture and analysis of key developments.

\section{Portugal: HEI governance reform}

\section{Key governance actors in the HE system}

Portugal is a centralised state without independent regional government; local authorities have limited responsibilities, relative to the role of their peers in other OECD countries (OECD, 2019[5]) The central government (through the Council of Ministers) holds exclusive responsibility for HE, which is under the control of the Ministry of Science, Technology and Higher Education (Ministério da Ciência e Tecnologia e Ensino Superior, MCTES). The Directorate-General of Higher Education (Direção-Geral do Ensino Superior, DGES) holds responsibility for the design, implementation and delivery of policy. The ministry holds a central role in the administration of the higher education system.

Additional key actors in the HE system are as follows:

- The Agency for Assessment and Accreditation of Higher Education (Agência de Avaliação e Acreditação do Ensino Superior, A3ES) provides evaluation and accreditation of HEls and programmes.

- The Portuguese Foundation for Science and Technology (Fundação para a Ciência e a Tecnologia, FCT) is the leading public funder of research (FCT is an independent foundation and research agency of MCTES).

- Strategic and operating bodies within government that administer European Structural and Investment Funds (ESIF) in areas of HE, research, and innovation are also important system actors (OECD, 2019[5]).

In 2016, EU Structural Funds accounted for $13 \%$ of income for research activities in public research institutions. Responsibility for distribution of these funds is divided among regional and national programmes under the management of subject-area aligned ministries, for example, the Ministry of Agriculture, Ministry of Economy, Ministry of Health, or Ministry of Planning and Infrastructure (OECD, $\left.2019_{[5]}\right)$.

As of 2019, core institutional funding for HEls in Portugal was delivered on a historical basis and is not based on HEl performance. In 2006, MCTES had proposed a formula-based institutional funding model which, while principally enrolment based, also included output-based funding (e.g. "graduation rate efficiency") (OECD, 2019 $\left.9_{[5]}\right)$. Despite "repeated efforts to develop a budget framework that is pluri-annual and systematically link to past performance", this model (and a further 2015 proposal) were not implemented, and instead, incremental adjustments have been made to historical institutional base funding annually, with mid-year budget reductions at times occurring to balance public accounts (OECD, 2019[5]). Core institutional funding delivered in this manner accounts for roughly half of total institutional income, with tuition and research funding delivered on a competitive basis, including through European Structural and Investment Funds, making up the balance.

The Co-ordinating Council for Higher Education (Conselho Co-ordenador do Ensino Superior, CCES) serves an advisory role to MCTES. The president of CCES and six other members are appointed by MCTES. Further members of CCES include two representatives of the Council of University Rectors (Conselho de Reitores das Universidades Portuguesas, CRUP), two representatives of the Council of Polytechnics (Conselho Coordenador dos Institutos Superiores Politécnicos, CCISP), a representative of the association of private higher education (Associação Portuguesa de Ensino Superior Privado, APESP), one university student representative, one polytechnic student representative, and the heads of DGES, 
FCT and A3ES (DGES, 2020[6]). Two other advisory councils, dedicated respectively to science and to innovation, have been largely inactive in recent years and CCES lacks "the clear mandate and sufficient resources to act as an independent advisory body, which combines higher education, research and innovation" (OECD, 2019[5]).

Governance at the level of HEls is addressed within the sections that follow through discussion of the 2007 Legal Regime for Higher Education Institutions (Regime Jurídico das Instituições de Ensino Superior, RJIES), development and implementation of which forms the key area of focus of this case study on HEI governance modernisation.

\section{The context for HEI governance reform}

The period between the democratic revolution of 1974 and 1986, when Portugal joined the European Economic Community (EEC), saw substantial growth in HE with this expansion supported by World Bank and OECD technical assistance and advice (Kauko and Diogo, 2012[7]). Formalisation of HE governance in Portugal began in the late 1980s.

In the 1980s and 1990s, demand for HE spaces grew, driving public and private system expansion, which saw new institutions founded, including in smaller centres and rural areas outside the traditional centres of HE in Lisbon, Porto and Coimbra (Fonseca, Encarnação and Justino, 2014[8]). In 1973, a "polytechnic/vocational subsystem" was formally established (and a binary system inaugurated), though its roots can be traced back to the OECD's 1959 "Mediterranean Regional Project (MRP)", which focused on addressing skills needs in participating countries (MTCES, 2006[9]). Implementation of the binary system began in 1977, following the transition to democracy. Additionally, focus on expansion of vocational HE was a key World Bank recommendation for Portugal during the post-revolution transition period (Kauko and Diogo, 2012[7]).

Only recently, in 2014, short-cycle post-secondary higher-education programmes were established in Portugal - Technical Professional Higher Education Courses (Cursos Técnicos Superiores Profissionais, CTeSP) (OECD, 2019[5]). While initially intended to support direct labour market entrance, about half of CTeSP students continue their studies at the bachelor level. As of the completion of the OECD Review of Higher Education; Research and Innovation: Portugal (2019[5]), uncertainty remains regarding the extent to which students who transition to bachelor-level studies from CTeSP programmes were prepared for the demands of these programmes. In addition, "it was acknowledged by $\mathrm{HEl}$ administrators and instructors that employers and wider society do not yet have a clear understanding of the CTeSP credential and the labour market outcomes of initial cohorts completing a CTeSP are not documented" (OECD, 2019, p. $179_{[5])}$.

While Portugal's gross domestic product (GDP) had "started to converge with the European Union average by the late 1980s", "growth slowed in the early 2000s, and the 2008 financial crisis brought the process of economic convergence to a halt" (OECD, 2019, p. 60 $0_{[5]}$ ). While growth recovered in 2014, poverty and inequality caused by unemployment due to the crisis continued to be felt. The impact of the post-2008 recession has been significant for Portuguese HE in general and the governance of HEls in particular, with a large impact on funding resulting from the 2011-14 Economic Adjustment Programme for Portugal from the European Commission (EC), European Central Bank (ECB) and the International Monetary Fund (IMF). As will be discussed, planned steps forward in institutional financial autonomy that had been put into motion immediately prior to the financial crisis were subsequently paused or reversed.

The governance of the HE system in Portugal, like in many other European countries, has developed in the Humboldtian tradition, which is characterised by institutional autonomy with respect to standards, curriculum and research, coupled with state control within areas falling outside of the realm of direct academic decision making (OECD, 2008 $[10])$. This approach contrasts with systems in which "institutions have by law and custom been substantially independent of state authority", a tradition predominantly 
reflected in the HE systems of English-speaking countries and in the Netherlands (OECD, 2008, p. 94[10]). Such areas of autonomy (or control) include, among other areas, freedom to:

- set up internal governance structures

- set staff salaries

- set academic staff appointment processes, and frame career structures

- select students and set student numbers

- borrow funds

- set and differentiate tuition fees

- accumulate financial capital

- undertake income-generating activities (OECD, 2008 $[10])$.

In Portugal, as in several other European countries, the general trend has been toward increased institutional autonomy, to allow institutions to manage their resources and more quickly respond to changes in their environment, coupled with accountability mechanisms providing transparent information about HEls' operations and output (OECD, 2019[11]).

Institutional autonomy is a separate concept from institutional governance. Following Mora (2001[12]), institutional autonomy is defined as the "right of the institution, not of its employees, to set its own objectives and manage its own affairs without interference from the State" (OECD, 2008, p. 81 [10]). Institutional governance refers instead to the way institutions as autonomous entities are governed, including the extent to which responsibilities are distributed among the various groups that may participate in the institution's governance, including institutional leaders, academic and non-academic staff, students, and broader community actors. For example, participation of employers in HEI governance bodies, on a voluntary or state-mandated basis, is becoming more common as a societal accountability mechanism and tool to promote labour market relevance among universities with increased autonomous capacity (OECD, 2019 [11]).

Portugal's University Autonomy Law (1988) formed a key step in the country's trajectory for HEI governances and autonomy. Among other changes, including the confirmation of pedagogical and scientific autonomy, it transferred ownership of buildings to universities (MTCES, 2006 $\left.{ }_{[9]}\right)$. Expectations surrounding what appropriate institutional autonomy, accountability and governance arrangements should be continued to evolve with time, domestically and internationally. In 2005, the Portuguese Minister of Science, Technology and Higher Education of the then new socialist-led majority government requested that the OECD undertake a review of the Portuguese system of HE to support government commitments to advance higher education reform and in fulfilment of legal requirements for periodic review of education systems (OECD, 2007[13]). The OECD review team published its work in 2007, finding that both institutional autonomy and institutional governance needed "a radical overhaul".

Specific concerns raised by the 2007 OECD Review included that:

- The civil servant status of academic and non-academic staff at both universities and polytechnics formed an undue interference from central government, with the requirement to seek approvals on any increases in tenured faculty particularly burdensome for universities. Approaches to academic staff hiring, tenure, and promotion were found to contribute to high levels of academic inbreeding (hiring from within institutions' own ranks), which decreases knowledge dissemination, as well as research quality and output.

- Autonomy for public universities was higher than for polytechnics, the latter of which did not own their own buildings and could not create or end programmes without ministry approval. In the private HE sector, there were further constraints on academic decision making with new programme and programme modification approvals required from government sometimes taking more than a year. 
- Absent or minimal representation of external stakeholders on university and polytechnic assemblies limited effective interactions with society and economy.

- Perceptions of weak institutional leadership were driven in large part by the internal election of rectors. This led to a political process in which commitments made in the election process had to be fulfilled, limiting strategic managerial capacity post-election.

- Multiple large governance bodies within HEI structures mandated by central government, often with equal representation for students and faculty, created slow and non-transparent decisionmaking processes. For example, at the time, membership of the "University Assembly in 14 public universities vari[ed] between 64 and 331, while the membership of University Senate vari[ed] from 36 to 179 " (OECD, 2007, p. 63[13]).

As a result of these factors characterising institutional autonomy and governance, the 2007 OECD Review found that:

...HEls are less engaged with national needs, and are less creative, responsive, entrepreneurial, innovative and transparent in their decision making than is required and expected by the country at large. While the detailed control exercised by government on the day-to-day operations of the higher education sector is considerable, it is out of touch with international trends where governments influence and steer, rather than direct, institutions (OECD, 2007, p. 66 $6_{[133)}$.

These findings echoed understanding at the time within MTCES that the governance approach and legal constructs surrounding Portuguese HEls needed to evolve in order to enable the HE sector to have greater societal impact (MTCES, 2006[9]). Portugal's movement toward institutional autonomy, governance reform, and greater accountability in the 2000s occurred alongside related developments in quality assurance. This included inauguration of the country's quality assurance agency, A3ES, first operational in 2009, which placed external programme quality validation alongside new autonomy and governance measures for institutions.

\section{Policy process: Formulation and adoption}

Based on the assessment presented in the preceding section, the 2007 OECD Review offered HEI governance and autonomy recommendations to the Portuguese government, which were incorporated to a significant extent, though not without modification, within the RJIES and approved by Law 62/2007 (OECD, 2019[5]). The 2007 OECD Review recommended, among other key directions, that new legislation should be created, introducing: (i) changes to institutional governance for all HEls; and (ii) a new autonomous status available to HEls based on application and meeting minimum qualifying conditions related to managerial preparedness.

Regarding institutional governance, the OECD recommended that the Portuguese government outline the structure of membership of the governing authority of each institution to include 10-15 members, with the majority of members and the chair representing external stakeholders. The remaining members would be internal stakeholders, the majority of whom would be faculty. For external members, the importance of credible selection procedures was highlighted, with the recommendation made to explore and borrow from international best practice in this regard. The OECD also recommended that the rector of each institution would be "appointed, not elected" with the governing authority responsible for holding a public competition and selection processes (OECD, 2007, p. 68 $[$ [13]).

The proposed new autonomous status recommended by the OECD for HEls that meet qualifying conditions was outlined as such:

...at a minimum, [it would] provide for the elimination of regulations that delimit stated autonomy, that faculty and staff of the HEls would be defined as employees of the HEI and would no longer be civil servants, that salaries would be a matter for the HEI, that the creation of employee positions would be subject to an internal process involving the formal agreement of the governing authority of the $\mathrm{HEl}$, and that all appointments to those 
positions (and promotions) would be fully transparent and subject to a formal advertising and appointment process involving a substantial number of outside individuals. The finances of the HEls would be considered not to be state finances. All of the above and other freedoms would be subject to any HEI producing a balanced budget in each year (OECD, 2007, p. 67[13]).

The key governance and institutional autonomy changes ultimately integrated within RJIES are profiled below, following a discussion of RJIES' path to legislative approval.

\section{RJIES: Legislative initiative}

Following Portugal's 2005 general election, a socialist majority government was formed. The Higher Education and Science Minister at the time, who had previously served as an influential Science Minister in the 1990s, had a significant role in advancing the reform agenda that ultimately took shape in RJIES. While some changes were made to the proposed law in Parliament (reducing the scale of initially proposed external member involvement in HEI governance bodies), in general, the process was one of direct implementation of a set of reforms through legislative powers of a majority government. HE sector stakeholders interviewed by the OECD team noted that while parliamentary hearings were held, as well as local institutional debates and media dialogue, formal consultations surrounding the proposed law did not take place. RJIES sat as one among a range of public sector reform initiatives that were moving forward with relative speed at the time. Others focused, for example, on basic education and social security.

All opposition parties at the time opposed RJIES within the framework of debate over wider public sector reform initiatives. HE sector actors, including faculty and staff unions, as well as student organisations, also opposed the law, fearing that it was motivated by a "privatisation agenda" and that reductions in faculty and student representation in governance bodies, which often featured a parity of representation, could foster inequality among students, staff and institutional management within HEls (Kauko and Diogo, $2012[7]$. HEI rectors, while largely in favour of streamlining institutional governance bodies and reducing their size, largely opposed RJIES. This opposition was based on concerns that the foundation status (further discussed below) would lead to a two-tiered system of elite and non-elite institutions. Stakeholders interviewed by the OECD team report that a key goal behind the introduction of the foundation status option was the vision that Portugal's largest universities would adopt the status and leverage it to advance internationalisation and research outputs.

While progress is evident, the relative merit of core elements of RJIES, including HEI governance reforms and foundation status, continues to be controversial within the HE sector and within wider political debates in Portugal. This continues to affect the legal regime's legacy. Prior to a discussion of RJIES' implementation, its core elements regarding $\mathrm{HEl}$ governance changes and foundation status are discussed.

\section{Governance changes for all HEls under RJIES}

RJIES resulted in institutional governance changes for all HEls, including the reform of elected governance bodies and in the selection of rectors (in the case of universities) and presidents (in the case of polytechnics).

The functions of former $\mathrm{HEI}$ assemblies and senates that could cumulatively have hundreds of members were replaced with unicameral general councils as the highest decision-making body. Under the legislation, general councils are composed of 15-35 members according to the size and structure of the institution. While staff-student parity was previously practiced within many $\mathrm{HEI}$ governance bodies, under the legislation, a minimum of only $15 \%$ of general council members have to be students (elected by their peers). Professors and researchers (elected by their peers) must account for more than half of the general council. While representation of community actors from outside of the HEI (such as employers) was previously possible (about half of universities previously had external representations in senates, ranging from $3 \%$ to $12 \%$ of members; see (OECD, $\left.2007_{[13]}\right)$ ), RJIES mandated that at least $30 \%$ of general council members must be "external people of recognised merit... with relevant knowledge and experience for the 
institution". These external members are nominated and selected by a vote of the internal student and academic general council members (Government of Portugal, $2007_{[14]}$ ). The chair of the general council is selected by a vote of all general council members, but must be one of the external (non-academic, nonstudent) council members (Government of Portugal, 2007[14]).

Under RJIES, university rectors and polytechnic presidents are elected by the general council through a secret ballot. This follows public announcement of openings, submission of applications and public hearings with candidates. In the case of universities, rectors may be professors or researchers from within the institution or from other Portuguese or international institutions. For polytechnics, the role of president is also open to non-academics who have relevant professional experience (Government of Portugal, 2007[14]).

As will be further discussed, RJIES opened the possibility for institutions to attain "foundation status". For institutions that attain foundation status, a further governance body, the board of trustees, is created. The board of trustees is a five-member body sitting above the general council, which is appointed by the government upon the advice of the general council. Its role lies primarily in ratifying decisions and directions set by the general council, some of which, in the case of non-foundation universities, would be subject to ministerial approval.

At the level of teaching and research units within institutions (faculties), a single-member executive is required who may be appointed by the rector, or who may be selected by a representative collegiate body, the composition of which is outlined in RJIES. Such representative bodies are generally in place. Prior to RJIES, large collegiate bodies at the teaching and research unit level collectively held managerial responsibilities. Stakeholders interviewed by the OECD team reported that under the pre-2007 governance approach, decisions on matters including the career progression of individual faculty members could be subject to the decision of faculty governance bodies with memberships numbering in the hundreds.

Under RJIES, similar HEI governance changes were made for both universities and polytechnics. For illustrative purposes, Table A A.2 (also included in the main report as Table 3.8) surveys HEl governance changes made by RJIES, compared to before the legislation was passed, from the vantage point of universities.

\section{Table A A.2. University governance bodies pre- and post-RJIES (2007) in Portugal}

\begin{tabular}{l|l}
\hline \multicolumn{1}{c|}{ Pre-RJIES } & \multicolumn{1}{c}{ Post-RJIES } \\
\hline $\begin{array}{l}\text { University assembly (64-331 members in 14 largest universities): } \\
\text { Primary governance body }\end{array}$ & $\begin{array}{l}\text { General council composed of 15-35 members. } \\
\text { In the case of foundation status institutions, board of trustees (five } \\
\text { members) sits above general council. It is appointed by the government } \\
\text { upon recommendation of the general council. }\end{array}$ \\
\hline Rector selected by university assembly & $\begin{array}{l}\text { Rector selected by the general council (ratified by the board of trustees } \\
\text { in the case of foundation institutions). }\end{array}$ \\
\hline $\begin{array}{l}\text { University assembly contains } 40 \% \text { academic staff, } 40 \% \text { students, } 20 \% \\
\text { other staff }\end{array}$ & $\begin{array}{l}\text { General council must have a majority of academic staff, 30\% external } \\
\text { members and } 15 \% \text { students. Internal members select the external. }\end{array}$ \\
\hline $\begin{array}{l}\text { Academic senate (36-179 members in } 14 \text { largest universities) with } \\
\text { managerial authorities (e.g. budget proposals and annual accounts) - } \\
\text { could include up to 15\% external members. Senates could include } \\
\text { faculty representation. }\end{array}$ & $\begin{array}{l}\text { Management council (maximum five members, chaired and appointed } \\
\text { by rector) holds authorities with respect to administration, finances, } \\
\text { assets and human resources. In the case of foundation status } \\
\text { institutions, the board of trustees approves the rector's recommended } \\
\text { appointments to the management council. }\end{array}$ \\
$\begin{array}{l}\text { Administrative council responsible for current financial administration } \\
\text { Collegiate governance bodies were mandated at the faculty level by } \\
\text { legislation, held managerial authorities, and selected their leadership }\end{array}$ & $\begin{array}{l}\text { Academic structures are decided by universities within their statutes. } \\
\text { Teaching and research units must have a single-member executive. } \\
\text { They may have a representative collegiate body (they have generally } \\
\text { chosen to do so), which has the function of selecting the executive. If } \\
\text { there is a representative collegiate body, it must have 15 members or }\end{array}$ \\
\hline
\end{tabular}


less, have at least $60 \%$ teacher and researcher members, and include students, non-academic staff and external representatives.

Scientific and technical councils and pedagogical councils with membership specified in RJIES play guidance and advisory roles at the teaching and research unit level.

Source: Government of Portugal $\left(2007_{[14]}\right)$, Regime Jurildico das Instituiçoles de Ensino Superio (RJIES), https://data.dre.pt/eli/lei/62/2007/09/10/p/dre/pt/html.

\section{Foundation status created by RJIES}

Beyond these governance changes made for all HEls, RJIES opened the possibility of HEls attaining "foundation status" that would see their exit from state consolidation. The objective was to give HEls greater operational autonomy, particularly in the areas of financial management and staffing, by allowing them to make use of the greater flexibility afforded by the employment, accounting and procurement legislation applicable to the private sector in Portugal. Foundation status is awarded by decision of the Council of Ministers on the recommendation of MCTES (OECD, 2019[5]).

Among other key changes, this reform would permit HEls to employ academic and non-academic staff independently under private employment law outside the scope of civil service procedures, pay-scales, and centralised MCTES approvals for staffing level changes. It is important to note that adoption of foundation status does not result in the automatic conversion of current staff to private sector employment law (a key difference from the initial OECD recommendation). Rather, foundation status enables institutions to hire under private law. Specific action on the part of the institution is required to change the status of specific positions from civil service to private status, or to hire new positions under private law.

As outlined in Box A A.1, the RJIES legal regime for foundation-status HEls confirms their status under private law, as well as their corresponding ability to hire under private law. It confirms the continuation of a mission of service to the public as well. The legal regime also enables continued civil service employment at foundation-status HEls, alongside private law employment. This unique formulation for civil service employment is part of what makes foundation-status HEls distinct. According to stakeholders interviewed by the OECD team, foundation-status HEls are not transferred to governance under general Portuguese legislation respecting foundations. Rather, they are specific entities governed by the provisions of RJIES, and more specific government policy directions with respect to their autonomy. The financial and managerial authorities originally intended for foundation-status HEls are further described in Box A A.1. As will be discussed in the following section, the full implementation of this vision for financial and managerial autonomy of foundation status institutions has been significantly challenged.

\section{Box A A.1. Legal regime for foundation-status institutions established under RJIES and} intended financial and managerial autonomy

Article 134 under RJIES (2007 $\left.{ }_{[14]}\right)$ defines the legal regime for foundation-status HEls under private law while referencing the possible coexistence of civil service and private staffing:

"Article 134 Legal regime

1. Foundations are governed by private law, namely with regard to their financial, property and personnel management, with the reservations set out in the following paragraphs.

2. The private law regime does not prejudice the application of the constitutional principles relating to Public Administration, namely the pursuit of the public interest, as well as the principles of equality, impartiality, justice and proportionality. 
3. Within the scope of the management of its human resources, the institution may create its own careers for its teaching staff, researcher and others, generally respecting, when appropriate, the parallelism in the list of categories and academic qualifications, in relation to those in force for the teaching and research staff from other public higher education institutions.

4. The provisions of the preceding paragraph are understood to be without prejudice to the safeguarding of the civil service regime enjoyed by the employees and agents of the higher education institution before it is transformed into a foundation."

According to the OECD Review of Higher Education, Research and Innovation: Portugal (2019, p. $150_{[5]}$ ) "When RJIES was adopted - and in the early years of its implementation - the law aimed to permit foundation institutions to operate with far wider financial and managerial autonomy than was previously the case, and created a new framework of financial management that was substantially 'outside the fiscal perimeter of the state'. Key aspects of this wider autonomy included:

- exemption from the Public Procurement Code for the acquisition of goods and services below EUR 200000

- exemption from the Public Procurement Code for the contracting of works below EUR 5000000

- authorisation to manage real estate, physical assets and financial assets in accordance with private financial management rules

- exemption, in part, from the obligation to render accounts according to the Official Plan of Public Accounting for the Education Sector (POC-Educação)

- authorisation to make financial investments according to the best offers on the market (rather than holding assets in cash or government bonds)

- exemption from the requirement of annual budgetary balance, permitting the institution to carry forward a surplus or deficit from one fiscal year to the next

- permission to borrow without authorisation by joint dispatch of the Minister of Finance and MCTES, thereby permitting additional financing to meet matching requirements in EU-funded activities

- $\quad$ authorisation to hire teaching and non-teaching staff under private law

- authorisation to buy and sell real estate with the approval of the institution's board of trustees, in place of approval by the Ministry of Finance."

Sources: Government of Portugal $\left(2007_{[14]}\right)$, Regime Juridico das Instituiçoles de Ensino Superio (RJIES), https://data.dre.pt/eli/lei/62/2007/09/10/p/dre/pt/html; OECD (2019[5]), OECD Review of Higher Education, Research and Innovation: Portugal, https://doi.org/10.1787/9789264308138-en.

\section{Policy process: Implementation and outcomes}

The institutional governance changes that apply to all Portuguese HEls and the inauguration of the foundation-status option under RJIES have followed distinct trajectories, with the former implemented more completely than the latter. In both cases, the impact of the post-2008 financial crisis in the specific Portuguese context has been significant. As the 2011-14 Economic Adjustment Programme proceeded, "sharp reductions were made to public investments in knowledge and innovation" (OECD, 2019[5]) and financial flexibilities available within the HE sector in Portugal declined. In the case of governance reform for all HEls, this led to new governance bodies in place, just as financial constraints limited capacity to exercise strategic leadership. In the case of foundation-status HEls, flexibility initially on offer with the new status was reduced and planned financial supports were not delivered. In both cases, this external pressure layered upon an existing lack of sector and political consensus regarding the best direction for the future 
governance and structure of HEls, a factor that at present continues to affect implementation and system development. Figure A A.1 presents illustrative goals, outputs and outcome indicators for reforms advanced by RJIES.

\section{Figure A A.1. Illustrative goals, outputs and outcomes of the HEl governance reform in Portugal}
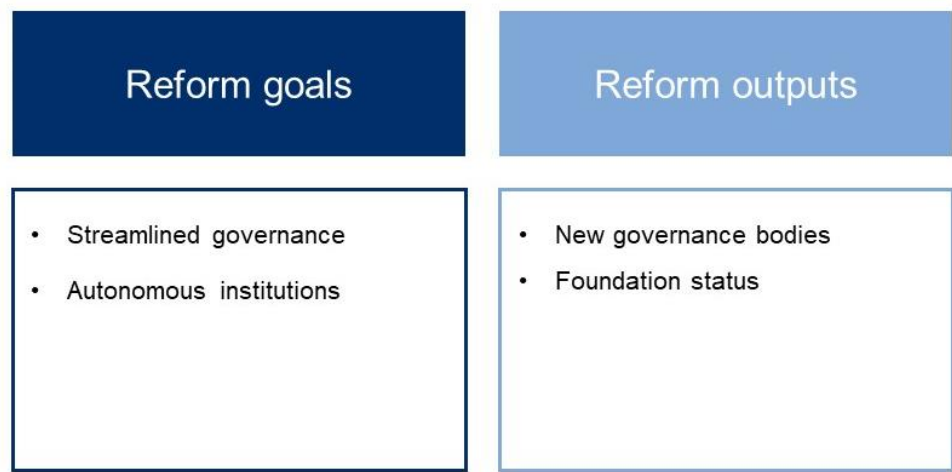

Reform outputs

- New governance bodies

- Foundation status

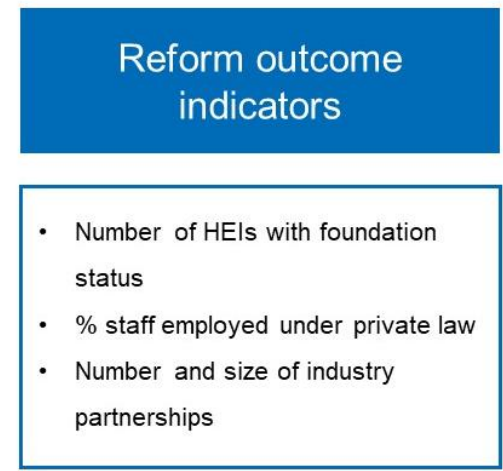

\section{Implementation of governance changes for all HEls}

Implementation of governance changes for HEIs under RJIES proceeded directly from the law's passage. RJIES required that HEls adopt new statutes in accordance with the law within eight months of its entry into force, outlining the new governance bodies. HEls were required to select members of newly named governance bodies (e.g. general councils) within four months of the new institutional statutes' publication. The reforms inaugurated streamlined governance bodies of reduced size and number, as outlined above.

One sector stakeholder interviewed by the OECD team highlighted that the process of recrafting university statutes carried an independent value at the time, opening discussion around HEls' broader goals and modes of operation beyond the scope of required statutory change. Still, the broader changes were and remain controversial, with a mixed legacy. This section discusses their implications for autonomy and strategic leadership capacity.

The European University Association (EUA) University Autonomy Tool rankings provide one window into autonomy implications of Portugal's approach to HEI governance under RJIES. The EUA tool focuses on assessing Portuguese universities that have not transitioned to foundation status. It was first conducted in 2010 (three years following RJIES) and again in 2017, so does not provide for a pre- and post-RJIES comparative analysis of Portuguese universities. However, the tool does provide a helpful internationally comparative vantage point into the current state of autonomy of the majority of Portuguese universities, which remain outside the foundation-status regime.

As noted, the EUA University Autonomy Tool assessments of 29 European HE systems was last published in 2017, which was ten years after the passage of RJIES in Portugal. On organisational autonomy, financial autonomy, and staff autonomy, Portugal received a "medium-high" rating, while in academic autonomy, its rating was "medium-low". These ratings were unchanged from 2010, when the assessment was first conducted. According to the EUA, "there have been no significant changes to university autonomy in Portugal since 2010 that would result in different scores for any of the autonomy dimensions" (EUA, 2017, p. $\left.154_{[15]}\right)$. Rankings for Portugal and for Finland and the Slovak Republic, for comparative purposes, are provided in Table A A.3.

Portugal receives relatively high rankings in the areas of organisational autonomy $\left(7^{\text {th }}\right)$ and financial autonomy $\left(7^{\text {th }}\right)$. In the lower ranking area of staffing autonomy, the EUA highlights the status of Portuguese university academic staff as civil servants, the regulation by law of senior academic staff recruitment, state control of salaries, state regulation of dismissals, and the fact that while senior academic staff promotions 
take place based on a competitive basis, post-2011 state budgetary controls (stemming from the Economic Adjustment Programme) have had a significant impact. For example, between 2011 and 2015, requirements to hold staffing costs to $0 \%$ increases meant that promotions could only happen in the event of a retirement. In the realm of academic autonomy, in which Portugal received its lowest ranking, the EUA has highlighted how universities "negotiate" overall student numbers with MCTES, how bachelor-level admission criteria (rules for entrance exams) are "co-regulated" between universities and the National Commission for Access to Higher Education (as noted, post-graduate level admissions criteria are set by universities), and the requirement for approval of new degree programmes at all levels by A3ES. Universities are, however, able to independently terminate programmes, decide on the content of degree programmes and choose the language of instruction (EUA, 2017 $\left.{ }_{[15]}\right)$. Reflecting on Portugal's low EUA rankings in staffing and academic autonomy, the OECD concluded in 2019 that "national legislation governing public sector employment, public procurement and financial management are burdensome, and limit the ability of institutions to plan and manage their operations efficiently and effectively" (OECD, 2019, p. $\left.16_{[5]}\right)$.

Table A A.3. EUA University Autonomy Tool ranking of Finland, Portugal and the Slovak Republic (2017)

\begin{tabular}{|c|c|c|c|c|}
\hline & Organisational autonomy & Financial autonomy & Staffing autonomy & Academic autonomy \\
\hline Finland & $3 r d$ & 11th & 6th & 2nd \\
\hline Portugal & 7th & 7th & 18th & 20th \\
\hline Slovak Republic & 28th & 7th & 19th & 18th \\
\hline
\end{tabular}

Note: The EUA defines the four dimensions of its analysis as follows: (i) Organisational autonomy refers to a university's ability to decide freely on its internal organisation, such as the executive leadership, decision-making bodies, legal entities and internal academic structures. Financial autonomy refers to a university's ability to decide freely on its internal financial affairs; (ii) The ability to manage its funds independently enables an institution to set and realise its strategic aims; (iii) Staffing autonomy refers to a university's ability to decide freely on issues related to human resources management, including recruitments, salaries, dismissals and promotions; (iv) Academic autonomy refers to a university's ability to decide on various academic issues, such as student admissions, academic content, quality assurance, the introduction of degree programmes and the language of instruction.

Source: EUA (n.d.[16]), University Autonomy Rankings, www.university-autonomy.eul.

Sector stakeholders interviewed by the OECD team highlighted that RJIES did result in minor autonomy gains for HEls that did not transition to foundation status. These areas of autonomy gain included broader flexibility to recruit staff (while staying within budget), and delivery of base funding as a single grant, as opposed to separate core line items. Stakeholders also relayed, however, that these flexibilities did not have a major practical impact because of overall budgetary reductions that followed the Economic Adjustment Programme, leading to challenges meeting costs. In 2017, the EUA University Autonomy Assessment noted that:

All Portuguese public institutions are currently subject to austerity rules, which also has an impact on universities and their autonomy. The annual budget law with its detailed restrictions on all areas of public administration places universities under quite tight controls in terms of their ability to develop their financial strategies and contracts with external partners (EUA, 2017, p. 155[15)).

While noting that the situation had improved, the EUA reported that the financial position of Portuguese universities had not recovered to pre-2011 conditions (this is also reflected in OECD data). Sector stakeholders interviewed by the OECD team in 2020 similarly reported continued improvement, but incomplete recovery.

Looking beyond their effects on autonomy, HEI governance reforms under RJIES have streamlined decision making within institutions following their implementation. Far smaller bodies are now involved in managerial decisions and rectors as well as executives at a teaching and research unit levels are further 
empowered to make decisions. HEls are seen now as "more governable" according to some stakeholders interviewed by the OECD team:

- Mandates to engage bodies with hundreds of people in strategic and routine managerial decisions are no longer required.

- External members now have an embedded role in governance.

- Accountability of rectors and executives has increased through clearer lines of responsibility.

However, perspectives of stakeholders interviewed by the OECD team on the outcomes of these governance reforms are mixed, with a few key concerns raised:

- While streamlining managerial capacity, the elimination of large collegial bodies governing institutions and teaching and research units has also resulted in a loss of the default spaces in which institutional matters are discussed, debated, and understood by members of the institutional community. This was seen by some to result in a lack of capacity to build understanding and buyin of institutional direction among faculty, staff, students and organisational units. In some cases, governance changes challenged alignment of strategic plans due to "fragmentation between the central administration and middle management" (Magalhães et al., 2013[17]).

- Some sector stakeholders reported that inclusion of external members in general councils has not brought discussion of broader societal and economic concerns, and rather, that following an initial period of more robust engagement from external members, internal members with deeper institutional familiarity have driven deliberations. Such concerns were also seen by stakeholders to differ by region, with more industrialised regions in the north seeing more robust participation from external employer members related to institutional linkages with the broader economy. Still other stakeholders emphasised that the key value that external members add to governance is less their unique perspectives and more their independence from internal institutional concerns.

- As noted, rectors were previously elected by broad university assemblies. Now they are elected by general councils, which include external members that are selected by the internal members. There are concerns that at times selection of external general council members by internal faculty and student members is based on internal members' perception of who external members would support in the selection of the rector. In other words, it appears that in some cases rector selection has continued within a political framework that can now also influence the composition of the governing body, in the form of the general council.

These are concerns that may be addressed through continued development of the post-RJIES HEI governance approach in Portugal. The transition to more centralised leadership may require a simultaneous adoption of more informal consultative mechanisms at an institutional level in order to lead the diffuse range of individuals and organisational units that form an HEl. These may be governance practices that fall outside of law or statute, including development of norms around expected consultation in relation to substantial decisions. Further consideration of the selection process and approach to involvement of external members in general councils may also be required, with potential for deepening effective engagement of individuals without institutional ties in governance. However, as will be discussed, there are currently challenges to opening consideration of options for further development of the RJIES governance framework.

\section{Implementation of foundation status}

Since RJIES' adoption, implementation of the foundation-status vision for Portuguese HEls has progressed slowly in terms of the number of HEls that are both eligible and choosing to take up this status. However, institutions that have attained foundation status include five of the country's ten largest universities (representing $25 \%$ of the country's HE student population in 2016). This contrasts with only one polytechnic having attained foundations status. 
The University of Porto, University of Aveiro and the Lisbon University Institute (Instituto Universitário de Lisboa - ISCTE) attained foundation status in 2009. With roughly 28000 students, the University of Porto is the country's second largest university, the University of Aveiro is the sixth largest university (12000 students) and ISCTE Lisbon is the eight largest university (9000 students). Two further universities, New University of Lisbon (the fourth largest university, at roughly 18000 students) and University of Minho (the fifth largest university, at roughly 17000 students) (ETER, 2021 [18]) later attained foundation status in 2015 and 2016 (OECD, 2019 ${ }_{[5]}$ ). Most recently, the Polytechnic Institute of Cávado and Ave (the ninth largest polytechnic, at roughly 4000 students) attained foundation status in 2018 (Eurydice, n.d.[19]).

Sector stakeholders interviewed by the OECD team noted that aside from the two universities mentioned above that are located in Lisbon, the remaining three universities and one polytechnic that have transitioned to foundation status are located in Portugal's more industrialised north (where the majority of HEls are located). The University of Lisbon, the largest and most research-intensive institution in Portugal, has not transitioned to foundation status, contrary to what stakeholders reported to be a core vision of the Minister of Higher Education and Science that led RJIES' development and initial implementation. Institutions that have adopted foundation status appear to be those that are more oriented toward leveraging the flexibility it offers toward entrepreneurial activity, and also those located within regions and economic contexts that are positioned to support these activities. Stakeholders also reported opposition to considering foundation status within some universities among faculty, staff and students that is based on the same views against perceived "privatisation" that were prevalent at the time of RJIES' initial passage in 2007 (CCES, 2017[20]). Stakeholders report that within some HEls, it is not possible to discuss the option of pursuing foundation status due to the prevalence of this view.

However, perhaps more important to determining institutions' choices regarding the pursuit or non-pursuit of foundation status are what it takes to qualify for the status, and the ultimate utility of foundation status to HEls. Compared to the initial vision, foundation status is in some ways both harder to attain and offers fewer benefits than originally planned.

For foundation-status qualification, RJIES formally requires baseline information about how the status would benefit an HEl's operations and mission as part of the process of government approval of proposals to transition to the status. The Ministry of Finance has applied a more specific requirement for HEls: they must be able to demonstrate that at least $50 \%$ of their revenues are from private sources in order to qualify for foundation status. This more stringent requirement established following the 2008 financial crisis challenges the ability of some HEls to meet the qualification threshold, particularly those with fewer links to the private sector, and as a result, lesser capacity to generate investment. Uncertainty regarding what forms of revenue count as public versus private sources, in particular, whether tuition fees count as private sources, has also created confusion in the past regarding whether or not specific HEls meet the $50 \%$ threshold and could qualify to achieve foundation status (OECD, 2019[5]). As of 2017, some of this confusion appears to be resolved (CCES, 2017[20]).

Soon after the adoption of RJIES, the global recession beginning in 2008 and the subsequent 2011-14 Economic Adjustment Programme for Portugal "led Portuguese authorities to adopt heightened public sector financial controls that sharply reduced the financial and managerial autonomy first envisioned for foundation universities" (OECD, 2019, p. 151[5]). Direct public operating funding to HEls declined from EUR 1.07 billion in 2011 to EUR 871 million in 2012 (OECD, 2019 ${ }_{[5]}$ ). In addition to funding decreases and the introduction of multi-year salary controls on public servant staff across all HEls (including at foundationstatus institutions), for foundation-status HEls in particular, exemptions from procurement codes, from controls on investment options, permission to carry forward budgetary balances (protection from "captivations"), independent authorisations to take on debt, and to buy and sell real estate were all effectively suspended. The financial and managerial autonomy envisioned for foundation-status HEls, as outlined in Box A A.1, was largely upended. 
A 2016 commission created by CCES to analyse the implementation of the foundation-status regime (CCES, 2017[20]) found that the foundation universities had been "integrated again into the state budget perimeter" (OECD, 2019, p. 151[5]). Sector stakeholders interviewed by the OECD team confirmed that foundation-status HEls remain within this state budget perimeter and have not recovered the financial and managerial autonomy that was initially envisioned. Additionally, the first wave of foundation-status universities in 2009 - University of Porto, University of Aveiro and ISCTE Lisbon - were supposed to receive an initial grant committed by the government to support development of independent endowments. Despite the universities meeting their agreed requirements for release of these funds, the committed investments were not delivered as a result of public sector financial controls in the 2011-14 period (CCES, $2017_{[20]}$. Such support has not been offered to other HEls transitioning to foundation since this time.

One area of managerial autonomy for foundation-status universities that has not been formally restricted is the ability to hire staff under private law outside of the civil service schema. However, confusion remains regarding "the extent to which staff working under public and private labour law must have parallel conditions for advancement and compensation" (OECD, 2019, p. 152[5]), given that foundation-status universities may employ staff under both private employment law and civil servant status. This confusion, among other factors, has contributed to mixed uptake of the private law employment pathway for HEls with foundation status. Across the board, private law hiring at foundation universities is far more prevalent for career researchers than for instructional faculty:

At the three public universities that were the first to adopt foundation status - Aveiro, Porto, and ISCTE - by 2016, 38\% of staff holding appointments as technical staff and $94 \%$ of all career researchers (investigadores) were employed under private law contracts, while about $12 \%$ of instructional faculty (docentes) held contracts under private employment law. Foundation universities vary in their willingness to use private law hiring with their docentes workforce - in some institutions it is effectively unused. The University of Minho, though awarded foundation status in 2015, appears to have made fuller use of its legal possibilities with respect to employment. For example, when its faculty members have obtained external offers that exceed the public sector salary scale, the Minho administrators have been able to retain faculty by creating teaching and research posts under private employment law, and thus outside public sector salary limits. (OECD, 2019, p. $\left.151_{[5]}\right)$.

The University of Porto has similarly used foundation status flexibilities to introduce two additional salary levels above what is available to civil service teaching staff, in order to increase its competitiveness in hiring (CCES, 2017[20]) (see Box A A.2).

\section{Box A A.2. Collaboration between the University of Minho and Bosch, supported by foundation} status

Founded in 1973 as one of the then named "new universities", with four campuses across the region of Minho, the University of Minho is one of the largest in Portugal. It received foundation status in 2015. The ability to hire staff under private law outside of the civil service schema is one of the key benefits available to foundation-status institutions. For the University of Minho, this has supported private partnerships with industries that have had a wider impact on the economy of the region.

With the increased flexibility in private hiring and financial management that foundation status provides, the University of Minho has been able to build and expand strategic partnerships with industry through a blend of internal and external hiring. One of the most successful of these projects has been an ongoing partnership with Bosch, a multinational engineering and technology company headquartered in Germany. The partnership began in 2012 with the HMIExcel programme. Focused on the development of new technologies and components for the automotive sector, this work was carried out at a new Bosch unit on the Braga campus of the university. The project, which operated between 2013 and 2015, included a private research and development (R\&D) investment of EUR 19 million from Bosch and 
resulted in 12 new patents and the publication of 32 scientific journal articles. It also led to a second, larger phase of collaboration.

This new project, the Innovative Car MHI programme, represented the largest ever R\&D contract between a private firm and a Portuguese university - a total investment of EUR 54.7 million. It involved hiring over 400 new staff, including Bosch engineers and over 200 university research fellows. Project outcomes included 22 new patents and 72 scientific publications.

The partnership between the University of Minho and Bosch has now entered its third phase - "Crossmapping the Future" - and represents a further EUR 35 million in investment and the hiring of 60 new Bosch employees and 70 university research fellows. The work includes new research and patents in the areas of automated cars, automobile multimedia and a "Factory of the Future".

Sources: Fibrenamics (n.d.[21]), Bosch Innovative Car HMI, https://www.fibrenamics.com/en/business/partners/bosch-innovative-car-hmi Universidade do Minho (n.d.[22]), Programme Innovative Car HMI,

https://www.eng.uminho.pt/en/researchinnovate/projectsinindustry/Pages/programmeinnovativecarhmi.aspx;

Crossmapping the future (n.d.[23]), Factory of the future, https://innovativecarhmi.com/factory-of-the-future\#factory-of-the-future1.

\section{Foundation status outcomes}

As of the 2019 OECD Review of Higher Education, Research and Innovation in Portugal, the OECD reached the following conclusions regarding the overall effectiveness of RJIES:

The goals underlying the 2007 legal framework for HEIs, the RJIES, have been only partly realised. One decade after the law's adoption, Portuguese HEls remain - on average - less autonomous, more inwardlyoriented, and less capable of providing agile and flexible support to innovation than those in leading higher education systems - such as the Netherlands, Finland or Switzerland. Foundation status, expected to transform institutional autonomy, has accomplished less than expected (OECD, 2019, p. $\left.149_{[5}\right)$.

The review further recommended the following actions to strengthen the $\mathrm{HEI}$ autonomy regime in Portugal:

- improving the effectiveness of foundation status for HEls that have it already

- approaching financial management for all institutions on a continual basis (multi-year budgeting) instead of being subject to annual budget decisions and the possibility of mid-year budget reductions to balance public accounts

- clearly exempting foundation universities from public accounting and contracting codes

- devising qualification criteria and extending foundation status to all HEls in the mid-term

- adopting revised financial management criteria for foundation status based on less restrictive good management practices (OECD, 2019 $\left.{ }_{[5]}\right)$.

RJIES was intended to be evaluated five years after its enactment, a requirement of Article 185 of the act. Stakeholders interviewed by the OECD team reported that with this scheduled date (2012) falling at the height of the Economic Adjustment Programme, the planned review did not occur, and has not occurred since. While there are issues related to foundation status as well as regarding the HEI governance framework outlined above that could be productively considered and tuned through an official evaluation, there is a reluctance to proceed. Reforms enabled by RJIES continue to be understood through a highly political lens. According to stakeholders interviewed by the OECD team, an evaluation in the current context would likely result in a debate over reversal of core RJIES reforms rather than tuning and adjustment to build upon them. This is due to greater parliamentary prominence of perspectives aligned to both the initial opposition to RJIES in 2007 and the continued opposition to RJIES and foundation status that, as discussed, is common within some HEls. It could be concluded that, in the present context, adjustment of approaches to utilising both reformed HEI governance structures and foundation status (within its limitations) is more likely to develop at an institutional, rather than system-wide, level. 


\section{Finland: Institutional landscape rationalisation}

\section{Key governance actors in the HE system}

Finland is a Northern European state that has operated as a presidential, unitary, parliamentary republic since 1919, following its independence from the Russian Empire in 1918 (Lukacs, 1992[24]). Finland's parliament is a unicameral legislature comprised of 200 members. Parliaments are elected on a four-year cycle utilising proportional representation. Parliaments with a majority government are uncommon in Finland, with the largest party capturing an average of 48 seats over the last 5 elections (Official Statistics of Finland, $\left.2019_{[25]}\right)$. As a result, coalition governments are the norm.

The Finnish central government is currently comprised of 12 ministries (Valtioneuvosto, n.d.[26]), including the Ministry of Education and Culture (MEDC), which has a current mandate covering HE as part of a wider remit, including "daycare, education, training and research; arts, culture, sports and youth work; the archival, museum and public library systems; the Evangelical Lutheran Church; the Orthodox Church and other religious communities; student financial aid; and copyright" (Government of Finland, 2020[27]).

Alongside central government, Finland has six regional state administrative agencies (RSAAs), which are responsible for delivering core public services, including primary and secondary education, administrating legal processes, such as allocating permits, and overseeing health and safety.

The primary actor in the governance of the HE system in Finland is the MEDC, which oversees both the public universities and universities of applied sciences (UAS). These two categories of institution represent Finland's binary tertiary education system. The HE system oversight activities of the MEDC are steered by a variety of policy plans and documentation that outline overall goals and desired national outcomes from the sector over forthcoming years. The National Development Plan for Education and Research is an example that was particularly important throughout the reform period (2004-10), with the 2007-12 and 2011-16 iterations of this plan in particular being most relevant to the system changes surveyed in this case study. These development plans were the result of extensive forecasting of future labour market needs at national and regional levels, strategising for the future research and development needs of the country, as well as economic analysis.

There are several smaller actors that have roles and responsibilities within the broader HE sector and related "innovation ecosystem". For example, Universities Finland (UNIFI) is a co-operational organisation that represents Finland's university sector and aims to influence policy decisions made by the central and local governments regarding HE (UNIFI was previously the Finnish Council of University Rectors) (UNIFI, n.d.[28]). The Academy of Finland oversees additional public funding of scientific research and in 2015 was given oversight of a EUR 50 million research fund for universities driving specialisation and building "areas of excellence" (OECD, 2017[29]). This new approach was introduced in the 2011-16 National Development Plan for Education and Research (NDPER) and is further discussed below.

Changes made within the structure and governance of Finland's HEI network (and, in particular, the mergers of a number of HEls) form the core area of focus of this case study.

\section{Funding for higher education}

Universities in Finland are funded to a substantial degree by public investment. This funding is agreed in four-year increments, and both the amount of funding, and output-based targets upon which receipt of funding is conditional, are agreed through bilateral negotiations between MEDC and the institutions. This funding structure for HEls, defined by the NDPER and outlined in Table A A.4, sets out the proportional provision of funding that institutions receive for each of their aims and outputs. It is important to note that this funding model was a key instrument for financial incentives used to support institutional mergers, and other areas of high-level policy steering, including for institutional specialisation, adapting to suit these needs over time. 
Table A A.4. Finnish higher education public funding allocation model (2020)

\begin{tabular}{|c|c|c|c|}
\hline Institution type & $\begin{array}{l}\text { Funding } \\
\text { stream }\end{array}$ & $\begin{array}{l}\text { Proportion of overall } \\
\text { funding (\%) }\end{array}$ & Sub-streams and funding proportions (\%) \\
\hline \multirow[t]{3}{*}{ Universities } & Education & 39 & $\begin{array}{l}\text { Impact/quality: Master's degrees awarded (13\%); bachelor's degrees } \\
\text { awarded }(6 \%) \text {; number of students who have gained at least } 55 \text { study } \\
\text { credits }(10 \%) \text {; study credits in open university, specialisation studies, } \\
\text { studies based on co-operation and in non-degree programmes }(2 \%) \text {; } \\
\text { student feedback (3\%); number of employed graduates }(2 \%) \text {. } \\
\text { Internationalisation: Master's degrees awarded to foreign nationals } \\
(1 \%) ; \text { student mobility to and from Finland }(2 \%) \text {. }\end{array}$ \\
\hline & Research & 33 & $\begin{array}{l}\text { Impact/quality: PhD degrees awarded (9); scientific publications }(13 \%) \text {. } \\
\text { Quality/internationalisation: Completed research funding }(9 \%) \text {. } \\
\text { Internationalisation: International teaching and research personnel } \\
(2 \%) \text {. }\end{array}$ \\
\hline & $\begin{array}{l}\text { Other education } \\
\text { and science policy }\end{array}$ & 28 & $\begin{array}{l}\text { Impacts/quality/internationalisation: National duties }(7 \%) ; \text { field- } \\
\text { specific funding }(9 \%) \text {; strategic development }(12 \%) \text {. }\end{array}$ \\
\hline \multirow[t]{3}{*}{$\begin{array}{l}\text { Universities of applied } \\
\text { science }\end{array}$} & Education & 79 & $\begin{array}{l}\text { Regional impact and links with business, and industry/quality and } \\
\text { internationalisation: Bachelor's degrees awarded }(40 \%) \text {; number of } \\
\text { students who have gained at least } 55 \text { study credits }(23 \%) \text {; number of } \\
\text { employed graduates (4\%); study credits in open UAS education and in } \\
\text { non-degree programmes }(5 \%) \text {; degrees in vocational teacher training } \\
(2 \%) \text {; student feedback (3\%); student mobility to and from Finland }(2 \%) \text {. }\end{array}$ \\
\hline & $\begin{array}{l}\text { Research and } \\
\text { development }\end{array}$ & 15 & $\begin{array}{l}\text { Regional impact and links with business, and industry/quality and } \\
\text { internationalisation: External R\&D funding }(8 \%) \text {; master's degrees } \\
\text { awarded (4\%); publications, public artistic and design activities, audio- } \\
\text { visual material and information and communication technology (ICT) } \\
\text { software (2\%); teacher and expert mobility }(1 \%) \text {. }\end{array}$ \\
\hline & $\begin{array}{l}\text { Strategic } \\
\text { development }\end{array}$ & 6 & $\begin{array}{l}\text { Regional impact and links with business, and industry/quality and } \\
\text { internationalisation: Strategic funding (5\%); field-specific funding (1\%). }\end{array}$ \\
\hline
\end{tabular}

Source: Eurydice (2020[30]). Finland Higher Education Funding, https://eacea.ec.europa.eu/national-policies/eurydice/content/highereducation-funding-25_en.

As Table A A.4 highlights, research and science play a larger role in the funding model of universities compared to the UAS, which have a far greater focus on teaching. This reflects the broader approach of the binary system in Finland: UAS receive the majority of their funding as a result of their education performance, highlighting the fact that UAS are seen as primarily regional teaching establishments (though with a role in research, aimed at technology transfer into industry), whereas universities are more deeply integrated into national R\&D ambitions and strategy.

The criteria for evaluation across these streams also differ between the two types of institution. The streams identified above are evaluated for universities against indicators aligned to one or more of three criteria: impact, quality and internationalisation. By comparison, UAS are measured against indicators aligned to two compound criteria: (i) regional impact and links with business; and (ii) industry, quality and internationalisation (Eurydice, $2020_{[30]}$ ). The funding model detailed here is also regularly adapted and updated by MEDC to reflect changes in the broader funding goals of the HE sector.

This funding model provides a framework for the negotiation of bilateral agreements between the ministry and HEls that cover each institutions' area of focus and developmental duties aligned to larger national priorities. These agreements have been a mechanism in use since 1998, although when introduced they only covered three years (Hölttä, 1998[31]). The funding itself is delivered to HEls on an annual basis, dependant on meeting performance goals in prior years. For example, for the University of Helsinki, 2021 funding is based on results from 2017-19 (Saarinen, 2019 [32]). Each agreement "defines the HEl's duties, profile, focus areas, development activities and public funding" (Eurydice, 2020[30]). Further to this, the funding areas of strategic development for universities (12\%) and strategic funding for UAS (5\%) are delivered based on unique institutional goals and profiles outlined within bilateral agreements. In recent 
years, funding within these areas has become based more on broad strategic actions and less on specific output measurement.

While funded through an output-based model enshrined in bilateral agreements, both universities and UAS have considerable day-to-day operational autonomy to meet their goals, which will be explored later in this case study.

\section{Evaluating higher education}

HEls have their own evaluation processes or "quality systems" that are used to verify the HEls' delivery against the agreed targets for funding set out in Table A A.4. These systems involve independent evaluation of their performance, carried out by a third party. HEls are free to contract this evaluation to organisations of their choosing and they are required to regularly carry out these evaluations and publicly publish the results. In addition, the quality systems themselves of each $\mathrm{HEl}$ are audited by the Finnish Education Evaluation Centre (FINEEC), an independent agency responsible for the evaluation of education. These audits are undertaken cyclically, the structure of which is determined by the National Plan for Education Evaluation (FINEEC, 2016[33]). The 2016-19 National Plan defines HEI quality management and describes the audit process as follows:

Quality management refers to the procedures, processes or systems that the HEI uses to maintain and develop the quality of its activities. Audit assesses how well the quality system meets the strategic and operations management needs of the $\mathrm{HEl}$ as well as how comprehensive and effective the quality management of the core duties of the HEl is (FINEEC, 2016, p. 13[33]).

The structure of Finland's funding and quality assurance systems have served as an important lever for reform, as will be discussed further.

\section{The context for institutional landscape rationalisation}

\section{Pre-reform higher education structure}

The governance structures detailed in the previous section represent a snapshot of the current HE landscape in Finland. They are the result of significant reform of the sector that has its roots in the 1990s, leading up to more substantive changes that took place between 2004 to 2010 , with some system features still undergoing development and adaptation. Prior to the period of policy shift that will be reviewed in this section, HE in Finland was substantially different in form and function. To some extent, this reform even extended to modifying underlying social and governmental expectations of the role of HE in Finnish society.

The Finnish university system as it existed at the turn of the millenium was the result of a rapid expansion that began after World War II. In line with the Finnish tradition of universal access to public services underpinned by a robust welfare state, higher education was guaranteed to be accessible for free for all Finnish youth in all regions of the large, but mostly sparsely populated country. This resulted in a significant number of HEls relative to the population, as every region of the country had one or more institutions that provided a comprehensive range of courses and credentials. This policy of regional provision for universities dominated from the 1960s through the 1970s and 1980s (Saarivirta, 2010[34]).

The peak of this post-war expansion occurred in the 1990s, when national policy changes established a second category of $\mathrm{HEI}$ to sit alongside the universities, solidifying a binary system of HE that remains in place today (Elander, Aarrevaara and Dobson, 2009[35]). These polytechnics (which would later be redefined as universities of applied sciences) were not entirely new institutions, but rather adapted and restructured upper-secondary-level educational institutions that had existed previously. They had a traditional focus on vocational courses, such as nursing, technical trades, as well as business, culture and social work, and maintained much of this educational focus, while expanding in some areas, based on regional labour market demand (Stenström and Virolainen, 2014[36]). 


\section{Catalysts for reform}

The structure of $\mathrm{HE}$, while still relatively new in some aspects (polytechnics had only come into existence in 1992), came under economic and political pressure at the turn of the $21^{\text {st }}$ century. This pressure was largely external to the education system itself, driven by the growing importance of globalisation within western economies - countries in Europe and around the world were becoming increasingly connected and interdependent as corporate multinationalism, and increasing global labour market fluidity began to impact the behaviours of national economies. Finland was seeking to become more competitive on a global scale, to diversify its economy away from low value-added sectors such as natural resource extraction, and to spur innovation (Kallo, 2009[37]). The country saw its future growth in the then-booming information technology (IT) sector - headed up by the global telecommunications company, Nokia - and other areas where growth would be driven by scientific and technology innovation as well as advanced human capital (OECD, 2017[29])

This view was further informed by the economic recession of the 1990s that highlighted existing structural weaknesses in Finland's economy, such as dependence on fluctuating natural resource prices and a reliance on trade with a small number of neighbouring countries, including the Russian Federation (Välimaa, 2012[38]). The public discourse increasingly focused on the HE sector as a key part of a responsive national strategy, centred around increasing the national research output, improving collaboration with industry and striving for the development of globally recognised institutions (Nokkala, Välimaa and Westerheijden, 2016[39]). Stakeholders interviewed by the OECD team emphasised the significant degree to which these priorities were advanced by many sectors of society, including the HE sector itself, as well as industry and members of parliament from multiple political parties. This form of multi-sector external and internal drive for policy change built considerable momentum and galvanised the government into action.

As these conversations were taking place among stakeholders, the HE sector was going through a process of reform resulting from another external factor: Finland's participation in the Bologna process, the panEuropean initiative to harmonise the structure of HE launched in 1998-99. This was a particularly disruptive process in Finland, which, at the time, did not use the structure promoted through the Bologna process (bachelor's degrees, followed by post-graduate study at master's or doctoral level) across all subject areas (Välimaa, Hoffman and Huusko, 2007[40]). Master's degrees could take up to ten years to complete and were predominantly part-time. Bachelor's degrees also took longer than the three to four-year common international standard. In addition, for employers, a bachelor's degree was seen as a preliminary step towards a master's degree, and rarely recognised as a qualification in its own right, failing to overcome the "barrier to entry" for a career within various industries (OECD, 2009 $\left.9_{[41]}\right)$. Sector stakeholders interviewed by the OECD team confirmed that low labour market acceptance of bachelor's degrees in Finland remains an ongoing area of discussion, and one largely not tackled by reforms to date.

Within Finland, the degree structure was seen as one of a set of impediments to internationalisation. A further concern surrounded the career development structure at HEls. Pre-reform, no Finnish HEls offered tenure tracks with a guaranteed availability of merit-based promotion opportunity to staff; all staff were on public service contracts in which availability of promotions could be dependent on retirements. Multiple HEls now offer some form of tenure track, however Aalto University, the first to move in this direction, has adopted the most robust merit-based approach, as will be discussed. A final area of concern with respect to internationalisation was the fact that degrees themselves took far longer than the international standard (OECD, 2009[41]).

The public debates taking place across wider society and central government led to the commissioning of two key reports that would help to guide new policy and legislation for reform of the HE sector, based on the desired outcomes: improving efficiencies of the sector, increasing national research output, driving industry collaboration and striving for the development of globally recognised institutions. The first of these reports, the Brunila Report, was commissioned by the Office of the Prime Minister and published in 2004. 
It criticised the previous policy of spreading smaller HEls around the country, arguing that "the number of small and regionally spread units were an inefficient use of resources". Instead, more specialisation in the form of "spearhead institutions", and, in particular, a world-class innovation university, were needed (Nokkala, Välimaa and Westerheijden, 2016[39]). The second report, produced internally by the MEDC, similarly criticised the existing policies, and proposed that higher education should be restructured to provide both regional (teaching-oriented universities) and global (research-oriented) universities (Nokkala, Välimaa and Westerheijden, 2016 ${ }_{[39]}$ ). In 2005, the Universities Act was updated to enable universities to enter into consortia, a policy that provided new ways for universities to collaborate and integrate their activities:

The university may have university consortia or other joint units with other universities and joint units with polytechnics, research institutes or other public or private organisations or foundations (Ministry of Education and Culture of Finland, 2009, p. 10[42]], Section 27.3

This change to the legislation in some ways lay the groundwork for the more substantial process of formal mergers that would follow. In practice, the consortia model has been used to develop a series of "university centres" - consortia of universities in six regions across the country that aim to improve the HE offerings to less well-served communities (Vartiainen, 2016[43]). One of the most prominent of these projects has been the University Consortium of Pori, developed by the University of Turku, Aalto University, Tampere University of Technology and University of Tampere, and located in the city of Pori in western Finland (University of Turku, n.d.[44]).

In 2005, the government officially called for large-scale reforms of what was termed the "innovation system", which included the higher education sector and the public research system (which was driven primarily through universities). This call for change came directly from the Prime Minister's Office. The proposed reforms contained provisions for a restructuring of the higher education sector, which would be executed by the MEDC. At this point, there were no legislative changes, but rather, the process began through a series of white papers and direct engagements with the universities and polytechnics.

At the heart of this effort was an overriding policy aim of "creat[ing] a high-quality university system, able to compete internationally at the top level in Finland's specified areas of expertise, while allowing for the development of new emerging research areas and initiatives." Given that the higher education sector was one part of the wider innovation system, the reform process also strived to ensure that "[research] fields that are essential to national economy, development of society and citizen welfare" would be prioritised as part of this effort (Nokkala, Välimaa and Westerheijden, 2016 $\left.{ }_{[39]}\right)$. Key to this was a drive to skill the workforce and publish research that drives innovation and economic growth (Nokkala, Välimaa and Westerheijden, 2016[39]). This approach created, in some sense, an overall industrial strategy that positioned changes in higher education alongside investments in other areas of national R\&D with sectoral investments (particular focus was paid to areas such as electronics and electrotechnology, metal and engineering, and forest industry products) (OECD, 2009[41]).

Alongside the development of these research and policy documents driven by the national government, Finland sought advice from the OECD with respect to the structural and governance reform of the higher education system. The OECD's 2009 report OECD Reviews of Tertiary Education: Finland summarises much of this advice, setting out a series of recommendations across a range of higher education policy areas, including access, the role of research, implications for the global positioning of Finland's higher education sector and quality assurance (OECD, 2009 $[41])$. The OECD recommendations included:

- improving the acceptance rate of HE programme applications by providing students in the secondary system better access to information on course content and requirements

- improving the adequacy and sustainability of tertiary funding through institutional mergers, and the elimination and merging of smaller departments within HEls 
- increasing the autonomy of institutions by redefining them as so-called "legal persons" rather than civil servant units

- reducing study times to get students into the labour market faster

- increasing the international reach of institutions by attracting more international staff and researchers with a reduction in immigration complexity and more attractive roles (including higher salaries and clearer progression) for less senior academics (OECD, 2009 ${ }_{[41]}$ ).

On the recommendation of institutional mergers, the report emphasised that:

This [full merger] model would clearly be possible in Finland, especially in those regions were there was an excess of provision and rather small HEls. However, the macro- and micropolitical backlash could be considerable, and the advantages of such arrangement would need robust demonstration - and there are many advantages. (OECD, 2009, p. 101 [41]).

In some areas, Finland responded to this OECD analysis and its own internal assessment with specific reforms. In other areas, instigating reform options remains an ongoing process.

\section{Policy process: Formulation and adoption}

This section details and examines key mechanisms used to drive the process towards four areas of reform: HEI mergers, HEl specialisation, institutional governance changes for universities, and parallel reforms for UAS, which took place between approximately 2004 to 2010 . The ordering of these processes is important. The approach of the Finnish government was to first incentivise the completion of the mergers, then follow with additional governance reform for the newly created and reduced number of universities (formalised in the Universities Act, 2009), as well as simultaneously promoting the specialisation of the institutions through funding.

\section{HEI mergers}

MEDC chose to drive this process through an approach that did not directly enforce specific HEI mergers, but rather created new incentives and mechanisms for change, and funding allocation. Fundamentally, the aim was to ensure that the institutions themselves collaborated and drove the mergers, creating buy-in and a level of institutional autonomy in the process. The key mechanisms that enabled this were:

- The 2006 MEDC discussion paper mentioned earlier on the structural development of higher education, which provided overall guidelines for the mergers.

- A fixed-term law that enabled Finnish citizens and companies to receive tax reductions for donating money to universities, thereby incentivising private financial contributions to the mergers taking place in a timely manner (equally important was the matching of these funds by the government, creating further incentives for universities to raise private investment).

- An invitation for universities to suggest structural changes (mergers); the initiation was open for proposals from spring through summer 2006. Universities that proposed mergers would have additional funding reflected in their budget from the year 2007.

- Additional funding for the years 2007-10 for institutions that had proposed mergers to MEDC was set at EUR 12-14 million. If the proposed mergers did not ultimately proceed, this was reduced to EUR 6.1 million (Williams, 2017[45]).

- Planning groups were appointed by the MEDC once a merger was officially agreed. These groups included prominent societal figures and sectoral experts, and were used to guide and support the merger process at each institution (Williams, 2017 $[45]$ ).

- Finally, the progress of adoption and pace of change was ensured through institutions' existing funding agreements with the ministry that are reviewed every four years, and approved through cyclical negotiation procedures, outlined above (Nokkala, Välimaa and Westerheijden, 2016[39]). 
The outcomes of this process are clear in the current landscape of higher education in Finland. Exceeding the goal of reducing the system to 15 universities, today Finland has 14 universities as a result of the reform process. Mergers of Finnish universities have included:

- The University of Kuopio and the University of Joensuu merged to create the University of Eastern Finland (merged in 2010, received EUR 12.6 million in merger funding).

- Helsinki University of Technology, Helsinki School of Economics and the University of Art and Design Helsinki merged to create Aalto University (merged in 2010, received EUR 13.9 million in merger funding, plus substantial additional funds outlined below).

- The University of Tampere, Tampere University of Technology and Tampere University of Applied Sciences (a UAS rather than a university) merged to create Tampere Universities (merged in 2019, received EUR 6.1 million in merger funding during the initial process in 2007 as this initial merger attempt did not move forward).

- University of Turku and Turku School of Economics and Business Administration merged to create University of Turku (merged in 2010, received EUR 13.4 million in merger funding).

- Academy of Fine Arts, Sibelius Academy and Theatre Academy merged to create University of the Arts (merged in 2013) (Nokkala, Välimaa and Westerheijden, 2016[39]).

The Universities Act, 2009 named all the newly merged institutions by that time, and legally recognised the universities as corporations under public law (public universities). In addition to this, Aalto University and Tampere University of Technology were further defined as foundation universities (these universities are legally non-profit foundations rather than public corporations), and are governed by the Foundations Act, which was amended in 2015 to recognise these institutions. Aalto University, seen by the government as a flagship institution - with aims of being the "world-class innovation university" envisioned by the Brunila Report, received significant additional public funding. Funding of EUR 100 million had been allocated to the merger until the end of 2015. Furthermore, the government's commitment to match raised private funds for the university's capital endowment meant that in practice, public funding to Aalto University exceeded this, and reached a total of EUR 500 million (Williams, 2017[45]).

The use of the mechanisms and policy approaches detailed above are credited with much of the success of the merger process, however the importance of the timing of this process should also be noted. A considerable amount of the policy and programmatic work, including instigating many of the mergers and drafting of legislation, took place just before the 2008 financial crisis. It was noted in stakeholder interviews that the mergers had required significant investment (outlined above) from government, and in the case of the foundation universities, large private financial contributions for capital endowments (matched by government and supported by tax relief). Had this process been attempted later, it may not have been possible, due to the significant recession experienced in Finland from 2008, which later resulted in reductions in higher education expenditure. Stakeholders interviewed by the OECD team suggested that these funding cuts were less impactful for foundation universities (and other merged institutions), as they had been incentivised to diversify their funding model (it was also noted that budget cuts had been felt most keenly by non-faculty staff at universities who had borne the brunt of staffing cuts).

It is important to note that not all of the HEI mergers followed the same process or had the same reasoning behind their execution, and the path to merged institutions has often featured considerable complexity, and at times, opposition from various stakeholders. Some mergers were geared toward providing a consolidated higher education offering to their region, with increased institutional efficiencies and financial stability (e.g. University of Eastern Finland), while other merger projects sought to represent Finland's international and R\&D ambitions for the higher education sector (e.g. Aalto University, further profiled below).

While the government's planning groups did provide some consistency to the approach, fundamentally it was the institutions that made the initial proposals for mergers and engaged in early discussions. As a 
result, while it would be a requirement that senior management and rectors bought in on the merger process (as the actors suggesting the merger to the ministry), the degree to which staff and faculty were engaged in the process differed in each case. As noted by Williams $\left(2017\right.$, p. $\left.79_{[45]}\right)$ :

Rectors of merging institutions generally bought in strongly. However decision-making processes largely excluded students and staff as presumably critical, at least until mergers were well under way, although institutional-level planning groups consulted students and staff in at least one case.

Whereas the creation of Aalto University (further discussed below in Box A A.3) was executed in response to national policy imperatives, the movement toward creation of Tampere Universities was more locally driven. The merger was initially planned as part of the first round of applications in 2007, however, the process did not advance at that time. In 2014, renewed interest and plans for a merger were announced by the three component institutions, with the MEDC appointing working, steering and management groups to support the merger in 2015. In 2016, the universities requested EUR 200 million in funding from MEDC for the merger, referencing the support that Aalto University received. The final merger funding approved by the ministry, however, stood at EUR 22 million (Keskinen, 2016 [46]).

The process, which was completed in 2019 , took place in two steps. First was the merger of the two universities, University of Tampere and Tampere University of Technology (driven from the then-leadership of the two universities and involving rounds of contentious internal consultation with staff and faculty, many of whom were committed to the existing separate institutions and their governance structures). This was followed by the creation of a university consortium, which allowed the new university to own the majority of stock in the Tampere University of Applied Sciences (divided stock-based ownership of UAS is further discussed below). This process allowed for a form of merger between two universities and a UAS. This approach was in part a response to historical concerns about merging institutions from the respective sides of the binary HE system (Williams, 2017[45]). In addition, it has been noted that the merging of the multiple and distinct HEls has caused ongoing challenges, both during the protracted merger process (Myklebust, $\left.2019_{[47]}\right)$, and since completion, where it has been noted that the institution has struggled in developing a strong university identity, as inter-disciplinary divisions remain (Vellamo et al., 2020[48]).

\section{University specialisation}

Beginning in parallel, and continuing through the merger process, MEDC sought to push institutions to specialise in specific research areas and subjects, becoming "centres of excellence" (Nokkala, Välimaa and Westerheijden, 2016[39]). The main methods proposed to deliver these outcomes outlined in the same 2006 MEDC discussion paper consisted of:

- institutional co-operation and mergers between universities, the aim of which was to increase the performance of individual institutions, both in terms of global recognition and research output

- allocation of government funding and resources that HEls would receive as a result of specialisation efforts (indicated in Table A A.4 as "strategic development")

- pushing for further reform of governance and leadership, which would drive a more focused and managerial approach, allowing institutions to execute specific strategies on research output and the development of sectoral expertise (Nokkala, Välimaa and Westerheijden, 2016[39]).

A further tool to facilitate specialisation and "centres of excellence" has been the creation of foundation universities. These two universities (Aalto University and Tampere Universities) operate similarly to nonfoundation, public universities. Stakeholders interviewed by the OECD team confirmed that in practical day-to-day management, there is little difference. However, in terms of their governance, foundation universities differ in that their board is made up entirely of members external to the university itself, representing the wider civic and business community. As highlighted in the description of the merger process, foundation universities can form a capital endowment (a policy later expanded to all universities) and also have improved financial independence. The outcome of these governance and fiscal differences is that foundation universities have been more successful in raising private funds (initially matched by the 
government), and as a result have larger endowments than non-foundation institutions (the value of Aalto's endowment stood at EUR 983 million in 2019) (Aalto University, 2020[49]). The foundation universities are two of the largest universities (2016 student enrolment was around 18000 for Aalto and 13000 for Tampere (ETER, 2021 $\left.{ }_{[18]}\right)$ ), and are prioritised by MEDC in seeking global recognition and as centres of collaborative international research.

Increasing differentiation was also an element of the Development Plan for Education and Research 2007-12 (the five-year strategy document that was in place during the reform period), which covers all UAS, foundation and public universities. The plan detailed a strategy for education specialisation and differentiation, linked again to an overarching innovation strategy and areas of economic sector prioritisation. Some universities would, for instance, specialise as international research universities and each university and polytechnic is expected to have a unique "profile" of teaching, research and industry alignment (Nokkala, Välimaa and Westerheijden, 2016[39]). The "strategic" sub-streams within the funding allocation model outlined in Table A A.4 have been used as a lever for advancing enhanced specialisation.

However, these initial approaches failed to deliver the expected specialisation outcomes. The ministry recognised in the mid-2010s that "the current performance-based funding model for universities in itself ... does not provide very strong incentive to making strategic profiling choices" (OECD, 2017, p. 92[29]). In response, it set aside an additional funding allocation to incentivise specialisation valued at EUR 50 million, to be administered between 2015 and 2019. This represented a moderate increase for recipient institutions. The core differentiation compared to previous funding through the allocation model was that decisions on which institutions would receive funding were assigned to the Academy of Finland to deliver outside the standard funding formula with an approach that rewarded HEls that developed clearer "research profiles" (OECD, 2017 [29]). As of 2020, five rounds of funding had been delivered from the initial 2015-19 fund, and the sixth was in process. Stakeholders felt that the fund had seen moderate success in shifting the research fields and disciplines of focus in a number of universities, with the majority of funding directed towards the hiring of principle investigators (PIs) and professors in emerging fields of research.

\section{Box A A.3. Aalto University, tenure as a mechanism for increasing internationalisation}

Aalto University is a public foundation university located in Espoo, Finland. It was established in 2010 through the merger of three existing institutions: Helsinki University of Technology, Helsinki School of Economics and the University of Art and Design Helsinki. Aalto University was one of the first mergers proposed following the release of the Brunila Report in 2004.

The merger was first suggested by the rector of the University of Art and Design Helsinki, in his opening speech of the 2005 academic year. This speech came a year after the Brunila Report, at a time when the public discourse among universities, industry and government focused on potential institutional mergers across Finland. The creation of an "innovation university" in Finland was committed in the programme of the 2007 government coalition. A more formal plan for the merger of the three institutions and the creation of the new university was developed in response and was formally presented in 2007. The plan was developed by a working group that included the constituent institutions and community stakeholders, with an overall lead by the then Secretary of State for Finance. This merger was finalised in late 2009, and the university began operation on 1 January 2010.

The core idea behind the establishment of Aalto University was to create a new kind of multi-disciplinary university, with a fundamentally international outlook. Aalto has focused on developing crossdisciplinary areas of expertise that leveraged the knowledge and talent base of its three component institutions. Aalto drove its international focus by introducing a number of policies that were relatively rare in the Finnish university system: delivering both bachelor's and master's courses in English, 
providing a merit-based tenure track to increase international staff appointments, and engaging heavily with industry to support international research partnerships.

Notable success has been achieved. In 2019, the university ranked 9th in the world by QS World University Rankings among universities founded less than 50 years ago and 20th in the Times Higher Education Young University Rankings in the same year. The introduction of the tenure track has been a particularly effective mechanism for increasing the proportion of international staff: $38 \%$ of Aalto's academic faculty are international appointments as of 2019 , an $111 \%$ increase over the $18 \%$ of international staff the university began with in 2010. Aalto University has adopted a four-stage tenure track process, with time allocations and progression from fixed to permanent status detailed in Table A A.5.

\section{Table A A.5. Aalto University tenure track time allocations}

\begin{tabular}{l|r|r|r|r|r}
\hline Time allocation & $\begin{array}{r}\text { Assistant professor } \\
(1)(f)\end{array}$ & $\begin{array}{r}\text { Assistant professor } \\
(2)(f)\end{array}$ & $\begin{array}{r}\text { Associate } \\
\text { professor (p) }\end{array}$ & Full professor (p) & $\begin{array}{c}\text { Aalto distinguished } \\
\text { professor (p) }\end{array}$ \\
\hline Research/artisticl & $65 \%$ & $60 \%$ & $50 \%$ & $40 \%$ & Negotiable \\
professional work & $+/-10 \%$ & $+/-10 \%$ & $+/-10 \%$ & $+/-15 \%$ & $30 \%$ \\
\hline Teaching & $30 \%$ & $30 \%$ & $30 \%$ & $30 \%$ & $+/-15 \%$ \\
\hline Service & $+/-10 \%$ & $+/-10 \%$ & $+/-10 \%$ & $+/-15 \%$ & Negotiable \\
\hline
\end{tabular}

Note: $(f)$ refers to a fixed-contract position; $(p)$ refers to a permanent position.

As the table above highlights, Aalto's tenure track offers variable flexibility in the proportion of time devoted to the various duties of academic staff, and this increases across the stages, culminating in the distinguished professor position, which allows for negotiation in the proportion of research and service duties. Advancement is based on evaluation criteria. Each stage also comes with commensurate salary increases (in line with national levels), and from assistant professor to associate professor, a transition to permanent status. Despite its success at Aalto, merit-based progression within a tenure track remains a controversial topic in the broader HE system and among Finnish university staff. While many other HEls now offer some form of tenure, the clarity of progression and equal opportunities is not always present. In some cases, more junior academics may have to wait for an existing tenured staff member to leave and "open up" the tenured position. In Aalto, anyone may qualify for tenure if they demonstrate the required competencies.

Stakeholders interviewed by the OECD team relayed that concerns within the broader HE system include that increasing salaries could be unaffordable to universities, that tenure tracks can create a competitive environment that is undesirable, and a perspective that universities should focus on hiring more local, rather than international, talent.

Sources: Aalto University (2019[50]), Aalto Tenure Track, https://www.aalto.fi/sites/g/files/flghsv161/files/201909/aalto_tenure_track_policies_and_procedures_eng_20190307.pdf; Tuulos (2017[51]), An experimental learning platform to foster university-industry collaboration, https://www.itu.int/en//TU-D/Capacity-Building/Documents/TU-Academia Partnership Meeting 2017/Presentations/Session 4/3TiinaTuulos.pdf; University of Helsinki (2020[52]), A tailored career path, https://www.helsinki.fi/en/university/careers-at-the-university-of-helsinki/tenure-track/a-tailored-career-path.

\section{Institutional governance changes for universities}

The Universities Act, 2009, also established additional provisions regarding institutional autonomy that built upon steps to expand autonomy in the late 1990s. The updated act refreshed the governance structure and increased autonomy for all universities. Under Chapter 1, Section 3 of the act: 
Universities have autonomy, through which they safeguard scientific, artistic and higher education freedom. The autonomy entails the right of universities to make their own decisions in matters related to their internal administration. When legislation is drafted concerning them, the universities shall be given the opportunity to express their opinion on the matter (Ministry of Education and Culture of Finland, 2009[42]).

The act also set out a new structure for the governance bodies of the universities, including the university collegium, the board and the rector (in foundation universities, these are the multi-member administrative body, the board and president, respectively). The overall effect of institutional governance changes made through the 2009 act was to reduce the size of governance bodies, increase external participation and streamline leadership selection. As a result, individual rectors and deans have been significantly empowered relative to the past system.

Prior to the Universities Act (2009), universities were not distinct legal entities, but were organisations under the management and provision of the public sector, specifically the MEDC. A process of increasing autonomy for universities was an ongoing policy project that met its first milestone with the passing of the Universities Act, 1997. Alongside changes to the governance structure of universities, the 1997 act allowed universities to decide upon the division of the university into faculties or other units, appoint professors, and accept donated funds and establish a university fund separate from the state. The updated Universities Act (2009) built upon these steps with greater involvement from external bodies (particularly for foundation universities), a clearer delineation of power-sharing between the different communities of the university and noted streamlining of governance. Table A A.6 (also included in the main report as Table 3.7) highlights how these changes were applied across the different levels of university governance.

\section{Table A A.6. University governance bodies pre- and post-Universities Act, 2009}

\begin{tabular}{|c|c|}
\hline Pre-Universities Act (Universities Act, 1997) & Post-Universities Act, 2009 \\
\hline $\begin{array}{l}\text { University Senate: The size is determined by the standing orders of the } \\
\text { university, but must contain representatives from the faculty, other } \\
\text { teaching and research staff and the student body. The senate is the } \\
\text { supreme executive body of the university. The senate is presided over } \\
\text { by the rector. }\end{array}$ & $\begin{array}{l}\text { University Board: } 7 \text { members for foundation universities, and } 7 \text { or } \\
9-14 \text { members for public universities. Boards in foundation universities } \\
\text { are elected by the multi-member administrative body. In public } \\
\text { universities, the board is selected by a combination of university } \\
\text { community groups and the university collegium. Foundation universities } \\
\text { have a board whose members are } 100 \% \text { external to the university. Public } \\
\text { university boards are } 40 \% \text { external (the remaining } 60 \% \text { of members are } \\
\text { a combination of representatives from the faculty, other teaching and } \\
\text { research staff and the student body). }\end{array}$ \\
\hline $\begin{array}{l}\text { Multi-member administrative bodies represent the individual faculties. } \\
\text { The senate decides the division of faculties and other departments. }\end{array}$ & Multi-member administrative bodies represent the individual faculties. \\
\hline $\begin{array}{l}\text { Universities may have a chancellor if they wish, with their tasks laid out } \\
\text { in university acts and decrees. }\end{array}$ & $\begin{array}{l}\text { Universities may have a chancellor if they wish; their tasks are laid out in } \\
\text { university acts and decrees. }\end{array}$ \\
\hline $\begin{array}{l}\text { Rector selected by the university electoral college; universities may have } \\
\text { one or more vice-rectors, decided by the university senate. }\end{array}$ & $\begin{array}{l}\text { Rector selected by the board in both foundation and public universities. } \\
\text { Foundation universities may replace the rector with the position of } \\
\text { president. }\end{array}$ \\
\hline $\begin{array}{l}\text { The electoral college must be composed of representatives of the } \\
\text { professors, teaching and research staff, other personnel and students. } \\
\text { Provisions pertaining to the membership and election of the electoral } \\
\text { college is laid out in the university's standing orders. }\end{array}$ & $\begin{array}{l}\text { For public universities, the university collegium consists of } 50 \text { members } \\
\text { representing both the faculty, other teaching and research staff and the } \\
\text { student body - no one group may represent more than half the total. } \\
\text { Foundation universities have a joint multi-member administrative body } \\
\text { with a maximum of } 50 \text { members, representing both the faculty, other } \\
\text { teaching and research staff and the student body - no one group may } \\
\text { represent more than half the total. }\end{array}$ \\
\hline $\begin{array}{l}\text { Faculties are directed by a dean or other director along with collegial } \\
\text { governance practices. }\end{array}$ & $\begin{array}{l}\text { A faculty or corresponding unit has a multi-member administrative body } \\
\text { chaired by the director of the unit. The administrative body must include } \\
\text { representation from university community groups. }\end{array}$ \\
\hline
\end{tabular}

Sources: Ministry of Education and Culture of Finland (1997 $\left.7_{[53])}\right)$, Universities Act 645/199, https://finlex.fi/fi/laki/kaannokset/1997/en19970645_20061453.pdf; Ministry of Education and Culture of Finland (2009[42]), Universities Act 558/2009, https://www.finlex.fi/en/laki/kaannokset/2009/en20090558.pdf. 
These structural changes to Finnish universities represented one-half of the higher education sector reform. The polytechnic institutions, which represent the other half of Finland's binary higher education sector, also underwent their own corresponding reform beginning in 2011. Similar to the reform process for the universities, the MEDC began with a series of discussion papers and external stakeholder engagement. This led to a proposed new act that was circulated for stakeholder feedback in 2013 (ReferNet Finland, 2014[54]) which resulted in the passing of the Universities of Applied Sciences Act (2014). The act re-defined the polytechnics as Universities of Applied Sciences (UAS), and adapted their purpose and remit in Chapter 1, Section 4:

The mission of universities of applied sciences is to provide higher education for professional expert jobs based on the requirements of working life and its development and on the premises of academic research and academic and artistic education and to support the professional growth of students. They shall also carry out applied research, development and innovation activities and artistic activities that serve education in universities of applied sciences, promote industry, business and regional development and regenerate the industrial structure of the region. In carrying out their mission, universities of applied sciences shall promote lifelong learning. (Ministry of Education and Culture of Finland, 2014[55])

The act also defined a new, more streamlined, governance structure which includes a board (which must have representation from the teaching staff and students) and responsibility for the overall running of the institutions assigned to the rector. In a point of differentiation from universities, UAS are defined as private limited companies and ownership is commonly divided between municipalities, regions and the private sector (OECD, 2017[29]). UAS have an explicit responsibility to provide education and training opportunities to their local market - as such, they are a common thread maintained throughout the higher education reform that ensures that elements of the "local provision" model of higher education are maintained. Despite the quasi-private ownership of UAS, they still receive the vast majority of funding from central government through MEDC, estimated at around 88\% of total income (OECD, 2017 [29]).

The funding formula for UAS (see Table A A.4 for full details) determining funds delivered by MEDC also reinforces the notion that UAS are primary teaching establishments with a focus on supporting regional labour markets. As noted, much like the universities, funding is also heavily tied to performance outcomes (OECD, 2017[29]).

\section{Policy process: Implementation and outcomes}

Given the relatively recent timeline, and rapid execution of higher education reform in Finland, capacity for long-term analysis of impact and success measured against the policy aims of the government is somewhat limited. However, there have been a number of reports that have sought to examine the efficacy of the reform process, potential unintended consequences, and its effects on the actors involved. Figure A A.2 presents illustrative goals, outputs and outcome indicators for reforms advanced through the reforms.

The European Commission's 2016 review of the structural reform of the Finnish higher education system summarised the status of reform implementation regarding both operational shifts and its effectiveness in achieving desired outcomes (increased international recognition of Finnish HEls, a streamlining of the higher education system, and an increased role of universities in the research and economic development ambitions of the country) (Nokkala, Välimaa and Westerheijden, 2016[39]). The review argued that the operational goals of the structural reform have been achieved, though some of the wider outcomes (such as large-scale increases in institutional specialisation, and a wider increase to the international rankings of institutions) remain areas for ongoing policy adaptation and improvement. 
Figure A A.2. Illustrative goals, outputs and outcomes of the HEl network rationalisation reform in Finland
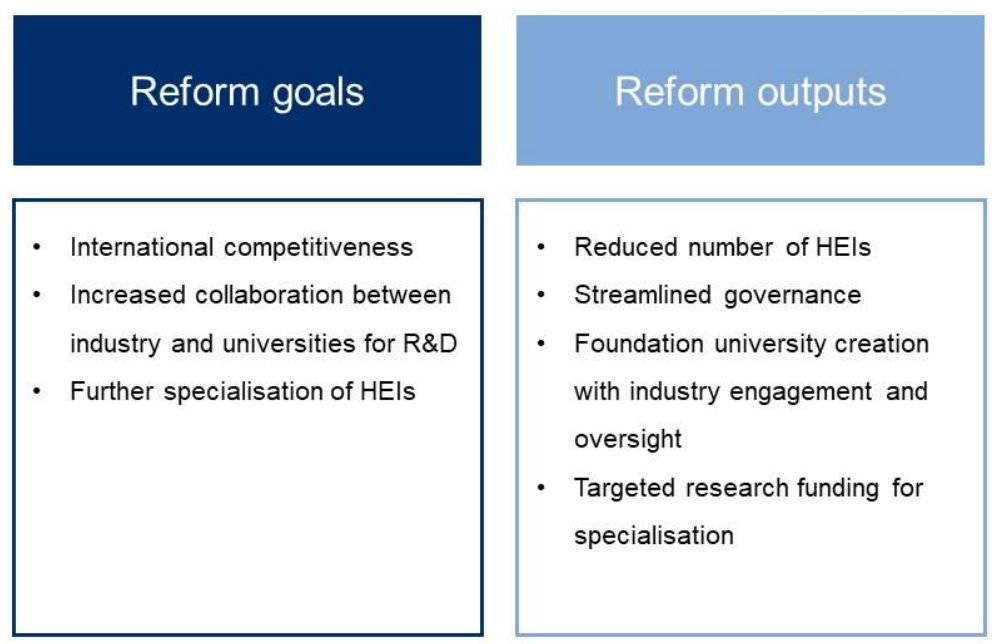

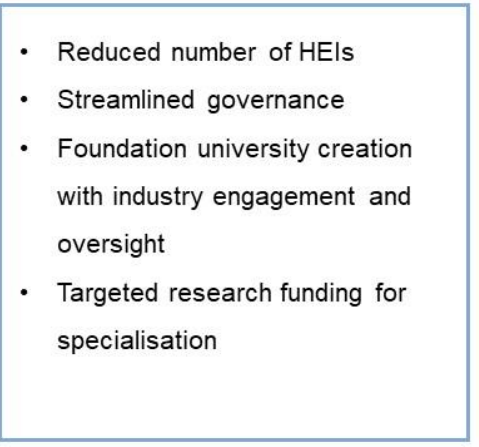

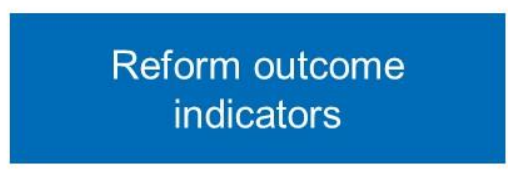

- HEls' international rankings; growth of international students; growth of international faculty

- Specialisation; number of collaborations with industry; level of private funding for HEls

- Increased research impact

\section{Institutional mergers}

The aim of streamlining the HE sector through a series of institutional mergers and restructuring has undoubtedly been successful. The initial aim of the reform policy was to reduce the number of HEls in

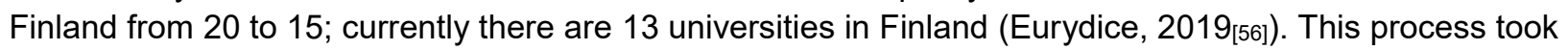
place with relative speed and without significant issues, a result which can in part be attributed to the softer, institution-driven approach taken by the MEDC, backed by investments to smooth transitions and manage change, as opposed to top-down legislative action.

The achievement of wider aims of increasing the international competitiveness of Finnish HEls is less clear. A key goal of reform in Finland held by government actors has been to achieve higher standing in international rankings. Depending on the ranking institution (Shanghai and Times Higher Education) and the HEls, institutions have both risen and fallen in rankings over the reform period, which can be defined as taking place between 2004 and 2010 (although it can be argued that due to the continued shifts to funding and other areas, the reform period remains ongoing). The University of Helsinki, for example - Finland's highest ranking university and which did not undergo a merger process - has seen modest declines in its ranking overall. Aalto University, by comparison, began far lower in rankings but, as noted in the case study, has seen more success when compared with other young institutions (Nokkala, Välimaa and Westerheijden, 2016[39]).

When it comes to some of the more nuanced areas of reform specific to certain institutions, such as the foundation universities, there are other points of success. For example, one of the major objectives in the Aalto merger was to create a university that would adopt organisational practices resembling HEI traditions found in English-speaking countries, with the aim of increasing international attractiveness to students and staff. Aalto University was the first Finnish university to adopt the tenure track practice of progressive, merit-based promotion as the sole recruitment procedure for entering professorial positions. This has been strongly linked to the significant increases in international staffing at the university (Nokkala, Välimaa and Westerheijden, 2016[39]).

\section{Institutional specialisation}

When it comes to higher education specialisation and differentiation, success has been difficult to achieve across the entire sector. According to the European Commission's analysis: 
The main problem for effective profiling is that universities tend to imitate successful universities rather than seek a strategy or niche different from others. Additionally, in research terms, "unproductive disciplines" (at least as they are measured by the global league tables) are often needed to complete the teaching provision of universities (Nokkala, Välimaa and Westerheijden, 2016[39]).

HEls striving for comprehensive status, in addition to incentives to maintain a wide programme range to serve students, has challenged specialisation executed through programme or faculty reductions. To the degree that specialisation has been achieved, it has been more through the delivery of increased research funding and through a joining of forces through mergers. As highlighted above, slower than anticipated movement toward specialisation is a weakness that has been recognised by the MEDC, and is an area of focus for ongoing policy adaptation, with the inclusion of new measures (including increased funding opportunities) to encourage institutions to engage in the process. Evidence also suggests that specialisation has been more successful in the case of universities such as Aalto, which has sought to leverage the specific structure that the mergers created - faculties from previously disparate institutions have been supported to explore potential for new inter-disciplinary research and expertise.

Specialisation is also strongly linked to R\&D developments, including increased partnerships with industry in Finland, and the internationalisation of the research sector. Analysis by the OECD in 2017 found that when it comes to positioning universities as key actors within a broader industrial strategy, driving research and international co-operation, Finland has seen mixed success. Using a measure of research internationalisation, Finland has seen notable improvements, but it still lags other Nordic countries:

In regard to international co-operation in research as reflected in the number of international co-publications, Finland has been improving significantly, moving from $42.2 \%$ of publications (involving co-authors located in a foreign country in total publications) in 2003 to $52.3 \%$ in 2012, which is above the OECD average. Yet most $O E C D$ countries, including the Nordic ones, have also increased this ratio significantly over the years (e.g. Demark from $47 \%$ to $55 \%$ and Sweden from $45 \%$ to 56\%) (OECD, 2017, p. 81 [29])

Turning to national collaboration with industry, outcomes are less positive. The same OECD report, OECD Reviews of Innovation Policy: Finland, found that industry financed higher education research and development had seen significant decline in the years of the core reform period and beyond: between 2008 and 2015, a funding drop from EUR 81 million to EUR 56 million was observed (OECD, 2017 [29]). It should be noted that the post-2008 recession may have played a significant factor here. The report also highlighted stakeholder concerns that current strategic funding models did not provide the levers needed for government to more directly influence specialisation, and that while mergers had been successful in reducing the number of overall universities, there remains an issue of large numbers of small departments within universities and a lack of institutional focus: in 2016, more than one-third of university disciplines employed three professors or less (OECD, 2017[29]).

Foundation universities have also seen more success in developing partnerships, facilitated by their increased fiscal autonomy. In 2016, the universities of Aalto and Tampere received $45 \%$ of total funding from domestic companies (OECD, 2017[29]).

\section{Institutional governance reform}

Perhaps the most contentious area of reform can be found in the area of HEl governance reform and the increased role for institutional managers. There have been a variety of still-unfolding effects viewed as positive and negative by system actors. According to one recent analysis of the reform, "Finnish universities are undergoing a major cultural change due to university reform; whose wider impacts remain to be seen" (Kohtamäki and Balbachevsk, 2018[57]). In a more critical review undertaken by the Finnish Department of Education in 2015, researchers reported that:

The new emphasis given to research management [created] a division between teaching and research activities. After the reform, university staff (both academic and administrative) had fewer opportunities to take part in decision making. Decision making is concentrated in the hands of individual managers (the rector and 
deans as the most powerful actors), who are dominating because the composition of new governing boards has changed radically. From the perspective of staff members, there are informal ways to influence the new governance structures (MEDC, 2015[58]).

A 2016 external evaluation commissioned by MEDC interviewed a number of academic staff across universities on their views of the management reform. It highlighted dissatisfaction felt by a significant proportion of the staff regarding university strategic decision making, and a sense of alienation from the institutions they worked, finding that "...changes have been heavily criticised by many university employees as severely undermining the collegiate's role and influence in decision making." The reforms, combined with significant budget cuts, have, according to the evaluation, led to a sense of alienation and dissatisfaction among a significant proportion of university staff (Owal Group, 2016[59]).

Overall, the $\mathrm{HEl}$ institutional network rationalisation process and related policy reforms can be seen as a success for Finland. This is true for outputs, even if achieving all desired outcomes may continue to require additional policy iteration. A clear reduction in university numbers, expanded autonomy and governance restructuring have been achieved, while ambitions for Finland's international presence and creating centres of public private niche innovation remain longer-term goals. At the core of this success has been ministry engagement and financial support, and a lengthy process of stakeholder engagement and buy-in for sector reform (although the institution-led merger process certainly did not always result in bringing all HEI community partners on side for change). Still, relevant actors in the system drove the process, particularly with respect to mergers, with guidance and support from government. The challenges that the process has faced, and that remain to some degree (e.g. contention regarding HEI governance), can be understood in light of the long-standing traditions of universities. Change, even with substantial stakeholder engagement and autonomy in decision making, requires considerable time, planning and ongoing adaptation to address issues as they arise.

\section{Conclusions and relevance to higher education in the Slovak Republic}

Having explored key factors involved in higher education reform efforts in Portugal and Finland, and the outcomes such as they are currently measurable, this concluding section explores lessons learned from the case studies relevant to the Slovak Republic's higher education system, first considering similarities and differences across specific dimensions of the cases - HEl governance reform in Portugal and HEI network rationalisation in Finland - followed by country-specific learnings from each.

\section{Top-down and bottom-up approaches to institutional reform}

\section{Institutional change is a difficult, long-term effort that benefits greatly from effective engagement} of relevant actors within both the HE system and in the sphere of national-level governance.

One of the more significant deviations between Finland and Portugal can be seen in the approach to reform development and implementation. At the HE system level, Finland sought the use of more bottom-up engagement and incentivising methods compared to a more top-down approach to system change seen in Portugal. At the level of national governance, Finland's reform process followed a broad-base societal dialogue on the future of the higher education system involving industry, the media and government, with a focus on the system's role in the wider economic development landscape. In Portugal, changes were driven centrally by government in the face of significant opposition.

Through a series of non-legislative white papers that provided guidance and parameters for institutional mergers, and ongoing dialogue with HEls, Finland guided a more autonomous process. HEls worked with one another to agree to the process of mergers. The outcome of this approach was a rapid execution (over approximately five years) of the initial merger process, which met and even exceeded its quantitative targets, though not without bumps on the road, which could be expected. The government intended to 
reduce the number of HEls from 20 to 15, and as of 2019 there were 13 universities in Finland. After the initial series of mergers, the Universities Act (2009) confirmed the revised institutional network in law, while also introducing governance change for all institutions, including those now designated as foundations. The reform process in Finland extended beyond parliamentary cycles, with stakeholders citing broadbased buy-in for the overall process as supportive of continuity (despite ongoing debate, particularly with respect to $\mathrm{HEI}$ governance matters).

By comparison, Portugal undertook a process of governance reform through legislative action, without a significant period of stakeholder engagement. Governance changes for all HEls and the foundation status framework were laid out in RJIES in 2007, with institutions then freed to act to pursue the new foundation status. However, guidelines for attaining the status soon shifted to more stringent requirements and benefits more restricted due to deep financial challenges facing Portugal in the 2011-14 Economic Adjustment Programme period, and beyond. This greater difficulty in accessing foundation status and lesser utility of it layered on top of low initial buy-in to the concept and the broader reform agenda. While some HEls have adopted foundation status and made use of its relatively limited benefits, opposition from national governance actors and some HE system actors has stretched beyond the moment of legislative adoption in 2007. At present, this opposition has contributed to difficulty opening discussions about the possibility of adopting foundation status within some HEls and stands as a barrier to undertaking an improvement-oriented evaluation of the RJIES regime at a national level.

\section{Incentivising institutional reform}

\section{Providing incentives and support for institutional change can be more effective than policy imposition. Maintaining a clear value proposition for HEls to undertake change is key.}

The overall approaches in Finland and Portugal also differed in the incentives offered to institutions and relevant actors. In Finland, financial incentives have been a key lever for driving change. These have taken multiple forms, from the tax incentives for donations to HEls, donation matching by government, through to adaptations of funding calculations from the MEDC, and most recently a new delivery mechanism for research funding aimed at increasing institutional specialisation. However, increasing institutional research specialisation has been a challenge for Finland, as evidenced by consistent "tinkering" with funding allocation models, with greater success achieved in incentivising mergers compared to achieving policy goals for greater institutional specialisation. Where specialisation has seen incremental success, the approach has been to drive areas of expertise with funding for research staff, creating an environment where the universities see value in increasing their focus in certain areas, as opposed to significant reallocation of resources between university units.

In Portugal, incentives to attain foundation status were not well understood by the sector at the outset and the initial promise of foundation status was undermined to an extent by the application of qualification criteria that were more stringent than the law (RJIES) initially envisioned and simultaneously, the roll out of benefits of autonomy for institutions were less than initially envisioned. The Ministry of Finance's requirement that $50 \%$ of institutional revenues must be from private sources in order to qualify posed an impediment to qualification for some institutions, while the cancellation of planned financial transfers to new foundation status universities as a result of the 2011-14 Economic Adjustment Programme, among a variety of re-imposed financial controls, reduced its benefits. With the benefits of foundation status reduced and the path to its attainment made more challenging and non-transparent, take-up was constrained. An unclear value proposition reduced take-up.

\section{Regional dimensions}

Higher education system changes can play out differently across regions depending on urban versus rural character, industrial density and local capacity. 
Institutional merger initiatives and HEI governance changes can have varying effects across regions. The merger of HEls within a single city does not have the same implications as a merger across a wider region. $\mathrm{HEI}$ governance changes that introduce the participation of external partners, including employers, on governance bodies can result in different outcomes in urban and industrialised areas compared to more rural areas.

Stakeholders interviewed by the OECD team reported that the creation of the University of Eastern Finland through the merger of the University of Joensuu and the University of Kuopio led to local issues regarding proposed changes to programme availability in some communities, which also had implications for local economies, given the broader range of businesses and economic activity that are supported by students and faculty. These are not prominent issues in the case of other mergers that have taken place within more metropolitan contexts, such as those leading to development of the Aalto University and the University of Tampere.

In Portugal, stakeholders interviewed by the OECD team reported that the inclusion of external members in university governance bodies has in some cases proceeded differently across institutions, with some of these differences having a regional character. HEls located in regions with strong employer bases, particularly of employers for whom HEl-driven innovation and human capital development are key concerns, have seen more effective involvement. In some cases, HEls in more rural regions with fewer employers with business links to them have seen less effective involvement.

\section{Influence of disruptive forces: 2008 financial crisis and the COVID-19 pandemic}

External events, like a financial crisis or pandemic, can upend planned system transformations and the levers or incentives that governments may have planned in order to achieve desired outcomes.

The 2008 financial crisis had a profound impact on HEl governance reform in Portugal. As a result of economic contraction and the 2011-14 Economic Adjustment Programme, public spending was reigned in and notable changes were made to the reform approach. HEls saw significant funding decreases and the introduction of multi-year salary controls on public servant staff at both foundation and non-foundation status universities, alongside a contraction in the level of autonomy provided to institutions. This in effect reversed the incentives that were intended to be offered to institutions by foundation status, which were again absorbed into the state perimeter (a situation that persists). Budgetary constraints have had a longlasting effect on HEls and arguably on the speed of adoption of foundation status.

Following the 2008 financial crisis, austerity measures had a disruptive impact on the public sector across many EU states, particularly those in receipt of adjustment programmes, such as Portugal. Due to the timelines involved, Finland's reform process was largely unaffected by the 2008 financial crisis, with the first phase of mergers and reforms largely completed before impacts had fully unfolded.

At present, the international response to the coronavirus (COVID-19) pandemic appears to be different than in the post-2008 period, with recovery funds being made available to respond to economic turmoil. It appears, at present, less likely that wide-scale reductions in public expenditure could imperil HE system reforms. On the contrary, recovery funds could potentially play a role in the crucial function of incentivising change.

\section{Timelines for measuring success}

Assessing the effectiveness of change within complex systems with multiple actors, pressures and priorities requires a long horizon. A robust, broad-ranging evaluation approach should include a variety of factors, considering impacted actors and desired outcomes. 
In both Finland and Portugal, several direct outcomes as a result of reform are evident. In the case of Portugal, changes to HEl governance were achieved, and in some cases, further autonomy attained (though with noted limitations). In Finland, the reduction in the number of HEls through mergers was successful. In both cases, primary changes (institutional network rationalisation in Finland and $\mathrm{HEI}$ governance reform in Portugal) could be better understood as outputs intended to achieve longer-term outcomes, namely institutions that better achieve societal goals, such as increasing international standing and research specialisation in Finland, or enhancing ability to hire and retain top level staff in Portugal, increasing the quality of teaching and research in both cases. In this sense, the question of time horizons is critical. In both countries, immediate outputs may still pre-figure longer-term achievement of desired outcomes, the measurement of which will continue to take a broad base of evidence and time. Crucial as well is the ability to adjust course based on evaluation of progress, which requires appropriate institutional mechanisms and buy-in to continue down a reform path. 


\section{References}

Aalto University (2020), 2019 Annual Board Report and Financial Statements, https://www.aalto.fi/sites/g/files/flghsv161/files/202003/board report and financial statements 2019 aalto university 0.pdf (accessed on 23 October 2020).

Aalto University (2019), Aalto Tenure Track, Aalto University, Helsinki, https://www.aalto.fi/sites/g/files/flghsv161/files/201909/aalto tenure track policies and procedures eng 20190307.pdf (accessed on 23 October 2020).

CCES (2017), The independent legal status in Portuguese higher education: Public Foundations, [20] Conselho Coordenador do Ensino Superior [Coordinating Council for Higher Education], Lisbon, document provided to OECD for the project "Improving Higher Education in the Slovak Republic".

Crossmapping the future (n.d.), Factory of the future, https://innovativecarhmi.com/factory-of-thefuture\#factory-of-the-future1 (accessed on 29 July 2021).

DGES (2020), Conselho Coordenador do Ensino Superior [Coordinating Council for Higher Education], https://www.dges.gov.pt/pt/noticia/conselho-coordenador-do-ensino-superior (accessed on 2 August 2021).

Elander, C., T. Aarrevaara and I. Dobson (2009), "Brave new world: Higher education reform in Finland", Higher Education Management and Policy, Vol. 21/2, pp. 1-18, https://dx.doi.org/10.1787/hemp-21-5ksj0twnffvl.

ETER (2021), European Tertiary Education Register (ETER), https://www.eter-project.com/ (accessed on 1 July 2021).

EUA (2017), European University Association, https://eua.eu/component/attachments/attachments.html?id=395 (accessed on 11 September 2020).

EUA (n.d.), University Autonomy Rankings, https://www.university-autonomy.eu/ (accessed on 14 October 2020).

Eurydice (2020), Higher Education Funding, https://eacea.ec.europa.eu/nationalpolicies/eurydice/content/higher-education-funding-25 en (accessed on 23 October 2020).

Eurydice (2019), Finland - Types of Higher Education Institutions, https://eacea.ec.europa.eu/national-policies/eurydice/content/types-higher-educationinstitutions-25 en (accessed on 1 July 2021).

Eurydice (n.d.), Portugal Overview, https://eacea.ec.europa.eu/nationalpolicies/eurydice/content/portugal en (accessed on 11 September 2020).

Fibrenamics (n.d.), Bosch Innovative Car HMI, https://www.fibrenamics.com/en/business/partners/bosch-innovative-car-hmi (accessed on 23 October 2020). 
FINEEC (2016), National education evaluation plan 2016-2019, Finnish Education Evaluation Centre, Helsinki, https://karvi.fi/app/uploads/2016/05/2-National-Education-Evaluation-Plan2016-2019.pdf (accessed on 23 October 2020).

Fonseca, M., S. Encarnação and E. Justino (2014), Shrinking Higher Education Systems, SensePublishers, Rotterdam, https://doi.org/10.1007/978-94-6209-746-9 9.

Government of Finland (2020), Ministry of Education and Culture, https://minedu.fi/en/ministry (accessed on 23 October 2020).

Government of Portugal (2007), "Regime Jurídico das Instituições de Ensino Superio (RJIES) [Legal framework of higher education institutions]", Diário da República, Vol. 174/2007, pp. 6358 - 6389, https://data.dre.pt/eli/lei/62/2007/09/10/p/dre/pt/html (accessed on 2 August 2021).

Hölttä, S. (1998), "The Funding of Universities in Finland: Towards Goal-Oriented Government Steering", European Journal of Education, Vol. 33/1, pp. 55-63, http://www.jstor.org/stable/1503784 (accessed on 1 September 2021).

Kallo, J. (2009), OECD Education Policy: A Comparative and Historical Study Focusing on the Thematic Reviews of Tertiary Education, Finnish Educational Research Association, Jyväskyla, document provided to OECD for the project "Improving Higher Education in the Slovak Republic".

Kauko, J. and S. Diogo (2012), "Comparing higher education reforms in Finland and Portugal: different contexts, same solutions?", Higher Education Management and Policy, Vol. 23/3, pp. 1-20, https://dx.doi.org/10.1787/hemp-23-5kg0sjtcnnzt.

Keskinen, E. (2016), Tampere 3 seems to be cracking, but so did Aalto - Where will the political game lead?, Aviisi, https://www.aviisi.fi/2016/11/tampere-3-seems-to-be-cracking-but-so-didaalto-where-will-the-political-game-lead/ (accessed on 23 October 2020).

Lukacs, J. (1992), "Finland Vindicated”, Foreign Affairs, Vol. 71/4, p. 50, http://dx.doi.org/10.2307/20045309.

Magalhães, A. et al. (2013), "Governance and institutional autonomy: Governing and governance in portuguese higher education", Higher Education Policy, Vol. 26/2, pp. 243-262, https://doi.org/10.1057/hep.2012.31.

MEDC (2015), Towards a future proof system for higher education and research in Finland, Ministry of Education and Culture, Department for Higher Education and Science Policy, Helsinki, http://urn.fi/URN:ISBN:978-952-263-349-1 (accessed on 1 September 2021).

Ministry of Education and Culture of Finland (2014), Universities of Applied Sciences Act 932/2014, Ministry of Education and Culture, Helsinki, https://www.finlex.fi/fi/laki/kaannokset/2014/en20140932 20160563.pdf (accessed on 29 July 2021).

Ministry of Education and Culture of Finland (2009), Universities Act 558/2009, Ministry of Education and Culture, Helsinki, https://www.finlex.fi/en/laki/kaannokset/2009/en20090558.pdf (accessed on 19 July 2021). 
Ministry of Education and Culture of Finland (1997), Universities Act 645/1997, Ministry of Education and Culture, Helsinki, https://finlex.fi/fi/laki/kaannokset/1997/en19970645 20061453.pdf (accessed on 19 July 2021).

Mora, J. (2001), "Governance and Management in the New University", Tertiary Education and Management, Vol. 7, pp. 5-110, https://doi.org/10.1023/A:1011338016085.

MTCES (2006), Tertiary Education in Portugal: Background Report, Ministry of Science, Technology and Higher Education, Lisbon, https://doi.org/10.1787/104853273381.

Myklebust, P. (2019), Merger makes Tampere the second-largest university, University World News, https://www.universityworldnews.com/post.php?story=2019011013130145 (accessed on 23 October 2020).

Nokkala, T., J. Välimaa and D. Westerheijden (2016), Finland - university mergers and institutional profiling, European Commission, Brussels, https://doi.org/10.2766/118884.

OECD (2021), Historical Population, https://stats.oecd.org/Index.aspx?DataSetCode=HISTPOP (accessed on 1 July 2021).

OECD (2020), Education at a Glance 2020: OECD Indicators, OECD Publishing, Paris, https://dx.doi.org/10.1787/69096873-en.

OECD (2019), Benchmarking Higher Education System Performance, Higher Education, OECD Publishing, Paris, https://dx.doi.org/10.1787/be5514d7-en.

OECD (2019), Education at a Glance 2019: OECD Indicators, OECD Publishing, Paris, https://dx.doi.org/10.1787/f8d7880d-en.

OECD (2019), OECD Review of Higher Education, Research and Innovation: Portugal, OECD Publishing, Paris, https://dx.doi.org/10.1787/9789264308138-en.

OECD (2017), OECD Reviews of Innovation Policy: Finland 2017, OECD Reviews of Innovation Policy, OECD Publishing, Paris, https://dx.doi.org/10.1787/9789264276369-en.

OECD (2009), OECD Reviews of Tertiary Education: Finland 2009, OECD Reviews of Tertiary Education, OECD Publishing, Paris, https://dx.doi.org/10.1787/9789264049048-en.

OECD (2008), Tertiary Education for the Knowledge Society: Volume 1 and Volume 2, OECD Reviews of Tertiary Education, OECD Publishing, Paris, https://dx.doi.org/10.1787/9789264046535-en.

OECD (2007), Reviews of National Policies for Education: Tertiary Education in Portugal 2007, Reviews of National Policies for Education, OECD Publishing, Paris, https://dx.doi.org/10.1787/9789264009769-en.

Official Statistics of Finland (2019), Parliamentary elections, http://www.stat.fi/til/evaa/index en.html (accessed on 23 October 2020).

Owal Group (2016), Yliopistolakiuudistuksen vaikutusten arviointi [Impact assessment of the University Reform], Ministry of Education and Culture, Helsinki, https://julkaisut.valtioneuvosto.fi/bitstream/handle/10024/75416/okm30.pdf?sequence=1 (accessed on 11 September 2020). 
Pekkola, E. et al. (eds.) (2018), University autonomy: From past to present, Tampere University Press, Tampere, http://library.oapen.org/handle/20.500.12657/28911.

Pusser, B. et al. (eds.) (2012), The Corporatization of National Universities in Finland, Routledge, New York, https://doi.org/10.4324/9780203847848.

ReferNet Finland (2014), Finland: Polytechnics reform focuses on performance-based funding, https://www.cedefop.europa.eu/en/news-and-press/news/finland-polytechnics-reformfocuses-performance-based-funding (accessed on 23 October 2020).

Saarinen, S. (2019), The new funding model for universities emphasises completed degrees, University of Helsinki, Helsinki, https://www.helsinki.fi/en/news/higher-education-sciencepolicy/the-new-funding-model-for-universities-emphasises-completed-degrees (accessed on 23 October 2020).

Saarivirta, T. (2010), "Finnish Higher Education Expansion and Regional Policy", Higher Education Quarterly, Vol. 64/4, pp. 353-372, http://dx.doi.org/10.1111/j.14682273.2010.00455.x.

Stenström, M. and M. Virolainen (2014), The History of Finnish Vocational Education and Training, Finnish Institute for Educational Research University of Jyväskylä, Jyväskylä, http://nord-vet.dk/indhold/uploads/History-of-Finnish-VET-29062014final.pdf (accessed on 11 August 2020).

Tompson, W. (2009), The Political Economy of Reform: Lessons from Pensions, Product Markets and Labour Markets in Ten OECD Countries, OECD Publishing, Paris, https://dx.doi.org/10.1787/9789264073111-en.

Tuulos, T. (2017), An experimental learning platform to foster university-industry collaboration, https://www.itu.int/en/ITU-D/Capacity-Building/Documents/ITU-Academia Partnership Meeting 2017/Presentations/Session 4/3TiinaTuulos.pdf (accessed on 11 September 2020).

UNIFI (n.d.), Universities Finland, http://www.unifi.fi/in-english/ (accessed on 23 October 2020).

Universidade do Minho (n.d.), Programme Innovative Car HMI, https://www.eng.uminho.pt/en/researchinnovate/projectsinindustry/Pages/programmeinnovati vecarhmi.aspx (accessed on 10 August 2021).

University of Helsinki (2020), A tailored career path, https://www.helsinki.fi/en/university/careersat-the-university-of-helsinki/tenure-track/a-tailored-career-path (accessed on 10 August 2021).

University of Turku (n.d.), University Consortium of Pori, https://www.utu.fi/en/universityconsortium-of-pori (accessed on 22 October 2020).

Välimaa, J., D. Hoffman and M. Huusko (2007), "The Bologna Process in Finland”, in Higher Education Dynamics, Creating the European Area of Higher Education, Springer Netherlands, Dordrecht, http://dx.doi.org/10.1007/978-1-4020-4616-2 3.

Valtioneuvosto (n.d.), Ministries' contact detail, https://valtioneuvosto.fi/en/ministries (accessed on 6 August 2020). 
Vartiainen, P. (2016), "Campus-based tensions in the structural development of a newly merged university: the case of the University of Eastern Finland", Tertiary Education and Management, Vol. 23/1, pp. 53-68, http://dx.doi.org/10.1080/13583883.2016.1205123.

Vellamo, T. et al. (2020), "Technical Identity in a MergerProcess-Between a Rock and a Hard Place", in Higher Education Dynamics, Technical Universities, Springer International Publishing, Cham, http://dx.doi.org/10.1007/978-3-030-50555-4 9.

Williams, J. (2017), "Collaboration, alliance, and merger among higher education institutions", OECD Education Working Papers, No. 160, OECD Publishing, Paris, https://dx.doi.org/10.1787/cf14d4b5-en. 



\section{Annex B. Participating stakeholder organisations}

The project "Improving Higher Education in the Slovak Republic" involved several stakeholder engagement activities, including regular meeting of a Working Group composed of policy makers, interviews and institutional roundtables with higher education stakeholders, and an international peer-learning webinar providing insights from international experts to interest Slovak stakeholders.

The table below lists the organisations that participated in the Working Group, interviews and roundtables, whose representatives provided input informing the analysis and recommendations contained in this report.

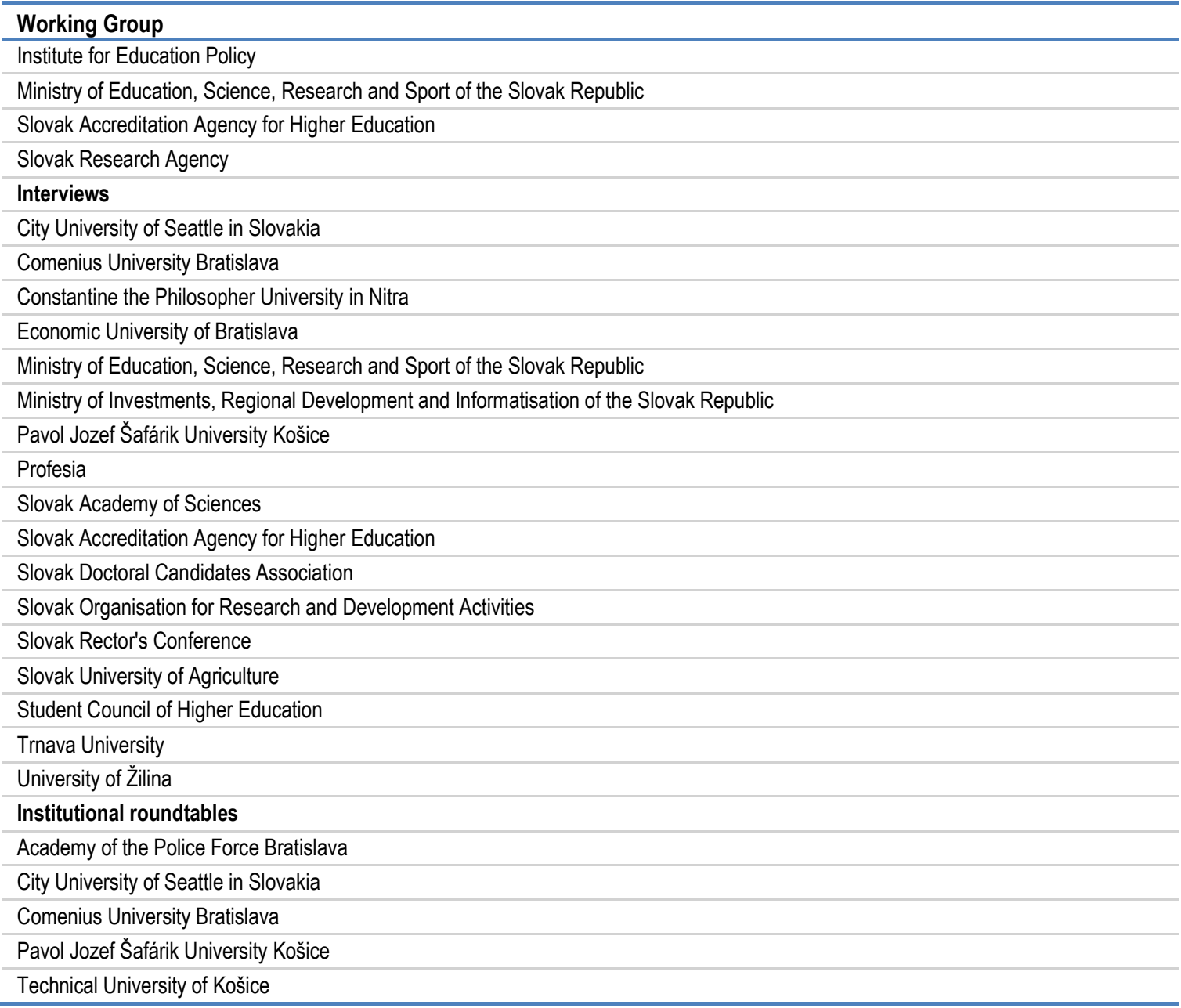




\section{Higher Education}

\section{Improving Higher Education in the Slovak Republic}

Higher education helps learners acquire the knowledge and skills they need to lead productive working lives, and it sparks the innovation that fosters economic growth and social progress. However, creating higher education systems that operate at a high level of research and teaching quality, with responsiveness to social and labour market demands, requires effective public policies and institutional practices. This report, which focuses on funding and governance reforms to improve higher education in the Slovak Republic, is a collaboration between the European Commission's Directorate-General for Structural Reform Support (DG REFORM), the Institute for Strategies and Analysis in the Office of the Government of the Slovak Republic and the OECD's Directorate for Education and Skills. Building on stakeholder engagement and comparative analysis, the report offers an international perspective on the performance of the Slovak higher education system and provides an action plan focused on governance and funding reforms, placing special emphasis on implementation planning to support reform success.

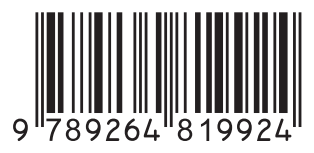

